
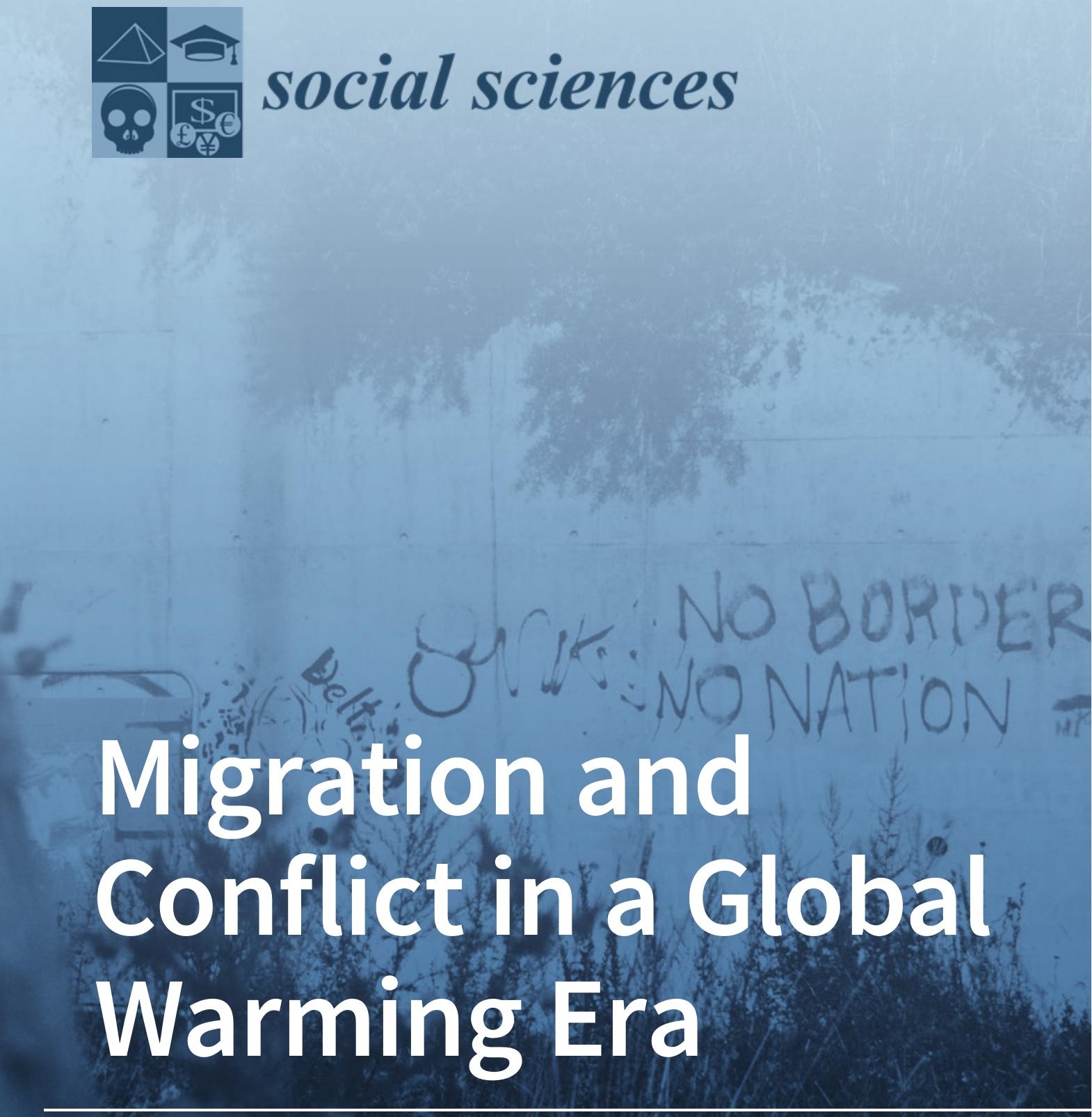

Edited by

Silja Klepp and Christiane Fröhlich Printed Edition of the Special Issue Published in Social Sciences

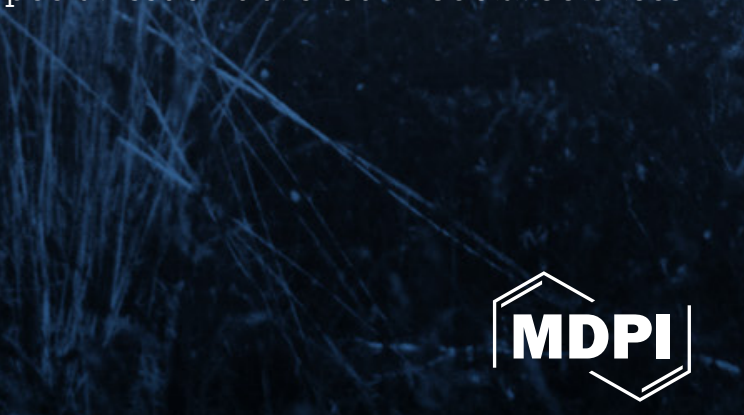


Migration and Conflict in a Global Warming Era 



\section{Migration and Conflict in a Global Warming Era}

\section{A Political Understanding of Climate Change}

Special Issue Editors

Silja Klepp

Christiane Fröhlich 
Special Issue Editors

$\begin{array}{ll}\text { Silja Klepp } & \text { Christiane Fröhlich } \\ \text { Kiel University } & \text { German Institute for Global and Area Studies (GIGA) } \\ \text { Department of Geography } & \text { Institute for Middle East Studies } \\ \text { Germany } & \text { Germany }\end{array}$

Editorial Office

MDPI

St. Alban-Anlage 66

4052 Basel, Switzerland

This is a reprint of articles from the Special Issue published online in the open access journal Social Sciences (ISSN 2076-0760) (available at: https://www.mdpi.com/journal/socsci/special_ issues/migration_conflict_globalwarming).

For citation purposes, cite each article independently as indicated on the article page online and as indicated below:

LastName, A.A.; LastName, B.B.; LastName, C.C. Article Title. Journal Name Year, Article Number, Page Range.

\section{ISBN 978-3-03936-352-0 (Hbk)}

ISBN 978-3-03936-353-7 (PDF)

Cover image courtesy of Radek Homola.

(C) 2020 by the authors. Articles in this book are Open Access and distributed under the Creative Commons Attribution (CC BY) license, which allows users to download, copy and build upon published articles, as long as the author and publisher are properly credited, which ensures maximum dissemination and a wider impact of our publications.

The book as a whole is distributed by MDPI under the terms and conditions of the Creative Commons license CC BY-NC-ND. 


\section{Contents}

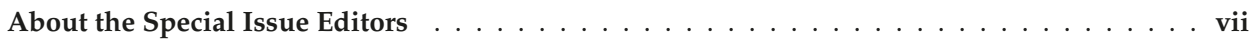

Silja Klepp and Christiane Fröhlich

Migration and Conflict in a Global Warming Era: A Political Understanding of Climate Change

Reprinted from: Soc. Sci. 2020, 9,78, doi:10.3390/socsci9050078 . . . . . . . . . . . . . . 1

\section{Ilan Kelman}

Imaginary Numbers of Climate Change Migrants?

Reprinted from: Soc. Sci. 2019, 8, 131, doi:10.3390/socsci8050131 . . . . . . . . . . . . . . . . . 11

Annah E. Piggott-McKellar, Karen E. McNamara, Patrick D. Nunn and Seci T. Sekinini

Moving People in a Changing Climate: Lessons from Two Case Studies in Fiji

Reprinted from: Soc. Sci. 2019, 8, 133, doi:10.3390/socsci8050133 . . . . . . . . . . . . . . . . 27

Tammy Tabe

Climate Change Migration and Displacement: Learning from Past Relocations in the Pacific

Reprinted from: Soc. Sci. 2019, 8, 218, doi:10.3390/socsci8070218 . . . . . . . . . . . . . . . 45

Celia Ruiz-de-Oña, Patricia Rivera-Castañeda and Yair Merlín-Uribe

Coffee, Migration and Climatic Changes: Challenging Adaptation Dichotomic Narratives in a Transborder Region

Reprinted from: Soc. Sci. 2019, 8, 323, doi:10.3390/socsci8120323 . . . . . . . . . . . . . . . . . 63

Yvonne Kunz, Fenna Otten, Rina Mardiana, Katrin Martens, Imke Roedel and Heiko Faust

Smallholder Telecoupling and Climate Governance in Jambi Province, Indonesia

Reprinted from: Soc. Sci. 2019, 8, 115, doi:10.3390/socsci8040115 . . . . . . . . . . . . . . . . 89

Michael Brzoska

Understanding the Disaster-Migration-Violent Conflict Nexus in a Warming World: The Importance of International Policy Interventions

Reprinted from: Soc. Sci. 2019, 8, 167, doi:10.3390/socsci8060167 . . . . . . . . . . . . . . . . . . 119

Caroline Zickgraf

Keeping People in Place: Political Factors of (Im)mobility and Climate Change Reprinted from: Soc. Sci. 2019, 8, 228, doi:10.3390/socsci8080228 . . . . . . . . . . . . . . . . . 137 



\section{About the Special Issue Editors}

Silja Klepp is a Professor of Human Geography at Kiel University. She is a trained social anthropologist. Her research group "Social Dynamics in Coastal and Marine Areas" deals with human-environment relations in the Anthropocene. In her current research on climate change migration and adaptation, she integrates postcolonial perspectives and critical theories in the study of the social effects of climate change. She is especially interested in how social and cultural diversity can be integrated into adaptation governance, and how self-determination of the affected communities can be assured. Klepp's field research experience was in countries such as Kiribati, Vanuatu, New Zealand, Italy, Libya, Malta, and Zambia. She won several awards for her PhD on refugees and border control in the Mediterranean Sea, such as the Christiane Rajewsky Award of the German Association for Peace and Conflict Studies. She is an alumna of the German Young Academy of Scientists (Die Junge Akademie), as well as an appointed member of the Council for Migration and the scientific advisory board of the Heinrich Böll Foundation. Together with others, in 2019 she founded the transdisciplinary network of environmental justice, EnJust. As a way to achieve more inclusive and creative ways of making science, she works with and develops transdisciplinary approaches and artistic research.

Christiane Fröhlich researches human mobility within and from the Global South at the German Institute for Global and Area Studies (GIGA) in Hamburg, Germany. She is particularly interested in understanding migration/mobility as "critical" in different socio-political contexts and in the interactions between people on the move and actors trying to control such movement. She approaches her respective research questions from a critical as well as post/decolonial perspective. Her focus is mainly on the Middle East (Syria, Jordan, Lebanon, Israel/Palestine, and Turkey), where she has conducted extensive field research, but she is also engaged in cross-regional comparative projects, including the EU-funded consortium "Migration Governance and Asylum Crises (MAGYC)", in which she leads a work package on "Comparing Crises: Lessons from "migration crises" in North Africa, the Middle East and the Greater Horn of Africa". Fröhlich recently received the first John Urry Memorial Award from the Journal Mobilities for her conceptual work on mobility justice in the context of global environmental change with Andrew Baldwin and Delf Rothe. Her work has been published widely in international journals like Political Geography, Journal of Peace Research and Global Policy as well as in numerous books and edited volumes. 



\title{
Migration and Conflict in a Global Warming Era: A Political Understanding of Climate Change
}

\author{
Silja Klepp ${ }^{1, *}$ and Christiane Fröhlich ${ }^{2}$ \\ 1 Department of Geography, Christian-Albrechts-Universität zu Kiel, 24098 Kiel, Germany \\ 2 German Institute for Global and Area Studies (GIGA), 20354 Hamburg, Germany; \\ christiane.froehlich@giga-hamburg.de \\ * Correspondence: klepp@geographie.uni-kiel.de; Tel.: +49-431-880-5641
}

Received: 16 April 2020; Accepted: 17 April 2020; Published: 13 May 2020

\begin{abstract}
This special issue explores underrepresented aspects of the political dimensions of global warming. It includes post- and decolonial perspectives on climate-related migration and conflict, intersectional approaches, and climate change politics as a new tool of governance. Its aim is to shed light on the social phenomena associated with anthropogenic climate change. The different contributions aim to uncover its multidimensional and far-reaching political effects, including climate-induced migration movements and climate-related conflicts in different parts of the world. In doing so, the authors critically engage with securitising discourses and resulting anti-migration arguments and policies in the Global North. In this way, they identify and give a voice to alternative and hitherto underrepresented research and policy perspectives. Overall, the special issue aims to contribute to a critical and holistic approach to human mobility and conflict in the context of political and environmental crisis.
\end{abstract}

Keywords: climate change; environmental migration; environmental justice; North-South relations; climate change politics; conflict; intersectionality; adaptation; vulnerability; postcolonial studies

\section{Governing the Effects of Anthropogenic Climate Change}

We now have a better understanding than ever of the social phenomena associated with anthropogenic climate change, as well as of its multidimensional and far-reaching political effects. These effects include climate-induced human mobility and climate-related conflicts about the distribution of, and access to, natural resources. Academic discourse and public debate around these topics have been pursued from myriad angles, yielding a diverse array of results. While empirical findings have shown that global environmental change engenders predominantly South-South movements (Weber 2015), internal displacement within the Global South (Foresight 2011), or immobility (Black et al. 2013; Zickgraf and Perrin 2017, Zickgraf, this Special Issue (SI)), securitisation discourses and anti-migration policies are currently gaining ground in the Global North (Baldwin et al. 2014; Fröhlich 2017; Rothe 2015). Furthermore, disenfranchised or marginalised groups are affected much more severely by climate change than elites; the intersectional discrimination that results from this is often insufficiently addressed in negotiation processes linked to the issue of environmental migration (Kaijser and Kronsell 2014). Lastly, conflicts linked to climate change are mostly—but not exclusively—non-violent, and climate change effects are not usually singular drivers of conflict, but rather inseparable from socio-political and economic dynamics (Ide et al. 2020; Brzoska and Fröhlich 2016). All of these findings and debates illustrate the inherently political and normative character of the nexus between climate change, migration and conflict (Baldwin and Bettini 2017). The authors of this special issue have chosen from among a wide range of analytical approaches and perspectives to bring these often-hidden dimensions and contexts of climate change discourses, politics and interventions to the forefront in their respective research topics. 
What becomes obvious looking at the fast-growing body of literature on climate change, migration and conflict is the fundamentally disparate narratives that are used to frame research topics, grey literature, policy papers and other publications in which these issues are negotiated. Some scholars and policymakers focus on securitisation, others on climate justice; some talk about how humans can or should adapt, others take the hopeful view that we as a species are resilient and will find a way to survive. Unfortunately, many of the approaches frame the discussion on climate change in a reductionist, depoliticised way (critical, from different perspectives: Whyte et al. 2019; Boas et al. 2019). Differing epistemologies (and a variety of so-called "epistemic communities"), competing political agendas and clashing ontologies lead to diverging ways climate change is linked to social effects (Klepp 2017). These debates are rarely used as an "imaginative resource" (Hastrup and Olwig 2012) to discourse proactively about the world in which we want to live; on the contrary, they help create conditions of fear, exclusion and discrimination. A recent EU Horizon 2020 funding call shows how much even public funding schemes for research have taken on a logic of securitisation, speaking about climate migration as a "real threat" to European security, which runs contrary to most empirical findings (cited in Boas et al. 2019).

This shows how deeply racist and racialised many narratives are in the realm of climate research and climate politics (Baldwin and Erickson 2020), and how important the role of language is in this regard. In particular, the concept of mobility justice can be instructive in uncovering such dynamics. "Mobility justice" emerged from the interdisciplinary field of mobility studies (Sheller 2018b; 2018a), and can help us better understand the conditions that restrict or constrain mobilities. The concept recognises that while mobility is a fundamental aspect of daily life for people everywhere, access to mobility is often experienced unequally along lines of gender, ethnicity, race, religion, age and social class. Mobility justice (or the lack thereof) is reflected in societal discourses on migration, as state power relies on policy categories to sort, to include and exclude and to distinguish between individuals and groups. In a migration context, categorisations or 'labels' are used to signify whether a person belongs, deserves protection, or is considered willing to integrate. Such labels often follow a binary logic and deny the complexity of migration trajectories and identities. For instance, people moving to diversify their economic income are often labelled "expats" if they have a Northern/Western background, but "economic migrants" if they hail from non-industrialised states; such labels have a direct impact on the normative dimensions of integration policies. Similarly, the labelling of forced migrants as 'refugees' or 'irregular migrants' (Squire 2011; Carling 2017) is central to formal and informal efforts to govern migration (Allen et al. 2018; Crawley and Skleparis 2018) and key to legal protections migrants can access. Scholarship has highlighted the socially constructed nature of such categories, and approaches such as intersectionality (Carastathis et al. 2018), de-migranticisation (Dahinden 2016) and groupness (Brubaker 2002, 2010) stress how complex and fluid they are. Nevertheless, neither academic research nor policy-making has found a way to work without categories and simultaneously generate tangible positive effects on migrants' lived realities (Erdal and Oeppen 2017).

In order to establish more unbiased language in the realm of climate migration and to acknowledge the variety of migration realities that might be linked to environmental and climate change, some scholars have urged for a terminology shift "from climate migration to climate mobilities" or to "Anthropocene mobilities" (Boas et al. 2019; Baldwin et al. 2019). This special issue draws attention to such alternativte, underrepresented research perspectives on second-order effects of climate change (e.g., through the effects of climate change politics) and identifies new ways of communicating research through co-operation with the visual arts.

So-called second-order effects can be observed in new configurations within North-South interactions and international cooperation projects. Climate change politics and international cooperation are increasingly exploring the possibilities of climate change as a new tool of governance (Klepp and Chavez-Rodriguez 2018), investing growing funds in climate-related interventions, such as adaptation and mitigation. The aims and purposes of these new tools of governance are still far from obvious and can be manifold. Control of, and access to, resources-for instance, through adaptation 
narratives (Vázquez 2017) or (re)territorialisation and reconstruction of statehood linked to climate policies and Reducing Emissions from Deforestation and Forest Degradation (REDD+) projects (Hein 2019) — can be understood as second-order effects of climate policies. When actors such as international organisations gain importance and their voice grows stronger, they can influence the power-knowledge nexus that is so crucial in climate and adaptation politics (Morchain 2018; Eriksen et al. 2015; Cameron 2012). These political implications and effects of climate change policies and adaptation or mitigation interventions are often neither recognised nor transparent. Power relations on the ground and local, indigenous knowledge are rarely taken into consideration. This can lead to shifting power relations, and in the worst case, it can weaken the most vulnerable. Although the articles in this SI focus on different world regions, all of them tackle the under-studied aspect of the justice implications of such political second-order effects of climate change. To gain a deeper understanding of the justice dimension of climate politics, and in the interest of achieving fairer and more transparent climate governance, we suggest analysing the asymmetrical knowledge production; the hidden ontologies of climate interventions; and the power-knowledge nexus in the fields of climate science, international cooperation and climate finance (Boas et al. 2019).

This interdisciplinary SI also brings together different ways of "doing" research. Due to varying disciplinary methods, professional cultures and empirical material, the articles assembled here present a range of methods and scales of analysis. This gives us the opportunity to benefit from various modes of understanding, tracking and even visualising the climate change-politics nexus. We are especially pleased that we had the opportunity to include the artistic research project "Climate Justice in Kiribati" in this volume. Such new ways of communicating research provide us with epistemological opportunities to develop a deeper understanding of the topic at hand, as the co-operation leading to this photo exhibition illustrates.

\section{The Papers in this Special Issue}

This special issue explores underrepresented aspects of the political dimensions of global warming, including post- and decolonial perspectives on climate-related migration and conflict, intersectional approaches and climate change politics as a new tool of governance. For instance, the case studies from the Pacific Islands discussed in this issue question the conceptual and theoretical constrictions that we are often encountering in debates on climate change and mobility. The Pacific region, or Oceania-as the islanders prefer to call this region from a post-colonial perspective-has become an iconic place for debates on "drowning islands", "climate migration", "climate refugees" and the like (Farbotko 2010; Baldwin and Bettini 2017; Klepp 2018).

There are three major reasons for this focus on Oceania: First, the recent effects of climate change have been severe in this region, and predictions about the future of the region are even more dire, including scenarios such as rising sea levels (predominantly in coastal areas), an intensification of the strength of cyclones, changing rainfall patterns and droughts, and increasing coastal erosion (IPCC 2014).

Second, the "multidimensional inequality" that Dietz discusses in relation to the effects of climate change and the relationship between the Global North and South (Dietz 2009) is especially applicable to Pacific Island countries (PICs). Many PICs suffer from structural inequalities at various levels. Their colonial histories evince the development of these "multidimensional inequalities" (ibid.), as the people of these islands have endured forced labour, forced migration and the plundering of their land's natural resources (Fröhlich and Klepp 2018). Given their historical and current low per capita emissions, they bear little responsibility for anthropogenic climate change, yet they are among those most strongly affected by it. This recognition leads us directly to the core of the climate justice debate and its political implications.

The third main reason that Oceania has become a bellwether in climate debates is that it has become a laboratory to study the social effects of climate change that draw on racist, stereotypical and victimising images of the inhabitants of Oceania. Pacific Islanders have become an iconographic 
warning symbol, a "canary in the coalmine", and distorted images of the victimisation of islanders are frequently used to answer questions concerning the relationship between climate change and human mobility (Farbotko 2010; Fröhlich and Klepp 2018). The agency of those affected is often denied in such discourses, which focus instead on alarmist numbers, scenarios and models, and draw racist pictures of helpless refugees from the Global South. Such discourses are not helpful in understanding the complexity of migration decisions, or in addressing the political root causes of migration or aspects of climate justice in the first place (Fröhlich and Klepp 2018; Baldwin and Bettini 2017).

In this special issue, we aim to diversify these discourses by including voices from within Pacific Island communities. The case studies discussed by Tammy Tabe (Gilbert Islands, today Kiribati; Solomon Islands) and Annah Piggott-McKellar, Karen McNamara, Patrick Nunn and Seci Sekinini (Fiji) each take a different approach. Based on extensive archival studies and ethnographic fieldwork, Tammy Tabe gives us rare insights into what forced relocations by the British colonial government have meant in the past and currently mean to the people of the Southern Gilberts. Due to poor planning and lacking any sort of participatory mechanisms or informed consent (Tabe, this issue), Gilbertese families were re-located to the Phoenix Islands in the late 1930s and then resettled in the 1950s and 1960s to the Solomon Islands due to environmental degradation. Annah Piggott-McKellar, Karen McNamara, Patrick Nunn and Seci Sekinini present two recent cases of Fijian villages whose residents were relocated within their own customary land due to climate-related hazards, following a step-by-step plan that included a neighbourhood consultation process (Piggott-McKellar et al., this issue). Both studies contribute to the still scarce empirical literature on relocation processes and mainly address the social implications and hardships thereof. The main takeaway from both of these articles is that the power to decide and act during the relocation process must lie with those affected-a perspective often missing in climate change and mobility research. "Successful" relocation hinges on questions of agency, which in turn is an issue of justice and ownership. This fact has become obvious since the first relocation processes in the post-colonial era. The Fijian cases illustrate that even in planned, "voluntary" relocations to a nearby place, the social cost is not to be underestimated. Cultural factors play an important role; for instance, lost access to sacred places can be painful and negatively affect the community (Piggott-McKellar et al., this issue). The risk of losing one's identity and agency and the feeling of up-rootedness during and after relocation become even clearer from a historical perspective.

Tammy Tabe takes up important questions of framing and conceptualising climate change and mobility in different ways, borrowing from Rudiak-Gould (2013), who underlines that in Oceania, people feel that migration is not an answer to climate change or a way to adapt, but rather "a genocide" (Rudiak-Gould 2013), as people are losing their communities, language and culture. Land is of utmost importance in Oceania, it has a spiritual reference of high priority, also because the ancestors are burried here, that give you guidance and security (Hofmann 2014).

Both articles address research gaps with thick empirical and historical material and, in this way, dissociate themselves from alarmist or victimising approaches. Oceania is illustrated as a region where relocation happened in the past and where it will happen in the future, and the importance of hearing Pacific Island voices in the relocation process is underscored. In fact, most regions of the world have experienced a lot of mobility in the past, which should normalise and de-scandalise our mostly sedentary perspectives on human life (Hastrup and Olwig 2012). From a perspective of climate justice, such an alternative perspective politicises climate mobility. As migration is already happening with the involvement of official institutions, we need to ask ourselves whether Oceania should be seen as a model in the emerging field of socially responsible and acceptable climate change relocation. Furthermore, we should consider less concrete but more radical and emancipatory processes where "Pacific solidarity" and new approaches to transnational citizenship are being developed (Klepp 2018).

The article by Celia Ruiz-de-Oña, Patricia Rivera-Castaneda and Yair Merlin-Uribe demonstrates how the field of climate change adaptation is often plagued by reductionist discourses and policies. By applying a trans-scalar approach and by introducing us to the socio-economic and political complexities of the lives of coffee farmers who have to cope with changing climates and coffee leaf rust in the 
trans-border region of Mexico and Guatemala, we learn about the urgent need to apply more politicised and holistic understandings of 'migration as adaptation'. Criticising the often very dichotomous and decoupled discussion of "in situ adaptation" versus "migration as adaptation", the authors show how such classifications disregard both the lived and the political realities of coffee farmers on different levels. Their adaptation strategies often evince a complex mix of trans-local livelihoods and adaptation strategies, which are mostly ignored by adaptation policies that exclusively focus on climatic impacts while overlooking the broader social-economic context (Ruiz-de-Oña et al., this issue). Even more critical, the dominant narrative of "migration as adaptation" completely ignores global migration and border realities and often takes on an underlying neoliberal tone of seeking to manage climate migration through labour migration (Foresight 2011; Felli and Castree 2012; Bettini 2013; Klepp and Herbeck 2016). The complex and violent border situation between Mexico and the United States and at the southern border of Mexico highlights the securitisation of both social problems (Bigo 2002) and climate change (Herbeck and Flitner 2010), as well as the mismatch between migration and adaptation discourses on the one hand and policies on the other (Ruiz-de-Oña et al., this issue). Ever more brutal global border and migration regimes remain antithetical to any declarations of intent that speak of international migration as a key adaptive response, such as the Global Compact for Safe, Orderly and Regular Migration of December 2018. The sooner these local, regional and global political realities are acknowledged by and included in adaptation and migration discourses and policies, the higher the likelihood more just and transparent climate change adaptation strategies will be conceived and implemented (Klepp and Chavez-Rodriguez 2018).

In their article on climate governance in Jambi Province, Indonesia, Yvonne Kunz, Fenna Otten, Rina Mardiana, Katrin Martens, Imke Roedel and Heiko Faust address the often under- and unreported political implications and second-order effects of climate change policies and interventions. The authors illustrate the effects, especially the unintended side effects, of supposedly socially conscious and climate-friendly certification schemes and eco-friendly labels for palm oil and rubber. They uncover the fundamental differences between interpretations of, and approaches to, sustainability in the Global North, where such policies are designed and often planned, and the lived realities of smallholders in the Global South affected by those policies. Similar to how Ruiz-de-Oña, Rivera-Castaneda and Merlin-Uribe. presented their case studies, Kunz and her co-authors. also emphasise the need for a more holistic, politicised and inclusive perspective on the effects of climate governance with their methodological choice: They employ a multilevel smallholder telecoupling framework to (a) analyse the connections between actors and resources of different levels and (b) ground a process-oriented approach to both land-use science and the analysis of human-environment relations generally. The telecoupling framework illustrates the challenges that smallholders face in the context of new certification schemes, such as a lack of information on trade-offs, of access to skills, and of technological equipment, in addition to other difficulties in applying certifications. While they also identify some positive effects of such climate policies (e.g., community-building), unintended negative or so-called second-order effects clearly prevail. The most absurd or perfidious peak of these side effects in terms of sustainability might be that a so-called eco-friendly model plantation for rubber, funded by a World Wildlife Fund (WWF) programme, is actually destroying the habitats of the endangered Sumatran elephant (Kunz et al., this issue). The authors examine the new dependencies and hegemonies that are created by the introduction of new actors into climate governmance programmes, which can produce new vulnerabilities and conflicts and have a negative effect on livelihoods (ibid.). Methodologically, the authors underline the usefulness of the smallholder telecoupling framework, which has revealed "second-order effects at a distance to the places where the triggers were kicked off" (Kunz et al., this issue, p. 115). Nevertheless, they also urge us to expand the framework to integrate more critical and power-sensitive issues and conflict spill-overs that a methodology focusing exclusively on coupled systems may otherwise miss.

Alongside these empirically rich case studies, the special issue also includes more conceptual articles. Michael Brzoska explores the linkages between disasters, migration and violent conflict, a nexus in need of further investigation, as the various strains of scholarly literature agree about neither 
the core element of these linkages nor the mechanisms driving them. Brzoska proposes that to get a clearer picture of these links, international policy interventions need to be included in the analysis of disaster risk reduction, conflict prevention, peacebuilding, migration management and humanitarian and development assistance. Building on comparative empirical evidence of how international policy interventions affect the disputed links between disasters, migration and violent conflict, he argues that a better understanding of these mechanisms can result in better policies.

Ilan Kelman tackles the link, often assumed to be causal, between climate change and migration. He explores different ways of developing a robust, replicable and verifiable method to calculate the number of people migrating (or not) because of climate change. Kelman critically engages with the subjective and arbitrary decision-making in the process of declaring future numbers of "climate migrants". In particular, he underscores how changing baselines and legitimate concerns about necessary assumptions can produce misleading calculations. This is particularly relevant as counting, calculating and labelling climate migrants has real effects not only on policy-making but on migrants themselves. Today, many authors agree that calculations of future climate migrants are likely to be inaccurate as there are too many incalculable future aspects (http://climatemigration.org.uk/climate-refugee-statistics/nevertheless), "big numbers" still play a key role in the media and in the grey literature about climate-related migration and mobility.

Caroline Zickgraf dismantles the 'mobility bias' of the study of climate-related migration by engaging with the large numbers of people who are affected by climate change, but do not want to or are not able to move. The few scholarly works that focus on the topic of immobility tend to overemphasise financial constraints as the main reasons for staying. This approach implicitly assumes that people do not choose to stay. Utilising empirical data gathered in Senegal and Vietnam, Zickgraf considerably broadens our understanding of the reasons for staying. Drawing on qualitative interviews, she uncovers how immobility is determined by socio-cultural, economic, and political forces. With a particular focus on international bilateral agreements (Senegal) and a relocation programme (Vietnam), Zickgraf carves out how policy interventions can simultaneously promote mobility and immobility, thereby challenging the traditional dichotomies between mobile/immobile and sedentary/migration policies.

The contributions to our SI show the genuinely political and normative character of the social effects of climate change. One consideration becomes very clear through these illustrations and analyses: Climate change can devastate societies when we pit people against each other and lack the solidarity to co-operate. As examples all over the world show, human beings are able to adapt to and deal with a huge variety of situations, be it extreme heat, cold or other changing or harsh environmental conditions. Our issue demonstrates that the scale of loss that people endure in connection with climate change most strongly depends upon the extent to which communities (Watts 2015) centre human and social environments. This means that alongside fighting for climate change mitigation and fair adaptation interventions, we must work to strengthen multilateral institutions, find new ways to co-operate, activate "imaginative resources" (Hastrup and Olwig 2012, p. 2) to "think out of the box" in climate change adaptation. This is a prerequisite to bolster democratic decision-making processes and to consistently act in solidarity with the most vulnerable and excluded in a rapidly changing political climate.

Author Contributions: All authors have read and agreed to the published version of the manuscript.

Funding: This research received no external funding.

Conflicts of Interest: The authors declare no conflict of interest.

\section{References}

Allen, William, Bridget Anderson, Nicholas Van Hear, Madeleine Sumption, Franck Düvell, Jennifer Hough, Lena Rose, Rachel Humphris, and Sarah Walker. 2018. Who Counts in Crises? The New Geopolitics of International Migration and Refugee Governance. Geopolitics 23: 217-43. [CrossRef] 
Baldwin, Andrew, and Giovanni Bettini, eds. 2017. Life Adrift: Climate Change, Migration, Critique. London and New York: Rowman \& Littlefield International.

Baldwin, Andrew, and Bruce Erickson. 2020. Introduction: Whiteness, Coloniality, and the Anthropocene. Environment and Planning D: Society and Space 38: 3-11. [CrossRef]

Baldwin, Andrew, Chris Methmann, and Delf Rothe. 2014. Securitizing "Climate Refugees": The Futurology of Climate-Induced Migration. Critical Studies on Security 2: 121-30. [CrossRef]

Baldwin, Andrew, Christiane Fröhlich, and Delf Rothe. 2019. From Climate Migration to Anthropocene Mobilities: Shifting the Debate. Mobilities 14: 289-97. [CrossRef]

Bettini, Giovanni. 2013. Climate Barbarians at the Gate?: A Critique of Apocalyptic Narratives on Climate Refugees. Geoforum 45: 63-72. [CrossRef]

Bigo, Didier. 2002. Security and Immigration: Toward a Critique of the Governmentality of Unease. Alternatives 27: 63-92. [CrossRef]

Black, Richard, Nigel W. Arnell, W. Neil Adger, David Thomas, and Andrew Geddes. 2013. Migration, Immobility and Displacement Outcomes Following Extreme Events. Environmental Science \& Policy 27: S32-S43. [CrossRef]

Boas, Ingrid, Carol Farbotko, Helen Adams, Harald Sterly, Simon Bush, Kees van der Geest, and Hanne Wiegel. 2019. Climate Migration Myths. Nature Climate Change 9: 901-3. [CrossRef]

Brubaker, Rogers. 2002. Ethnicity without Groups. European Journal of Sociology/Archives Européennes de Sociologie 43: 163-89. [CrossRef]

Brubaker, Rogers. 2010. Migration, Membership, and the Modern Nation-State: Internal and External Dimensions of the Politics of Belonging. Journal of Interdisciplinary History 41: 61-78.

Brzoska, Michael, and Christiane Fröhlich. 2016. Climate Change, Migration and Violent Conflict: Vulnerabilities, Pathways and Adaptation Strategies. Migration and Development 5: 190-210. [CrossRef]

Cameron, Emilie S. 2012. Securing indigenous politics: A critique of the vulnerability and adaptation approach to the human dimensions of climate change in the Canadian Arctic. Global Environmental Change 22: 103-14. [CrossRef]

Carastathis, Anna, Natalie Kouri-Towe, Gada Mahrouse, and Leila Whitley, eds. 2018. Intersectional Feminist Interventions in the "Refugee Crisis". Refuge 34. [CrossRef]

Carling, Jørgen. 2017. Refugee Advocacy and the Meaning of "Migrants". PRIO Policy Brief, No. 2. Available online: https:/www.prio.org/utility/DownloadFile.ashx?id=326\&type=publicationfile (accessed on 5 March 2020).

Crawley, Heaven, and Dimitris Skleparis. 2018. Refugees, Migrants, Neither, Both: Categorical Fetishism and the Politics of Bounding in Europe's "Migration Crisis". Journal of Ethnic and Migration Studies 44: 48-64. [CrossRef]

Dahinden, Janine. 2016. A Plea for the "de-Migranticization" of Research on Migration and Integration". Ethnic and Racial Studies 39: 2207-25. [CrossRef]

Dietz, Kristina. 2009. Prima Klima in Den Nord-Süd-Beziehungen? Die Antinomien Globaler Klimapolitik: Diskurse, Politiken Und Prozesse. In Nord-Süd-Beziehungen Im Umbruch. Neue Perspektiven Auf Staat Und Demokratie in Der Weltpolitik. Edited by Hans-Jürgen Burchardt. Frankfurt am Main: Campus, pp. 183-218.

Erdal, Marta Bivand, and Ceri Oeppen. 2017. Forced to Leave? The Discursive and Analytical Significance of Describing Migration as Forced and Voluntary. Journal of Ethnic and Migration Studies 6: 981-98. [CrossRef]

Eriksen, Siri, Nightingale Andrea J., and Hallie Eakin. 2015. Reframing adaptation: The political nature of climate change adaptation. Global Environmental Change 35: 523-33. [CrossRef]

Farbotko, Carol. 2010. Wishful Sinking: Disappearing Islands, Climate Refugees and Cosmopolitan Experimentation. Asia Pacific Viewpoint 51: 47-60. [CrossRef]

Felli, Romain, and Noel Castree. 2012. Neoliberalising Adaptation to Environmental Change: Foresight or Foreclosure? Environment and Planning A 44: 1-4. [CrossRef]

Foresight. 2011. Migration and Global Environmental Change. Final Project Report. The Government Office for Science. Available online: https://www.gov.uk/government/publications/migration-and-globalenvironmental-change-future-challenges-and-opportunities (accessed on 13 February 2020).

Fröhlich, Christiane. 2017. A Critical View on Human Mobility in Times of Crisis. Global Policy 8: 5-11. [CrossRef]

Fröhlich, Christiane, and Silja Klepp. 2018. Effects of Climate Change on Migration Crises in Oceania. In The Oxford Handbook on Migration Crises. Edited by Cecilia Menjívar, Marie Ruiz and Immanuel Ness. Oxford: Oxford 
University Press, Available online: http://www.oxfordhandbooks.com/view/10.1093/oxfordhb/9780190856908. 001.0001/oxfordhb-9780190856908-e-52 (accessed on 8 March 2020).

Hastrup, Kirsten, and Karen Fog Olwig, eds. 2012. Climate Change and Mobility. Global Challenges to the Social Sciences. Cambridge: Cambridge University Press.

Hein, Jonas. 2019. Political Ecology of REDD+ in Indonesia-Agrarian Conflicts and Forest Carbon. Routledge Series: Routledge Studies in Political Ecology. Abingdon/New York: Routledge.

Herbeck, Johannes, and Michael Flitner. 2010. A Climate of Insecurity?: A Short Review of Discussions on Security Implications of Climate Change in the United Nations, the European Union and Germany. Universität Bremen, Forschungszentrum Nachhaltigkeit (artec). Available online: https://www.ssoar.info/ ssoar/bitstream/handle/document/42517/ssoar-2010-herbeck_et_al-A_climate_of_insecurity_a.pdf (accessed on 18 March 2020).

Hofmann, Rebecca. 2014. The Cultural Space of Climate Change, Adaptation, and Mobility in the Pacific Islands. In Denaturalizing Climate Change: Migration, Mobilities and Spaces. Artec paper No. 200. Edited by Friederike Gesing, Johannes Herbeck and Silja Klepp. Bremen: University of Bremen, pp. 34-44.

Ide, Tobias, Michael Brzoska, Jonathan F. Donges, and Carl-Friedrich Schleussner. 2020. Multi-Method Evidence for When and How Climate-Related Disasters Contribute to Armed Conflict Risk. Global Environmental Change 62: 102063. [CrossRef]

IPCC. 2014. IPCC Report 2014, Part A: Global and Sectoral Aspects, Chapter 17: Livelihoods and Poverty. Available online: https://www.ipcc.ch/report/ar5/wg2/livelihoods-and-poverty/ (accessed on 10 March 2020).

Kaijser, Anna, and Annica Kronsell. 2014. Climate Change through the Lens of Intersectionality. Environmental Politics 23: 417-33. [CrossRef]

Klepp, Silja. 2017. Climate Change and Migration. Oxford Research Encyclopedia of Climate Science. Oxford: Oxford University Press.

Klepp, Silja. 2018. Framing Climate Change Adaptation from a Pacific Island Perspective-The Anthropology of Emerging Legal Orders. Sociologus 68: 149-70. [CrossRef]

Klepp, Silja, and Libertad Chavez-Rodriguez, eds. 2018. A Critical Approach to Climate Change Adaptation: Discourses, Policies, and Practices. Routledge Advances in Climate Change Research. London and New York: Routledge/Taylor \& Francis Group.

Klepp, Silja, and Johannes Herbeck. 2016. The Politics of Environmental Migration and Climate Justice in the Pacific Region. Journal of Human Rights and the Environment 7: 54-73. [CrossRef]

Morchain, Daniel. 2018. Rethinking the framing of climate change adaptation. Knowledge, power, and politics. In A Critical Approach to Climate Change Adaptation Discourses, Policies, and Practices. Edited by Silja Klepp and Libertad Chavez-Rodriguez. London and New York: Routledge/Taylor \& Francis Group.

Rothe, Delf. 2015. Securitizing Global Warming: A Climate of Complexity. London: Routledge. [CrossRef]

Rudiak-Gould, Peter. 2013. Climate Change and Tradition in a Small Island State: The Rising Tide. New York: Routledge.

Sheller, Mimi. 2018a. Theorising Mobility Justice. Tempo Social 30: 17-34. [CrossRef]

Sheller, Mimi. 2018b. Mobility Justice: The Politics of Movement in an Age of Extremes. London and Brooklyn: Verso. Squire, Vicki. 2011. The Contested Politics of Mobility. Borderzones and Irregularity. London and New York: Routledge. Vázquez, Luz Maria. 2017. Implementation challenges of climate change adaptation initiatives in coastal lagoon communities in the Gulf of Mexico. Maritime Studies 16: 14. [CrossRef]

Watts, Michael J. 2015. Now and Then. The origin of political ecology and the rebirth of adaptation as a form of thought. In The Routledge Handbook of Political Ecology. Edited by Tom Perreault, Gavin Bridge and James McCarthy. New York: Routledge, pp. 19-51.

Weber, Eberhard. 2015. Envisioning South-South Relations in the Fields of Environmental Change and Migration in the Pacific Islands - Past, Present and Futures. Bandung: Journal of the Global South 2: 1-21. [CrossRef] 
Whyte, Kyle, Jared L. Talley, and Julia D. Gibson. 2019. Indigenous Mobility Traditions, Colonialism, and the Anthropocene. Mobilities 14: 319-35. [CrossRef]

Zickgraf, Caroline, and Nathalie Perrin. 2017. Immobile and Trapped Populations. In Atlas Der Umweltmigration. Edited by François Gemenne, Dina Ionesco and Daria Mokhnacheva. München: oekom, pp. 44-46.

(c) (2)

(C) 2020 by the authors. Licensee MDPI, Basel, Switzerland. This article is an open access article distributed under the terms and conditions of the Creative Commons Attribution (CC BY) license (http://creativecommons.org/licenses/by/4.0/). 



\title{
Article
}

\section{Imaginary Numbers of Climate Change Migrants?}

\author{
Ilan Kelman ${ }^{1,2}$ \\ 1 Institute for Global Health and Institute for Risk and Disaster Reduction, University College London, \\ London WC1E 6BT, UK; ilan_kelman@hotmail.com \\ 2 University of Agder, 4630 Kristiansand, Norway
}

Received: 19 February 2019; Accepted: 23 April 2019; Published: 27 April 2019

\begin{abstract}
Within the extensive scientific and policy discussions about climate change migrants, detailed analyses continue to highlight the lack of evidence thus far for climate change directly causing migration. To understand better how climate change might or might not lead to migration, this paper explores possibilities for developing a robust, repeatable, and verifiable method to count or calculate the number of people migrating or not migrating due to climate change. The discussion starts by examining definitions of "climate change" and "migration", then looking at how to determine numbers of climate change migrants based on those definitions. These points lead to descriptions of the subjectivity and arbitrariness of the decisions needed for counting or calculating climate change migrants and non-migrants. While the scientific study of working out numbers of climate change migrants and non-migrants is challenging and interesting, especially due to its complexity, changing baselines alongside legitimate concerns about necessary assumptions lead to questions regarding the usefulness of the calculations for policy and action. Ultimately, labelling, counting, and calculating climate change migrants and non-migrants depend on political choices, so any numbers reached might not be scientifically robust. Improved understanding of people's motivations for migrating and not migrating under different circumstances, including under climate change and perceptions thereof, would be preferable to a starting point assuming that climate change inevitably causes migration.
\end{abstract}

Keywords: climate change; climigration; environmental change; migration; mobility; refugees

\section{Introduction}

Extensive scientific and policy discussions persist regarding climate change migrants and variations of the term such as "climate refugees", "climate change refugees", and "environmental migrants" (Felli and Castree 2012 in their apt critique of Foresight 2011; Gemenne 2011; Hall 2013; Leckie 2014; Manrique et al. 2018; Rakova et al. 2009). Detailed analyses continue to highlight (i) the lack of evidence linking climate change directly to migration through linear causality and (ii) the multitude of factors influencing any connections between the two (Baldwin et al. 2014; Bettini 2013; Brzoska and Fröhlich 2016; Hartmann 2010; Klepp 2017; Nicholson 2014; Watts et al. 2018a, 2018b). These critiques do not necessarily preclude ongoing interactions between climate change and migration alongside the possibility of future occurrences of large-scale migration linked to climate change.

Consequently, the question remains regarding how climate change might connect to or cause migration; that is, attribution must be ascertained. Attribution means determining that people are moving because climate change causes the migration. As another dimension of attribution, it would be important to investigate if people are forced not to migrate due to climate change when they would otherwise want to move.

Nicholson (2014) challenges the need to focus on causality, using climate change and migration to illustrate how "causality can prove a blind alley for substantive research when we become mired in trying to distil certainty from what are, in truth, irredeemably equivocal categories" (p. 159). The same difficulties could be raised regarding the drive to quantify climate change and migration links by 
asking, and trying to answer, how many climate change migrants exist and how many there could be in the future under different scenarios. Is it worthwhile trying to count? What would a calculation method be? How meaningful would the numbers be? Would the answers to these questions be different from scientific, policy, or political perspectives?

A major consequence is that providing numbers of climate change migrants or projections thereof could create tangibility whether or not the numbers are credible-and irrespective of limitations in the method(s). That is, quantifying might bypass the criticisms of, and the large uncertainties surrounding, the notion of climate change causing migration (as discussed by Baldwin et al. 2014; Bettini 2013; Brzoska and Fröhlich 2016; Hartmann 2010; Klepp 2017; Nicholson 2014) because quantitative science is often assumed to have robustness without accounting for inevitable and implicit biases in calculations (Martin 1979). For example, World Bank (2018) estimated numbers of forced migrants displaced inside their country of origin by climate change until 2050. This report's arbitrary definitions and limitations in the calculation method are described for Bangladesh by Abubakar et al. (2018), most notably how the projected environmental changes are not necessarily attributable to climate change. Rather than counting for the sake of counting to confer unsubstantiated credibility, if an accepted method could be developed for determining the numbers of climate change migrants, then many criticisms of climate change and migration links could possibly be overcome. An evidence basis for policy and action on climate change migration would therefore exist.

This paper explores possibilities for developing a robust, repeatable, and verifiable method to count and calculate the numbers of people migrating or not migrating due to climate change impacts. The discussion starts by examining definitions of "climate change" and "migration", then looking at how to count and calculate numbers based on those definitions. These points lead to descriptions of and conclusions regarding the subjectivity and arbitrariness of making necessary decisions for determining climate change migrants and non-migrants. In the end, calculation methods at the moment do not seem to be able to provide a usable evidence basis for policy or action.

\section{Background}

This section defines the two baseline concepts linked by this paper: population movement encompassing migration, mobilities, and refugees (Section 2.1) and climate change plus its impacts (Section 2.2). Defining the connectors and connections between the two is then set out (Section 2.3).

\subsection{Population Movement}

Human migration and mobilities research has long offered two truisms with respect to human population movements:

1. Mobile, sedentary, and mixed lifestyles are and always have been part of humanity (Fiddian-Qasmiyeh et al. 2016; Meir 1986; Urry 2007).

2. Many factors, including climate-related ones, influence and have always influenced human migration and non-migration decisions and forced actions (Felli and Castree 2012; Fröhlich 2017; Ritchey 1976; Stojanov 2014).

The word "migrant" generally implies movement with some level of voluntariness, as in "cases where the decision to migrate is taken freely by the individual concerned, for reasons of 'personal convenience' and without intervention of an external compelling factor" (UN Commission on Human Rights 1998, p. 9). Hence, the potential exists for "forced migrants" where there is "an external compelling factor", so a decision to move is not taken freely. Here, "forced migrant" is defined as a subset of "migrant" where "some level of voluntariness" is zero.

An immediate definitional dilemma appears: What is the distance which someone must move in order to be termed a migrant? Moving ten meters is not far, yet sometimes shifts across an international border within the same residential block or to the opposite side of the street. This situation occurs along 
parts of the France-Monaco border, e.g., Avenue d'Alsace, and along parts of the Belgium-Netherlands border, e.g., the adjoining cities of Baarle-Nassau (Netherlands) and Baarle-Hertog (Belgium).

In other places, moving ten meters could mean leaving the expected floodplain under climate change projections several decades into the future. Pingelap is an atoll within the Federated States of Micronesia in the Pacific. Some parts of the atoll are higher than $15 \mathrm{~m}$ above sea level, but all the atoll's land sits within $300 \mathrm{~m}$ of the ocean. In theory, the inhabitants could redesign and rebuild their community on the higher parts of their atoll to avoid expected sea-level rise impacts, meaning that no one would move especially far. They would do so because climate change is expected to force them to move to new locations within their atoll, so they are climate change forced migrants, yet they remain living in Pingelap, near their original homes. Rather than moving inland, buildings in the new floodplain or tidal zone could instead be raised above the new sea level. Multi-story buildings could be constructed with their ground floors opened up to permit water flow through them while upper stories remain dry and livable. People would live in the same location having migrated upwards. Would these people be vertical climate change forced migrants, having migrated vertically to deal with climate change? Or is this simply sensible adaptation to one's ever-changing environment?

For a subset of forced migrants, the term "refugee" applies, although the two phrases are frequently used synonymously in common, rather than professional, parlance. In international law and humanitarian relief, a specific definition exists that "refugees" are people with:

[ ... ] a well-founded fear of being persecuted for reasons of race, religion, nationality, membership of a particular social group or political opinion is outside the country of his nationality and is unable or, owing to such fear, unwilling to avail himself of the protection of that country; or who, not having a nationality and being outside the country of his former habitual residence [ ... ] is unable or, owing to such fear, is unwilling to return to it. (UNHCR 1951/1967, p. 14)

This definition precludes vertical-forced migrants as being refugees in most circumstances (see Elden (2013) for a discussion of the vertical geopolitics of borders). As above, the same distance question applies for refugees, in that movement could be a matter of meters to cross an international border or it could be hundreds of kilometers without crossing into another country.

\subsection{Climate Change}

Two separate United Nations (UN) agencies are responsible for addressing different aspects of climate change and each has its own definition of the term. The Intergovernmental Panel on Climate Change (IPCC) was created by the UN's World Meteorological Organization (WMO) and UN Environment (UNEP). It publishes assessments of what member states can agree is the current state of climate change science. IPCC (IPCC 2013-2014, p. 1760) defines climate change as "a change in the state of the climate that can be identified (e.g., by using statistical tests) by changes in the mean and/or the variability of its properties, and that persists for an extended period, typically decades or longer". These words are clarified by defining "climate" as "the statistical description in terms of the mean and variability of relevant quantities over a period of time ranging from months to thousands or millions of years" (IPCC 2013-2014, p. 1760) followed by reference to the WMO typically taking thirty years as the timeframe over which climate is calculated.

UN Climate Change is the secretariat of the United Nations Framework Convention on Climate Change (UNFCCC) which deals with the intergovernmental policy and legal frameworks for addressing climate change topics. UNFCCC (1992, Article 1, para. 2) states that "'Climate change' means a change of climate which is attributed directly or indirectly to human activity that alters the composition of the global atmosphere and which is in addition to natural climate variability observed over comparable time periods". The IPCC's definition of "climate" is used. The difference in definitions of "climate change" is that the IPCC investigates any change in climate whereas UN Climate Change addresses only anthropogenic climate change. 
In aiming to determine causality from climate change or its impacts to population movements, a decision must be made regarding which definitions of "climate" and "climate change" to use. For developing a method to count and calculate climate change migrants, both definitions of "climate change" could be considered, with a separate tally for each. Given WMO's definition of "climate" as being calculated over thirty years, this choice would be reasonable for climate change migrants, but calculations could be made for different definitions of climate's time period in order to see how sensitive the results are to different definitions.

\subsection{Climate Change Causing Migration?}

Why climate change is purported to cause migration needs to be considered. Fundamentally, the suggestion is that climate change will make the environment much worse for living, thereby interfering with food, water, health, livelihoods, and infrastructure to the extent that people think they will be better off in other locations. At times, the alternatives might to move or to die. The presumption of all conditions inevitably becoming worse for everyone due to climate change has long been challenged in discussions of winners and losers (Glantz 1995).

For instance, many storms around the world are expected to become more intense and less frequent due to climate change (Walsh et al. 2016). A lower storm frequency means less experience in dealing with them while increased intensity requires more measures to reduce vulnerability. Without learning from experience and adjusting to increased intensity, both of which require investment, augmented storm damage could lead to migration-related decisions. The real cause of such migration would be the lack of investment rather than the storms changing due to climate change. Similarly, climate change influencing the environment involves factors both supporting and inhibiting the spread of insect-borne disease (Costello et al. 2009). In cases where insect-borne disease spread is supported by climate change, investment could avoid adverse effects, just as eradication campaigns continue today for diseases such as polio and dracunculiasis. If migration is induced by climate change influenced storms or diseases, then the migrants might be not be climate change migrants, but rather "lack of investment in dealing with climate change impacts" migrants.

Not all climate change impacts can necessarily be tackled with investment. As heat-humidity combinations over several days reach a regime precluding outdoor labor, and precluding indoor survival without expensive air-conditioning, people across large areas might have little option except to move or to die (Watts et al. 2018a, 2018b). Sea-level rise salinating freshwater supplies and agricultural land, while inundating previously dry land (depending on coastal morphological responses), has the potential for providing similar circumstances. Ocean acidification combined with warmer seas could possibly cause significant coral reef mortality, augmenting coastal erosion and wiping out coastal and shallow-water livelihoods. Projecting such outcomes in specific locations is difficult, but they remain realistic scenarios precipitating migration from climate change with little chance of averting the impacts.

\section{Counting and Calculating Climate Change Migrants}

With Section 2's understanding of the two key elements of climate change and migration, the next step in counting and calculating climate change migrants is to seek causality from climate change to population movement via climate change impacts. This approach requires a step-by-step understanding of how people would be labelled as climate change migrants.

\subsection{Attributing Migration to Climate Change Impacts}

The first step is counting individuals who are moving, leading to the challenges articulated in Section 2.1 regarding distance moved and determining labels, namely amongst "migrant", "forced migrant", and "refugee". If climate change refugee (or climate refugee) numbers are expected to have standing in international legal frameworks, then counting or calculating them is easy. At the moment, 
this number is zero and could be only zero, since the current legal definition of 'refugee' does not include moving for environmentally related reasons (Section 2.1).

If climate change migrants are being counted irrespective of refugee or other forced status-that is, people are moving any distance due to climate change- - then Watts et al. (2018b, p. 594) suggest a baseline of "climate change is the sole contributing factor" to migration, hence no other factors influence the migration. This criterion is stringent, running into the challenge of being too confined compared to Baldwin (2014) description of why the discussion should be pluralized. It nonetheless serves to establish a minimum number of climate change migrants. Watts et al. (2018b) report this value as 4400 people, from the Carteret Islands, Papua New Guinea; several Alaskan villages; and possibly Isle de Jean Charles in Louisiana.

Watts et al. (2018b) aimed to achieve a baseline of climate change migrant numbers by considering only peer-reviewed literature, although there would be no guarantee that every peer-reviewed paper is entirely accurate. Furthermore, in the end, they referred to a USA government report (General Accounting Office 2003) with regards to Alaskan communities, because no peer-reviewed paper had independently published data as detailed and as comprehensive as General Accounting Office (2003). The scientific literature, in fact, has never been especially detailed or reliable in identifying and proving that specific communities or people are moving due to climate change impacts only or attributing parts of their movement to climate change impacts, making the task set by Watts et al. (2018b) extremely complex.

For instance, Ahmed (2018) starts with the assumption that climate change will force people to move within or from Bangladesh, without providing evidence of cause and effect. Specific examples given in Ahmed (2018) to demonstrate "climate refugees" are all weather-related disasters without demonstrating links to climate change by either definition. Other reasons for Bangladeshis migrating, post-disaster and irrespective of disasters, are given short shrift. The focus is on assumed climate change impacts with limited connection to the wider literature on Bangladeshi mobilities (e.g., Kumāra 2006; Mortuza 1992; Paul 2005).

Watts et al. (2018a) update the list of case studies from Watts et al. (2018b), explaining that subsequent work suggested that people from the Carteret Islands and Isle de Jean Charles are being forced to move for a variety of reasons, amongst which climate change impacts are included but are not the sole factor. From the beginning of understanding climate change impacts on low-lying atolls, Carteret Islanders were seen as perhaps being forced to move due to sea-level rise (Connell 1990), garnering significant attention for their plight (Rakova et al. 2009) despite the wider contexts in which Connell (1990) had placed his analysis. Those wider contexts were often subsumed by climate change migrant (and climate change refugee) rhetoric. A later study (Connell 2016) re-evaluated the contexts, suggesting that the Carteret situation is caused more by local human changes such as constructing a sea wall as well as natural variations, even while other authors continue to label the situation as "climate-related migration" partly because sea walls did not help (Schwerdtle et al. 2018).

The construction of sea walls is of particular interest in trying to attribute forced movement to climate change. Vunidogoloa, Narikoso, and Denimanu are Fijian villages which are mentioned in studies as moving inland because climate change impacts have led to the sea encroaching (McNamara and Combes 2016). Hermann and Kempf (2017) deconstruct such discussions, supporting the notion that little physical evidence exists for climate change impacts causing the villages to move. This point is especially important given that poorly designed sea walls can cause or exacerbate beach and other coastal erosion (Pilkey and Wright 1988; Thomas and Hall 1992). Even if climate change impacts were one factor amongst many for these Fijian villages, it is unclear how much of a role climate change impacts are proven to have played in the decision to move, because the evidence to make this judgement has not been collected.

Consequently, from the list of climate change migrants in Watts et al. (2018b), only the Alaskans from General Accounting Office (2003) (validated more recently by Albert et al. (2018) and Manrique et al. (2018)) remain considered as forced migrants with climate change as the only factor causing their 
move (Watts et al. 2018a). All these villages seem likely to move several kilometers inland, so still within Alaska and near their communities of origin, yet nonetheless forced by climate change impacts.

Outside of these Alaskan villages, people have a multitude of reasons for moving, even when impacted substantially by climate change, making attribution difficult. Therefore, the next step in counting and calculating climate change migrants would be establishing how much climate change influences their decisions to move. Research methods such as interviews, surveys, focus groups, and participatory activities can gather data in this regard and have been applied for the topic (Findley 1982; van der Velde et al. 2009; Vargas-Silva 2012). Limitations and ethical dilemmas of these methods are well-known in that people might not always provide their complete views, deliberately or inadvertently, while viewpoints expressed are always subject to power relations and interpretation (Cooke and Kothari 2001; Hickey and Mohan 2004; Lykes et al. 2011).

Overall, for almost all cases, attributing movement to climate change wholly or partially is not straightforward. Robust, repeatable, and verifiable methodologies might not exist apart from the (currently few) clear-cut instances such as Alaska. This situation might change in the future.

\subsection{Time Scale of the Movement}

Following attribution, the second step in counting and calculating climate change migrants is to establish the time scale of the population movements. If it were a requirement that people move permanently, then counting would need to wait until the migrants had died, as it could not be certain that they would never return otherwise. There is no specific need to establish permanence or expectations of permanence. Migration has always been an important and often essential part of human life and livelihoods (Fiddian-Qasmiyeh et al. 2016; Meir 1986; Stojanov 2014; Urry 2007). Such population movement studies have long established that people are not necessarily sedentary; can presume to move permanently but then return; or might be circular migrants meaning that they move temporarily and return temporarily to their place of origin in a continuing cycle which might be seasonal or for several years at a time in each location (see also Bellwood 2013; Solé et al. 2016).

The temporal key for counting and calculating climate change migrants, perhaps, is to be time-independent regarding movement while seeking climate change impacts over the timeframe of climate which is at least thirty years. If people move, then they are included in the tally, no matter how long it takes them to move and no matter how long they remain in their new location. In such cases, an inconsistency might emerge if people purport to move due to climate change impacts, deciding later to move back to their original location irrespective of continuing or perceived climate change impacts. People might also claim to move due to climate change impacts when they are really seeking other opportunities. They might determine that they do not like their destination, so they move back to their origin or move to another location, no longer mentioning climate change-or perhaps claiming climate change impacts as the reason for moving from their new place.

Counting, calculating, and projecting climate change migrant numbers through time produce another conundrum. Projections regarding climate change and its impacts have been studied for the next 10,000 years (Clark et al. 2016). Projecting human responses to climate change impacts over a similar timeframe, or a fraction thereof, is fraught with difficulty given how rapidly society and technology change.

While speculation, scenarios, and futurology are important components within this science (Attali 2011; Goldthorpe 1971), little confidence would exist regarding accurate and precise indications of how people might or might not respond to environmental stimuli over centuries and millennia, especially in terms of population movements. At these time scales, fiction might provide as much help as peer-reviewed studies. Aside from forced migration novels such as John Steinbeck's The Grapes of Wrath (1939), notable futurist novels involving forced migration include Arthur C. Clarke's The Songs of Distant Earth (1986), Margaret Atwood's The MaddAddam Trilogy (2003, 2009, 2013), and Cormac McCarthy's The Road (2006). Examples of science fiction movies about environmental migration are Waterworld (1995) and The Day After Tomorrow (2004). At the extreme end of environmental or climate 
change, migrants would be fleeing the Earth (so perhaps they are refugees?) which is slowly dying due to human activity, such Ben Elton's novel Stark (1989) and the movie WALL-E (2008). Making defensible projections of such scenarios, the decision-making processes, and the success or failure would not be feasible, apart from the range being from zero to the entire human population.

\subsection{Space Scale of the Movement}

The third step in counting climate change migrants is to establish the spatial scale of the population movements. Section 2.1 explained that no set answer exists regarding how far people must move in order to be considered a migrant or a refugee. For the purposes of counting and calculating, it might be a useful step to adopt part of the legal definition of "refugee" that the migrants must cross an international border-or, at minimum, a political jurisdiction which could include municipal boundaries. Even though such boundaries are comparatively clearly delineated, notwithstanding border disputes and arbitrariness, would this scoping actually assist?

One consequence would be an inevitable underestimate of numbers, because internal movements would not be included. Regarding internal movements, the Alaskans identified in General Accounting Office (2003) are moving due to climate change impacts only, so they should be counted as climate change migrants. Except, by moving their villages, they are moving their municipal jurisdiction, so technically they are not crossing a municipal boundary. Alaska has boroughs, rather than counties, and it seems unlikely that all villages will traverse a borough boundary, again potentially removing them from the count. As another example, if tens of thousands of people had to move from Shanghai or southern Bangladesh due to climate change impacts, then depending on exactly where they moved would determine whether or not a political boundary had been crossed. It is certainly unlikely that all would move across an international border, since they could move hundreds of kilometers and still be in the same country.

Furthermore, regarding international borders, it is possible to migrate across an ocean without crossing an international border. France has five departments and regions which are fully part of the country and the European Union, but which are not in Europe: French Guiana (South America), Guadeloupe (Caribbean), Martinique (Caribbean), Mayotte (Indian Ocean), and La Réunion (Indian Ocean). Montserrat is a UK Overseas Territory in the Caribbean and, after its volcano started erupting in 1995, more than two-thirds of this Caribbean island's population ended up leaving, many to the UK. Although Montserrat is not fully within the UK, there is not an international border between the island and the UK, so it would unclear whether or not Montserratians could be "volcano refugees" in principle even though they are "volcano migrants" in practice. Conversely, there are no direct commercial Montserrat-UK travel options, so most people would travel via the country of Antigua and Barbuda - and perhaps additionally other countries such as the USA-meaning that they have crossed an international border. Similarly, if climate change impacts undermine infrastructure or livelihoods in northern Norwegian towns such as Vardø or Nesseby, so people decide to move south to Trondheim or Oslo, packing up and driving their possessions would find the quickest route through Finland and Sweden-moving internally but crossing international borders.

Political jurisdictions and their boundaries change, including international borders, adding further complications to categorizing spatial movement. Bangladesh is often cited as being a country at high risk of producing "climate refugees" (Ahmed 2018). The country gained independence from Pakistan in 1971, which followed the 1948 partition creating India and Pakistan as separate, sovereign states. Had these country-level splits not occurred, then most Bangladeshi migrants, climate change related or not, would probably be moving internally as they often did, (i) overland to other parts of India prior to 1948 when Bangladesh was East Bengal, and then (ii) when it was East Pakistan until 1971, moving to West Pakistan. In 2019 and beyond, Bangladeshis are still moving for ostensibly similar reasons as before, including political persecution, sometimes moving within Bangladesh and sometimes crossing into Assam, India or other countries, although recently not going to Pakistan much (e.g., Kumāra 2006; Swain 1996; UNICEF 2018). 
Such arbitrariness of some international borders, and when they were created, leads to an arbitrary change from forced or unforced migrants to potential refugees for some people moving. The same argument could be made for South Sudan gaining independence in 2011 and Timor-Leste becoming sovereign in 2002. Independence movements continue in Greenland, New Caledonia, Nevis, Québec, and Scotland. Over the decades-scale impacts of climate change potentially forcing movement, international borders are likely to appear and disappear. Yemen and Germany each unified their two parts in 1990. Land swaps to realign borders occur as with Netherlands and Belgium in 2016 along the River Meuse/Maas. Sub-national borders are not immune from changes. In Toronto, Canada, a new municipal jurisdiction with its own government was created in 1954 and then provincially dictated amalgamation dissolved several of its constituent parts in 1998.

Moreover, even if migration is forced by climate change impacts, the need to cross a jurisdictional border might result from non-climate change related factors. Many coastal countries have reasonably high topography such as Mauritius and Barbados. In many locations in these countries, a relatively short move from coastal locations, without crossing a political jurisdiction, should leave people high enough above sea level to avoid the worst expected impacts from sea-level rise until at least the year 2100. Such a move might not be feasible because so much land is already owned or otherwise allocated. Uses include natural heritage protection, ancestral land, cemeteries, resorts, golf courses, and agriculture. Meanwhile, moving inland in countries such as Comoros and St. Lucia might lead to living in volcano or landslide hazard zones. Consequently, people might leave their country because they are not permitted to move internally or because it increases their risks to environmental hazards. In these circumstances, are climate change impacts the real or predominant cause of moving? Would other factors supersede climate change, namely, current land use practices or lack of resources allocated for supporting safe internal migration?

Thus, even a fairly straightforward and monitorable decision such as crossing into another jurisdiction does not lead to unambiguous counting or calculating of climate change migrants, yielding large error bars. Yet an underestimate is not necessarily a detrimental situation, because it establishes a minimum level, similarly to the calculations in Watts et al. (2018b). If a good percentage of a parish's or country's population move internally, then the underestimate (often close to zero) might be so low as to be unusable for policy and action (see also the discussion on "maximalists" and "minimalists" in Klepp 2017).

\subsection{Summary}

Given the discussion in this section, a robust, repeatable, and verifiable method for counting and calculating climate change migrants might not be feasible without arbitrary, inconsistent, and unreliable choices to begin, the baselines for which might change. The complexities raised regarding attribution, time scale, and space scale corroborate and add to the concerns about the already articulated complexities of climate change migration (Baldwin 2013; Brzoska and Fröhlich 2016; Nicholson 2014). It would certainly be possible to establish a minimum number or a set of minimum numbers using different assumptions, but they would have large error bars and these numbers might not be useful for policy and action.

\section{Subjectivity of Decisions for Calculating Climate Change Migrants and Non-Migrants}

Section 3 demonstrated that, ultimately, counting and calculating numbers of climate change migrants depend on the definitions selected. One decision described is how much climate change needs to influence migration in order for the migrants to be included in the count. Then, decisions are needed regarding the time and space scales of movement. The descriptions show how these decisions are principally subjective, meaning that they would be easily disputable leading to different results depending on who is counting, and perhaps, the political reasons for making the count. As with the arbitrary decision of defining climate change and its timeframe (Section 2.2), multiple calculations could be completed to determine high and low values. The range would be large, leading to the vastly 
varying numbers which are reported (Gemenne 2011), usually with limited empirical or verifiable basis (Brzoska and Fröhlich 2016; Hartmann 2010; Nicholson 2014). That is, labelling or not labelling people as "climate change migrants" or variations, and hence the total numbers tabulated, becomes to a large extent a political choice.

The choice of vocabulary is also political. With respect to migrants, "climate" is often conflated with "climate change" despite science clearly differentiating these terms (Section 2.2). Phrases such as "climate migrants" and "climate refugees" are used to refer to people moving due to climate change, confusing the causation amongst (i) weather (which, over decades, is "climate"), (ii) changes in weather statistics over decades (IPCC's definition of "climate change"), and (iii) changes in weather statistics over decades due to human activities (UN Climate Change's definition of "climate change"). Further conflation is made with all "environmental migrants" and "environmental refugees", even though climate change is one influence on the environment amongst many. Environmental migration has long occurred for a range of reasons from dam construction (World Commission on Dams 2000) to volcanic eruptions (Lane et al. 2003).

Another political element in vocabulary is the choice of "refugees", "migrants", "forced migrants", "population movement", and variations. Objections to using the term "refugee" for climate change movement are (i) the lack of inclusion of environmental reasons within UNHCR 1951/1967 (UNHCR 1951/1967) and (ii) fear that including environment-related reasons in the "refugee" definition will force the entire document to be renegotiated and potentially weakened (Hall 2013; IOM 2014; Nishimura 2015). Others, including some of the people directly affected, consider the labelling of people as "climate (change) refugees" to be pejorative. As McNamara and Gibson (2009) report, many Pacific islanders potentially affected by forced migration due to climate change do not wish to be termed "refugees" and do not wish to be seen as poor, helpless victims. Wyett (2014) describes the policy from Kiribati at the time of "migration with dignity", aiming for population movement related to climate change to be conducted as the last option and on the terms of the people who are moving, not as forced migration with the migrants needing external assistance.

These considerations tend not to be fully incorporated into the numerous proposals for mechanisms to formalize climate change related migrants such as "The peninsula principles on climate displacement within states" (Leckie 2014) and a new convention (Docherty and Giannini 2009). Many other practical problems emerging from counting and calculating climate change migrants, as discussed here, are also not fully addressed in these attempts to define, label, or otherwise produce a specific, delineated category.

Family-level dynamics are one example. If one family member-perhaps the one bringing in the most income-decides to migrate due to experienced, perceived, or presumed climate change impacts, and this individual brings the rest of the family, are all family members equivalently climate change migrants? Rather than counting people, the problem could be reformulated as counting families or households. This task would entail delving into the extensive literature on how to define a family or a household (e.g., Malinowksi 1913; Solien 1960) and interpreting such discussions in the context of assumptions about cultures and cultural superiority. An alternative would be to total the number of communities or settlements which are relocating, again under a presumption that these units are easily delineated and are meaningful, which is not necessarily the case (see Titz et al. 2018).

A further difficulty in counting climate change migrants regardless of the unit of analysis is that people will sometimes move based on perceived or expected climate change impacts without having witnessed many or any impacts. Connell (2016) explains this possibility for the Carteret Islands, indicating the potential that the desire to move has impetus in assumptions or discourses of climate change migration rather than in definitely experienced impacts of climate change causing migration. In Miami-Dade County, Florida, Keenan et al. (2018) indicate that prices of single-family dwellings are increasing faster at higher elevations than at lower elevations, seemingly because of increased flooding at lower elevations. They are careful in how they express their findings, especially in terms of caution about linking climate change with changes in flooding or perceived changes in flooding. They 
explain how perceptions of future climate change impacts are likely to influence the observed property value trends. The question remains that if people move due to assumed or speculative climate change impacts, should they be considered to be climate change migrants, whether or not their expectations of climate change impacts are eventually met by reality?

Climate change impacts might remove migration options for people who would otherwise wish to move or who might consider moving. That is, given that climate change impacts are forcing some people to move, namely in Alaska, what are the prospects for climate change impacts forcing non-migration? An example could be a couple in northern England saving up to retire in southern Spain when climate change is attributed to the increasing frequency, length, and intensity of heat waves (Achebak et al. 2018) making it dangerous to be outdoors and, in the end, dangerous to be indoors without air conditioning. Consequently, the couple does not move, remaining in their northern England home. Attribution science is reaching the point where specific weather parameters can sometimes be connected to climate change with a high degree of confidence (National Academies of Sciences, Engineering, and Medicine 2016). It is trickier to determine whether or not this couple are climate change forced non-migrants. They could stay indoors in Spain with air conditioning during the heat waves, provided they could afford the electricity bill and wish to consume this amount of electricity. They could retire to coastal Germany or southern England instead, again provided they would wish to and could afford it.

Another example would be a landholder with a small coastal plot who has been saving up to move when sea-level rise starts salinating and inundating their land. As they have not been able to afford insurance or companies would not sell them insurance, the landholder's savings are now used trying to survive each year to the point that they can no longer afford to move. They become trapped on their coastal land due to climate change impacts-or possibly due to lack of external assistance to support them with insurance or moving. This scenario parallels experiences in the Czech Republic in which people wish to move from their regularly flooding house, but they cannot afford to move because their property is unsellable and uninsurable (Stojanov et al. 2015). This Czech example could be used to forecast by analogy (Glantz 1988) for climate change forced non-migration, because the Czech floods have not been attributed to climate change.

The same difficulties and complexities for calculating climate change migrants (Sections 2 and 3) appear for calculating climate change non-migrants: definitions, attribution, spatial scales, and temporal scales. If all these problems could be overcome, then for counting and calculating, should climate change non-migrants be subtracted from climate change migrants to yield a net climate change migration total? The result might be negative numbers of climate change migrants.

Given that counting and calculating numbers of climate change migrants and non-migrants involve political choices to reach the tallies, meaning that the results are inherently political, is it worthwhile making the effort? If numbers, or even their ranges, might be robust, advantages might exist. Certainly, the Alaskan villages are examples of people being forced to move only because of climate change. In these instances, staying would require such extensive engineering and maintenance of the coastlines that moving might be cheaper and easier (plus, the communities would be changed about as much by in-situ actions as they will be changed by moving). Coastal engineering might not even work for very long. The Alaskan numbers are robust and verifiable, providing an absolute minimum to the numbers of climate change migrants for the moment.

As climate change impacts become more evident over coming decades, shorelines will continue to be monitored to determine their responses to sea-level rise (especially from thermal expansion and perhaps from ice sheet collapse, if it starts); ocean acidification; changing ecosystems, especially coral reefs; altered storm, wave, and current regimes; and freshwater supplies. For now, the geomorphological, ecological, and biogeochemical responses of tidal and coastal zones to climate change impacts are packed with uncertainties, unknowns, and complexities. The range of coastal outcomes under similar environmental changes runs from substantial retreat and disappearing islands through to expansion in area and volume (Albert et al. 2016; Ford 2012; Yates et al. 2013). 
Consequently, going beyond the numbers from the clear-cut case studies in Alaska might be unworkable, so explanatory and predictive models of climate change migrants and non-migrants would cover wide spectra with substantive error bars. This situation does not preclude pursuing the work for the sake of science, to establish likely maxima, minima, distributions, and probability functions. In doing so, one outcome to be aware of and to try to avoid is that pre-established ideological perspectives will tend to use selected results to justify existing viewpoints rather than developing viewpoints which encompass all the results (Nicholson 2014). Specifically, political interests intent on disparaging climate change impacts as a problem would adopt the low estimates whilst those seeking to amplify concerns about climate change impacts would adopt the high estimates.

This statement is not hypothetical. Watts et al. (2018b), using numerous nuances and provisos, reported counts of people migrating due to climate change impacts. They concluded that approximately 4400 people fell into this category at the time of the report, but by 2100 , in the absence of concerted action, the number could reach one billion plus or minus fifty percent. Reporting Watts et al. (2018b), the center-left UK-based newspaper The Independent, known for its pro-environmentalist stances, published the headline "Climate change could force more than a billion people to flee their homes, says major health report" for a 31 October 2017 story highlighting the potential negative health effects of climate change. One week later, the USA-based center-right Inside Sources published the headline "Lancet Study Finds Climate Change Has Uncertain Impact on Migration" emphasizing the 4400 number in a fairly balanced piece which highlighted the uncertainties. Comments on "climate change refugees" have also been used to fuel unscientific anti-immigrant rhetoric, such as the UK right-wing tabloid Daily Mail reporting on IPCC (IPCC 2013-2014) imbalanced human security chapter with the headline "UK warned of 'climate change flood of refugees': Droughts and heatwaves could force millions to flee their country" (1 April 2014).

Examining climate change migrants including through (but not limited to) quantification could be tackled by careful, rigorous, systematic science, especially to analyze what could and could not be achieved. Research methods can explore whether or not it would be appropriate, useful, and usable to try to assign a number or label to a process as complex as migration and non-migration with different degrees of being forced and voluntary, given all the factors involved. Mixed motives for migration and non-migration — within individuals, families, households, and populations—could be explored, developing models to determine percentages of different reasons inputting into a decision. Methodologies would draw on previous studies, such as for Canada (Currie and Halli 1989) and the Philippines (Amacher et al. 1989).

Science can be a powerful process to identify, deconstruct, and overcome these complexities, as long as the limitations, provisos, biases, nuances, and subtleties are always admitted and accepted. Instead, political agendas exist on this topic from many standpoints, pushing forward non-scientific drivers for counting and calculating in order to support existing beliefs (Baldwin et al. 2014; Bettini 2013; Hartmann 2010). In the USA, a militarized and securitized response has dominated (Hartmann 2010). Elsewhere, dystopian narratives prevail. Humanitarian needs (based on climate change migrants being victims) and securitization (based on climate change migrants being threats) are pushed to the forefront (Bettini 2013), thereby circumventing scientific discussions of definitions, categories, labels, and complexities. Nicholson (2014) even challenges the point of trying to determine causality which he explains might not be feasible while, for Syria, Fröhlich (2016) deconstructs the superficially presumed causality from climate change to migration to conflict.

Ultimately, these analyses combined with the discussion in Section 3 lead to an understanding regarding root causes of forced migration or forced non-migration which might be linked to climate change: It is typically a lack of support mechanisms to deal with climate change impacts, rather than the climate change or its impacts per se, which forms the root causes. Such migration and non-migration are, in effect, simultaneously (i) a failure to adapt to climate change due to lack of support, thereby forcing (ii) non-migration as adaptation or migration as adaptation to climate change impacts. These points are imbued with and driven by deeply entrenched political processes constructing climate 
change as a physical manifestation without connecting to the underlying politics of why the physical changes are happening (see analyses in Felli and Castree 2012; Klepp and Chavez-Rodriguez 2018; Klepp and Herbeck 2016; Hartmann 2010; Nicholson 2014; Stojanov 2014).

The Alaskan villages represent an exception to this analysis and more exceptions could yet emerge. For the most part, discussion about counting and calculating climate change migrants tends to make numerous assumptions about definitions, attributions, and linear cause-and-effect pathways. These assumptions do not stand up to scrutiny and do not admit or try to tackle the inherent complexities.

\section{Conclusions}

Trying to label, count, and calculate people as climate change migrants—or as variations such as climate refugees, climate change refugees, and environmental refugees-poses an interesting and challenging scientific problem. With clear definitions and explicit starting assumptions, some headway can be made in tabulating the numbers, but mainly as minimal values with large error bars. Changing baselines, legitimate concerns about the assumptions, and complexities question the usefulness of even these calculations for policy and action.

This situation contrasts with efforts to quantify in order to justify pre-decided policies and actions. Underestimates could justify an already decided political stance that action on climate change need not be substantive. Overestimates could justify a political stance about preventing migration because migration is presumed to be inherently bad or a political stance that climate change is a massive, possibly existential, threat to humanity. It is straightforward to ensure that numbers present what a political stance wishes them to say, in the face of the methodological decisions which must be made yet which are inherently subjective and arbitrary.

Given these methodological challenges and the political uses of the resulting numbers, a robust, repeatable, and verifiable methodology might not be feasible for counting and calculating climate change migrants. Instead, even while the politics drives the calculation methodologies and the numbers, the numbers are then used to pose as an objective and indisputable reason to implement policies which were desired anyway, trying to bypass the political or ideological reasons for those policies. This includes attaching labels to people based on decisions which are made about attributing movement to climate change, the spatial scales of movement, and the temporal scales of movement.

Ultimately, counting, calculating, and labelling climate change migrants and non-migrants depend on the definitions selected and debatable choices. The futility of finding a robust, repeatable, and verifiable methodology could also mean that the attempts to do so distract from those who are moving only due to climate change, such as in Alaska. Apart from those few exceptions, which might expand in the future, labelling or not labelling people as "climate change migrants" or variations is a subjective, and hence political, choice. Efforts would be better spent contributing to the ongoing efforts to understand people's motivations for migrating or not migrating under all circumstances. In such work, climate change would be one potential factor amongst many, rather than starting with the assumed inevitability of climate change causing migration.

Funding: The Lancet Countdown's work is supported by an unrestricted grant from the Wellcome Trust (200890/Z/16/Z).

Acknowledgments: This paper was completed as part of the Lancet Countdown project (Tracking the connections between public health and climate change) http://www.lancetcountdown.org.

Conflicts of Interest: The author declares no conflicts of interest.

\section{References}

Abubakar, Ibrahim, Robert W. Aldridge, Delan Devakumar, Miriam Orcutt, Rachel Burns, Mauricio L. Barreto, Poonam Dhavan, Fouad M. Fouad, Nora Groce, Yan Guo, and et al. 2018. The UCL-Lancet Commission on Migration and Health: The health of a world on the move. The Lancet 392: 2606-54. [CrossRef]

Achebak, Hicham, Daniel Devolder, and Joan Ballester. 2018. Heat-related mortality trends under recent climate warming in Spain: A 36-year observational study. PLoS Medicine 15: e1002617. [CrossRef] [PubMed] 
Ahmed, Bayes. 2018. Who takes responsibility for the climate refugees? International Journal of Climate Change Strategies and Management 10: 5-26. [CrossRef]

Albert, Simon, Javier X. Leon, Alistair R. Grinham, John A. Church, Badin R. Gibbes, and Colin D. Woodroffe. 2016. Interactions between sea-level rise and wave exposure on reef island dynamics in the Solomon Islands. Environmental Research Letters 11: 054011. [CrossRef]

Albert, Simon, Robin Bronen, Nixon Tooler, Javier Leon, Douglas Yee, Jillian Ash, David Boseto, and Alistair Grinham. 2018. Heading for the hills: Climate-driven community relocations in the Solomon Islands and Alaska provide insight for a $1.5^{\circ} \mathrm{C}$ future. Regional Environmental Change 18: 2261-72. [CrossRef]

Amacher, Gregory S., Wilfrido Cruz, Donald Grebner, and William F. Hyde. 1989. Environmental Motivations for Migration: Population Pressure, Poverty, and Deforestation in the Philippines. Land Economics 74: 92-101. [CrossRef]

Attali, Jacques. 2011. A Brief History of the Future: A Brave and Controversial Look at the Twenty-First Century. New York: Arcade.

Baldwin, Andrew. 2013. Racialisation and the Figure of the Climate-Change Migrant. Environment and Planning A: Economy and Space 45: 1474-90. [CrossRef]

Baldwin, Andrew. 2014. Pluralising Climate Change and Migration: An Argument in Favour of Open Futures. Geography Compass 8: 516-28. [CrossRef]

Baldwin, Andrew, Chris Methmann, and Delf Rothe. 2014. Securitizing 'Climate Refugees': The Futurology of Climate-induced Migration. Critical Studies on Security 2: 121-30. [CrossRef]

Bellwood, Peter. 2013. First Migrants: Ancient Migration in Global Perspective. Chichester: Wiley Blackwell.

Bettini, Giovani. 2013. Climate Barbarians at the Gate? A Critique of Apocalyptic Narratives on 'Climate Refugees'. Geoforum 45: 63-72. [CrossRef]

Brzoska, Michael, and Christiane Fröhlich. 2016. Climate Change, Migration and Violent Conflict: Vulnerabilities, Pathways and Adaptation Strategies. Migration and Development 5: 190-210. [CrossRef]

Clark, Peter U., Jeremy D. Shakun, Shaun A. Marcott, Alan C. Mix, Michael Eby, Scott Kulp, Anders Levermann, Glenn A. Milne, Patrik L. Pfister, Benjamin D. Santer, and et al. 2016. Consequences of twenty-first-century policy for multi-millennial climate and sea-level change. Nature Climate Change 6: 360-69. [CrossRef]

Connell, John. 1990. The Carteret Islands: Precedents of the Greenhouse effect. Geography 75: 152-54.

Connell, John. 2016. Last days in the Carteret Islands? Climate change, livelihoods and migration on coral atolls. Asia Pacific Viewpoint 5: 3-15. [CrossRef]

Cooke, Bill, and Uma Kothari, eds. 2001. Participation: The New Tyranny. London: Zed Books.

Costello, Anthony, Mustafa Abbas, Adriana Allen, Sarah Ball, Sarah Bell, Richard Bellamy, Sharon Friel, Nora Groce, Anne Johnson, Maria Kett, and et al. 2009. Managing the health effects of climate change. The Lancet 373 : 1693-733. [CrossRef]

Currie, Raymond F., and Shiva S. Halli. 1989. Mixed motivations for migration in the urban prairies: A comparative approach. Social Indicators Research 21: 481-99. [CrossRef]

Docherty, Bonnie, and Tyler Giannini. 2009. Confronting a rising tide: A proposal for a convention on climate change refugees. Harvard Environmental Law Review 33: 349-403. [CrossRef]

Elden, Stuart. 2013. Secure the volume: Vertical geopolitics and the depth of power. Political Geography 34: 35-51. [CrossRef]

Felli, Romain, and Noel Castree. 2012. Neoliberalising Adaptation to Environmental Change: Foresight or Foreclosure? Environment and Planning A 44: 1-4. [CrossRef]

Fiddian-Qasmiyeh, Elena, Gil Loescher, Katy Long, and Nando Sigona, eds. 2016. The Oxford Handbook of Refugee and Forced Migration Studies. Oxford: Oxford University Press. [CrossRef]

Findley, Sally E. 1982. Migration Survey Methodologies: A Review of Design Issues. Liège: International Union for the Scientific Study of Population.

Ford, Murray. 2012. Shoreline changes on an urban atoll in the Central Pacific Ocean: Majuro Atoll, Marshall Islands. Journal of Coastal Research 28: 11-22. [CrossRef]

Foresight. 2011. Migration and Global Environmental Change: Final Project Report; London: The Government Office for Science.

Fröhlich, Christiane. 2016. Climate Migrants as Protestors? Dispelling Misconceptions about Global Environmental Change in Pre-Revolutionary Syria. Contemporary Levant 1: 38-50. [CrossRef]

Fröhlich, Christiane. 2017. A Critical View on Human Mobility in Times of Crisis. Global Policy 8: 5-11. [CrossRef] 
Gemenne, François. 2011. Why the numbers don't add up: A review of estimates and predictions of people displaced by environmental changes. Global Environmental Change 21: S41-S49. [CrossRef]

General Accounting Office. 2003. Alaska Native Villages: Most Are Affected by Flooding and Erosion But Few Qualify for Federal Assistance; Washington: United States General Accounting Office.

Glantz, Michael H., ed. 1988. Societal Responses to Regional Climatic Change: Forecasting by Analogy. Boulder: Westview.

Glantz, Michael H. 1995. Assessing the impacts of climate: The issue of winners and losers in a global climate change. Studies in Environmental Science 65: 41-54.

Goldthorpe, John H. 1971. Theories of Industrial Society: Reflections on the recrudescence of historicism and the future of futurology. European Journal of Sociology/Archives Européennes de Sociologie 12: 263-88. [CrossRef]

Hall, Nina. 2013. Moving Beyond its Mandate? UNHCR and Climate Change Displacement. Journal of International Organisations Studies 7: 91-108.

Hartmann, Betsy. 2010. Rethinking Climate Refugees and Climate Conflict: Rhetoric, Reality and the Politics of Policy Discourse. Journal of International Development 22: 233-46. [CrossRef]

Hermann, Elfriede, and Wolfgang Kempf. 2017. Climate Change and the Imagining of Migration: Emerging Discourses on Kiribati's Land Purchase in Fiji. The Contemporary Pacific 29: 231-63. [CrossRef]

Hickey, Samuel, and Giles Mohan, eds. 2004. Participation-From Tyranny to Transformation? Exploring New Approaches to Participation in Development. London: Zed Books.

IOM. 2014. IOM Outlook on Migration, Environment and Climate Change. Geneva: IOM (International Organization for Migration).

IPCC. 2013-2014. Fifth Assessment Report, Working Group II Glossary. Geneva: IPCC (Intergovernmental Panel on Climate Change).

Keenan, Jesse M., Thomas Hill, and Anurag Gumber. 2018. Climate gentrification: From theory to empiricism in Miami-Dade County, Florida. Environmental Research Letters 13: 054001. [CrossRef]

Klepp, Silja. 2017. Climate Change and Migration. In Oxford Research Encyclopedia of Climate Science. Oxford: Oxford University Press. [CrossRef]

Klepp, Sijla, and Libertad Chavez-Rodrìguez, eds. 2018. A Critical Approach to Climate Change Adaptation. Discourses, Policies and Practices. Abingdon: Routledge.

Klepp, Silja, and Johannes Herbeck. 2016. The politics of environmental migration and climate justice in the Pacific region. Journal of Human Rights and the Environment 7: 54-73. [CrossRef]

Kumāra, Braja Bihārī, ed. 2006. Illegal Migration from Bangladesh. New Delhi: Concept Publishing.

Lane, Lucille R., Graham A. Tobin, and Linda M. Whiteford. 2003. Volcanic Hazard or Economic Destitution: Hard Choices in Baños, Ecuador. Environmental Hazards 5: 23-24. [CrossRef]

Leckie, Scott, ed. 2014. Land Solutions for Climate Displacement. Abingdon: Routledge.

Lykes, M. Brinton, Rachel M. Hershberg, and Kalina M. Brabeck. 2011. Methodological Challenges in Participatory Action Research with Undocumented Central American Migrants. Journal for Social Action in Counseling and Psychology 3: 22-35.

Malinowksi, Bronisław. 1913. The Family among the Australian Aborigines. London: University of London Press.

Manrique, David Romero, Serafín Corral, and Ângela Guimarães Pereira. 2018. Climate-related displacements of coastal communities in the Arctic: Engaging traditional knowledge in adaptation strategies and policies. Environmental Science and Policy 85: 90-100. [CrossRef]

Martin, Brian. 1979. The Bias of Science. Canberra: Society for Social Responsibility in Science.

McNamara, Karen E., and Helene Jacot Des Combes. 2016. Planning for Community Relocations Due to Climate Change in Fiji. International Journal of Disaster Risk Science 6: 315-19. [CrossRef]

McNamara, Karen E., and Chris Gibson. 2009. We do not want to leave our land': Pacific ambassadors at the United Nations resist the category of 'climate refugees. Geoforum 40: 475-83. [CrossRef]

Meir, Avinoam. 1986. Demographic Transition Theory: A Neglected Aspect of the Nomadism-Sedentarism Continuum. Transactions of the Institute of British Geographers 11: 199-211. [CrossRef]

Mortuza, Syed Ali. 1992. Rural-Urban Migration in Bangladesh: Causes and Effects. Dhaka: D. Reimer.

National Academies of Sciences, Engineering, and Medicine. 2016. Attribution of Extreme Weather Events in the Context of Climate Change. Washington: National Academies Press. [CrossRef]

Nicholson, Calum. 2014. Climate Change and the Politics of Causal Reasoning: The Case of Climate Change and Migration. The Geographical Journal 180: 151-60. [CrossRef] 
Nishimura, Lauren. 2015. 'Climate Change Migrants': Impediments to a Protection Framework and the Need to Incorporate Migration into Climate Change Adaptation Strategies. International Journal of Refugee Law 27: 107-34. [CrossRef]

Paul, Bimal Kanti. 2005. Evidence against disaster-induced migration: The 2004 tornado in north-central Bangladesh. Disasters 29: 370-85. [CrossRef]

Pilkey, Orrin H., and Howard L. Wright III. 1988. Seawalls versus beaches. Journal of Coastal Research SI 4: 41-64. [CrossRef]

Rakova, Ursula, Luis Patron, and Citt Williams. 2009. How-to Guide for Environmental Refugees. United Nations University Our World, June 16. Available online: https://ourworld.unu.edu/en/how-to-guide-forenvironmental-refugees (accessed on 28 September 2018).

Ritchey, P. Neal. 1976. Explanations of Migration. Annual Review of Sociology 2: 363-404. [CrossRef]

Schwerdtle, Patricia, Kathryn Bowen, and Celia McMichael. 2018. The health impacts of climate-related migration. BMC Medicine 16: 1. [CrossRef]

Solé, Carlota, Sonia Parella, Teresa Sordé Martí, and Sonja Nita. 2016. Impact of Circular Migration on Human, Political and Civil Rights: A Global Perspective. Basel: Springer. [CrossRef]

Solien, Nancie L. 1960. Household and Family in the Caribbean: Some Definitions and Concepts. Social and Economic Studies 9: 101-6.

Stojanov, Robert, ed. 2014. Migration as Adaptation? Population Dynamics in the Age of Climate Variability. Brno: Global Change Research Centre, Academy of the Sciences of the Czech Republic.

Stojanov, Robert, Ilan Kelman, and Barbora Duží. 2015. Floods and migration in the Czech Republic. Forced Migration Review 49: 49-50.

Swain, Ashok. 1996. Displacing the Conflict: Environmental Destruction in Bangladesh and Ethnic Conflict in India. Journal of Peace Research 33: 189-204. [CrossRef]

Thomas, R. S., and B. Hall. 1992. Seawall Design. Oxford: Butterworth-Heinemann. [CrossRef]

Titz, Alexandra, Terry Cannon, and Fred Krüger. 2018. Uncovering 'Community': Challenging an Elusive Concept in Development and Disaster Related Work. Societies 8: 71. [CrossRef]

UN Commission on Human Rights. 1998. Measures to Improve the Situation and Ensure the Human Rights and Dignity of All Migrant Workers. Report of the Working Group of Intergovernmental Experts on the Human Rights of Migrants Submitted in Accordance with Commission on Human Rights Resolution, 1997/15. E/CN.4/1998/76. New York: United Nations Economic and Social Council.

UNFCCC (United Nations Framework Convention on Climate Change). 1992. United Nations Framework Convention on Climate Change. Bonn: UNFCCC.

UNHCR 1951/1967. Convention and Protocol Relating to the Status of Refugees. Geneva: UNHCR (United Nations High Commissioner for Refugees).

UNICEF. 2018. Bangladesh, Migration Profiles. New York: UNICEF, Available online: https://esa.un.org/MigGMGProfiles/ indicators/files/Bangladesh.pdf (accessed on 27 November 2018).

Urry, John. 2007. Mobilities. Cambridge: Polity.

van der Velde, Jeannette, Deanna L. Williamson, and Linda D. Ogilvie. 2009. Participatory Action Research: Practical Strategies for Actively Engaging and Maintaining Participation in Immigrant and Refugee Communities. Qualitative Health Research 19: 1293-302. [CrossRef] [PubMed]

Vargas-Silva, Carlos. 2012. Handbook of Research Methods in Migration. Cheltenham: Edward Elgar.

Walsh, Kevin J.E., John L. McBride, Philip J. Klotzbach, Sethurathinam Balachandran, Suzana J. Camargo, Greg Holland, Thomas R. Knutson, James P. Kossin, Tsz-cheung Lee, Adam Sobel, and et al. 2016. Tropical cyclones and climate change. WIREs Climate Change 7: 65-89. [CrossRef]

Watts, Nick, Markus Amann, Nigel Arnell, Sonja Ayeb-Karlsson, Kristine Belesova, Helen Berry, Timothy Bouley, Maxwell Boykoff, Peter Byass, Wenjia Cai, and et al. 2018a. The 2018 report of the Lancet Countdown on health and climate change: Shaping the health of nations for centuries to come. The Lancet 392: 2479-514. [CrossRef]

Watts, Nick, Markus Amann, Sonja Ayeb-Karlsson, Kristine Belesova, Timothy Bouley, Maxwell Boykoff, Peter Byass, Wenjia Cai, Diarmid Campbell-Lendrum, Jonathan Chambers, and et al. 2018b. The Lancet Countdown on health and climate change: From 25 years of inaction to a global transformation for public health. The Lancet 391: 581-630. [CrossRef]

World Bank. 2018. Groundswell: Preparing for Internal Climate Migration. Washington: World Bank. 
World Commission on Dams. 2000. Dams and Development: A New Framework for Decision-Making. London: Earthscan. Wyett, Kelly. 2014. Escaping a Rising Tide: Sea Level Rise and Migration in Kiribati. Asia E Pacific Policy Studies 1: 171-85. [CrossRef]

Yates, Marissa L., Gonéri Le Cozannet, Manuel Garcin, Emilie Salaï, and Patrice Walker. 2013. Multidecadal atoll shoreline change on Manihi and Manuae, French Polynesia. Journal of Coastal Research 29: 870-82. [CrossRef]

(C) 2019 by the author. Licensee MDPI, Basel, Switzerland. This article is an open access article distributed under the terms and conditions of the Creative Commons Attribution (CC BY) license (http://creativecommons.org/licenses/by/4.0/). 


\title{
Article \\ Moving People in a Changing Climate: Lessons from Two Case Studies in Fiji
}

\author{
Annah E. Piggott-McKellar ${ }^{1, *}$, Karen E. McNamara ${ }^{1}$, Patrick D. Nunn ${ }^{2}$ and Seci T. Sekinini ${ }^{2}$ \\ 1 School of Earth and Environmental Sciences, The University of Queensland, Brisbane, \\ Queensland 4072, Australia; karen.mcnamara@uq.edu.au \\ 2 School of Social Sciences, University of the Sunshine Coast, Sippy Downs, Queensland 4556, Australia; \\ pnunn@usc.edu.au (P.D.N.); sts009@student.usc.edu.au (S.T.S.) \\ * Correspondence: a.piggottmckellar@uq.edu.au
}

Received: 27 February 2019; Accepted: 26 April 2019; Published: 29 April 2019

\begin{abstract}
High levels of vulnerability to climate change impacts are rendering some places uninhabitable. In Fiji, four communities have already initiated or completed the task of moving their homes and livelihoods to less exposed locations, with numerous more communities earmarked for future relocation. This paper documents people's lived experiences in two relocated communities in Fiji-Denimanu and Vunidogoloa villages-and assesses the outcomes of the relocations on those directly affected. This study in particular seeks to identify to what extent livelihoods have been either positively or negatively affected by relocation, and whether these relocations have successfully reduced exposure to climate-related hazards. This study shows that planned climate-induced relocations have the potential to improve the livelihoods of affected communities, yet if these relocations are not managed and undertaken carefully, they can lead to unintended negative impacts, including exposure to other hazards. We find that inclusive community involvement in the planning process, regular and intentional monitoring and evaluation, and improving livelihoods through targeted livelihood planning should be accounted for in future relocations to ensure outcomes are beneficial and sustainable.
\end{abstract}

Keywords: relocation; resettlement; livelihoods; Pacific Islands; migration; SIDS; vulnerability; exposure

\section{Introduction}

Despite high levels of internal resilience, Small Island Developing States (SIDS), as which all Pacific Island Countries (PICs) identify (Barnett and Campbell 2010), have been labelled as some of the most vulnerable places to climate change. This is largely due to a combination of high exposure to climate change impacts as well as a range of underlying social, historical, political, and economic vulnerabilities (Huq and Reid 2007; Jackson et al. 2017; Kelman 2014). Climate change impacts experienced in PICs are predominantly coastal and include rising sea levels, intensification of cyclones resulting in increased storm surge extent, coastal erosion, and changing rainfall patterns (Chand et al. 2016; IPCC 2014b; Keener et al. 2012). Exposure to such climate change impacts is exacerbated by the presence of people, livelihoods, services, and assets in places that can be adversely affected (IPCC 2014a). PICs have high coastline to land mass ratios and primarily coastal settlements (Barnett and Campbell 2010) leading to a significant percentage of the population at higher risk of exposure (Kumar and Taylor 2015). This is further exacerbated by a range of underlying vulnerabilities, such as exposed infrastructure, comparatively low incomes, declining traditional knowledge and practice, historical factors such as colonial legacies, and a dependence on climate-sensitive resources and industries, such as agriculture and fishing (Barnett and Campbell 2010; Connell 2015; Kelman 2014; 
Nunn 2009). For some communities, this confluence of factors has led to people being unable to sustain their everyday livelihoods in their current locations.

The vulnerability of PICs reveals the deeply inequitable nature of climate change, in that those contributing the least to climate change through their greenhouse gas emissions are also those that are currently most impacted (Althor et al. 2016). For example, SIDS combined contribute less than $1 \%$ of the total annual global output of carbon dioxide (Voccia 2011), with PICs contributing less than $0.3 \%$ (Weir et al. 2017). Layers of inequality also exist intra-nationally. The peripherality of a community can indicate higher exposure and vulnerability due to distance from core centers and associated resources (McNamara et al. 2017; Nunn and Kumar 2018). Further, certain groups of people within a community are more vulnerable than others (Arora-Jonsson 2011; Dodman and Mitlin 2013; Heltberg et al. 2009). Owing to traditional gender roles in patriarchal contexts, women often have less access than men to information as well as decision making power (George 2010, 2014), as is the case in many rural Pacific Island communities. Accounting for this, all women (as well as other groups within a community) are not equal with individual vulnerability dependent on a range of intersecting factors including class, education, employment, income, and status (Arora-Jonsson 2011). If these factors are not accounted for when planning adaptation responses, they can perpetuate such inequalities (Carr 2008) and subsequently reduce the legitimacy, equity, and sustainability of adaptation.

When adapting to coastal threats such as sea-level rise and associated impacts there are three typologies of adaptation measures employed: Accommodate, protect, and retreat (Williams et al. 2018). It is important to make the distinction between autonomous retreat (or relocation) of communities, as opposed to planned relocation, which usually involves the coordination and management of the process by an external entity. The causes and evolution that have led to the increase in the latter form of relocation are worth briefly exploring. First, it is important to recognise that internal migration within PICs has occurred throughout history and has been a vital aspect of island communities' livelihoods, resilience, and survival (Barnett and McMichael 2018), with people and entire communities moving in response to changing environmental conditions, as well as in search of improved resources (Campbell 2014). The change towards a less mobile lifestyle, a consequence of colonisation and globalisation, has resulted in communities that have become increasingly permanently attached to place. As such, an inherent adaptation strategy of intentional impermanence common in oceanic island societies has been largely lost (Campbell and Bedford 2014; Gharbaoui and Blocher 2016; Janif et al. 2016).

Planned relocation refers to a "process in which persons or groups of persons move away from their homes or places of temporary residence, are settled in a new location, and provided with the conditions for rebuilding their lives" (UNHCR 2015, p. 9). Of note, within this definition is the explicit mention that relocation should include a focus on providing conditions through which relocated persons can rebuild their livelihoods. This is especially important to consider as research into other forms of resettlement (such as development-induced displacement and resettlement) shows that frequently relocations are unsuccessful in providing successful and holistic outcomes for affected communities because they fail to address such ancillary concerns (Donner 2015; Tadgell et al. 2018). Rather, detrimental outcomes of unemployment, landlessness, homelessness, increased morbidity, loss of access to common property resources, marginalisation, and food insecurity have ensued (Cernea 1997). From this emerges the need to ensure that forethought is built into relocation planning so that such deleterious livelihood outcomes are not replicated.

Communities are already undertaking the process of planned climate-induced relocation in PICs, including in the Solomon Islands (Albert et al. 2018), Papua New Guinea (Connell 2016; Lipset 2013), and Fiji (Barnett and McMichael 2018; Charan et al. 2017; Martin et al. 2018; McMichael et al. 2018). Climate change impacts are projected to be amplified in the future, affecting an increasing range and number of people (IPCC 2014b; Foresight 2011). As a result, it is likely that a greater proportion of people will have to relocate, with some estimates predicting millions may be affected (Ferris 2015), yet the exact numbers are extremely challenging and problematic to predict and quantify (Barnett and O'Neill 2011). 
The process of planned relocations from climate change has therefore emerged as a critical new field of research and policy debate. Viewing climate-induced relocation as not only an adaptation response, but a form of loss and damage has been argued (McNamara et al. 2018) and is being considered by the United Nations Framework Convention on Climate Change (UNFCCC) through its work program on loss and damage. An international set of guidelines pertaining to climate-induced relocation was established by the United Nations High Commissioner for Refugees (UNHCR) in conjunction with Georgetown University in 2015 (UNHCR 2015). Ferris (2015) argues the importance of further developing country-level policies and plans that can provide a framework and ensure that relocation facilitates positive outcomes. Fiji has recently released Relocation Guidelines (that were not publicly available at the time of this research) and is the first country in the world to have such a national framework (Fiji Government 2018), while Vanuatu has recent guidelines on climate change and disaster-induced displacement (IOM 2018).

As climate-induced relocations are likely to increase, the importance of understanding and appropriately managing the process is evident. Within Fiji, four iTaukei (Indigenous) communities have already initiated or completed the relocation of their communities with over 80 further communities recognised by the Fijian Government as in need of future relocation (Barnett and McMichael 2018; Republic of Fiji 2014). Key to reducing the vulnerability of communities to current and anticipated climate change impacts is: Ensuring the process of planned climate change-induced relocation is undertaken in a manner that both reduces the exposure of affected communities to climate change impacts, a key driving force of relocation (Hino et al. 2017); and guaranteeing affected communities have a chance to successfully rebuild their livelihoods in the new location (De Sherbinin et al. 2011). With this context in mind, this research is driven by two key questions:

(1) To what extent have livelihoods been either positively or negatively affected by relocation?

(2) Have relocations reduced exposure to climate-related hazards?

This analysis will be undertaken through an exploration of two recently relocated communities_-Vunidogoloa and Denimanu_on Vanua Levu Island, Fiji. This will then provide the context through which to generate insights and lessons that can be applied to future relocation initiatives going forward.

\section{Study Sites}

Two case study sites are considered in this research, both of which are located on Vanua Levu Island in Fiji. There are 330 islands in Fiji, of which just over 100 are permanently inhabited. The two largest islands, Viti Levu and Vanua Levu, are home to a significant percent of the total population of just over 900,000. Vanua Levu, the second largest island, is where both case study sites in this research are located, although Denimanu is technically offshore. Across Fiji many people live in rural coastal areas, relying on a subsistence lifestyle involving both terrestrial and marine resources. Land in Fiji is an important part of the culture in terms of identity, spirituality, and subsistence (Campbell 2010). Among iTaukei (Indigenous) Fijians, land is codified as mataqali (family land ownership). Almost 90\% of land in Fiji is customarily owned (Campbell 2010). For this reason, this also makes relocation a practical issue raising broader questions of land insecurity. Yet, in both case studies for this research, communities were able to move within or across closely-related mataqali lands. Figure 1 shows the location of Fiji in the Pacific Islands region, Vanua Levu island, and the two case study sites. 


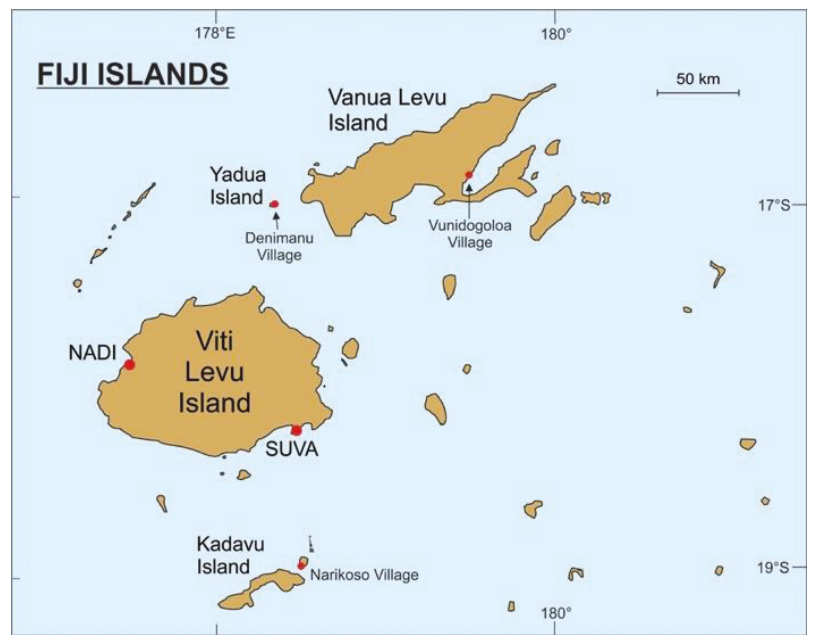

Figure 1. Map of Fiji showing the two case study sites (Vunidogoloa and Denimanu villages).

It is noteworthy that these two case studies exhibit the common contrasts within the range of such relocations. First is the portion of the village relocated, with one case study having a complete village relocation and the other a partial village relocation. Second is the impacts that drove the relocation. The first case study describes how relocation was driven by slow-onset climate change impacts while the other study site is an example of sudden-onset impacts, in this case driven by cyclonic storm surge activity. While not uncritically attributable to anthropogenic climate change, the increased strength of cyclonic and storm activity has a level of climate change attribution (Walsh et al. 2016). Both of these planned relocations were supported by the Fiji Government through both its Ministry of Rural and Maritime Development and its National Disaster Management Office.

\subsection{Vunidogoloa}

Vunidogoloa is located approximately a two-hour bus ride from the nearest town of Savusavu on Vanua Levu Island. It has a population of 153. The people rely heavily on fishing and subsistence agriculture for their livelihoods, as well as cash from market sales of fish and crop surpluses and locally-made crafts. Vunidogoloa has been labeled as the first climate-induced relocation undertaken by the Fiji Government (Charan et al. 2017; Witschge 2018).

Vunidogoloa presents a case of an entire village relocation. The old village was originally situated on the coast. It is important to note that the village had only been in this coastal location for approximately 100 years. Prior to this, they were part of a larger inland village and had relocated to the coast autonomously to be closer to the sea and access its resources (pers. comm. Village Headman 2017). In its former location, the village was increasingly experiencing slow-onset climate impacts including tidal inundation, coastal erosion and saltwater intrusion. This impacted on infrastructure and made growing food crops increasingly difficult. In response, the village was relocated roughly 2 $\mathrm{km}$ inland, adjoining the main road (Figure 2). This relocation occurred on land belonging to the same matagali. The relocation included with it housing, as well as livelihood provisions including fish ponds, pineapple plantations, and cattle. An in-depth recent review of the Vunidogoloa relocation is provided by Charan et al. (2017). 


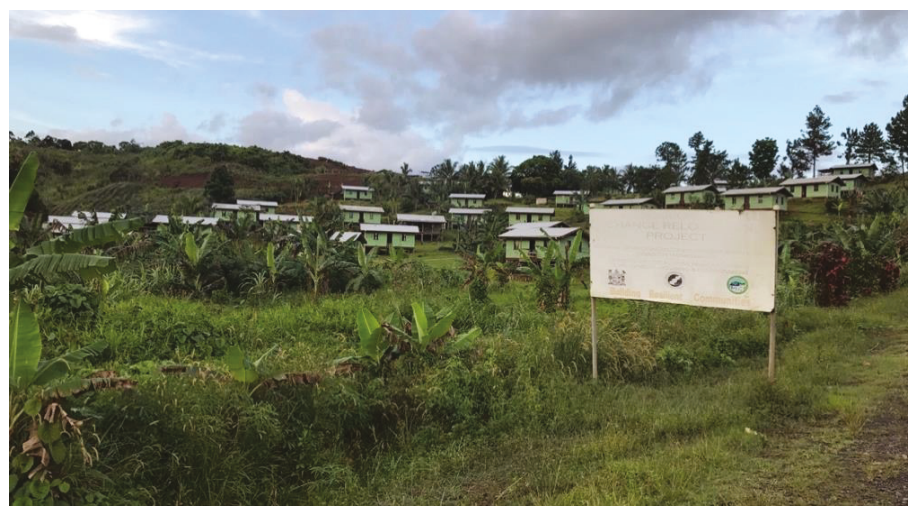

Figure 2. The new village relocation site of Vunidogoloa.

\subsection{Denimanu}

Denimanu village is on Yadua Island, situated off the western extremity of Vanua Levu Island. The village is accessible only by boat. Denimanu is the only village today on Yadua Island with a total population of approximately 170 people. It is also worth noting that Denimanu village has previously independently relocated, prior to this planned relocation. The village has moved (at least) twice in search of better food and living conditions. They have been living in their current location for at least 100 years (pers. comm. Village Headman 2017). The village also relies heavily on subsistence fishing and crop agriculture with surplus sold for income.

The planned relocation that took place in Denimanu was a partial relocation, with approximately half (19 households) of the village relocated. The houses of the affected people were destroyed by impacts from Cyclone Evan in December 2012. The 19 affected dwellings were located at the front of the village, closest to the coastline. New houses were built approximately $500 \mathrm{~m}$ away on a slope of the hill in rows (see Figure 3). The new houses were completed in mid-late 2013. This new location was chosen because the boundaries of the village and the encroaching shoreline made it impossible to rebuild the houses in the location they were previously as the land had been lost. There are two mataqali in Denimanu. A consultation was undertaken between the government and these mataqali to agree on the new location. A more detailed recent review of this relocation is provided by Martin et al. (2018).



Figure 3. The new village relocation site of Denimanu. 


\section{Methods}

This section will describe the methods undertaken during this field study. This has been broken into sections: Data collection and analysis, ethical procedures, and limitations.

\subsection{Data Collection and Anlaysis}

Fieldwork was undertaken in both villages in November and December 2017. A local government official acted as a protocol officer and was present throughout the duration of these visits to act as a liaison and entry point to the communities. Both the protocol officer and one of the researchers/authors (a Fijian national) were translators throughout the research.

The method of data collection included focus groups (FGs), interviews and participant observation. Initially two FGs were undertaken in Vunidogoloa (one men's and one women's), and three in Denimanu (two women's groups and one men's group). As Denimanu was a partial relocation, both groups (those that relocated and those that remain in the original village) were engaged in the research. A second visit to Vunidogoloa was undertaken three weeks after the initial fieldwork where a further two FG discussions were undertaken (one women's and one men's). This was done to both gather additional information and clarify findings to date. This resulted in a total of seven FGs involving 54 participants across both sites. The division of FGs by gender allowed both genders to talk freely, an integral aspect of this research. This is especially important in Fiji as women are often excluded from decision-making processes and do not always have opportunities to speak up in group settings (Singh-Peterson and Iranacolaivalu 2018). The FGs involved discussion about the relocation including participants' experiences and involvement in the process of relocation, and the outcomes since it occurred. Group activities were undertaken that involved participants ranking their perspectives of life before and after relocation across a range of variables. These FGs were recorded, and later transcribed, with detailed notes taken.

Interviews were also undertaken with key members of the community, including leaders, church representatives, and teachers. Interview participants were identified largely from the FGs. From this, the snowball method was used to identify other participants. In this way, discussions with 15 people were undertaken across both sites. Notes were taken during these discussions. Participant observation was an added aspect of the research that gave context to discussions and deepened the research team's understanding of everyday life in these communities.

The data were analysed through a livelihoods framing, owing to the often-detrimental impact relocating communities can have on the livelihoods of those affected. Livelihoods are understood as the resources through which people have access to live a sustainable and fulfilling life and can be measured through numerous avenues and framings (Mallick and Sultana 2017). The Sustainable Livelihood Approach (SLA) is one common lens to understand how people generate a livelihood and how interventions can be designed effectively and appropriately in light of these (Scoones 1998). The SLA considers assets across five capitals (natural, social, financial, human, physical) to be essential to how people can build a livelihood (Bebbington 1999; Morse and McNamara 2013). Owing to the impact of relocation on culture, as well as this being an often-understudied aspect of livelihoods, including the invisible assets of spirituality, connection to place, and ritual (Kingston and Marino 2010), the addition of cultural capital is included here. Assessing the outcomes of relocation using the livelihood assets from the SLA framework has similarly been employed by previous researchers (Mallick and Sultana 2017).

The data gathered from the seven focus groups and 15 interviews were compiled. This data were disaggregated according to the six livelihood asset groups employed in this research: Natural, social, financial, human, physical, and cultural capital. The livelihood analysis focussed on changes in livelihoods as experienced by community members since the relocation. Changes that were commonly identified within the data were coded as a positive, negative or no change. This allowed understanding and exploration of the impact from relocation across each asset group and formed the basis for the results. 


\subsection{Ethical Procedures}

Ethical procedures under the guidelines of the University of Queensland were followed. This included gaining informed consent from participants to participate in this study, and undertake and record FGs and interviews. It is important to acknowledge that Vunidogoloa, known widely as the first climate change relocation site, has had many visitors. This was especially prominent as the research team visited while the recent Conference of the Parties (COP) to the United Nations Framework Convention on Climate Change (UNFCCC) was occurring. As Fiji was hosting this event (externally in Germany), there was high exposure of this site and numerous journalists had recently visited Vunidogoloa. As such, undertaking appropriate ethical procedures such as discussing the research, including aims, data collection, storage and analysis, expectations, confidentiality, outputs, and opportunities for feedback, prior to seeking participants' informed consent was essential.

\subsection{Study Limitations}

There were a number of limitations experienced in this research. First, as the research used primarily qualitative methods, there is the assumption that the information provided by participants was true and honest as to their own experiences. Alternatively, there might have been a high level of positive response bias during FGs and interviews. This is especially relevant when considering how the large number of visitors in Vunidogoloa might influence participants' responses. Second, the use of translators can cause issue with difficulty translating some words (Rudiak-Gould 2012). Third, not revisiting Denimanu for a follow-up visit to allow clarification is seen as another limitation. Finally, many questions involved asking the participants to retrospectively provide information on life prior to relocation for which there could be some issues related to memory.

\section{Socio-Political Context of Relocations}

The socio-political context in which these two relations sit varies significantly. In Vunidogoloa, it was the village headman who approached the government asking to be relocated (Charan et al. 2017). After initial discussions, the village was planned to be relocated in 2012, although this was eventually delayed until January/February 2014. The delays stemmed from a range of factors including concerns that the chosen site was not stable and unduly exposed to erosion, as well as delays in building the new houses (Tronquet 2015). Vunidogoloa is seen as the 'poster child' for climate change relocations, exemplified by the numerous publications and news articles about the relocation (Brill 2017; Charan et al. 2017; Meakins 2017; Rubeli 2015; Tronquet 2015; Witschge 2018). Since the most recent election (November 2018), Fijian Prime Minister Bainimarama has publicly referred to the people of Vunidogoloa as liumuri (backstabbers) as they stated they did not vote for him despite his government relocating the village (Rawalai 2018), possibly exemplifying a level of political expectation resulting from the relocation. On the contrary, the relocation in Denimanu sits within a different context, garnering little public and media attention with few articles that discuss it in detail (exceptions include Bukalidi 2013; Martin et al. 2018).

Within both villages, there was an expressed lack of involvement in decision-making processes by the village members themselves. Within Vunidogoloa while it has been posited that the process was based on "a consensual and participative decision-making process" (Tronquet 2015, p. 29) local residents stated that a lot of what was discussed did not come to fruition: "All the government agencies came in to the new site so we think that everything will be done ... once it is about to finish and we find out that some things were wrong because we were never informed, we were just told. We believe [decisions] were just between the contractors and the government" (Vunidogoloa FG, Men). In Denimanu, village members stated that there was no real consultation with the community at all pertaining to what would be included in the relocation, but rather it was informed by the government that a relocation would happen: "They came to the village and notified us of the relocation in an information session and they gave us the reason why we have to relocate" (Denimanu FG, Men). 
While there were concerns expressed about a lack of participatory consultation with the entire community, women felt that due to societal and cultural norms they were specifically unable to voice their opinions about the relocation. This sentiment is expressly voiced through the following comments by both villages: "The men agreed to relocate ... we would like to say that the men don't consult us. Only the men, the village headman, and the chief, they discuss ... We are just told to listen. When the men say we have to go, we have to go. If they say we have to relocate, we relocate." (Denimanu FG, Women); and "For us, the women, we just listen to whatever the men say and we just agree. They never consult us. The voice of the men is the only voice that is heard, so we just listen to that voice. So whatever the men has agreed we just consent to it" (Vunidogoloa FG, Women). These comments confirm that the gendered cultural and societal norms, which often exclude women from decision-making processes, were not adequately addressed through the process of these relocations, serving to perpetuate rather than alleviate such inequalities.

\section{To What Extent Have Livelihoods Been Either Positively or Negatively Affected by Relocation?}

The UNHCR climate change relocation guidelines state Relocated Persons should be supported to maintain their traditional or previous livelihoods, and, if not able to be done, the provision of new opportunities for livelihoods suitable to the resettlement site should be afforded. Owing to the importance of accounting for livelihoods both through a long history of deleterious outcomes arising from resettlements, as well as being an important aspect of vulnerability reduction, here a livelihood perspective is taken to understand the impacts on affected people from the relocation process. The outcomes of relocation as expressed by community members are shown in Table 1 across natural, social, financial, human, physical and cultural capital. Four sub-sections will be discussed below as they offer insights and contrasts between the two relocated communities: Housing and community infrastructure, social cohesion and cultural assets, health and education, and access to common property resources and food security.

\subsection{Housing and Community Infrastructure}

In both villages, following relocation, there were improvements in housing and community infrastructure. Of note is the provision of facilities in the new village compared to the old village. Solar power was made available for all new households in both villages, and water tanks were provided in Denimanu. In the previous locations only a limited number of people had access to electricity. Further, flush toilets and showers were also installed in both new villages. While the relocation did provide numerous benefits to the villages as documented above, concerns surrounding appropriateness and sustainability of such were raised. In Vunidogoloa, the houses did not include a kitchen as promised, a potential outcome of the rush to finalise the relocation. This meant that villagers had to build kitchens themselves. In Denimanu, when the rain is strong the water leaks into the houses in the new village: "So when it rains heavily the whole house is wet ... overall it is just poor because we have water seep through the door frames and go inside so it rusts and then you can't open the door" (Denimanu FG, Women). This is a key concern considering Fiji is located in the tropics with heavy rainfall throughout much of the year. It was further explained that the showers and toilets blocked regularly. Further, drainage systems were not sufficiently implemented in either village, causing major erosion concerns. In Vunidogoloa, the government came back to address this aspect of the relocation, but it has still not been completed at the time of research with unused drain pipes scattered around the village. 
Table 1. Outcomes on community livelihoods from the village relocations in two communities, denoted as: Positive change (+), no change (0), negative change (-).

\begin{tabular}{|c|c|c|}
\hline & & Outcomes from Village Relocation \\
\hline Livelihood & Change & Description \\
\hline \multicolumn{3}{|l|}{ Natural } \\
\hline Water security & + & Improved water security through provision of water tanks in Denimanu \\
\hline Food security & $\begin{array}{l}+ \\
+\end{array}$ & $\begin{array}{l}\text { Improved food growing potential due to improved land quality in Vunidogoloa } \\
\text { Provision of pineapple crops, fish ponds, and cattle in Vunidogoloa }\end{array}$ \\
\hline $\begin{array}{l}\text { Common } \\
\text { property } \\
\text { resources }\end{array}$ & $\begin{array}{l}0 \\
-\end{array}$ & $\begin{array}{c}\text { Maintained access to common property resources such as wild food crops and } \\
\text { ocean resources } \\
\text { Reduced access to ocean for fishing in Vunidogoloa }\end{array}$ \\
\hline \multicolumn{3}{|l|}{ Social } \\
\hline Feelings of safety & $\begin{array}{l}+ \\
+ \\
+\end{array}$ & $\begin{array}{l}\text { Improved feelings of safety from climate change hazards in Vunidogoloa } \\
\text { Improved feelings of safety from coastal hazards in Denimanu } \\
\text { Heightened feelings of fear associated with mass sediment movement in } \\
\text { Denimanu }\end{array}$ \\
\hline $\begin{array}{l}\text { Community } \\
\text { cohesion }\end{array}$ & $\begin{array}{l}+ \\
+ \\
+\end{array}$ & $\begin{array}{l}\text { Strengthened sense of community in Vunidogoloa } \\
\text { Strengthened sense of cohesion amongst women in Denimanu } \\
\text { Some division across relocated and non-relocated villages in Denimanu } \\
\text { experienced by men }\end{array}$ \\
\hline \multicolumn{3}{|l|}{ Financial } \\
\hline Financial Security & + & Improved financial security due to improved access to markets in Vunidogoloa \\
\hline Access to markets & + & $\begin{array}{l}\text { Improved access to markets through better access to the main road in } \\
\text { Vunidogoloa }\end{array}$ \\
\hline Livestock & + & Provision of cattle in Vunidogoloa \\
\hline \multicolumn{3}{|l|}{ Human } \\
\hline Heath & $\begin{array}{l}+ \\
- \\
-\end{array}$ & $\begin{array}{l}\text { Increased access to town services, including medical facilities in Vunidogoloa } \\
\text { Detrimental impacts on women health from cleaning septic tanks in Denimanu } \\
\text { Reduced distance to health center for the relocated village in Denimanu }\end{array}$ \\
\hline Education & + & Improved access to school in Vunidogoloa \\
\hline \multicolumn{3}{|l|}{ Physical } \\
\hline Housing & $\begin{array}{l}+ \\
+ \\
-\end{array}$ & $\begin{array}{c}\text { All affected residents received new houses } \\
\text { High satisfaction with the layout of housing } \\
\text { Water leaks through walls during periods of heavy rain }\end{array}$ \\
\hline Access to services & + & Solar power provided to all new houses \\
\hline Facilities & $\begin{array}{l}+ \\
+ \\
-\end{array}$ & $\begin{array}{l}\text { Showers and flush toilets provided to new houses } \\
\text { Water tanks provided for households in Denimanu } \\
\text { Kitchens not built in Vunidogoloa }\end{array}$ \\
\hline $\begin{array}{l}\text { Communal } \\
\text { infrastructure }\end{array}$ & - & $\begin{array}{l}\text { Drainage systems were not built } \\
\text { Limited septic tanks in Denimanu }\end{array}$ \\
\hline \multicolumn{3}{|l|}{ Cultural } \\
\hline \multirow[t]{2}{*}{ Land } & - & Reduced access to the ocean which is important spiritually in Vunidogoloa \\
\hline & 0 & Both villages remained on village owned land \\
\hline $\begin{array}{l}\text { Religious } \\
\text { practices }\end{array}$ & + & Strengthened level of faith through the relocation process \\
\hline
\end{tabular}

Note: Comments apply to both villages unless a village name is explicitly used. 


\subsection{Social Cohesion and Cultural Assets}

Vunidogoloa residents were emphatic that they felt the sense of community had strengthened during and since the relocation. This was expressed because participants felt that the community had come together and made the decision to move themselves, representative of the fact that it was the village headman who approached the government to relocate. People also stated that they found strength in their Christian faith through coming together as a community and overcoming the struggle of moving: "A lot of our faith in relocating was placed in our belief. We did a lot of prayer sessions" (Vunidogoloa Interview). In Denimanu, while on average there was an overall improvement in social cohesion, when disaggregating this across men and women, women noted improvements while men experienced negative outcomes. The women's group noted that the relocation has strengthened a sense of community because the process forced them to work together. The men discussed some challenges with working together on village projects. These findings pertaining to social cohesion can be largely explained by two factors: the size of the village and the type of relocation. Vunidogoloa being a small village and relocated as an entire unit meant that they were able to stay together and united throughout the process. Denimanu on the other hand is a larger village and was only partially relocated therefore disrupted aspects of daily life and activities for some residents. In terms of the cultural impact of the relocation on communities, the impacts were reduced due to both villages relocating within closely-related mataqali lands. Yet, the move away from the ocean in Vunidogoloa has impacted spiritual ties as the ocean is an important part of village culture.

\subsection{Health and Education}

Mixed outcomes across health and education were noted across villages. In Denimanu, challenges associated with septic tanks in the relocated village were noted regularly throughout village discussions. There were only two sewage septic tanks provided for the 19 houses. As a result of this, health concerns were noted by some women, as they were responsible for regularly cleaning out the septic tanks. These issues experienced by women pertaining to cleaning the septic tank are explained through the following comment: "We have to do it. So we put on our pants, cover our noses, cover our hair with plastic, and we wear gloves and we take turns bailing the septic tank. So all the women in the house have to help out, the men don't and say wait for the government but we know the children will get sick" (Denimanu FG, Women). Further, the relocated village expressed that the health center was going to be moved in between the original and relocated villages yet remains at the opposite side of the original village, thus making access more challenging for them. As the relocated village only moved roughly $500 \mathrm{~m}$ this is not seen as a major detriment.

In Vunidogoloa, positive outcomes occurred in terms access to services, specifically schooling for children and medical services. This is due to the relocated village being close to the main road as these services are only available using road transport: "The relocation was good because it is [now] easy to go to school as you have been to the old village you know how hard it is to get to the main road to catch the bus to go to school" (Vunidogoloa FG, Women).

\subsection{Access to Common Property Resources and Food Security}

Access to common property resources has been maintained in both villages due to the short distance of the relocations. In Vunidogoloa the community moved within walking distance from the old site. This makes the old site and the resources that are there still available for people to use. Examples include the ocean where people still go down to fish regularly. Yet this has resulted in fishing becoming harder because of the extended distance to access the ocean, formerly their main livelihood source. People also go down to the old site to collect coconuts and pandanus leaves for weaving. As Denimanu moved only 500m there has been no disruption to access of common property resources. While food security has been unperturbed in Denimanu, in Vunidogoloa village members noted improvements since the village is now located on the land where previous agriculture and crop 
production was undertaken. Closeness to agricultural fields has resulted in reduced labour inputs due to reduced walking distances. Further, within Vunidogoloa there was provision of pineapple crops, cattle, and fish ponds, all of which are utilized by the village, although the residents expressed the quantity of each provided to the village were less than promised: "Just to give an example, the pineapple farm, the Ministry of Agriculture promised we would be given 48,000 tops but they only gave 5000. This is just an example, for the fish ponds they told us they were going to dig eight they only gave four" (Vunidogoloa FG, Men). These outcomes have also improved the financial security of village members in Vunidogoloa due to surplus food crops to sell at markets, especially since access to markets has improved from road access.

Overall, there have been numerous positive livelihood outcomes that have arisen as a result of the relocation. Yet, notably there have been some serious implications as well. We can see that the benefits of both villages in being able to move within close mataqali is clear as it has allowed spiritual connections to be maintained as well as access to common property resources which are important components of village livelihoods. Further, the positive outcomes associated from the whole community relocating, as was the case in Vunidogoloa, has allowed the community to maintain a strong sense of social cohesion and unity.

\section{Have Relocations Successfully Reduced Exposure to Climate-related Hazards?}

Vulnerability to climate change is a product of much more than exposure to hazards. Yet when referring to climate-induced relocation, moving rural villages from areas of high exposure to those of lower exposure remains a critical process. As such, this section explores whether the planned relocations have been successful in reducing exposure to climate-related hazards for affected people in these two case studies.

Prior to relocation, Vunidogoloa was primarily exposed to coastal pressures including flooding, coastal erosion, and salt water intrusion. This is aptly exemplified through a FG exercise; participants were asked to draw homes in the old village, one group drew a home surrounded by water (Figure 4) describing the threat this posed to livelihoods. This exposure to coastal pressures resulted in the village moving roughly $2 \mathrm{~km}$ inland, a significant distance from the ocean and the associated locational exposure. As such, people expressed a strong sense of improved feelings of safety since the relocation: "We were so fearful because of the tides living at the old site. We were happy to move away from that fear" (Vunidogoloa FG, Women) (see Table 1).

In Denimanu, the village members who were relocated were originally situated at the front of the village. As such, they were exposed to erosion and tidal inundation and were most severely impacted from Cyclone Evan in 2012, prompting the relocation. The relocation saw 19 new houses built on the hill roughly $500 \mathrm{~m}$ from the village. While reducing exposure to coastal threats, the relocation site has presented new kinds of exposure. The location of the new settlement on a hillslope, coupled with the clearing of land to make way for the houses, has resulted in concerns about mass movements including soil erosion. This was briefly yet similarly noted in a recent analysis of an impending relocation in Narikoso, Fiji (Barnett and McMichael 2018). In Denimanu, these concerns were further exacerbated by inadequate site drainage, as described above. This threat is pertinent as a landslide had recently destroyed the primary school on the opposite side of Denimanu village (see Figure 5) and people noted a recent, smaller landslide had occurred close to their homes. This concern is illustrated through this quote from the women's focus group: "We were delighted with the move to the new houses but we were still worried about the landslide because the houses were on the hill and we know this place. Although we were happy we were moving away from the wave surges, we were worried about this landslide. Especially when there is rain" (Denimanu FG, Women). 




Figure 4. Focus group exercise showcasing water surrounding a home in the old site of Vunidogoloa village.

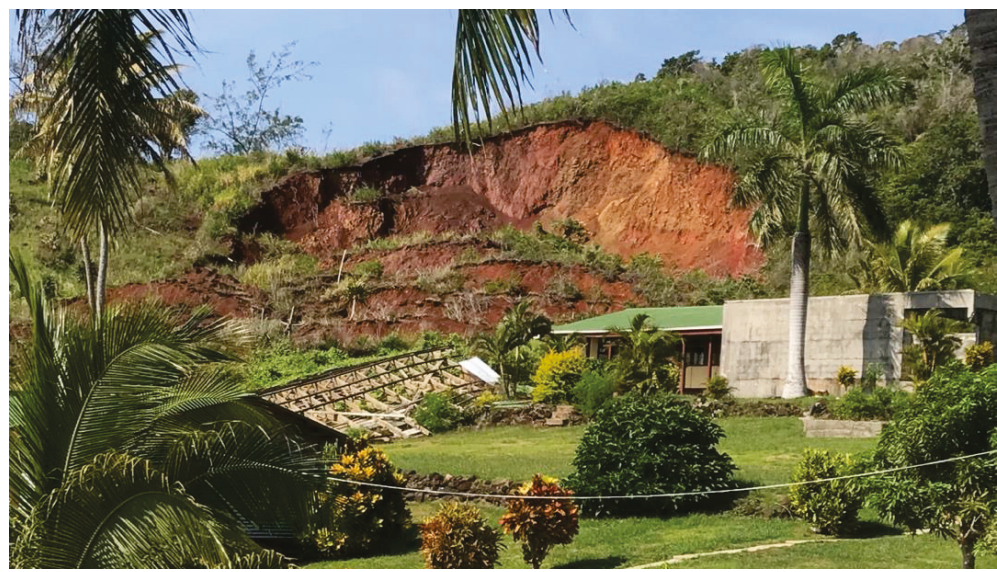

Figure 5. The landslide that destroyed the primary school in Denimanu village.

People in relocated Denimanu regularly expressed that they felt they would have to move again in the future. It is important to note that erosion is not a specific climate change related hazard, yet it is one that can be exacerbated by climate change with the increasingly intensified rainfall events on a reduced number of days. This coupled with the clearing of land to build houses and environmental practices of slash and burn agriculture enhances this threat. These signify secondary climate impacts where the impact is not direct, yet exacerbated by the changing climate. It is important to note that fieldwork was undertaken during the wet season when these threats are particularly high.

Reducing exposure to climate-related hazards is one factor, albeit an important one, to consider when relocating communities. From these case studies we see that relocation has the potential to reduce exposure to climate-related hazards of affected communities, as seen in the case of Vunidogoloa. Yet, if relocations are not planned appropriately, accounting for future climatic and environmental processes, they can instead expose communities to other kinds of hazards, as experienced in Denimanu. 


\section{What Lessons Can Be Taken from These Case Studies Going Forward?}

Relocations resulting from climate change and associated impacts are likely to significantly increase into the future (Ferris 2015). As early cases of planned relocation, these two examples provide an important avenue to take lessons that can be applied to future relocation efforts in order to move toward more effective, beneficial and sustainable outcomes for relocated communities. This is especially relevant in a Fijian context as at least 80 communities have been earmarked for relocation but can also apply to other comparable island communities.

Participatory decision-making process is the first theme that emerged from the case studies. Namely, the lack of involvement community members expressed they had in the decision-making pertaining to the relocation. The importance of such a participatory process has been outlined by researchers (Correa et al. 2011; De Sherbinin et al. 2011; Ferris 2015; Kingston and Marino 2010; McAdam and Ferris 2015; McNamara and des Combes 2015) as well as in the established international guidelines (UNHCR 2015) and the Fiji guidelines for relocations (Fiji Government 2018). Yet as we see from these case studies, communities expressed that transparency throughout the process was lacking, specifically in the case of Denimanu. The process employed can be seen as consultation rather than participation, of which a distinct difference exists (McAdam and Ferris 2015). While communities in both villages were consulted (in that they were instructed about the relocation), there was an expressed lack of comprehensive participation, through which communities felt they were not able to significantly contribute to decision-making processes. Including affected communities throughout the relocation process, to ensure the opportunity for self-identified priorities is essential if affected communities are to have the possibility to not only rebuild but also improve their livelihoods in the relocated site (Kingston and Marino 2010; McNamara et al. 2018). Building on top of this, through the planning stage of relocation critical concepts of human rights, dignity, equity, and sustainability should be closely considered and applied (Henly-Shepard et al. 2018). For example, while processes must aim to include local perspectives, they must further intentionally aim to include multiple and diverse groups within the process to ensure there is an equitable avenue for a range of perspectives to be expressed.

Long term monitoring and evaluation is the second theme that emerged. There have been numerous issues that have arisen since the relocation, expressed in both villages. These span issues with water leaking into homes, incomplete drainage systems, inadequate sewage, and safety concerns from erosion. Unforeseen outcomes, even with appropriate planning and forethought, would not be unexpected when implementing such large-scale adaptation interventions. As seen in these two cases, these issues that have arisen have not been rectified. Further, both villages expressed that contact with the government since the relocation has been limited with no formal avenue available to express ongoing concerns. Without a level of reflection and a willingness to rectify errors then there is a genuine concern that these unintended negative outcomes could lead to maladaptation, in that there is an increase in community vulnerability in the long term. As such, incorporating formal mechanisms through which village members can express such concerns and ensure a level of accountability is seen as essential going forward.

Targeted livelihood planning is the third theme that emerged. Vulnerability to climate change goes beyond solely a reduction of exposure to physical hazards and includes improving livelihood resilience (Jackson et al. 2017). The relocation of vulnerable communities should be used as an opportunity to not only reduce physical exposure to climate threats, but also build upon other social and economic vulnerabilities and processes (De Sherbinin et al. 2011). In Vunidogoloa, the provision of livelihood alternatives in the new sites (such as pineapple plantations, fish ponds, and cattle) improved outcomes across natural and financial capital, with further improvements of access to assets from moving closer to the main road. This is an example of how improving services, assets, and availability of resources is one avenue through which positive outcomes from relocation can be achieved. As such, a focus on this aspect of relocation, in not only reducing the physical threat of climate change hazards communities are facing but taking a holistic view of community vulnerability, and ensuring that 
relocation aims to improve upon the livelihood resilience of affected communities, should be considered as an essential part in achieving success during the relocation process.

\section{Conclusions}

This research documented the experiences of two communities that have been relocated as a consequence of climate change related impacts. The two case studies showcase differences in the contexts around relocation with Vunidogoloa, labeled as the first 'climate-induced' relocation, being a full village relocation resulting from slow-onset impacts. Garnering much less attention, the second case study, Denimanu, was a partial village relocation from sudden-onset impacts. The outcomes of the relocations have shown several positive outcomes, namely in relation to improved housing, and improved access to electricity and facilities. Yet for some residents, these have been somewhat overshadowed by many negative outcomes. For example, serious concerns were raised pertaining to the quality of housing in Denimanu with water leaking through walls. Further, impacts resultant from poor design of sewage septic tanks in Denimanu, and drainage systems in both villages are of concern. This is especially the case in Denimanu where these have led to increased levels of exposure to new threats surrounding mass movement of sediment. The results from this research further indicate wider implications across how women and men experience planned adaptation, both in terms of access to decision-making and on resultant outcomes on lives and livelihoods.

As planned climate-induced relocations will become more common in the future, key lessons from people's experiences in these two case studies are presented that should be built into future planning going forward. These lessons include: Inclusive decision-making processes, as communities felt they did not have adequate input and agency in the process; long term monitoring and evaluation to ensure an avenue is provided for people to voice concerns and issues that have arisen from the process; and targeted livelihood planning to improve livelihoods with the aim of reducing overall vulnerability. Relocation of entire villages is a complex and significant undertaking, so it is imperative that governments and external parties involved in the process take appropriate steps to ensure the process serves to improve the livelihoods and lives of those directly affected.

Author Contributions: Conceptualization, A.E.P.-M., K.E.M., and P.D.N.; Methodology, A.E.P.-M., K.E.M., P.D.N., and S.T.S.; Formal analysis, A.E.P.-M.; Investigation, A.E.P.-M. and S.T.S.; Writing-original draft preparation, A.E.P.-M.; Writing-review and editing, A.E.P.-M., K.E.M., and P.D.N.; Supervision, K.E.M. and P.D.N.; Project administration, P.D.N., S.T.S. and A.E.P.-M.; Funding acquisition, K.E.M. and P.D.N.

Funding: This research was funded through an Australian Research Council Linkage grant (number LP160100941).

Acknowledgments: The authors would like to sincerely thank the residents of Vunidogoloa and Denimanu for welcoming the research team into their homes and sharing their story. This research would not be possible without them. Further, to Sekaia Malani who acted as a gatekeeper and aided the research team immensely with the organization and logistics of fieldwork. Finally, to Jacqueline Ryle and Jasmine Pearson who provided important contributions and insights during fieldwork.

Conflicts of Interest: The authors declare no conflict of interest.

\section{References}

Albert, Simon, Robin Bronen, Nixon Tooler, Javier Leon, Douglas Yee, Jillian Ash, and David Boseto. 2018. Heading for the Hills: Climate-driven Community Relocations in the Solomon Islands and Alaska Provide Insight for a $1.5^{\circ} \mathrm{C}$ Future. Regional Environmental Change 18: 2261-72. [CrossRef]

Althor, Glenn, James E. M. Watson, and Richard A. Fuller. 2016. Global Mismatch between Greenhouse Gas Emissions and the Burden of Climate Change. Scientific Reports 6: 20281.

Arora-Jonsson, Seema. 2011. Virtue and Vulnerability: Discourses on Women, Gender and Climate Change. Global Environmental Change 21: 744-51. [CrossRef]

Barnett, Jon, and John Campbell. 2010. Climate Change and Small Island States: Power, Knowledge, and the South Pacific. London and Sterling: Earthscan.

Barnett, Jon, and Celia McMichael. 2018. The Effects of Climate Change on the Geography and Timing of Human Mobility. Population and Environment 39: 339-56. [CrossRef] 
Barnett, Jon, and Saffron J. O'Neill. 2011. Islands, resettlement and adaptation. Nature Climate Change 2: 8-10. [CrossRef]

Bebbington, Anthony. 1999. Capitals and Capabilities: A Framework for Analyzing Peasant Viability, Rural Livelihoods and Poverty. World Development 27: 2021-44. [CrossRef]

Brill, Barry. 2017. Fiji's 'Sinking' Vunidogoloa Village-Victim of AGW or Opportunistic at \#COP23? Available online: https:/wattsupwiththat.com/2017/11/08/fijis-sinking-vunidogoloa-village-victim-of-agwor-opportunistic-at-cop23/ (accessed on 10 December 2018).

Bukalidi, Litia. 2013. Yadua Village Relocated. Available online: http://fijisun.com.fj/2013/04/13/yadua-villagerelocated/ (accessed on 10 December 2018).

Campbell, John. 2010. Climate-Induced Community Relocation in the Pacific: The Meaning and Importance of Land. In Climate Change and Displacement: Multidisciplinary Perspectives. Edited by Jane McAdam. London: Hart Publishing, pp. 58-59.

Campbell, John. 2014. Climate-Change Migration in the Pacific. The Contemporary Pacific 26: 1-28. [CrossRef]

Campbell, John, and Richard Bedford. 2014. Migration and climate change in Oceania. In People on the Move in a Changing Climate: The Regional Impact of Environmental Change on Migration. Edited by Etienne Piguet and Frank Laczko. Global Migration Issues. Dordrecht: Springer, vol. 2, pp. 177-204.

Carr, Edward R. 2008. Between Structure and Agency: Livelihoods and Adaptation in Ghana's Central Region. Global Environmental Change 18: 689-99. [CrossRef]

Cernea, Michael. 1997. The risks and reconstruction model for resettling displaced populations. World Development 25: 1569-87. [CrossRef]

Chand, Savin S., Kevin J. Tory, Hua Ye, and Kevin J. E. Walsh. 2016. Projected Increase in El Niño-driven Tropical Cyclone Frequency in the Pacific. Nature Climate Change 7: 123-27. [CrossRef]

Charan, Drishna, Manpreet Kaur, and Priyatma Singh. 2017. Customary Land and Climate Change Induced Relocation-A Case Study of Vunidogoloa Village, Vanua Levu, Fiji. In Climate Change Adaptation in Pacific Countries: Fostering Resilience and Improving the Quality of Life. Edited by Walter Leal Filho. Cham: Springer, pp. 19-33.

Connell, John. 2015. Vulnerable Islands: Climate Change, Tectonic Change, and Changing Livelihoods in the Western Pacific. The Contemporary Pacific 27: 1-36.

Connell, John. 2016. Last days in the Carteret Islands? Climate change, livelihoods and migration on coral atolls. Asia Pacific Viewpoint 57: 3-15. [CrossRef]

Correa, Elena, Fernando Ramirez, and Haris Sanahuja. 2011. Populations at Risk of Disaster: A Resettlement Guide. Washington, DC: World Bank.

De Sherbinin, Alex, Marcia Castro, Francois Gemenne, M. M. Cernea, Susana Adamo, P. M. Fearnside, Gary Krieger, S. Lahmani, A. Oliver-Smith, A. Pankhurst, T. Scudder, and et al. 2011. Preparing for Resettlement Associated with Climate Change. Science 334: 456-57. [CrossRef]

Dodman, David, and Diana Mitlin. 2013. Challenges for Community-Based Adaptation: Discovering the Potential for Transformation. Journal of International Development 25: 640-59. [CrossRef]

Donner, Simon D. 2015. The legacy of migration in response to climate stress: Learning from the Gilbertese resettlement in the Solomon Islands. Natural Resources Forum 39: 191-201. [CrossRef]

Ferris, Elizabeth. 2015. Climate-Induced Resettlement: Environmental Change and the Planned Relocation of Communities. The SAIS Review of International Affairs 35: 109-17.

Fiji Government. 2018. Planned Relocation Guidelines: A Framework to Undertake Climate Change Related Relocation. Available online: https://www.refworld.org/docid/5c3c92204.html (accessed on 18 April 2019).

Foresight. 2011. Migration and Global Environmental Change: Final Project Report; London: The Government Office for Science.

George, Nicole. 2010. 'Just like your Mother?' The politics of feminism and maternity in the Pacific Islands. Australian Feminist Law Journal 32: 77-96. [CrossRef]

George, Nicole. 2014. Promoting women, peace and security in the Pacific Islands: Hot conflict/slow violence. Australian Journal of International Affairs 68: 314-32. [CrossRef]

Gharbaoui, Dalila, and Julia Blocher. 2016. The reason land matters: Relocation as adaptation to climate change in Fiji Islands. In Migration, Risk Management and Climate Change: Evidence and Policy Responses. Edited by Andrea Milan, Benjamin Schraven, Koko Warner and Noemi Cascone. Cascone: Springer International Publishing Switzerland, pp. 149-73. 
Heltberg, Rasmus, Paul Bennett Siegel, and Steen Lau Jorgensen. 2009. Addressing human vulnerability to climate change: Toward a 'no-regrets' approach. Global Environmental Change 19: 89-99. [CrossRef]

Henly-Shepard, Sarah, Karen E. McNamara, and Robin Bronen. 2018. Stories of climate change and mobility from around the world: Institutional challenges and implications for community development. In The Routledge Handbook of Community Development Research. Edited by Shevellar Lynda and Peter Westoby. London: Routledge, pp. 197-209.

Hino, Miyuki, Christopher B. Field, and Katharine J. Mach. 2017. Managed Retreat as a Response to Natural Hazard risk. Nature Climate Change 7: 364-70. [CrossRef]

Huq, Saleem, and Hannah Reid. 2007. Community-Based Adaptation: A Vital Approach to the Threat Climate Change Poses to the Poor. International Institute for Environment and Development Briefing. Available online: http://www.iied.org/pubs/pdfs/17005IIED.pdf (accessed on 10 November 2018).

IOM. 2018. Vanuatu Launches National Policy on Climate Change and Disaster-Induced Displacement. Available online: https://www.iom.int/news/vanuatu-launches-national-policy-climate-change-and-disasterinduced-displacement (accessed on 15 January 2019).

IPCC. 2014a. Annex II: Glossary [Mach, K.J., S. Planton and C. von Stechow (eds.)]. In Climate Change 2014: Synthesis Report. Contribution of Working Groups I, II and III to the Fifth Assessment Report of the Intergovernmental Panel on Climate Change. Edited by Core Writing Team, R. K. Pachauri and L. A. Meyer. Geneva: IPCC, pp. 117-30.

IPCC. 2014b. Climate Change 2014: Synthesis Report. Contribution of Working Groups I, II and III to the Fifth Assessment Report of the Intergovernmental Panel on Climate Change. Edited by Core Writing Team, R. K. Pachauri and L. A. Meyer. Geneva: IPCC.

Jackson, Guy, Karen McNamara, and Bradd Witt. 2017. A Framework for Disaster Vulnerability in a Small Island in the Southwest Pacific: A Case Study of Emae Island, Vanuatu. International Journal of Disaster Risk Science 8: 358-73. [CrossRef]

Janif, Shaiza Z., Patrick D. Nunn, Paul Geraghty, William Aalbersberg, Frank R. Thomas, and Mereoni Camailakeba. 2016. Value of traditional oral narratives in building climate-change resilience: Insights from rural communities in Fiji. Ecology and Society 21: 7. [CrossRef]

Keener, Victoria. W., John J. Marra, Melissa L. Finucane, Deanna Spooner, and Margaret Smith. 2012. Climate Change and Pacific Islands: Indicators and Impacts. Report for the 2012 Pacific Islands Regional Climate Assessment (PIRCA). Washington, DC: Island Press.

Kelman, Ilan. 2014. No change from climate change: Vulnerability and small island developing states. Geographical Journal 180: 120-29.

Kingston, Deanna M., and Elizabeth Marino. 2010. Twice Removed: King Islanders' Experience of "Community" through Two Relocations. Human Organisation 69: 119-28. [CrossRef]

Kumar, Lalit, and Subhashni Taylor. 2015. Exposure of coastal built assets in the South Pacific to climate risks. Nature Climate Change 5: 992-96. [CrossRef]

Lipset, David. 2013. The New State of Nature: Rising Sea-levels, Climate Justice, and Community-based Adaptation in Papua New Guinea. Conservation and Society 11: 144-58. [CrossRef]

Mallick, Bishawjit, and Zakia Sultana. 2017. Livelihood after relocation-evidences of Guchchagram project in Bangladesh. Social Sciences 6: 76. [CrossRef]

Martin, Piérick C. M., Patrick D. Nunn, Javier Leon, and Neil Tindale. 2018. Responding to multiple climate-linked stressors in a remote island context: The example of Yadua Island, Fiji. Climate Risk Management 21: 7-15. [CrossRef]

McAdam, Jane, and Elizabeth Ferris. 2015. Planned relocations in the context of climate change: Unpacking the legal and conceptual issues. Cambridge Journal of International and Comparative Law 4: 137-66. [CrossRef]

McMichael, Celia, Carol Farbotko, and Karen E. McNamara. 2018. Climate-migration responses in the Pacific region. In The Oxford Handbook of Migration Crises. Edited by Cecilia Menjívar, Marie Ruiz and Immanuel Ness. Oxford: Oxford University Press.

McNamara, Karen E., and Helene Jacot des Combes. 2015. Planning for Community Relocations Due to Climate Change in Fiji. International Journal of Disaster Risk Science 6: 315-19. [CrossRef] 
McNamara, Karen E., Rachel Clissold, Annah E. Piggott-Mckellar, Lisa Buggy, and Aishath Azfa. 2017. What is shaping vulnerability to climate change? The case of Laamu Atoll, Maldives. Island Studies Journal. [CrossRef]

McNamara, Karen E., Robin Bronen, Nishara Fernando, and Silja Klepp. 2018. The complex decision-making of climate-induced relocation: Adaptation and loss and damage. Climate Policy 18: 111-17. [CrossRef]

Meakins, Brook. 2017. An Inside Look at the One of the First Villages Forced to Relocate Due to Climate Change. Available online: https:/www.alternet.org/environment/inside-look-one-first-villages-forced-relocate-dueclimate-change (accessed on 2 January 2019).

Morse, Stephen, and Nora McNamara. 2013. Sustainable Livelihood Approach: A Critique of Theory and Practice. Dordrecht: Springer, ISBN 9789400762688.

Nunn, Patrick D. 2009. Responding to the challenges of climate change in the Pacific Islands: Management and technological imperatives. Climate Research 40: 211-31. [CrossRef]

Nunn, Patrick D., and Roselyn Kumar. 2018. Understanding climate-human interactions in Small Island Developing States (SIDS). International Journal of Climate Change Strategies and Management 10: 245-71. [CrossRef]

Rawalai, Luke. 2018. Villagers Branded as 'Liumuri' after No One Voted for Party. Available online: https://www. fijitimes.com/villagers-branded-as-liumuri-after-no-one-voted-for-party/ (accessed on 20 January 2019).

Republic of Fiji. 2014. Second National Communication to the United Nations Framework Convention on Climate Change. Available online: https://unfccc.int/resource/docs/natc/fjinc2.pdf (accessed on 1 November 2018).

Rubeli, Ella. 2015. Escaping the Waves: A Fijian Village Relocates. Available online: https://www.smh.com.au/ lifestyle/escaping-the-waves-a-fijian-villages-forced-relocation-20150831-gjc0k1.html (accessed on 5 October 2018).

Rudiak-Gould, Peter. 2012. Promiscuous corroboration and climate change translation: A case study from the Marshall Islands. Global Environmental Change-Human and Policy Dimensions 22: 46-54. [CrossRef]

Scoones, Ian. 1998. Sustainable Rural Livelihoods: A Framework for Analysis. IDS Working Paper 72. Brighton: IDS.

Singh-Peterson, Lila, and Manoa Iranacolaivalu. 2018. Barriers to market for subsistence farmers in Fiji-A gendered perspective. Journal of Rural Studies 60: 11-20. [CrossRef]

Tadgell, Anne, Brent Doberstein, and Linda Mortsch. 2018. Principles for climate-related resettlement of informal settlements in less developed nations: A review of resettlement literature and institutional guidelines. Climate and Development 10: 102-15.

Tronquet, Clothilde. 2015. From Vunidogoloa to Kenani: An Insight into Successful Relocation. Available online: http://labos.ulg.ac.be/hugo/wp-content/uploads/sites/38/2017/11/The-State-of-Environmental-Migration2015-121-142.pdf (accessed on 5 October 2018).

UNHCR. 2015. Guidance on Protecting People from Disasters and Environmental Change through Planned Relocation. Available online: https:/environmentalmigration.iom.int/sites/default/files/Guidance $\% 20$ on $\%$ 20Planned\%20Relocations\%20-\%20Split\%20PDF.pdf (accessed on 10 October 2018).

Voccia, Alexander. 2011. Climate Change: What Future for Small, Vulnerable States? International Journal of Sustainable Development \& World Ecology 19: 101-15.

Walsh, Kevin J. E., John L. McBride, Philip J. Klotzbach, Sethurathinam Balachandran, Suzana J. Camargo, Greg Holland, Thomas R. Knutson, James P. Kossin, Tsz-cheung Lee, Adam Sobel, and et al. 2016. Tropical Cyclones and Climate Change. Wiley Interdisciplinary Reviews: Climate Change 7: 65-89. [CrossRef]

Weir, Tony, Liz Dovey, and Dan Orcherton. 2017. Social and Cultural Issues Raised by Climate Change in Pacific Island Countries: An Overview. Regional Environmental Change 17: 1017-28. [CrossRef]

Williams, A. T., Nelson Rangel-Buitrago, Enzo Pranzini, and Giorgio Anfuso. 2018. The management of coastal erosion. Ocean \& Coastal Management 156: 4-20.

Witschge, Loes. 2018. In Fiji, Villages Need to Move Due to Climate Change. Available online: https://www. aljazeera.com/indepth/features/fiji-villages-move-due-climate-change-180213155519717.html (accessed on 10 October 2018).

(C) 2019 by the authors. Licensee MDPI, Basel, Switzerland. This article is an open access article distributed under the terms and conditions of the Creative Commons Attribution (CC BY) license (http://creativecommons.org/licenses/by/4.0/). 



\title{
Climate Change Migration and Displacement: Learning from Past Relocations in the Pacific
}

\author{
Tammy Tabe \\ Pacific Centre for Environment and Sustainable Development (PaCE-SD), Laucala Campus, \\ The University of the South Pacific, Suva, Fiji; tammy.tabe@usp.ac.fj; Tel.: +679-323-2897
}

Received: 1 March 2019; Accepted: 26 June 2019; Published: 19 July 2019

\begin{abstract}
It has been projected that the single greatest impact of environmental changes will be on human migration and displacement. Migration has been extensively discussed and documented as an adaptation strategy in response to environmental changes, and more recently, to climate change. However, forced relocation will lead to the displacement of people, and although much has been written about it, very little has been documented from the Pacific Islands perspective, especially by communities that were forced to relocate as a result of colonialism and those that have been forced to migrate today as a result of climate change impacts. Using the Gilbertese resettlement from the Phoenix Islands to the Solomon Islands, in particular, Wagina Island in the 1960s as a case study of forced relocation and displacement of Pacific Islands people during the colonial period, this paper aims to underline some of the important lessons that can be learned from this historical case to inform the present and future challenges of climate change migration and displacement. Without dismissing migration as a coping strategy, the paper argues that the forced relocation of people from their home islands as a result of climate change will lead to displacement. It accentuates that in the case of Pacific Islands, forced relocation will lead to displacement if they are forced to leave their land because of their deep relationship and attachment to it. The paper also emphasizes the need to acknowledge and honor Pacific Islands' voices and perceptions in discourses on climate change migration and displacement at national, regional and international forums.
\end{abstract}

Keywords: climate change migration; adaptation; displacement; forced relocation; forced migration; Gilbertese people; Phoenix Islands; Wagina Island

\section{Introduction}

Mobility has always been in the nature of Pacific Islanders, and people move for various reasons. During the colonial period, movements of Pacific Islanders have often been associated with economic and political interests of Colonial Empires (Maude 1968; Silverman 1971; Tabucanon and Brian 2011; Tabe 2011; Connell 2012; Edwards 2013; Campbell 2014; McAdam 2014; Teaiwa 2015). Some of these precolonial movements have resulted in the forced relocation and displacement of Pacific Islands people. For instance, in 1945, the population of Banaba was forcefully relocated to Rabi Island in Fiji by the Administration of the Gilbert and Ellice Islands Colony (GEIC) so the British Phosphate Company (BPC) could continue mining the island without resistance from the Banaban community (Hermann 2005; Teaiwa 2015). In 1946, the inhabitants of Bikini atoll were also forcefully relocated to Rongerik, an uninhabited atoll in northern Marshall Islands so the United States of America could use their home island as a nuclear testing ground (Kiste 1977). In the late 1930s, groups of Gilbertese families were relocated from the Southern Gilbert Islands to Phoenix Islands as a result of overpopulation and land hunger. In the mid-1950s and early 1960s, these groups of Gilbertese families were resettled again from the Phoenix Islands to the Solomon Islands as a result of periodic droughts and environmental degradation (Maude 1968; Knudson 1964; Meyen 1992; Tabe 2011). 
Other forced relocations that have occurred in the Pacific Islands had been caused by natural hazards such as volcanic eruptions and tsunamis. While at times these movements were temporary, other times, they were permanent. For example, in 1946, the population of Niuafo'ou was forced to relocate as a result of volcanic eruptions on the island of Eua in southern Tonga. Similarly, in 1950, a small population of Ambrym in Vanuatu was forced to relocate to the central island of Efate after a major volcanic eruption on the island. Although, people were displaced during these events, many of them later returned to their home islands to rebuild their lives (Connell 2012). In recent years, tsunamis have also caused both temporary and permanent relocation and displacement of people in the Pacific. For instance, in 2007, parts of the Western Province in Solomon Islands were devastated by a tsunami that struck Gizo town and nearby coastal communities. The tsunami forced many of the coastal communities including the Gilbertese community on Gizo to relocate uphill. However, many of them later returned to the coast to rebuild their homes while others remained on the hilltop and formed new settlements (Zamora et al. 2011; Hagen 2013). Similarly, in 2009, Upolu in Samoa was also devastated by a tsunami that caused extensive damages to the islands infrastructure and forced many of the coastal communities to relocate inland and established new settlements (EERI Special Earthquake Report 2010).

The forced relocation and displacement of people in the Pacific has also been driven by climate change, and it is anticipated to increase in the future. Scientific studies have projected an increase of surface and ocean temperatures, intensity of tropical cyclones, wind speed, rainfall, storm surges, and increase of sea-level rise, coastal inundation, droughts, and other climatic related activities (Mimura et al. 2007; Hulme 2009; Goldring 2015). Many of these impacts have already materialized and have affected Pacific Islands' communities. Tropical cyclones have intensified and their impacts have resulted in extensive damages to national infrastructure and homes, and have also led to the forced relocation and displacement of many people. For instance, in 2015, Category 5 tropical cyclone Pam impacted Vanuatu and caused severe damages to the country's national infrastructure and homes, which was estimated to be equivalent to US $\$ 449.4$ million. The cyclone also affected many communities and displaced thousands of people in the country (IOM 2015). In 2016, Category 5 tropical cyclone Winston severely affected Fiji and resulted in extensive damages of national infrastructure and homes worth US $\$ 0.9$ billion. The cyclone uprooted houses and devastated villages across Fiji and displaced many of the people (Government of Fiji 2016).

Heavy rainfall and flash flooding have also affected and displaced many communities. For instance, in 2014, heavy rainfall caused major flash flooding in the Mataniko River, which affected Honiara, the capital town of Solomon Islands. While it caused severe damages to national infrastructure and homes estimated to worth US\$109 million, it also led to the forced relocation and displacement of settlements located along the river and at river mouth (Government of Solomon Islands 2014). In 2017, the community of Tukuraki in Fiji was also relocated due to Cyclone Evan in 2012, which resulted in a landslide that buried part of the village, and was again affected by cyclone Winston in 2016 (SPC 2017). Climate change impacts such as sea level rise and coastal erosion have also forced the relocation of several Pacific Islands communities. For instance, in 2014, the community of Vunidogoloa in Fiji was relocated 2 kilometers inland from their original village site as a result of sea level rise, coastal erosion, and storm surges (Charan et al. 2017; Tronquet 2015; McNamara and Combes 2015). Similarly, the clearing and construction of the new town site in 2009 to relocate the Taro Township in Choiseul Province, Solomon Islands, which is being threatened by sea level rise and coastal erosion was suspended due to lack of funding (Yeo 2014).

According to the IPCC report, the rate of global mean seal level rise during the 21st century will likely exceed the rate observed during 1971-2010. This means that the global sea level rise is likely to increase from 0.52 to 0.98 meters between 2081-2100 (Church et al. 2013). This increase will have significant impacts on Pacific Islands who are highly vulnerable to climate change (McAdam 2012; Yamamoto and Miguel 2012). Effects such as coastal erosion, saltwater inundation, and contamination of ground water have already been experienced in many low-lying atolls and coastal communities 
and will likely intensify in the future. This will pose future threats to sustainable agriculture and food security for many Pacific Islands because of their high dependency on natural resources for subsistence and income. The increase impacts of climate change will also deteriorate natural ecosystems that they will no longer be able to support the populations of the islands (O'Brien et al. 2012; Mortreux and Barnett 2009). Low lying atolls are particularly prone to coastal erosion and inundation because of their physical limitations in terms of land, water, and food resources. These impacts will likely force people to migrate elsewhere for safety and to seek better access to land, livelihood resources, and income (Gordon-Clark 2012; Legatis 2011; Campbell 2014; Oxfam 2012). Studies have also predicted that low lying atolls in the Pacific will no longer be inhabitable long before they become completely submerged (McAdam 2012; Campbell 2014). Among those greatly affected are low-lying Islands such Kiribati, Tuvalu, and the Marshall Islands, and many coastal communities across the Pacific region whose populations are likely to migrate or forced to relocate in the future as a result of sea level rise.

Migration as an adaptation strategy has always been used for coping with environmental changes. Adaptation in the context of migration is the 'process of adjustment to actual or expected climate effects, or to seek to moderate or avoid harm, and to exploit beneficial opportunities' for vulnerable groups of people (Adger et al. 2014, p. 758). However, Campbell (2014) argues that when dealing with migration, it is important to understand the difference between 'migration as an adaptation strategy' and 'migration as displacement'. Migration as an adaptation strategy has positive implications for migrants and occurs at the individual and household levels. Migration in this case is voluntary based on people's choices to migrate elsewhere for better livelihoods and economic opportunities (Mortreux and Barnett 2009). Migration as an adaptation strategy also involves the relocation of vulnerable people from danger zones to safe areas (McAdam 2015). However, migration as displacement has negative implications. It does not provide people the choices or agency to choose whether they want to migrate or to continue to stay where they are, and occurs mainly at the community level. This is accentuated by Hugo (2012) who emphasizes that communities become displaced when it is no longer possible for them to remain in their islands because the ecosystems and the environment in which they depend on for their livelihoods can no longer sustain them. Migration as displacement can also be viewed as maladaptation — the failure to adapt-which reduces the chances of people to remain in their homes and thus forces them to migrate elsewhere (IPCC 2007).

Much has been written by scholars on 'migration as an adaptation strategy' and 'migration as displacement', but what does this means for vulnerable Pacific Islands that are subject to forced relocation in the future. It is important to reflect on past relocation cases in the Pacific Islands, as they provide relevant lessons for present and future challenges of climate change migration and displacement. Using the Gilbertese resettlement to Solomon Islands, in particular to Wagina Island during the colonial period as a case study, this paper discusses some of the lessons that can be learned from this historical case of forced relocation and displacement of Pacific people. Without dismissing migration as an adaptation strategy, the paper argues that forced relocation will lead to the displacement of Pacific Island communities and people because of their deep relationship and attachment to the land. The paper also emphasizes the need for the acknowledgment privileging of Pacific voices and perceptions on issues of climate change migration and displacement at national, regional, and international forums.

\section{Methodology and Terminology}

\subsection{Study Sites}

This paper is based on an ethnographical study of the Gilbertese resettlement to Solomon Islands that was carried out in the Western Pacific Archives in New Zealand and in the Gilbertese communities on Wagina in Solomon Islands. The Western Pacific Archives is housed at the University of Auckland library and contains most of the colonial records of the British Colonial Administration during its colonization of the Western Pacific. Some of these records have been destroyed to safeguard the 
reputation of the British Empire. Wagina Island is located in the southeast of Choiseul Province in Solomon Islands (See Figure 1). The island was uninhabited for many years prior to the Gilbertese resettlement so it became registered as a Crown Land under the British Solomon Islands Protectorate (BSIP). The island comprised of three villages; Kukutin, Arariki, and Nikumaroro, which today are populated by the Gilbertese settlers and their descendants.

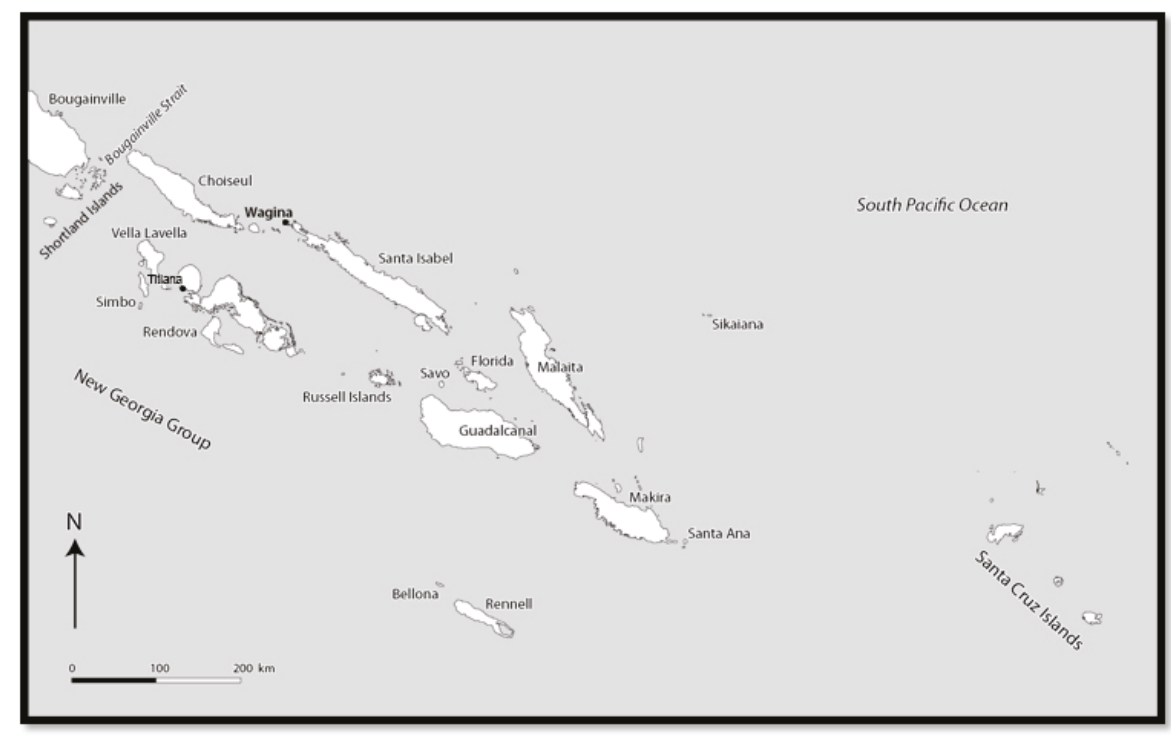

Figure 1. Map of Solomon Islands with the location of Wagina Island in the Southeast of Choiseul and Titiana on Gizo Island.

\subsection{Literature Review}

An extensive review of literature on the Gilbertese resettlement from the Southern Gilbert Islands to Phoenix Islands in the late 1930s, and from Phoenix Islands to the Solomon Islands during the mid-1950s and early 1960s was conducted prior to the fieldwork in the Western Pacific Archives and in the Gilbertese communities on Wagina. Limited accounts have been published on the resettlement from the Phoenix Islands to the Solomon Islands, and most of the history that had been written was mainly on the first resettlement of the Gilbertese from the Southern Gilbert Islands to the Phoenix Islands (Maude 1968). Knudson (1964) recorded the accounts of the resettlement of the first group of Gilbertese people to Titiana (Knudson 1964), and Cochrane (1970) recorded the accounts of the resettlement of the second group of Gilbertese to Wagina Island. Much of what was written emphasized 'severe droughts' as the main cause of environmental degradation and the primary driver for the Gilbertese resettlement to the Solomon Islands. The resettlement of the Gilbertese to the Solomon Islands were administered as a form of humanitarian assistance by the GEIC administration to provide opportunities for the Gilbertese people to better livelihoods that will eventually lead to economically self-sufficient communities in the future. It was evident that much of what was published encapsulated colonial perspectives of the Gilbertese resettlements. However, recent accounts of the resettlement to Wagina Island by Meyen (1992) and Tabe (2011) explored for the first time the Gilbertese perceptions of what they believed to have caused their resettlement to the Solomon Islands.

\subsection{Western Pacific Archives}

The use of colonial resources in the Western Pacific Archives (WPA) were strictly regulated so permission to access the Archives was obtained prior to my visit. The Archives were contained in 
a Special Collection that regulates the access and use of colonial resources, and I needed consent to access the records. It contained many documents consisting of dialogues, proposals, plans, and reports among colonial administrators about the Gilbert and Ellice Colony (GEIC) and the Gilbertese people. My intention of visiting the archives was to investigate colonial records and uncover information that underline the reasons for the Gilbertese resettlement to Solomon Islands. I had previously learnt from the Gilbertese settlers and from the recently published materials that although periodic droughts were the main reason for the resettlement, the settlers on Wagina Island indicated that the reasons for their resettlement were far too complex than what had been written. They believed that their forced relocation to the Solomon Islands was a result of Britain's nuclear activities on Christmas Island. However, these events were not documented in the history of the Gilbertese resettlement to Solomon Islands or made available in the Archive.

An ethnographical approach that involved close observation and deep analysis of the records, letters, and dialogues in the Archive was employed, not only to uncover reasons for the resettlement but also to understand why the Gilbertese were relocated to the Solomon Islands instead of within the Colony. Many of the records contained information that was fragmented and poorly written so it was difficult to read. The files and letters were not organized in sequence to the date of events and much of the information was missing. A period of two months was spent at the WPA. Photocopying and photography were also used during the archival research to produce copies of the records, which could not be read thoroughly in the Archives.

\subsection{Ethnographic Fieldwork}

Fieldwork was carried out in the three villages on Wagina. The fieldwork was conducted in two phases. The first phase employed the use of focus group discussion and interviews that involved male and female villagers between the age of 50 and 75 years who were anticipated to have a better understanding of the Gilbertese resettlement from Phoenix Islands to the Solomon Islands. The second phase used survey and participant observation to examine the livelihoods of the villagers in terms of subsistence, income, fishing practices, and the land in which they occupy on the island. Results obtained from the first phase of fieldwork will be used in this paper to highlight stories and perceptions of the Gilbertese on Wagina about their resettlement. Prior to the fieldwork, permission was sought from the church ministers in Arariki and Nikumaroro, and from the Catholic priest in Kukutin to conduct research in their communities. The focus group discussions were conducted on Sundays after the church service and mass in each of the villages because it was the only day that most of the villagers were available and free from daily chores. The focus group discussions in each of the three villages were held in the maneaba - the Gilbertese meeting house, and involved about 30-50 participants, both women and men. There were also teenagers and children present but they all sat quietly and listened to the conversations. The elderly men were given the privilege to share their stories first before the women contributed to the conversation. The setting of the focus group discussions was open to allow young people and children to also listen to the history of the resettlement.

Interviews were conducted subsequent to the focus group discussions in each of the villages. A total of 20 participants that included both men and women were identified based on their age, gender, and roles in the villages for the interviews. The 20 participants included ten women and ten men, between the age of 50 to 75 years. The primarily purpose of the interviews was to allow the participants to reflect and share their own personal stories, experiences, and perceptions of the resettlement to Wagina, and what they believed to have caused them to resettle to Solomon Islands. The interviews were guided by a set of questions related to the topic of discussion.

\subsection{Terminology}

The following concepts will be used based on their definitions for the purpose of this paper. Migration as the process of moving within or across borders, temporarily, seasonally, or permanently. It is commonly associated with an element of choice and is often considered to be voluntary in 
nature, or sometimes forced; but in this be used to describe the voluntary movement of people (ODI and UNDP 2017). Displacement refers to situations where people are forced from their homes as direct result of slow or quick onset events (ODI and UNDP 2017). In this paper, it will be used to refer to groups of people and communities that are being forced to relocate from their islands as a result of sea level rise, lack of agency and participation in the decision processes, and forced removal from their land. Resettlement refers to the process that describes the large-scale movements of people whether voluntarily or forced as a result of development or political projects as replacement of their assets, livelihoods, land and resources to maintain the continuity of their communities and livelihoods. It will be used in this paper to refer to the large-scale movement scheme organized by the GEIC and BSIP administrations. Relocation can be voluntary or forced. Voluntary relocation occurs when there is still freedom to choose between realistic options, whereas Forced Relocation takes place when the freedom to choose from the realistic options is no longer available (McAdam and Ferris 2015). Planned relocation refers to a solution-oriented measure facilitated by the state in which a community is physically moved resettled in another location. It differs from evacuation even though it may play a role after the evacuation, especially in circumstances where the places of origins are no longer suitable for living (UNHCR 2014).

\section{The Gilbertese Resettlement: From Gilbert to Phoenix Islands, and to the Solomon Islands}

The following history of the Gilbertese resettlement (see Figure 2) has been compiled based on findings from the Western Pacific Archives, literature review, and research on Wagina Island.

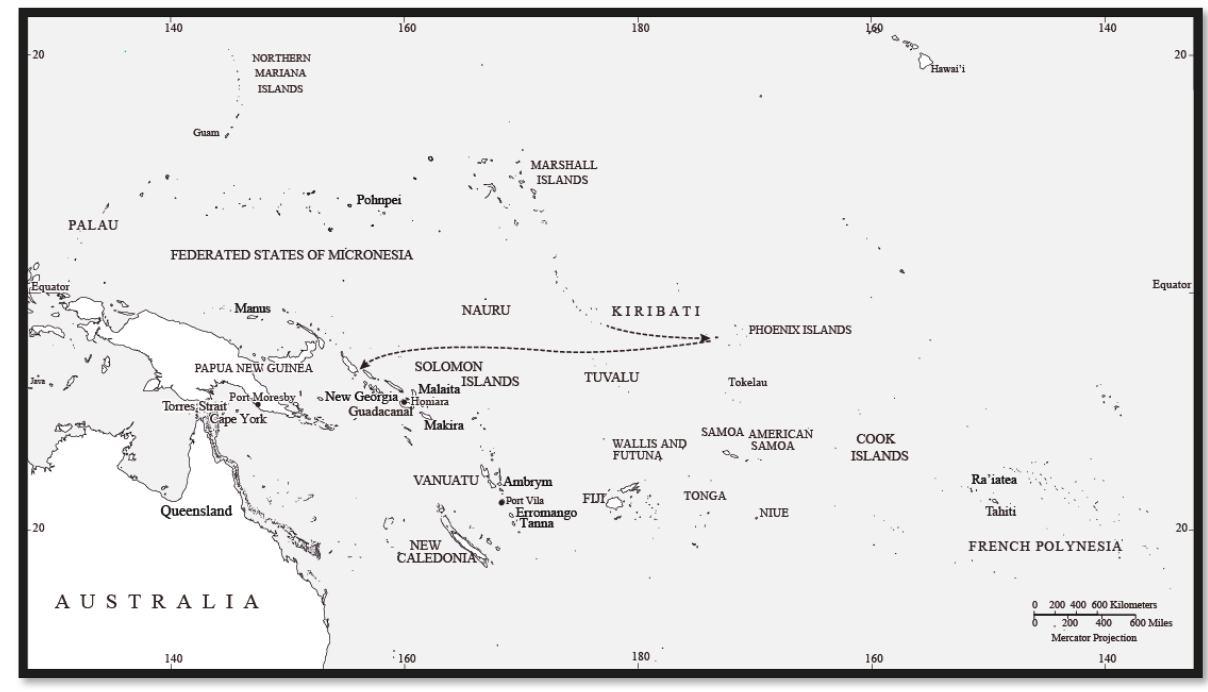

Figure 2. Map showing the Gilbertese resettlement routes from Gilbert Islands to Phoenix Islands, and Phoenix Islands to Solomon Islands.

Overpopulation and land hunger became major issues during the initial colonization of the Gilbert Islands. Despite efforts of the GEIC administration to resolve these problems, it was evident that it would only create more problems for the Gilbertese people in the long term. As a result, the administration saw that the only feasible solution to the problems was to redistribute the surplus population to uninhabited islands in the Colony. In October 1937, an administrative tour was conducted throughout the Colony to investigate the suitability of the islands for the resettlement of the surplus Gilbertese population. The Phoenix Islands provided an ideal location for the Gilbertese population because they consisted of a few uninhabited islands that could support large populations, and they also 
had similar environmental and climatic conditions with the Gilbert Islands (Maude 1968). In the same year, an expedition team set out to investigate the Phoenix Islands for the possibility of permanent settlement and the number of people each island could support (Knudson 1964). The islands of Hull, Gardner, and Sydney were identified to be suitable for the Gilbertese settlement. One of the important activities carried out during the expedition was the christening of these islands. Hull was named Orona, Gardner was named Nikumaroro, and Sydney Island was named Manra.

The surplus population of the Gilbert Islands was anticipated to be relocated to Phoenix Islands, but priority was given to families from Nonouti, Nikunau, Onotoa, Tamana, Tabiteuea, Beru, and Arorae in the Southern Gilbert that were considered to have high poverty rates, land shortages, be overpopulated, and in need of immediate resettlement. Although, many refused to leave their home islands, they were persuaded of the adequate land and better life in the Phoenix Islands. Between 1939 and 1941, groups of Gilbertese families were relocated from the Southern Gilbert Islands to Phoenix Islands under the Phoenix Islands Resettlement Scheme. The scheme was conducted with the hope to provide opportunities for the Gilbertese families to access adequate land and to have better livelihoods, while reducing the population pressure on limited land and resources in the Gilbert Islands. However, the resettlement scheme was suspended in 1941 due to the outbreak of World War II (Maude 1968). The impacts of the war on many of the islands were severe. Mining infrastructures on Banaba were destroyed, including most of the coconut trees on which people depended for subsistence and income; and it would take some time for the islands to rehabilitate from the damages caused. The phosphate and copra industries were the only backbone of the Colony's economy and their slow recovery after the war was recognized by the GEIC administration to likely result in increased economic expenses, if the islands were to be rehabilitated from the damages caused by the war.

It also became apparent after the war that a poor choice had been made about the Phoenix Islands. The islands turned out to be highly vulnerable to long periods of drought and the lack of food and water resources proved that they were inadequate to support the Gilbertese growing population. Manra at that time was largely affected by droughts and the elders had requested the GEIC administration to relocate them elsewhere. With its dwindling revenue, the GEIC administration became concerned with the management of the Colony, in particular the Phoenix Islands if it were to remain operative. The GEIC administration saw the management of Phoenix Islands would only incur further expenses due to its isolation from Tarawa and increased costs of transportation and relief supplies. Seen as a potential and major economic threat and burden for the GEIC administration in the long-term, the Phoenix Islands Resettlement Scheme was declared a failure. This led the GEIC administration to seek potential resettlement sites in other British colonies and territories, but all its enquiries were unsuccessful. At that time, the Lever's Brothers Company had made a proposal to the BSIP administration for the recruitment of laborers to work in its plantations in the Solomon Islands. This was proposed to the GEIC administration, which saw the opportunity as a solution to its problem. Negotiations were held immediately between the GEIC and the BSIP administrations which were also made easier because both administrations were part of the Western Pacific High Commission. The BSIP administration agreed to take in at least 2000 Gilbertese settlers from the Colony, especially the population of Manra, with prospects of permanent settlement. This eventually led to the facilitation of the large-scale resettlement of the Gilbertese people from Phoenix Islands to Solomon Islands.

The relocation of the entire population of Phoenix Islands was viewed as a solution for both administrations. It would relieve population pressure in the Colony and prevented further economic costs for the GEIC administration from the management of Phoenix Islands. At the same time, the Gilbertese resettlement to the Solomon Islands would provide an additional population and a source of labor for the Lever Brother's copra plantations and contribute to the Protectorate's economy through cash crops. The resettlement to the Solomon Islands was conducted in two waves jointly by the GEIC and the BSIP administrations. The first wave was facilitated under the Titiana Resettlement Scheme and it was conducted through several phases between 1955 and 1958. The population of Manra was relocated to Titiana on Gizo Island in the Western District, today known as the Western Province 
(Weber 2016; Tabe 2016). Prior to the resettlement, a pilot team comprised of GEIC administrators and several Gilbertese men travelled to the Protectorate to identify islands that would be suitable for the Gilbertese settlement. Titiana, Wagina, and Tetepare, all three sites located in the Western District at that time were identified as potential locations for the Gilbertese settlements. Of the three sites, Titiana was selected as the most suitable for the Manra population due to its location along the coast and adjacent to a fringing reef, and its close proximity to the Western District headquarters in Gizo town.

The second wave of resettlement was carried out subsequent to the successful resettlement of the entire population of Manra to Titiana. The resettlement was administered under the Wagina Resettlement Scheme whereby the remaining population of the Phoenix Islands on Nikumaroro and Orona were relocated to Wagina Island, which today is part of Choiseul Province. The resettlement was planned in two phases and anticipated to be carried out from 1963-1964 given the emergency nature of the scheme. The scheme was intended to be carried out in different stages to allow the clearing of the village sites and the gradual absorption of the settlers into their new homes. Prior to the resettlement, a meeting was conducted by the Colony officers in the islands of Nikumaroro and Orona, to which the Gilbertese people were informed about the resettlement and the opportunity of a better life in the Solomon Islands. Many of the Gilbertese people did not want to be relocated to the Solomon Islands, especially the elderly people who were not keen on rebuilding their homes and establishing themselves in a new environment. Others were curious to go and see Solomon Islands but had no intentions of settling there. After the meeting, a mandate was issued to the people on both islands that everyone should be relocated to the Solomon Islands and that no person should remain behind. The mandate significantly stressed that those who decided to remain in the islands of Nikumaroro and Orona would be of great economic burden to the GEIC administration, and that it would not be responsible for their welfare; thus, the entire population on both islands was persuaded to be relocated to Wagina (Tabe 2016).

The Gilbertese people encountered many challenges when they arrived on Wagina given the geographical, environmental, and cultural differences of the islands. Wagina was nothing like the atoll islands in the Phoenix. The island was densely forested and swampy, and characterized by a coastline with rocky limestones that made walking unbearable. Clearing of the village sites was still underway when the entire Gilbertese population on Nikumaroro and Orona arrived on Wagina. The people were accommodated in communal housings and were encouraged to build their houses immediately after the allocation of land so that their families could move out of the housings. Three acres of land within the village area was allocated to each head of households including couples that were newly married, and an additional 10 acres in the mountainous area of the island for agricultural purposes. The Gilbertese were expected to develop their land subsequently to the allocation of plots so that they could sustain their families, but they lacked experience in clearing land with big trees, and had to work hard to develop the land for agricultural purposes.

The isolation of the island from the Western District headquarters in Gizo also raised concerns among the Gilbertese, especially the delay of assistance provided by the District during the settlement of Wagina. At that time, the ocean environment between Wagina and Gizo was unfamiliar to the Gilbertese so they were reluctant to journey in small boats between the two locations. The indigenous people from the nearby islands were also very different in their physically and culturally, and many of the Gilbertese made no efforts in getting to know the people because they were afraid of them. Resources were abundant in fishing areas around the island but the lack of coconut trees was an issue for the Gilbertese who were highly dependent on coconuts for nourishment and income. The prevalent of malaria on the island also affected many of the Gilbertese who had no knowledge of the disease and believed that they were being possessed by spirits of the land. The neighboring indigenous communities believed Wagina was haunted by spirits which had prevented people from being able to settle on the island. The lack of environmental and cultural awareness of Solomon Islands also created an enclave Gilbertese community and did not encourage integration of people into the larger Solomon Islands community. The hard labor, lack of political will and access to economic opportunities, and the 
struggle to re-establish themselves in a new environment, and with challenges of not having absolute rights over the land in which they were allocated on Wagina, created a sense of displacement among the Gilbertese people who resented the GEIC administration for bringing them to Solomon Islands-a place unknown to them. However, the Gilbertese on Wagina have continued to live as a community and observed their cultures and languages, and have also gradually integrated into the larger Solomon Islands society through intermarriages, education, employment, and the adaptation of the Solomon Islands way of life (Tabe 2016).

\section{Lessons from the Gilbertese Resettlement}

The Gilbertese resettlement to the Solomon Islands presents both negative and positive implications of forced relocation and displacement. Although it is unclear whether or not the Gilbertese resettlement to Solomon Islands was successful, it nevertheless provides important lessons for future climate change migration and relocation of Pacific Islands, especially those that will be forced to relocate from their home islands as a result of sea level rise. According to the World Bank, the success of a resettlement demonstrates a situation where the settlers' livelihood conditions are at least minimally restored (Voutira and Barbara 2000). However, resettlement success is not only achieved as a result of economic development, but also through genuine establishment of the community and the transfer of a sustainable resettlement process to the later generation of settlers, as new institutions are formed (Scudder 2005). With a prospective view of future relocation of Pacific Islands as a result of climate change, Tabucanon (2012) argues that it is important to re-evaluate how a successful resettlement is defined, without neglecting the economic and social costs involved, while aiming at the long-term sustainability of social and community fabrication.

A number of frameworks and models have also been designed and implemented to assist effective and successful resettlement projects. Cernea's model and conceptualization of resettlement as a process that often involves the risks of being landless, homeless, jobless, marginalized, having a lack of food security, loss of access to common property resources, and increased health issues and social distraction has been used to assist in the evaluation of prospective environmental migration in the Pacific Islands (Cernea 2004). It has been used as a framework to assess certain resettlement features that may prove successful while also taking into account the different cultural and social criteria that may be viewed by settlers as what truly constitutes success significant for possible future resettlements. However, a thorough evaluation of the Gilbertese resettlement to Solomon Islands has yet to be conducted but the movement itself provides important lessons that can be used to inform decisions for Pacific Islands that may be subject to future relocation as a result of sea level rise. There are six primary lessons that can be learned from the Gilbertese resettlement.

\subsection{Planning and Preparations}

It was clear that not a lot of thought was put into the planning and preparation of the Gilbertese resettlement to Solomon Islands, especially in the relocation of an ethnically different group of people from atoll islands to a high island in Solomon Islands. The Gilbertese resettlement was conducted as an emergency measure by the GEIC administration to evacuate the entire population of Phoenix Islands to Solomon Islands with intentions to provide them an opportunity to improve their livelihoods in a new environment. Unlike the Titiana Resettlement Scheme, which involved considerable planning and preparation, the Wagina Resettlement Scheme lacked preparation and proper planning. The resettlement involved a large-scale scheme, which comprised of more than 1000 settlers who were relocated directly from Phoenix Islands to Wagina between 1963 and 1964. This would also cut relocation costs of moving a large number of people between the Colony and Protectorate in several phases over a period of years. However, the island had not been prepared adequately to absorb a large number of Gilbertese who had no familiarity with their new environment. The Gilbertese had to work intensively to re-establish themselves in their new homes. Most of the old men on Wagina indicated that the hard labor they experienced during the clearing of village sites 
and land plots on Wagina was nothing like they had experienced before in their lives. One of the old man said 'the trees were too big and we did not know how to cut them down with knives and axes given to us because we have never conducted such heavy labor on the atolls where we came from'. If resettlements are not planned properly, they will result in the impoverishment of the relocated communities and people (UNHCR 2014). Proper planning and a realistic provision for substantial and properly allocated funding must be prepared in advance. Such funds may be required for land purchases or house constructions and the development of the newly established community (Wrathall 2011).

\subsection{Consent}

Although, the Gilbertese were curious to know more of their new home during the meeting held in Nikumaroro and Orona, they only wanted to see the island, but had no desire of relocating permanently to the Solomon Islands. Limited knowledge of the environment and cultures of the Solomon Islands was also a factor that prevented the elders from wanting to leave their islands and re-establish themselves in a new environment. Many families also did not want to be relocated because they do not want to abandon the graves of their loved ones on the islands. It was apparent that the resettlement to Wagina was decided primarily by the GEIC administration and the settlers had no involvement in the decision. There was lack of consultation with the people about the resettlement and they were not made aware of the reasons for their immediate relocation to Solomon Islands. The meeting was organized primarily to inform the elders in both the islands of the decision to relocate, without consultation or involvement of the people in the decision processes. Although, the settlers refused to be relocated, they were given strict orders that they should all leave and that no person should remain behind. Those who remained behind would not be supported by the GEIC administration; everyone had to be convinced to leave. The settlers were not given the option to decide for themselves but were forced to adhere to the orders and were therefore relocated. It was this lack of informed consent that the Gilbertese felt strongly that their relocation to Wagina was forced on them.

McAdam (2014) writes that consent is important when planning any relocation and it is not the same as consultation and participation. It involves processes of informing, negotiating, and liaising with the prospective settlers concerning the reasons and procedures of the movement while offering alternatives to the relocation that should be considered by authorities. Any relocation should only occur with the consent of the communities and people concerned. The lack of consent usually results in the trauma of displacement and social tensions by the recipient community towards the relocated group (Connell 2012). It is the lack of consent that resulted in sense of displacement, loss of home, land, and identity, and deprivation of opportunities in the new home among the Gilbertese.

\subsection{Challenges Encountered}

The Gilbertese experienced many challenges when they arrived on Wagina because the island which was allocated to them as a new home had not been developed adequately to be able to absorb a large number of people, such that they had to be housed in communal housings, which were overcrowded and lacked privacy for families. The environmental features of the atoll islands contrasted that of Wagina. The island was densely forested without any sandy beaches but was instead characterized by a rocky and limestone coastline. Clearing of the village sites and land plots involved intensive labor for the Gilbertese people. The construction of houses also differed from those built in the atolls because of the difference in weather conditions; therefore, strong materials had to be used to withstand climatic events. The island was also believed to be haunted by spirits; thus, it was uninhabited and many felt that they had been relocated to Wagina purposely to be exterminated. Malaria was one of the major challenges faced by the Gilbertese in Solomon Islands and it caused an unaccounted number of deaths among the Gilbertese during the initial settlement of Wagina, especially coming from non-malarial areas in the Pacific. Many of the settlers were not aware of the symptoms of malaria and assumed on several occasions that they were possessed by the spirits of the land. 
The GEIC administration failed to acknowledge that the Gilbertese were not accustomed to densely forested and mountainous islands and that agriculture was not the Gilbertese way of life, and expecting them to contribute towards the Protectorate's economy through cash crops was impractical. If they were expected to become economically self-sufficient in their new homes, they would require continuous assistance, advice, and encouragement to develop their land for their own benefits, and contribute to the Protectorate's economy in the future. It was clear that the complexity of the problems involved in the movement of the settlers to a different geographical environment were not fully appreciated by the Colony administration and the greater financial responsibility it had to provide for the Gilbertese over a lengthy period of time than originally planned, was unavoidable. However, they should have not been convinced that life in the Protectorate was easy, but instead, should have been informed that their relocation to the Protectorate would involve intensive physical labor beyond levels that they have ever worked before in their lives. This should have begun in the Colony where they were made aware of the Protectorate, its geographical isolation and its climatic, environmental, and cultural conditions, prior to their departure, so that they could prepare themselves physically, psychologically, and materially for their new home.

\subsection{Migrants and Recipients}

Although the BSIP administration had a positive outlook on the Gilbertese resettlement to Solomon Islands, the indigenous population was not made aware of the arrival of the Gilbertese settlers which resulted in some social tensions and marginalization between the local population and the settlers. Up to this day, most of the indigenous Solomon Islands people still do not know how and why the Gilbertese ended up in Solomon Islands. The Colony and Protectorate administrations as facilitators of the Wagina Resettlement Scheme failed to establish any responsibilities to the Gilbertese and the indigenous Solomon Islands population, which should have been the basis of the resettlement schemes. The Gilbertese were unaware that their relocation to the Protectorate was to relieve the Colony government from further economic responsibilities, while being expected to contribute economically towards the Protectorate's economy.

The motives behind the resettlement was based on the notion that the Colony had little to offer in the future and on an unsighted belief that life in the Protectorate was easy and comfortable. While the desire for the Gilbertese resettlement could also be of assistance in the development of future successful resettlement schemes, the Gilbertese were denied a clear knowledge of what their relocation to the Protectorate would mean for them, and for the receiving country. The indigenous population of the Protectorate should also be informed about the scope and aim of the Gilbertese resettlement to the Protectorate. It would have been significant to obtain the support of the indigenous population right from the beginning of the scheme that the influx of the Gilbertese into Solomon Islands would by no means threaten their future. However, the Colony and Protectorate administrations failed to ensure that these obligations were fulfilled prior to the relocation, and, as a result, created hostility between the indigenous communities and the Gilbertese over the occupation of Wagina and access to education and employment opportunities in the Solomon Islands.

\subsection{Land}

The allocation of land and titles was also a major problem experienced by the Gilbertese. Prior to their relocation, the Gilbertese were advised by the GEIC administration to revert all the lands that they owned in Phoenix Islands in exchange of the land which would be allocated to them when they arrived on Wagina. The land assumed for settlement was inadequate for Gilbertese on Wagina and additional land had to be acquired from the offshore islands for coconut planting. However, the ownership of land allocated to the people on Wagina remains contested to this day. Their rights to the allocated land plots and ownership of Wagina are not legally recognized under the Solomon Islands Law up to this day, despite being acknowledged as occupants of the island. With no absolute rights over the land that they occupy and ownership of Wagina, the Gilbertese continue to feel insecure about their future and 
the future of their children. Some of the village leaders have pursued the documented evidence of the Gilbertese ownership of Wagina, but so far, no documentation has been found. As a result, land issues continue to persist to this day with the proposed bauxite prospecting on the island, which has caused tensions between the Gilbertese, the government, and the prospecting company. The Gilbertese on Wagina, whose rights were never formalized when they arrived in the Solomon Islands, fear further displacement should any development activities proceed on the island.

\subsection{Identity}

The Gilbertese on Wagina have been continuously constructing and reconstructing identities according to their home of origin, ethnicity and citizenship. The people identify themselves as Gilbertese based on their home of origin and I-Kiribati based on their ethnicity, and as Solomon Islanders based on their citizenships. The Gilbertese strongly identify as I-Kiribati people because of the language they speak and the cultural practices and way of life they continue to observe in the Solomon Islands. Despite being identified as I-Kiribati in the Solomon Islands, this self-acclaimed identity is often perceived differently by I-Kiribati people from Kiribati, who consider them as Solomon Islanders. Whereas in the Solomon Islands, the local population still identify the Gilbertese people as 'Gilbertese' to identify them as people from the Gilbert Islands, or as neiko. Neiko in the Gilbertese language is used to refer to a woman or female, and therefore is used in reference to any Gilbertese. Multiple identities have been continuously constructed through intermarriages with indigenous Solomon Islanders, Asians, Europeans, and other ethnic groups. However, the older generation feared that the Gilbertese identity would one day vanish as more Gilbertese people intermarry with other ethnic groups especially indigenous Solomon Islanders as a mechanism to access to land, for social integration and permanency in the Solomon Islands.

\section{Implications of Displacement for the Pacific Islands}

While voluntary migration is most effective when decisions are made at the individual and household levels, forced migration leads to displacement (Mortreux and Barnett 2009; Brown 2012; Campbell 2014; McAdam and Ferris 2015; Ferris et al. 2011; Hugo 2012). The Gilbertese resettlement provides an example of migration as an adaptation strategy and migration as displacement. The relocation to the Solomon Islands was intended for the Gilbertese to escape the detrimental effects of droughts in their islands and improve their livelihoods in their new home. However, this example of adaptation was unsuccessful due to the lack of adequate planning and preparation by the GEIC and BSIP administrations that failed to ensure a smooth transition of the Gilbertese into their new home given the environmental and cultural differences of Wagina and Phoenix Islands. It was also evident that the relocation was orchestrated primarily to benefit both administrations economically and in demographic terms. While the BSIP administration was generous with its intake of the Gilbertese population, the GEIC administration saw it as a remarkable offer that could address the overpopulation issues in the Colony and free itself from further economic expenses of managing Phoenix Islands. On the other hand, the Protectorate's copra plantations had suffered labor shortages after the war. It was anticipated that the Gilbertese resettlement would not only benefit the Solomon Islands through additional population, but that they would also supply the required labor for the plantations, and contribute towards the Protectorate's economy in exchange for permanent settlement.

The Gilbertese settlers refused relocation to the Solomon Islands when they were informed by the GEIC administration. According to the Gilbertese on Wagina, many of them refused to leave their home islands, but believed that they were forced to be relocated to escape the aftermath impacts of Britain's nuclear activities on Christmas Island. According to an old man in his seventies who was part of the relocation to Wagina Island as a young man, 'my family refused to leave Orona because of the graves of our loved ones that would be left behind on the island'. An old woman in her late sixties expressed her resentment towards the GEIC administration by articulating that due to 'the crowns of the coconuts trees fell after that thing [bomb] fell on Christmas Island. Yes, it was their doing', she said, 'that's why we moved 
here. They lied to us that our land is dead ... we saw that the coconut trees were on fire because of that thing [bomb] that fell, it's like fire... so when the crown of the coconut trees fell, the place became dead'. Although, the colonial records have been silent about these activities, there was evidence that Britain launched several hydrogen bombs between 1957 and 1959 on Christmas Island (Firth 1986).

The Gilbertese resettlement to Wagina was only made possible because the Colony had political, economic, and demographic ambitions in the schemes, without taking into account the impacts of relocation on the Gilbertese people as well as the Solomon Islands population. Today, the Gilbertese on Wagina have lived in Solomon Islands for more than 50 years, but they continue to experience cultural discrimination, land issues, and a lack of employment and education opportunities. Many have sought intermarriages to facilitate the integration of Gilbertese into the larger Solomon Islands society. However, many Gilbertese continue to see themselves as minorities, migrants and second class citizens in the Solomon Islands.

With the increase of climate change impacts, particularly sea level rise, migration, whether voluntary or forced, may be inevitable for many coastal communities, especially low lying atolls in the Pacific, given their low adaptive capacity and the lack of land to move further inland or uphill (Mortreux and Barnett 2009; Gemenne 2010). Although much has been written and discussed about migration as an adaptation strategy and migration as displacement by many scholars, very little has been documented about these forms of movements from the Pacific Islanders' point of view. The forced relocation of the Gilbertese to the Solomon Islands was described by the people on Wagina as being uprooted from their land by the GEIC administration and forced to relocate to Solomon Islands. They were very sad to leave behind their homes, the lands that they have worked hard to develop, and the graves of their loved ones buried on the islands. As one of the old men from Arariki village said; 'our hearts were very heavy when we sailed away from the islands. We could see our hard work and the graves of our loved ones left behind'.

This grief reflects Pacific Islands' anxieties of being forced to relocate from their home islands if sea level rise continues to increase. Land plays an important cultural and spiritual role for many Pacific Islands. It is important because it is indicative of prestige, wealth, heritage, security, and identity; it represents people's birthplace and place of origin (Crocombe 1987; Bonnemaison 1985; Campbell 2014; Tabe 2011). The Gilbertese on Wagina expressed a sense of displacement because they felt that they were forcefully uprooted from their land and denied agency to decide whether they want to be relocated or remain in their home islands. This sense of being displaced is expressed by Pacific people through fears of being uprooted from their islands. To be 'uprooted' in the Gilbertese language symbolizes detachment from the land in which roots are entrenched. To be uprooted from the land signifies the loss of ties to the ancestral lands and history, cultural values and identity, and the sense of belonging. This means that the forced migration of Pacific Islands as a result of climate change will lead to displacement, even if they were to re-establish themselves in a new place or country. For example, Rudiak-Gould (2013, p. 157) observation of the Marshall Islands highlights that 'migration is not a solution to climate change, but rather a genocide for its people, because there will be no more Marshallese people, no language, and no culture'. This was accentuated recently in a news statement by the President of the Marshall Islands, Hilda Heine, where she reiterates that 'her government won't consider relocating her citizens in responses to climate change' (RNZ 2018).

However, migration may be inevitable for Pacific Islands if sea level rise continues to increase. If so, planned relocation will be essential because most of these movements will take place internally within the state's territory. Although it is the state's responsibility to facilitate all planned relocations within its national borders, it should only be carried out if all other alternatives and solutions have been exhausted and relocation is decided by the communities as the preferred form of adaptation to sea level rise. Planned relocation should enable the rebuilding, integration, and sustainability of relocated communities in the new destinations and should only take place with informed consent of the vulnerable communities and the people (UNHCR 2014). For instance, Tuvalu has emphasized on the fact that 'there is no Plan B', which is to be relocated. The country is working on building 
climate resilience and to enhance the adaptive capacity of its people to adapt better to the impacts of climate change. If they have to migrate, it will be the very last response after every available option to remain on the island has been explored and exhausted (Mortreux and Barnett 2009; Campbell 2014; Ransan-Cooper et al. 2015).

However, it has been argued that migration as an adaptation strategy to climate change should not deter the focus of developed countries from cutting down their carbon emissions, because for Pacific Islands, forced migration will lead to displacement. Instead developed countries should take responsibility in mitigating climate change and assist the Pacific Islands in building innovative adaptation strategies so that the islands remain habitable for many years to come. It is also important that Pacific Islands' narratives on forced relocation and displacement of their people from their land are acknowledged and privileged in climate change discourses and policy making. This is not to completely reject migration as an adaptation strategy, but rather to recognize Pacific Islands' voices and perceptions on migration as displacement for them. This is also to help inform decisions on how forced migration of vulnerable communities in the Pacific can be carried out effectively and in line with best practices for future relocations that have been developed by the United Nations of High Commissioner for Refugees (UNHCR 2014) to reduce risks associate with climate change and ensure the continuity of communities in the new destinations.

\section{Conclusions}

Campbell (2014) clearly argues that when discussing migration, it is important to differentiate between 'migration as adaptation' and 'migration as displacement'. The Gilbertese resettlement to Solomon Islands provides a relevant example of forced relocation and displacement of Pacific Island people during the colonial period. It also illustrates an example of the relocation of people as an adaptation measure, but also as one that led to the displacement of the Gilbertese people. The resettlement offers some lessons that can inform decisions and policies on climate change migration and relocation, especially of vulnerable Pacific Islands that may be subject to relocation in the future as a result of sea level rise. The Gilbertese resettlement provides lessons that implicates the need for planned relocations to involve proper planning and preparation with informed consent from the communities and people. People who may be subject to forced relocation in the future as a result of climate change must be given the agency to choose whether they want to be relocated or to remain behind to minimize potential challenges likely to be encountered in the new destinations and a sense of displacement.

The environmental and cultural differences of the islands need to be taken into account during the planning and preparation of any community relocation to minimize the challenges that are likely to be encountered. Consultation with the host communities prior to any relocation (unless the relocation site is within the community's land boundaries) is significant so that they can provide the relevant support needed in the integration of the communities in their new homes and to prevent any form of hostility and marginalization. Land is evidently a major issue in migration processes and discourses, especially in the Pacific Islands. Land should be acquired legally with rights and allocated to the relocated communities so that they can re-establish themselves and continue to exist as a community. Rights and access to fishing grounds should also be allocated to relocated communities that are dependent on marine resources to provide them means for subsistence and income-generating activities. Identity is also very important to many Pacific Islands and it is one of the reasons why many do not want to migrate. However, it is important that relocated communities continue to thrive in the new destinations so that they can maintain their cultures, languages, and maintain their identity.

While a lot has been documented and discussed about migration as an adaptation strategy and migration as displacement, very little has been written from the Pacific Islands standpoint. Many Pacific Island countries view forced migration or relocation as a form of displacement. This is not to dismiss migration as an adaptation to climate change, but rather to understand why many Pacific Island countries resist the idea of being forced to leave their home islands and relocate elsewhere due to 
climate change. This resistance embodies the fear of losing their genealogies, cultures, and identity imbedded in the land. Land is culturally and spiritually important for Pacific Islanders and is greatly valued, and to be forcefully uprooted from the land leads to displacement. The resistance towards forced relocation also challenges developed countries must reduce their global carbon emissions so that Small Island Developing States (SIDS) like the Pacific Islands should not become displaced from their home islands as result of sea level rise. It also accentuates Pacific Islands' voices and position in global discourse as small island states for developed countries to take responsibility in curbing their carbon emissions. If migration was to take place, it must be carefully planned and conducted properly with consent of the communities and people. The relocation must be planned and facilitated in a way that enables the continuity and sustainability of the community in the new destinations. However, the recognition and support of Pacific voices and perceptions in discourse on climate change migration and displacement is crucial at regional and global forums, particularly to inform decisions and policies for effective planning of future climate change migrations in the Pacific region.

Funding: This paper received no external funding.

Acknowledgments: This paper is part of a Ph.D. thesis at the University of Bergen, Norway. Many thanks to Akosita Rokomate-Nakoro for the constructive feedback on the paper, and to John R Lee for the continuous encouragement.

Conflicts of Interest: The author declares no conflict of interest.

\section{References}

Adger, W. Neil, Juan M. Pulhin, Jon Barnett, Geoffrey D. Dabelko, Grete K. Hovelsrud, Marc Levy, Ursula Oswald Spring, and Coleen H. Vogel. 2014. Human security. In Climate Change 2014: Impacts, Adaptation, and Vulnerability. Part A: Global and Sectoral Aspects. Contribution of Working Group II to the Fifth Assessment Report of the Intergovernmental Panel on Climate Change. Edited by Christopher B. Field, Vicente R. Barros, David Jon Dokken, Katharine J. Mach, Michael D. Mastrandrea, T. Eren Bilir, Monalisa Chatterjee, K. L. Ebi, Y. O. Estrada, R. C. Genova and et al. Cambridge and New York: Cambridge University, pp. 755-91.

Bonnemaison, Joel. 1985. The Tree and the Canoe: Roots and Mobility in Vanuatu Societies. Pacific Viewopoint 26: 30-62. [CrossRef]

Brown, Oli. 2012. Climate Change and Forced Migration: Observation, Projections and Implications. In Climate Change and Displacement Reader. Edited by Scott Leckie, Ezekiel Simperingham and Jordan Bakker. Oxon: Earthscan.

Campbell, John. 2014. Climate Change Migration in the Pacific. The Contemporary Pacific 26: 1-28. [CrossRef]

Cernea, Michael M. 2004. Impoverishment risks, risk management, and reconstruction: A model of population displacement and resettlement. Paper Presented at the UN Symposium on Hydropower and Sustainable Development, Beijing, China, October 27-29.

Charan, Dhrishna, Manpreet Kaur, and Priyatma Singh. 2017. Customary Land and climate change induced relocation-A Case Study of Vunidogoloa Village, vanua Levu, Fiji. In Climate Change Adaptation in Pacific Islands. Cham: Springer, pp. 19-33.

Church, John A., Peter U. Clark, Anny Cazenave, Jonathan M. Gregory, Svetlana Jevrejeva, Anders Levermann, Mark A. Merrifield, Glenn A. Milne, R. Steven Nerem, Patrick D. Nunn, and et al. 2013. Sea Level Change. In Climate Change 2013: The Physical Science Basis. Contribution of Working Group I to the Fifth Assessment Report of the Intergovernmental Panel on Climate Change. Edited by Thomas F. Stocker, Dahe Qin, Gian-Kasper Plattner, Melinda Tignor, Simon K. Allen, Judith Boschung, Alexander Nauels, Yu Xia, Vincent Bex and Pauline M. Midgley. Cambridge and New York: Cambridge University Press.

Cochrane, Glynn. 1970. The Administration of Wagina Resettlement Scheme. Human Organization 29: 129. [CrossRef]

Connell, John. 2012. Population Resettlement in the Pacific: Lessons from a hazardous history? Australia Geographer 43: 127-42. [CrossRef]

Crocombe, Ron G., ed. 1987. Land Tenure in the Pacific, 3rd ed. Suva: University of the South Pacific.

Edwards, Julia. 2013. Phosphate and Forced Relocation: An Assessment of the Resettlement of the Banabans to Northern Fiji in 1945. The Journal of Imperial and Commonwealth History 41: 783-803. [CrossRef] 
EERI Special Earthquake Report. 2010. Samoa Earthquakes and Tsunamis of September 29. 2009. Available online: https://www.eeri.org/site/images/eeri_newsletter/2010_pdf/Samoa-Rpt.pdf (accessed on 12 October 2015).

Ferris, Elizabeth, Micheal M. Cernea, and Daniel Petz. 2011. On the Frontline of Climate Change and Displacement. London: Brookings Institute, London School of Economics.

Firth, Stewart. 1986. The Nuclear Issue and South Pacific Security. Sydney: HV Evatt Memorial Foundation.

Gemenne, François. 2010. Migration, a Possible Adaptation Strategy? IDDR. Available online: https://www. iddri.org/fr/publications-et-evenements/propositions/migration-possible-adaptation-strategy (accessed on 26 January 2019).

Goldring, Mark. 2015. Vanuatu Won't Be the Last Poor Country Devastated by Climate Change Inaction. The Guardian (UK). Available online: http://www.theguardian.com/global-development/2015/mar/20/sendaiclimate-change-inaction-poor-countries-vanuatu-cyclone-pam (accessed on 12 October 2015).

Gordon-Clark, Matthew. 2012. Paradise Lost? Pacific island archives threatened by climate change. Archival Science 12: 51-67. [CrossRef]

Government of Fiji. 2016. Fiji Post-Disaster Needs Assessment; Suva: Government of Fiji.

Government of Solomon Islands. 2014. Rapid Assessment of the Macro and Sectoral Impacts of Flash Floods in the Solomon Islands, April 2014. Honiara: Government of Solomon Islands, Available online: https: //www.gfdrr.org/sites/default/files/publication/pda-2014-solomonislands.pdf (accessed on 26 January 2019).

Hagen, Kim. 2013. Resilience: Response, Recovery, Ethnicity in Post-Disaster Processes. Suva: SPC Applied Geoscience and Technology, Available online: http://gsd.spc.int/sopac/docs/KimHagenPaper/ (accessed on 26 January 2019).

Hermann, Elfriede. 2005. Emotions and the Relevance of the Past: Historicity and Ethnicity among the Banabans of Fiji. History and Anthropology 16: 275-97. [CrossRef]

Hugo, Graeme. 2012. Climate Change-Induced Migration Mobility and the Existing Migration Regime in Asia and the Pacific. In Climate Change and Displacement: Multidisciplinary Perspectives. Edited by Jane McAdam. Oxford: Hart Publishing, pp. 9-35.

Hulme, Mark. 2009. Why We Disagree About Climate Change. Cambridge: Cambridge University Press.

IOM. 2015. Cyclone Pam causes devastating impact on employment and livelihoods. Available online: https: //www.ilo.org/suva/public-information/WCMS_368560/lang--en/index.htm (accessed on 12 October 2015).

IPCC. 2007. Climate Change 2007. Impacts, Adaptation and Vulnerability. Cambridge: Cambridge University Press.

Kiste, Robert C. 1977. The Relocation of the Bikini Marshallese. In Exiles and Migrants in Oceania. Edited by Michael. D. Lieber. Honolulu: University Press of Hawai'i, pp. 81-120.

Knudson, Kenneth E. 1964. Titiana: A Gilbertese Community in Solomon Islands. Eugene: Department of Anthropology, University of Oregon.

Legatis, Rousbeh. 2011. Climate Change: A Rising Sea Threatens Pacific Islands. Available online: http://www. ipsnews.net/2011/11/climate-change-a-rising-sea-threatens-pacific-islands/ (accessed on 3 March 2015).

Maude, Harry E. 1968. The Colonization of the Phoenix Islands. In Of Islands and Men. Edited by Harry E Maude. London: Oxford University Press, pp. 315-42.

McAdam, Jane. 2012. 'Disappearing States', Statelessness and the Boundaries of International. In Climate Change and Displacement: Multidisciplinary Perspectives. Edited by Jane McAdam. Oxford: Hart Publishing, pp. 105-29.

McAdam, Jane. 2014. Historical Cross-Border Relocations in the Pacific: Lessons for Planned Relocation in the Context of Climate Change. Journal of Pacific History 49: 301-27. [CrossRef]

McAdam, Jane. 2015. Relocation and Resettlement from colonization to climate change: The perennial solution to 'danger zones'. London Review of International Law 3: 93-130. [CrossRef]

McAdam, Jane, and Elizabeth Ferris. 2015. Planned Relocations in the context of climate change: Unpacking the legal and conceptual Issues. Cambridge Journal of International and Comparative Law 4: 137-66. [CrossRef]

McNamara, Karen E., and Helene Jacot Des Combes. 2015. Planning for Community Relocation due to climate change in Fiji. International Journal of Disaster Risk Science 6: 315-19. [CrossRef]

Meyen, Natalie. 1992. One Babai Pit in a Lifetime: Gilbertese Migration in the Pacific. Master's thesis, Australia National University, Canberra, Australia. 
Mimura, Nobuo, Leonard Nurse, Roger McLean, John Agard, Lino Briguglio, Penehuro Lefale, Rolph Payet, and Sem Graham. 2007. Small islands. In IPCC. Climate Change 2007: Impacts, Adaptation and Vulnerability. Contribution of Working Group II to the Fourth Assessment Report of the Intergovernmental Panel on Climate Change. Edited by Martin L. Parry, Osvaldo F. Canziani, Jean P. Palutikof, Paul J. van der Linden and Clair E. Hanson. Cambridge: Cambridge University Press, pp. 687-716.

Mortreux, Colette, and Jon Barnett. 2009. Climate change, migration and adaptation in Funafuti, Tuvalu. Global Environmental Change 19: 105-12. [CrossRef]

O’Brien, Karen, Linda Sygna, Robin Leichenko, W. Neil Adger, Jon Barnett, Tom Mitchell, Lisa Schipper, Thomas Tanner, Coleen Vogel, and Colette Mortreux. 2012. Disaster Risk Reduction, Climate Change Adaptation and Human Security. A commissioned Report for the Norwegian Ministry of Foreign Affairs. In Climate Change and Displacement Reader. Edited by Leckie Scott, Ezekeil Simperingham and Jordon Bakker. Oxon: Earthscan.

ODI, and UNDP. 2017. Climate Change, Migration and Displacement: The Need for a Risk-Informed and Coherent Approach. Available online: https:/www.odi.org/publications/10977-climate-change-migration-and-displacementneed-risk-informed-and-coherent-approach (accessed on 9 May 2019).

Oxfam. 2012. The Future is Here: Climate change in the Pacific. In Climate Change and Displacement Reader. Edited by Scott Leckie, Ezekiel Simperingham and J. Bakker. Oxon: Earthscan.

Ransan-Cooper, Hedda, Carol Farbotko, Karen E. McNamara, Fanny Thornton, and Emilie Chevalier. 2015. Being (s) framed: The means and ends of framing environmental migrants. Global Environmental Change 35: 106-15. [CrossRef]

RNZ. 2018. Gita Caused \$US156 Million in Damages in Tonga. Available online: https://www.radionz. co.nz/international/pacific-news/357542/gita-caused-us156-million-in-damages-in-tonga (accessed on 17 February 2019).

Rudiak-Gould, Peter. 2013. Climate Change and Tradition in a Small Island State. New York: Routledge.

Scudder, Thayer. 2005. The Future of Large Dams: Dealing with Social, Environmental, Institutional and Political Costs. London: Earthscan.

Silverman, Martin G. 1971. Disconcerting Issue: Meaning and Struggle in a Resettled Pacific Community. Chicago: University of Chicago Press.

SPC. 2017. Tukuraki Village Relocates to New Site, Post Land-Slide Disaster. Available online: https://reliefweb. int/report/fiji/tukuraki-village-relocates-new-site-post-land-slide-disaster (accessed on 17 February 2019).

Tabe, Tammy. 2011. Sapon riki ba kain toromon: A Study of the I-Kiribati in Solomon Islands. Master's thesis, University of Hawai'i, Manoa, Honolulu, HI, USA.

Tabe, Tammy. 2016. Ngaira kain tari: We are people of the Sea. A study of the Gilbertese Resettlement to Solomon Islands. Ph.D. thesis, University of Bergen, Bergen, Norway.

Tabucanon, Gil M. 2012. The Banaban Resettlement: Implications for Pacific Environmental Migration. Pacific Studies 35: 343-70.

Tabucanon, Gil M, and Opeskin Brian. 2011. The Resettlement of Nauruans in Australia. Journal of Pacific History 46: 337-356. [CrossRef]

Teaiwa, Katerina M. 2015. Consuming Ocean Island: Stories of People and Phosphate from Banaba. Indiana: Indiana University Press.

Tronquet, Clothilde. 2015. From Vunidogoloa to Kenani: An Insight into Successful Relocation. Available online: http://labos.ulg.ac.be/hugo/wp-content/uploads/sites/38/2017/11/The-State-of-EnvironmentalMigration-2015-121-142.pdf (accessed on 26 January 2019).

UNHCR. 2014. Planned Relocation, Disasters and Climate Change: Consolidating Good Practices and Preparing for the Future. Available online: www.unhcr.org/54082cc69.pdf (accessed on 26 January 2019).

Voutira, Eftihia, and Harrell-Bond Barbara. 2000. Successful refugee settlement: Are past experiences relevant? In Risks and Reconstruction: Experiences of Resettles and Refugees. Edited by Cernea Michael and Christopher McDowell. Washington: World Bank, pp. 56-76.

Weber, Eberhard. 2016. Only a pawn in their games? Environmental? Migration in Kiribati-Past, Present and Future. Available online: https://www.die-erde.org/index.php/die-erde/article/view/291 (accessed on 6 January 2019). 
Wrathall, D. 2011. Synthesis of expert contributions and discussions. Population-Environment Research Network cyber seminar on preparing for population displacement and resettlement associated with climate change and large climate mitigation and adaptation projects. Available online: http://www.iussp.orgiActivities/ perniSynthesisNov2011.pdf (accessed on 6 January 2019).

Yamamoto, Lilian, and Esteban Miguel. 2012. Atoll Island States and International Law: Climate Change Displacement and Sovereignty. Heidelberg: Springer.

Yeo, Sophie. 2014. Solomon Islands Town to Relocate as Climate Pressures Mount. RTCC. Available online: http://www.rtcc.org/2014/08/15/solomon-islands-town-to-relocate-as-climate-pressures-mount/ (accessed on 3 March 2015).

Zamora, Natalie, Giovanni Franchello, and Alessandro Annunziato. 2011. 01 April 2007 Solomon Islands Tsunami: Case Study to Validate JRC Tsunami Codes. JRC Scientific and technical Reports. Luxembourg: Joint Research Centre, European Commission.

(C) 2019 by the author. Licensee MDPI, Basel, Switzerland. This article is an open access article distributed under the terms and conditions of the Creative Commons Attribution (CC BY) license (http://creativecommons.org/licenses/by/4.0/). 


\title{
Article \\ Coffee, Migration and Climatic Changes: Challenging Adaptation Dichotomic Narratives in a Transborder Region
}

\author{
Celia Ruiz-de-Oña ${ }^{1, *}$, Patricia Rivera-Castañeda ${ }^{2}$ and Yair Merlín-Uribe ${ }^{3}$ \\ 1 Multidisciplinary Research Center on Chiapas and the Southern Border (CIMSUR), National Autonomous \\ University of Mexico, Calle Ma. Adelina Flores \# 34-A, Barrio de Guadalupe, \\ San Cristóbal de Las Casas C.P. 29230, Mexico \\ 2 Departamento de Estudios Urbanos y Medio Ambiente, Colegio de La Frontera Norte, Tijuana C.P. 22560, \\ Mexico; privera@colef.mx \\ 3 Department of Agriculture, Society and Environment, El Colegio de la Frontera Sur (ECOSUR), \\ Carretera Panamericana y Periférico Sur S/N, Barrio María Auxiliadora, San Cristóbal de Las Casas, \\ Chiapas C.P. 29290, Mexico; yairmerlin7@gmail.com \\ * Correspondence: celiardo@unam.mx; Tel.: +52-967-672-0538
}

Received: 3 September 2019; Accepted: 15 November 2019; Published: 25 November 2019

\begin{abstract}
The narratives of migration as adaptation and in situ adaptation are well established in mainstream adaptation policy and are usually presented as independent and opposing trends of action. A common and fundamental element of such narratives is the depoliticized conception of both migration and adaptation. Using a trans-scalar approach, we address the migration-coffee-climate change nexus: first at a regional scale, at the conflictive border of Guatemala-Mexico, to show the contradiction between the current Central American migratory crisis and the narrative of migration as adaptation; second, at a local scale and from an ethnographic perspective, we focus on the process of in situ adaptation in shade-grown coffee plots of smallholder coffee farmers in the Tacaná Volcano cross-border region, between Chiapas and Guatemala. We argue that the dichotomy "in situ adaptation" versus "migration as adaptation" is not useful to capture the intertwined and political nature of both narratives, as illustrated in the case of the renovation of smallholders' coffee plots in a context of climatic changes. We provide elements to contribute towards the repolitization of adaptation from an integral perspective.
\end{abstract}

Keywords: migration-climate change-coffee nexus; migration as adaptation; in situ adaptation; coffee leaf-rust; transborder region; narratives

\section{Introduction}

In the field of adaptation and its relation to the migration-climate change nexus, one of the most frequent and debated issues is the notion of migration as an adaptation strategy. It implies that migration can be considered-and encouraged—as a viable strategy for coping with the impacts of climate change, mainly due to climate disasters (Black et al. 2011). It is further argued that local development strategies linked to the notion of in situ adaptation have proven to be ineffective (Foresight 2011, p. 24). Alternatively, migration as adaptation has been presented as a failure of adaptive capacity in specific territories (Gemenne and Blocher 2017; Bardsley and Hugo 2010). Both notions-migration as adaptation and in situ adaptation-seem to be approached in mutually exclusive terms or at least in terms disconnected from each other. This paper argues that this dichotomous perspective has limitations in addressing and understanding the complex political nature of the adaptation-migration nexus and the multiple forms and expressions that the intersection of migration and climate change reveals in specific contexts. 
In this article both notions, conceived as depoliticized narratives (Klepp 2017), are put into play in the particular context of the southern border of Mexico and from the perspective of the problem of coffee production in Mesoamerica (Central America and Chiapas, Mexico).

We focus on the crisis that the outbreak of the fungus Hemileia vastatrix, known as coffee leaf rust, has caused since 2012 as well as its complex interactions with the phenomenon of migration in the context of climatic changes. Because of the amplitude and virulence of the outbreak, coffee farmers in Central America and Chiapas were confronted with the necessity to conduct a deep renovation of coffee plants. The high-quality Arabica coffee varieties were no longer apt for cultivation at altitudes that before thrived well. Diverse institutional actors, national and international, were supporting this process that took different expressions according to political and local conditions.

However, migration rocketed in some countries where institutional support was absent or feeble, such as Guatemala or Honduras. Crops failure, violence, poverty and climatic changes merged into a cocktail that unleashed massive migrant movements that were partially deterred at the southern border of Mexico, due to the new immigration policies pushed from the United States.

The resulting migratory crisis (Isacson et al. 2014) offers an opportunity to analyze and jointly address the concept of migration as a form of adaptation put forward from mainstream adaptation practice and its interplay with those adaptive strategies on the ground-in situ adaptation-that seek precisely to curb migration.

To illustrate such interplay, we selected an emblematic coffee-producing region, the transborder Tacaná Volcano area, where we explored, in three communities at different altitudes, the process of adapting smallholders' coffee plots to the new climatic and producing conditions. We registered subjective narratives that evaluated how the government program for coffee renovation unfolded and the drawbacks that jeopardize a successful adaptation. Then, the role of national internal migration and international emigration to the Unites States was brought into the analysis.

The objective of the paper is to show the limitations of both approaches in capturing the fundamental political nature that underlays the adaptation practice and the interactions with the migratory phenomenon. What form do these interactions take for our case study? What are the implications of conceiving "migration as adaptation" as opposed to "in situ adaptation"? What lessons can it teach us regarding conceptions of migration and adaptation that do not recognize the political dimension that largely determines the future success of adaptation strategies?

To address these questions, we portray the multiple facets of migration, climate change and adaptation and their interweaving at different scales-following the suggestion of Eklund et al. (2016) in which scale issues are critical to present a rich and integrated understanding of the complexity attached to the migration phenomenon.

We maintain that the dichotomization of both streams of action simplifies and leaves unaddressed the web of causes and effects on which the migration-climate change nexus is continually being recreated. This is illustrated in our case study.

The ultimate purpose of the paper is to provide elements that contribute towards the repoliticization of adaptation practice and research (Klepp 2017), that pose new counternarratives enrooted in the political realities we face and, from there, to design adaptation strategies under a more integrated light, away from dichotomic options.

Such an approach has not been addressed in the academic literature dealing mainly with capacity adaptation of coffee systems in Chiapas (c.f. Frank et al. 2011; Götz et al. 2009) in which migration, although present, is not the analytical focus. The only study that tackles the nexus of migration-adaptation-coffee is that also conducted for the southern border of Mexico by Ruiz Meza (2010, 2015).

However, studies dealing with the tension of migration as adaptation and in situ adaptation are lacking. This article seeks to fill this gap and motivate further discussion to strengthen the analytical nexus of migration-coffee-climate change. 
The paper is structured as follows: first, we present a regional overview of the migration crisis in our area of study, a coffee-growing region, and the point of entry for Central American migratory caravans that intersect with local migratory flows. We highlight the connection between migrant caravans and the coffee crisis in which the issue of climate change is gaining presence. In a context of increasing militarization and enforcement of border control, we seek to evidence the mismatch between the narrative of migration as adaptation and the migratory crisis of Mexico's southern border.

Second, to provide a political economy view of the context in which coffee cultivation develops in our region of study, we present a descriptive statistical profile of macro factors, such as coffee productivity and demographics, at the level of the state of Chiapas and at the municipal level, which have repercussions on the communities of study. On this, we follow the recommendation offered by Gemenne and Blocher (2017), according to which an examination of recent changes in migration patterns should be a starting point of research in specific contexts.

Third, at the community level, we present ethnographic notes on local perspectives and experiences in migration and coffee farming as a way of life, trying to decipher those micro factors that add knowledge towards a more integrated view of the way migration is understood by locals and how it interferes with adaptation in the face of climatic changes.

The findings based on our case study reveal how political and economic constraints largely determine the success or failure of adaptation strategies. The case also reveals how the narrative of migration as adaptation does not make much sense in the case of coffee production, in which climatic and environmental factors aggravate population expulsion factors in territories that were largely shaped by waves of migrants. Findings also illustrate the inadequacy of the dichotomy "migration as adaptation" and "in situ adaptation" for slow-onset impacts or progressive climatic impacts. The interactions that occur between those who migrated and those who remained in the territories of origin, seeking to adjust their livelihoods to conditions of high climatic variability, cannot be captured when conceiving adaptation in such dichotomic terms.

\section{Literature Review}

The concept of "migration as adaptation" seems to have been firmly established in the sphere of international development aid agencies and global financers since the publication of the influential Foresight Report (2011), an extensive study by the UK government addressing the influence of global environmental change on migratory patterns in developing countries.

Since then, several international reports have taken up and strengthened this position (cf. FAO 2017; Rigaud et al. 2018). From this perspective, a narrative is constructed that emphasizes a positive view of migration as one of the most effective ways to diversify household income and contribute to a country's wealth, as well as to avoid climate threats, in particular, the increase in extreme weather events (rapid onset impacts). In addition, it is argued that preventing migration can lead to unsustainable outcomes and create a situation of trapped populations (Foresight 2011, p. 4).

The notion of migration as adaptation refers above all to the forced displacement of populations by extreme climatic and weather conditions. There is a substantial body of literature that qualifies these movements as climatic migration or environmentally induced migration (Gemenne and Blocher 2017; Piguet et al. 2011; Black et al. 2011; Tacoli 2009; Bardsley and Hugo 2010). Although with important conceptual and methodological nuances in the form and intensity of the role played by climate factors (conceptualized in the debate between maximalist and minimalist positions) and in the way of qualifying the population fleeing disasters (see Klepp 2017 for an in-depth review of the political implications of the terms used to categorize human mobility associated with climate change), these studies coincide in pointing out the multicausal nature of most migratory flows and emphasize the complex interaction between economic, social and political factors with environmental factors (Bardsley and Hugo 2010; Tacoli 2009, p. 107). Furthermore, Felgentreff and Plott (2016) indicate that it is not clear how to identify and separate environmental factors influencing migration empirically. 
The common premise of this diverse literature is that migration is and will be a key response-conceived as an adaptation strategy - to the future impacts of climate change, whether they are rapid or slow-onset impacts. Therefore, it is argued that it is urgent to insert migration as an adaptive response in National Adaptation Plans (Sward and Codjoe 2012). Similarly, adaptation to climate change should be considered as part of migration policies, in order to regulate migration in an orderly and safe manner. In this sense, in December 2018, the intergovernmental Global Compact for Safe, Orderly and Regular Migration was agreed to by states globally, establishing the political basis at the international level to operationalize the migration and adaptation nexus, and raising the issue of climate change and migration on the international migration agenda (Newland 2019).

On the contrary, "adaptation in situ" refers to the idea that the practice of adaptation should take place in local environments so that people continue to live in their homeland and do not have to emigrate.

In situ adaptation is framed within the community-based approach to adaptation (c.f. McNamara and Buggy 2017 for an extended review of the concept) and ecosystem-based adaptation (c.f. Nalau and Becken 2018 for a review of the concept). Both lines share the common assumption of adaptation as a local scale intervention and in specific territories, although ecosystem-based adaptation extends its scope to biophysical scales such as watersheds or landscapes. This emphasis on the biophysical dimension and its connection to local livelihoods is the guiding principle of the in situ adaptation approach, although the question of how to scale up results is increasingly important. Therefore, the focus is primarily on environmental preservation, the introduction of sustainable agronomic practices and rural development planning. Most in situ adaptation is about defining adaptation strategies based on participatory management of environmental resilience and is carried out under the auspices of international agriculture and development organizations. The aim is to move towards greater environmental and climate resilience, which will eventually deter migration. In general, however, the analytical link with the migration issue is circumstantial. In Mesoamerica, and for the issue of coffee, a key cash-crop in the region, there is a considerable academic production which reflects the importance of in situ adaptation in this area of the world (c.f. Harvey et al. 2018; Chain-Guadarrama 2019; Imbach et al. 2017).

At the policy-realm, both approaches-on-site adaptation and migration as adaptation-are addressed in a decoupled manner. In the field of research, studies are also divided into one or the other line, as shown in the review by Upadhyay and Mohan (2014).

On this dichotomous view between in situ adaptation and migration as adaptation, Saleemul Huq, Director of the International Centre for Climate Change and Development (ICCCAD) and recognized expert in the field of adaptation, renamed this dichotomy as in situ adaptation versus planned relocation (or assisted migration), introducing an important nuance to the idea of denominating human mobility in catastrophic circumstances and in the face of climatic threats such as migration. Professor Huq questions the initial assumptions of the field of adaptation research as limited to the local scale, leaving aside the global and transboundary scale, advocating for a new paradigm of adaptation away from reactive responses to more proactive planning (Huq 2013).

Critical Perspectives on Adaptation: From a Depolitized to a Re-Politized Adaptation View

Scholars in the field of critical political ecology have criticized the idea of adaptation that prevails in the international policy arena on climate change and adaptation and in the literature linked to science and technology (c.f. Scoville-Simonds et al. 2019 for a recent review of the critical literature on adaptation). The fact that such a notion is rooted in the field of evolutionary biology (Taylor 2015) contributes to the neglect of social science analysis and the opinions and perspectives of local populations, often conceived as voiceless victims (Scoville-Simonds et al. 2019; Klepp 2017).

Following their critiques, we can postulate that narratives engrained in the notions of in situ adaptation and migration as adaptation share a depoliticized view of adaptation in the sense that they 
obscure long-term dynamics in rural environments that give rise to strongly unequal socio-ecological relationships (Taylor 2015; Klepp and Chavez-Rodriguez 2018).

Issues such as the effect of agrarian transformation by liberalization of agricultural policies, uneven access to resources such as credit or the lack of distributive strategies of land and income (Taylor 2015); the role played by capitalist accumulation (Turhan and Armiero 2017); the dominant role of techno-science; and the asymmetries on which global markets are based, are all structural causes that remain excluded from the dominant narratives of adaptation (Taylor 2015, pp. 51, 61; Klepp and Chavez-Rodriguez 2018, p. 15).

This lack of attention to economic and climatic justice considerations (Klepp 2017) yields a reductionist narrative that evades tackling migration and its link with climate change as manifestations of a systemic crisis. In turn, the depiction of climate change as a purely biophysical phenomenon external to social reproduction generates the illusion of being something natural and apolitical. Such an image gives rise to a naturalized view of both adaptation and climate change in which social relations, power imbalances and the active coproduction between humans and meteorological forces remain obscured (Taylor 2015; Klepp 2017).

Regarding the migration-climate change nexus, scholars have also questioned the notion of migration as an adaptive strategy, based on similar criticism expressed for the idea of adaptation (Felli and Castree 2012). Another line of criticism points out that the discourse of "climate refugees" linked to "climate migration" implies a view of migrants as a threat to security but currently under the terminology of human security, resilience and adaptation (Bettini 2014). This discourse contributes to legitimating the neoliberal capitalist logic currently operating in the management of the migratory crisis (Felli 2013).

\section{Migration as Adaptation? A Depoliticized Narrative in the Context of the Mexican Southern Border Migratory Crisis}

The notion of migration as adaptation highlights certain positive aspects of the migration experience (Rigaud et al. 2018; Delavelle 2013; FAO 2017), while leaving out the current context in which border crossing takes place for a large majority of the world's migrant population.

The core narrative thread upon which the narrative of migration as adaptation is built is the idea of planning and advancing a safe, orderly and efficient migration. Another of its tenets is that migration is something that societies have undertaken throughout the existence of humanity in search of better living conditions. What is omitted from these narrative threads is an explicit reference to the increasingly restrictive and violent conditions in which migration currently takes place.

While noting that migration is a complex phenomenon and that environmental factors are difficult to isolate from economic, social or political factors, the notion of migration prevalent in reports, such as the World Bank's Groundswell (Rigaud et al. 2018), is greatly simplified. It operates on the illusion that current massive migratory movements can be controlled and managed in nonproblematic ways.

Underlying this flat notion of migration is the age-old fear of migration as a threat to national security and the invasion of hordes of migrants drawn as criminals and dispensable human beings (Hartmann 2010). This representation matches a long-standing discursive thread that inherited characteristic Malthusian stances and northern environmentalist discourses articulated around the fear of poor countries' populations (Bettini 2017, p. 11).

This narrative, although so conspicuous in the immigration politics exhibited by the Trump administration, is not exclusive to it. It also extends to those conflict borders of the Latin American world, such as the Venezuelan border (Valero Martínez 2016) and the Mexico-Guatemala border.

The southern border of Mexico has recently been subjected to new programs to control political borders (Ribando Seelke and Davis-Castro 2019; Torre Cantalapiedra and Quintero 2018; Castañeda 2016; Isacson et al. 2014). These programs were designed under the securitization doctrine (Varela Huerta 2015; Bigo 2002; Hernández-Gutiérrez and Sáenz 2018, p. 2), a term that refers to the militarization of social problems as a way to address them. 
Neither the toughening of immigration control policies by the Trump administration (or that of his predecessor Barack Obama), nor his discourse of hate and criminalization against migrants, were able to dissuade thousands of Central Americans from fleeing poverty, widespread violence and a lack of opportunity in their home countries, in the so-called "Northern Triangle" that includes El Salvador, Guatemala and Honduras (ELCOLEF 2018).

\subsection{What Does This Situation Have to Do with the Coffee Rust Crisis in Central America?}

The humanitarian crisis on Mexico's southern border takes on media relevance when, starting in October 2018, several massive movements of Central American migrants-in groups of 2000 to 5000 people-crossed the Mexican borders towards the northern border with the United States (ELCOLEF 2018). A 70\% share of the members of the migrant caravans were of Honduran origin (ELCOLEF 2018). We have mentioned the importance of coffee for this country and its continued erosion since the impact of coffee leaf rust. It should also be noted that Honduras is a country with one of the highest vulnerability indexes ${ }^{1}$ due to climate change and that it is part of the Central American Dry Corridor, where most of its coffee production takes place and which is currently suffering from a long-term severe drought (Canet Brenes et al. 2016).

At the start of the crisis, the link between migration and climate change were hardly referenced in international media (Milman et al. 2018). From April 2019 onwards, reports and news relating to migrant caravans, the dry Central American corridor and rampant drought in recent years, water scarcity, and crop losses first appeared in the pages of international media (among many others see, for example: Gustin and Henninger 2019; Markham 2019; Blitzer 2019; Semple 2019). The role of the effects of climate change on coffee crops and its relationship with coffee leaf rust as a catalyst for migration in a context of poverty is thus linked to the phenomenon of Central American migrant caravans.

\subsection{Is a Safe and Orderly Migration Possible in the Current Context of Border Closures?}

As the increase in the transit of migrants in caravans increases, the situation on both Mexican borders worsens. Trump's threats to impose tariffs on Mexican exports to the U.S. have taken effect and the southern border has been militarized to prevent caravan transit. Thousands of people have been detained in temporary centers. We can refer here to a situation of trapped populations, but of a different nature to that alluded to in the literature of migration as adaption (Foresight 2011).

The approach of a safe and orderly migration is proposed against the backdrop of realities such as the one described above. We can question the possibility of articulating regional proposals based on the Global Compact for Migration. In this sense, few studies have analyzed the potential for coordination among states to establish migration policies that include the environmental component. For Neumann and Hilderink (2015), the possibility to partially operate the Global Compact for Migration is remote. For the European context, considered as a system of governance with experience in sectoral and interstate coordination, Geddes and Jordan (2012) conclude that the possibilities of designing policies that address migration, environmental change and adaptation to global environmental change in a combined manner are limited, partly due to the prevalence of the focus on securitization of current migration policies. For Latin America (Lejtreger 2019), results from evaluation of the integration of climate change and migration conclude that there is very little progress on the inclusion of migration in the proposals on climate change and adaptation.

However, there are signs of the emergence of a counternarrative that addresses the migration-climate change-coffee nexus in Central America with novel approaches not included in the global reports. First, at the XXVI Ibero-American Government Summit (16 November 2018),

1 Between 1993 and 2012, Honduras suffered more than any other country in the world from the scourge of extreme hydro meteorological events and is ranked first in the Germanwatch vulnerability index (CCAFS 2015: CGIAR Research Program on Climate Change, Agriculture and Food Security 2015. https://ccafs.cgiar.org/honduras (accessed on 23 October 2019). 
in a brief speech, the president of Honduras addressed issues of climate justice, redistribution and regulation of the coffee trade chain-of which barely $1 \%$ of the benefits reaches the coffee grower-and the consideration of dignity and humanitarian treatment for those in transit to the United States, in a clear reference to the official violence against migrants (Presidencia 2018).

In parallel, two major reports have been published in 2019, raising the issue of human rights and migration, in conjunction with climate change, to the international policy arena. The first refers exclusively to the current coffee crisis. Elaborated by the Columbia University professor Jeffrey Sach, (Sach et al. 2019), it deals exclusively with the serious crisis of the coffee sector which, in 2019, experienced the lowest price level of the past 10 years. Sach proposes concrete measures to make effective a redistribution policy that guarantees a fair price to coffee growers, as well as the creation of a USD 10 billion fund to face the effects of climate change.

The second, from the Economic Commission for Latin America and the Caribbean (CEPAL 2019), prepares, along the same lines, an integral plan of development for Central America and Mexico with the suggestive title of "Towards a different style of development", with a narrative emphasizing the construction of a migration regime based on human rights and advocating for the development of migrants' places of origin and the generation of well-being by altering the patterns of inequity typical of the region. The plan received the joint signatures of the governments of the region.

The foundations for a new counternarrative are being set, based on the politics of wealth redistribution, the reformulation of the migratory framework, and with an integral adaptation proposal articulating economics, the environment and migration at all scales.

\section{Methods}

\subsection{Case Study}

The cultivation of coffee is of vital importance in Mesoamerica (Central America and Chiapas). The following data provided by the International Inter-American Institute for Cooperation on Agriculture (IICA by its Spanish acronym) (Canet Brenes et al. 2016) gives a snapshot of the importance of this cash-crop for the survival of the Central American rural population.

In Central America, coffee accounts for $20 \%$ of world exports and its cultivation occupies more than 1 million hectares. Small producers account for $80 \%$ of coffee growers. Coffee generates 1.8 million jobs. Of all the countries of the Central American isthmus, Honduras stands out as the third largest producer of Arabica coffee in the world, with $70 \%$ of its rural population below the poverty line (Canet Brenes et al. 2016). On average, the pest has affected more than $50 \%$ of the total coffee producing area of Central America and production for the 2012/2013 harvest was reduced by approximately $20 \%$. According to the World Forum Program (WFP), the impact of coffee leaf rust has led to a situation of food insecurity for more than 157,000 families in Honduras, Guatemala and El Salvador, mainly small producers and day laborers (Canet Brenes et al. 2016).

Chiapas, located at the southern border of Mexico with Guatemala, is the first coffee producer in Mexico. In 2018, it contributed 41\% of the total coffee produced in Mexico (INCAFECH 2019). It is also the first state producing organic coffee (73\%) in the country, whereas Mexico is the world's second largest producer of organic coffee (SIAP 2015). In Chiapas, approximately 180,000 families live on coffee-related income, of which $61 \%$ are indigenous. Chiapas is also the state with the largest cultivated area of coffee in the country (35\%, 252,744 ha) (INCAFECH 2019).

One of the most emblematic coffee-growing areas is the cross-border territory of the Tacaná Volcano, at the southwestern end of the border strip of the Soconusco region. Three municipalities-Unión Juárez, Tapachula and Cacahoatán-administratively make up this volcanic massif at an altitude of $4000 \mathrm{~m}$ above sea level. Over its summit passes the border line that divides Chiapas and Guatemala. At the end of the 19th century, the production of coffee began in this area (Figure 1) in a context of colonization. To this day, coffee is still the main crop in the area, now on community-owned land. Small producers grow Arabica coffee under shade at altitudes between 1000 and $1700 \mathrm{~m}$ above sea level 
in agroforestry plots of an average of 2.5 ha. Robusta coffee-the other commercial coffee species used in soluble coffees-dominates at low altitudes between 600 and $1100 \mathrm{~m}$. In 2001, a conservation zone was established that includes the volcanic crater and the high slopes, the Tacaná Volcano Biosphere Reserve. In the buffer zone, coffee production established prior to the conservation decree is permitted; however, the establishment of new production plots is not.

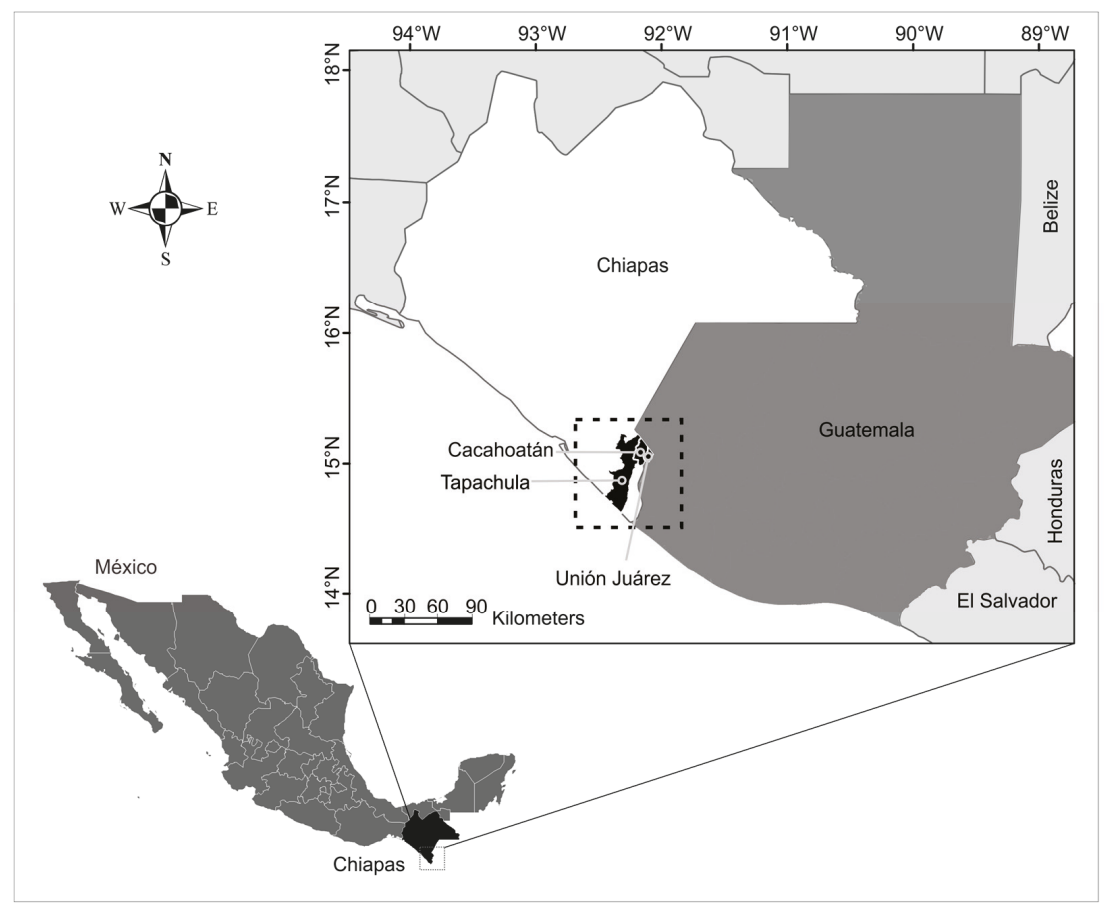

Figure 1. Map of the locations of the three municipalities of study along the Mexico-Guatemala border in the Soconusco region. Tapachula is the second most populated municipality of Chiapas. The three municipalities are part of the highlands of the Tacaná Volcano, but only Unión Juárez (at 1200 m.a.s.l.) lies entirely within the buffer area of the Biosphere Reserve of the Tacaná Volcano. Prepared by Yair Merlín-Uribe.

Coffee production, both in the past and in the recent history of the area, has triggered migratory flows of diverse nature. The intensity and frequency of these migratory flows have varied throughout the last century, depending on fluctuations of international coffee prices and of the Mexican and Guatemalan national agricultural and migratory policies. Today, to these are added the current climatic variability, such as the alteration of rainfall and temperature regimes, commonly associated with climate change (Hannah et al. 2017; Imbach et al. 2017; Gay et al. 2006). Experts on climate change modelling agree that these alterations widen the range of action of pathogens that attack crops (Avelino et al. 2015).

This seems to be the case of the last epidemic of coffee leaf rust, a disease produced by the fungus Hemileia vastatrix, during 2010-2013 in the whole area of Mesoamerica, as well as in Colombia and Peru (McCook and Vandermeer 2015). The fungus was present at higher altitudes, previously free of this disease, and its unusual appearance seems to be associated with the effects of climate change. The link between climate change and coffee leaf rust has been deduced indirectly from climate scenarios that forecast conditions that would favor the propagation of illnesses and plagues (Bebber et al. 2016). Avelino et al. (2015), clearly establish that the spread of leaf rust cannot be fully attributed to climate 
variability. Other factors, the effects of which are aggravated by climate change, include the difficulty of replacing old coffee plants; limited management given the lack of income; market shocks; and, in particular, according to Renard and Torres (2017), the long-term negligence of the state in drafting policies that protect coffee cultivation.

\subsection{Analytical Strategy, Data Sources and Collection}

Following a case study approach, the article adopts a narrative analysis to the research of the migration-adaptation-coffee nexus. We follow the concept of narrative proposed by Bell (2013), understood as the way humans organize experience by formulating stories at collective or individual level, with which an argumentation over a particular topic is constructed, that entails the production of shared understandings and interpretations of social life (Bell 2013).

The analytical strategy is based on the proposal of the thematic narrative analysis "that mainly examines what content communicates a narrative, rather than how a narrative is constructed" (Riessman 2008, p. 73), and has been used to understand the production of meaning (Felgentreff and Plott 2016).

The analysis is divided into two distinct lines: the first adopts a regional scale of observation to develop the discussion on migration as adaptation. We analyze the main narrative threads-or arguments that are repeated through the different policy documents of international organizations.

The second strategy focuses in our case study and adopts a local scale of observation at municipal and community level to address in situ adaptation from the coffee leaf rust epidemic case.

We first present a statistical description (Section 4), to show basic trends of the migration dynamics in Chiapas and in our three municipalities of study (Figure 1), where coffee is a key economic activity. This was done to provide a quantitative view of the magnitude of the migration phenomenon in the area of study. We selected a time series from 2003, just after the onset of the international coffee crisis, until 2015, to include the peak, in 2013, of the coffee leaf rust outbreak.

We attempted to identify the signs of migration associated with coffee leaf rust and describe demographic variations before and after this year with the data available. Different national data sets were consulted (see Table 1): sources 1 and 2, for demographic variability at state and municipal level; source 3, for migratory dynamics; and source 4 to analyze coffee producing trends at state and municipal level.

At community level, and adopting an ethnographic approach, we conducted a qualitative analysis to represent the subjectivity of coffee growers and their experience in addressing the renovation of their coffee plantations in a context of climate change. We focus on three transboundary communities of the Tacaná Volcano that are adjacent to the buffer zone of the Biosphere Reserve (Section 5).

The narrative data around the in situ adaptation strategy are constructed from extensive conversations-mostly recorded-of personal stories of the coffee growers who live in this transboundary region between Guatemala and Chiapas. We conducted in-depth interviews with coffee growers on the Mexican side of the border in the communities of Talquián (1700 m.a.s.l., 27 interviews), Unión Juárez (1200 m.a.s.l., 12 interviews) and Santo Domingo (1000 m.a.s.l., 8 interviews), in the Municipality of Unión Juárez (Section 5). Most of the interviews took place in the coffee plots. Leaders of Mexican farmers' organizations, technical government personnel in the field, and experts and agronomists from non-governmental organizations and regional companies involved in the reproduction of new hybrid varieties of coffee were also interviewed. This allows a triangulation of sources between the experience of the coffee grower and the more institutionalized narratives. The fieldwork took place between October 2017 and June 2019 (Figure 1), in periods of approximately one week per month and as part of a wider project. 
Table 1. Data used to cover analysis in Section 4. A variety of data sources have been used to compensate for gaps in information. Elaborated by Yair Merlín.

\begin{tabular}{|c|c|c|c|c|}
\hline Item & Data Source & Temporal & Spatial Coverage & Measure Used \\
\hline $\begin{array}{l}\text { 1. National } \\
\text { Population } \\
\text { Censuses }\end{array}$ & $\begin{array}{l}\text { National Institute of } \\
\text { Statistics, Geography } \\
\text { and Informatics } \\
\text { (INEGI). Federal } \\
\text { government. }\end{array}$ & $\begin{array}{l}1990,1995, \\
2000,2010\end{array}$ & $\begin{array}{c}\text { Chiapas } \\
\text { municipalities }\end{array}$ & $\begin{array}{l}\text { Count of the } \\
\text { resident population } \\
\text { and distribution by } \\
\text { municipality }\end{array}$ \\
\hline $\begin{array}{l}\text { 2. Intercensal } \\
\text { survey }\end{array}$ & $\begin{array}{l}\text { National Institute of } \\
\text { Statistics, Geography } \\
\text { and Informatics } \\
\text { (INEGI) }\end{array}$ & 2015 & $\begin{array}{c}\text { Chiapas } \\
\text { municipalities }\end{array}$ & $\begin{array}{l}\text { Count of the } \\
\text { resident population } \\
\text { and distribution by } \\
\text { municipality }\end{array}$ \\
\hline $\begin{array}{l}\text { 3. Survey of } \\
\text { Migration at } \\
\text { Mexico's Southern } \\
\text { and Northern } \\
\text { Border }\end{array}$ & $\begin{array}{l}\text { Northern Frontier } \\
\text { College (COLEF). } \\
\text { Public research } \\
\text { center. }\end{array}$ & 2009-2016 & $\begin{array}{c}\text { Southern and } \\
\text { Northern Border } \\
\text { of México }\end{array}$ & $\begin{array}{l}\text { Count of flows } \\
\text { coming to Mexico } \\
\text { in southern border } \\
\text { and count of flows } \\
\text { going to United } \\
\text { States in the } \\
\text { northern border* }\end{array}$ \\
\hline $\begin{array}{l}\text { 4. Annual Coffee } \\
\text { production report } \\
\text { of Chiapas } \\
\text { municipalities }\end{array}$ & $\begin{array}{c}\text { Agrifood and } \\
\text { Fisheries Information } \\
\text { Service (SIAP); } \\
\text { Ministry of } \\
\text { Agriculture and } \\
\text { Rural Development. } \\
\text { Federal government. }\end{array}$ & 1995-2016 & $\begin{array}{c}\text { Chiapas } \\
\text { municipalities }\end{array}$ & $\begin{array}{c}\text { Production, yield } \\
\text { and prices of coffee } \\
\text { by municipalities } \\
\text { of Chiapas }\end{array}$ \\
\hline
\end{tabular}

${ }^{*}$ It refers to the number of migrants entering and leaving (the inflows and outflows) of a country during a specific period of time and space.

The interviews were analyzed using Atlas-ti software (Scientific Software Development GmbH 2018), following a qualitative strategy of coding in several stages (Creswell 2013). Due to the focus on narratives, we moved away from the classic microanalysis of word-by-word coding (Glaser and Strauss 1967). Instead, we privileged the paragraph as the basic unit of analysis to preserve the narrative structure and construction of meaning in the argument provided (Riessman 2008). First, a predefined set of topics of interest was used to classify the interview material. Second, emerging socio-ecological processes associated with these issues were then identified. In a third phase, migration issues were crossed with those of coffee production in a matrix of meaning.

The initial thematic classification was on the experience of coffee growers with new coffee varieties-problems encountered, preferences and traditional varieties versus new hybrid varieties; knowledge of coffee leaf rust and its relationship with climate change; participation in Procafé's federal program and its deficiencies; participation in private renewal programs carried out by international companies or international foundations; perceptions of climate change and how coffee farmers have been dealing with it; and the future of coffee activity in the region and personal views on how to address the coffee leaf rust crisis.

The theme of migration was codified into the following topics, not previously predefined: current and past migration patterns; international migration and internal migration and their relationship to in situ adaptation measures for coffee renovation; the influence of living in a cross-border region for coffee production; and the experience of being deported. Finally, issues related to coffee production and issues related to migration experiences were combined in a matrix and new codes were assigned. 


\section{Migration, Coffee and the Market in Chiapas and the Tacaná Volcano: Dimensions, Interactions and Effects}

Migration in Chiapas has been a historical reality. At present, flows of out-migration, immigration and transit migration converge and overlap in this territory. Among the easily identifiable migratory flows of the Soconusco cross-border region, we find asylum-seekers and economic migrants from Central America-and, during the first semester of 2019, Cuban, Haitian and Central African migrants; workers that daily cross to the Mexican border city of Tapachula, the largest urban center of the zone; Guatemalan and Mexican workers in agro-industrial banana or palm oil plantations on the region's coastal plains; the historic flow of Guatemalan migrant farm workers to large private coffee plantations in the Soconusco region during the coffee harvest (Figure 2); and the out-migration of residents of Chiapas toward the states of northern Mexico to work in agro-industrial plantations, or try to cross illegally into the United States (Villafuerte and del Carmen Aguilar 2006).

Despite this complexity, Chiapas' current migration profile resembles major global trends, particularly those highlighted in a recent World Bank report (Rigaud et al. 2018), pointing to the growing importance of internal migration around the world. For its part, the Economic Commission for Latin America and the Caribbean (CEPAL 2018) and other Latin American regional organizations emphasize the importance of transboundary migration in this region. Both tendencies are prominent in the migratory dynamics of Chiapas (see Figure 2).

On the one hand, international out-migration to the United States dropped sharply since the 2007 crisis and continues to decline: from 2010 to 2016, this flow decreased by up to 80\% (COLEF 2016b). On the other hand, internal migration to the northern states of the country has increased: since 2014, national emigration has remained slightly greater than international out-migration (COLEF 2016b) (see Figure 3).

Finally, return immigration to the state of Chiapas is reaching levels similar to the current level of out-migration: by the year 2016 the gap between emigrants going to the United States and those who returned from it approached the same level, with a slight upward trend of the in-migration flow towards the south (Figure 3) (COLEF 2016a). In spite of this, Chiapas still maintains a negative migratory balance: emigration exceeds immigration by $25 \%$ (INEGI 2015).

In this context of reduced international out-migration and increased return flows, cross-border migratory movements have intensified (see Figure 2).

Migratory crossings in the municipalities of Tacaná Volcano, on Mexico's southern border: places of origin and destination and percentages of crossings:

This migratory dynamic makes Chiapas a state with slow population growth with average annual rates below 2.3\% since the 1990s. Our area of study follows this same dynamic, which is even accentuated in the case of Unión Juárez, whose population decreased during 1990-1995 and 2000-2005 below the average state rate (Figure 4). No newer data are available regarding the number of people who departed from the municipalities that we studied. The most recent data are for 2009-2014, and they are aggregated at the state level in the 2014 National Demographic Dynamics Survey (INEGI 2014). 


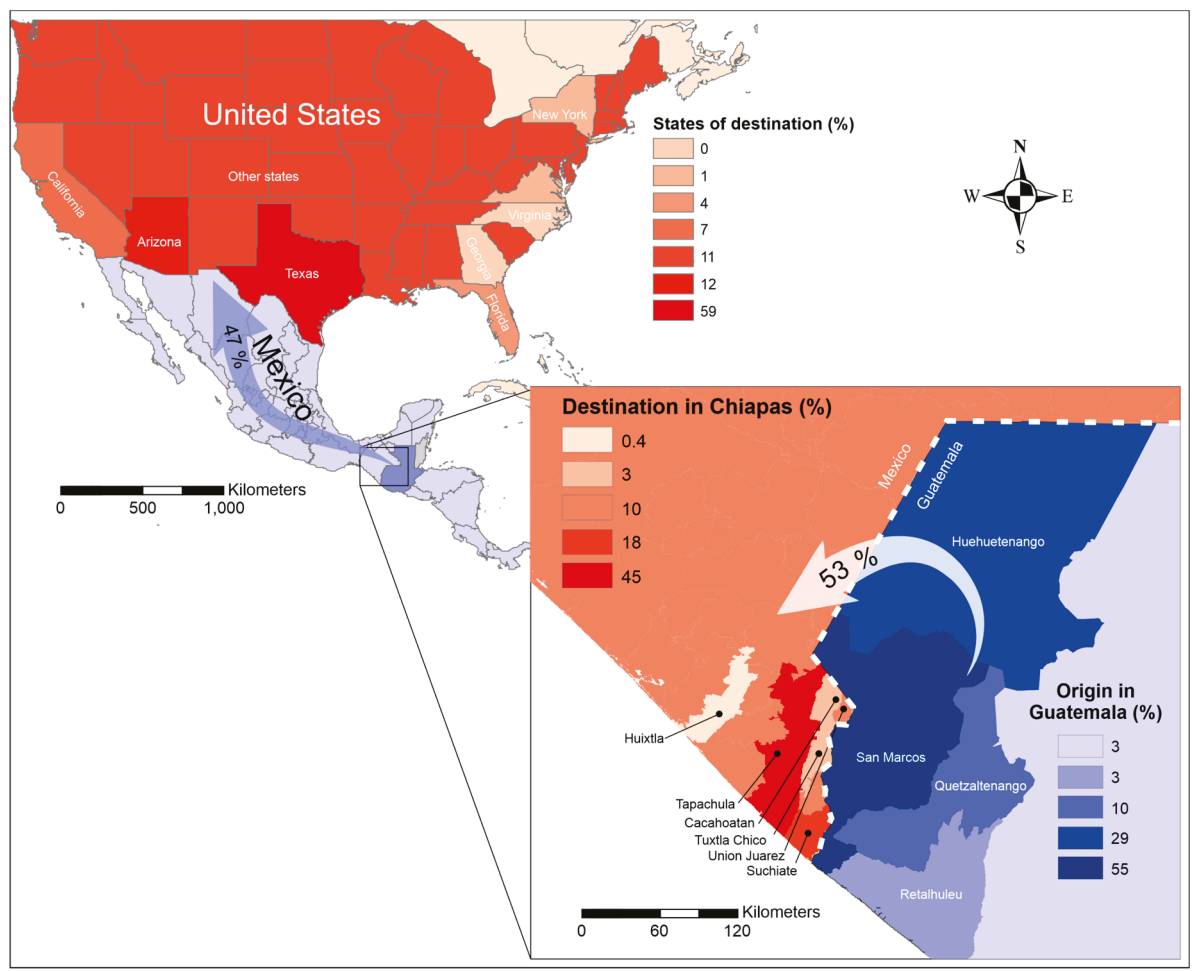

Figure 2. International and transborder migratory flows of the Guatemalan population on the Chiapas-Guatemala border, differentiating percentages of cross-border migration to the main municipalities of Chiapas and the flow of Guatemalan migrants to the United States (transit migration), with Texas and Arizona being the main destinations of this trans-migrant population. Sources: (COLEF 2016a, 2016b). Prepared by Yair Merlín-Uribe.

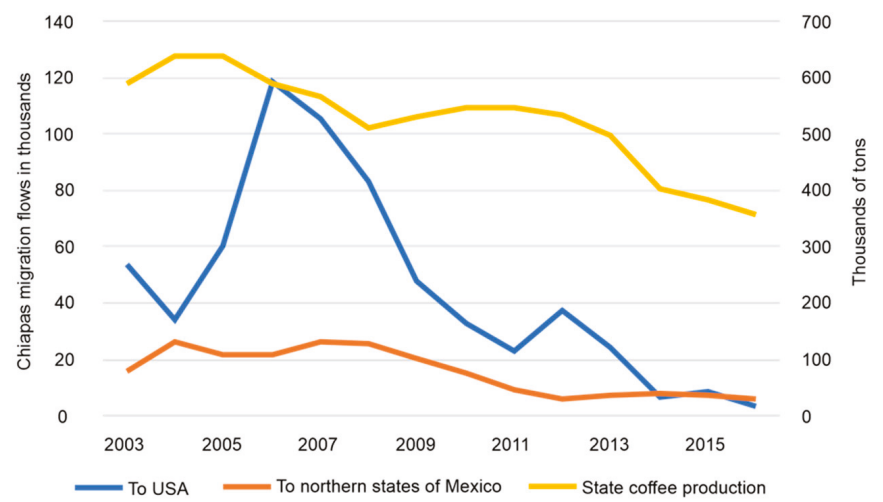

Figure 3. Dynamics of migratory flow and coffee production in Chiapas. Since 2012, lower production has coincided with declining out-migration to the north of the country or the U.S. Source: (COLEF 2016b) and (SIAP 2015). Prepared by Yair Merlín-Uribe. 


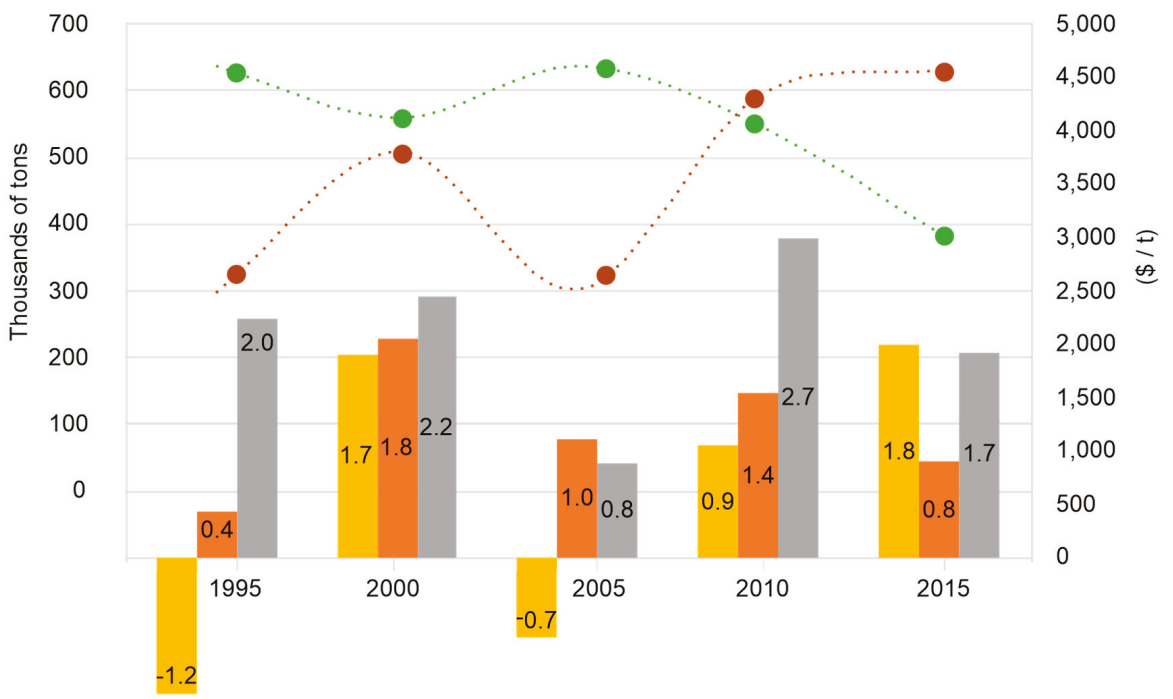

\footnotetext{
Annual growth rate Union Juarez (\%)

- Annual growth rate Tapachula (\%)

Annual growth rate Cacahoatan (\%)
}

Price of coffee in rural areas (Mexican pesos)

Chiapas coffee production (thousands of tons)

Figure 4. Population growth in the municipalities of Tacaná Volcano and Chiapas coffee production and prices. Depiction of how the price and productivity of coffee affects the population dynamics of the municipalities of interest. Annual increases and decreases in average population growth follow the ups and downs of coffee prices. In addition, coffee production and price are inversely related. Source: INEGI, 2015 and SIAP, 2015. Prepared by Yair Merlín.

4.1. How Does Coffee Leaf Rust Interfere with Current Migratory Flows? Coffee Productivity, Prices and Migration in Chiapas and in the Municipalities of the Tacaná Volcano

In order to answer this question, we contrast the demographic alterations that occurred between 2003 and 2018 in the state of Chiapas and in the municipalities under study, with the variables of coffee production and price in the same period, to identify joint or disparate patterns.

International migration peaked in 2007, after recovering from the international coffee crisis in 2002, when it had one of its lowest levels. From 2007 onwards, a period of abrupt decline began and continues to this day, as stated above (Figure 3).

In relation to coffee productivity, a downward trend associated with the liberalization of the international coffee market and the end of the sponsored coffee cultivation by the Mexican government began in 2005 and has continued steadily to this day (Renard and Breña 2010).

Between 2003 and 2016, coffee production decreased constantly (Figure 3). At the state level, the decrease was $42 \%$. However, losses in coffee production in the municipalities we studied exceeded the state average by far: 74\% in Cacahoatán, 69\% in Tapachula and 81\% in Unión Juarez (the municipality most affected). Yields follow the same downward trend: the state-level loss was 31\%, but losses in our study locations dropped by more than double that amount (64\%-68\%, FIRA 2016).

During 2013-2014, production losses accelerated as a result of coffee leaf rust (Figure 3), whereas out-migration to the US decreased sharply during that same period-precisely at the peak of the disease. It is notable that both the 2014 migratory crisis at Mexico's U.S. border and the ensuing enforcement of migration controls at its Guatemala border ultimately coincided with the attack of coffee leaf rust in our location of study. 


\subsection{Low Prices as a Push Factor for Migration? Migration, Low Coffee Prices and Declining Productivity}

The comparison of the trends in coffee productivity with price behavior (Figure 4) offer some insights to understand relationships between production decline and market behavior and its effect on migration in the municipalities of Tacaná Volcano.

The post-2010 decrease in production occurred while coffee prices increased, a tendency that continued and became more marked during the coffee leaf rust outbreak. The peak of coffee leaf rust in our study area took place in 2013. In that year, the price of coffee reached its peak, while the decline in harvests accelerated (Figure 4). Following the signals of supply and market demand, the production level and purchase price of coffee seem to show the opposite behavior: the higher the production, the lower the purchase price.

From a long-term perspective, the price paid to producers for a ton of coffee in rural areas trended upward from 2005 to 2015 (Figure 3) ${ }^{2}$. At the state level, the increase was $130 \%$. However, it was significantly lower in the three studied municipalities: $11.4 \%$ in Cacahoatán, $19.9 \%$ in Tapachula and only 9.9\% in Unión Juarez (SIAP 2015).

Data also show that when production is high, and prices fall, there is a downward trend in population-possibly an effect of migration (Figure 4). For the period 2010-2015, moderate population growth in these municipalities is observed when the price peaks, despite the downward trend in harvests.

The data shows a coupled relationship between the price of coffee and the size of the population. Low prices unleash migratory flows that lead to a reduction in population. Considering that tendency and considering that coffee leaf rust implies losses in production, the epidemic itself would not affect the migratory process directly, but the low prices of coffee would (Figure 3).

Two more factors could be interfering with the decision to migrate in the face of declining harvests, in addition to low prices. One is that the positive effect of prices on restraining migration can be downplayed if inflation rates are taken into account. In this sense, the high rate of inflation of $83.6 \%$ during the same period (INEGI 2019) prevented an increase in household income from the sale of coffee, despite the moderate rise in coffee prices.

The other refers to the spatial insertion of the study municipalities on the transborder space of the Chiapas-Guatemala border, adjacent to the hot spot of the migratory crisis on the southern border of Mexico. Despite the loss of coffee productivity, the new anti-migration policies in the United States could have exerted a deterrent effect on the intention to migrate, while interfering with coffee production and commercialization.

The importance of having prices above the poverty line for coffee to prevent migration should prompt rethinking of the wisdom of following a coffee renovation strategy that promotes quantity of yields over quality, as we shall show in the next section. If market prices for coffee are not giving returns that exceed the necessary investments, perhaps it is time to consider alternatives that produce moderate yields of high-quality coffee that fetch higher prices.

Current neo-liberalization policies exemplified by a highly inequitable market in the distribution of benefits are downplaying coffee benefits to the coffee farmers, while allowing for substantial profit margins to international roasters and retailers (Renard and Torres 2017; Merlín-Uribe et al. 2018). Far from promoting sustainable means of living (Merlín-Uribe et al. 2018), they are driving current waves of migration. The following testimony crudely reflects the inequality of the effects of the coffee leaf rust epidemic on those involved in coffee cultivation: "You know who was the hardest hit by the coffee leaf rust? Only the poor." (JM, 61 years. Córdoba Matasanos, Unión Juárez, 29 January 2019).

2 This was associated with the long drought that affected production in Brazil, whose green grain harvest dictates the price level. This is because Brazil is the world's largest coffee producer and exporter (Canet Brenes et al. 2016). 


\section{In Situ Adaptation: Ethnographic Notes on Migration, Coffee Leaf-Rust and Climate Change from the Tacaná Volcano Borderland Region}

The changes introduced in the wake of the coffee leaf rust outbreak can be viewed as a strategy for adaptation in situ, which, if it achieved the desired success, would help reduce future emigration. However, these adaptive changes are marked by paradoxes and contradictions, some of which interfere in different ways with migratory flows, whether international, internal or cross-border.

Paradoxically, this migration is helping to finance coffee plantation renovation efforts that would fall under the category of "adaptation in situ". Might we, then, speak of an in situ adaptation financed by migration as adaptation? Before addressing this issue, we present a brief overview of how in situ adaptation is taking place in the coffee plantations in our study area.

\subsection{Chaotic In Situ Adaptation: Coffee Leaf Rust, Institutional Mismatches and Unknown Seeds}

The replacement of locally-adapted varieties of Arabica coffee-primarily Typica and Bourbon, which are highly susceptible to coffee leaf rust-with hybrid varieties like those derived from the hybrid of Timor (Arabica-Robusta crosses, in principle resistant to coffee leaf rust), became the focus of the renovation efforts to improve productivity after the coffee leaf rust infestations.

This substitution process was led, among others, by a government program called Procafé, which organized the production and distribution of hybrid coffee seeds and plants through peasant organizations and private farms. However, in our area of study, the substitution process was rife with inefficiency, lack of information and uncertainty about the quality of the plant material delivered, together with patronage practices that detracted from the efficacy of the renovation process and heightened the risks of coffee production in the ejido (communal-owned land) sector.

" (... ) In the beginning, the government entrusted the large coffee farms with the production of coffee plants. Yes, they made billions of plants and paid them well ( . . ), MEX \$ 4 for the plant, and to produce a plant in that time, it cost MEX $\$ 1$ with 28 cents ... It was a good business. Then the peasant organizations, like mine, began to fight ( ...), and they became producers of plants. Now they are being paid MEX $\$ 6$ a plant, and the cost of production is MEX \$1.98. Some peasant leaders have become millionaires by producing and selling coffee plants with government seeds". (HG. 65, leader of the Democratic Peasant Union and Commissariat of the community of Santo Domingo, municipality of Unión Juárez, 19 November 2018).

In the course of our field work, we identified problems such as poor quality of the plants delivered, which were sometimes already afflicted with other sicknesses and confusing information about the variety delivered and its management requirements. All this generated mistrust among the producers about the quality of the seed delivered and the process of plant production in nurseries, as one of the youngest coffee growers we talked to told us.

"How is it possible that the coffee plants came already infected from a nursery? I mean, they delivered plants of bad quality ... I don't think they were a $100 \%$ selected seeds, treated seeds ... Last year, from the community of Trinidad, they brought in plants, and they had already coffee leaf rust!". (GM, 43, coffee grower, Unión Juárez community, 16 November 2018).

Other situations recounted by coffee farmers were the need to apply agrochemicals in a context of organic production; yields with initially high productivity but lower bean weight; difficulties in maintaining coffee leaf rust resistance in successive generations of recently introduced cultivars due to the speed at which the fungus mutates; delivery of fewer seedlings than promised by the program; and the lack of sustained technical assistance.

On some occasions, the same service providers contracted by PROCAFE federal program refused to use the seeds handed in to produce coffee plants and distribute them to coffee farmers. 
"Look, (the informant breaks a sack of seeds, grabs a handful and throws them to the ground), this seed is useless. I told my boss, "I won't plant that seed again because it creates problems for me with the people, because that seed doesn't work". And with my boss, we went to buy catimore seed here, on the other side, in Guatemala". (DJ., 62, worker in PROCAFE service provider nursery, Unión Juárez, 17 November 2018).

Similar situations were encountered in other regions of the country and in other municipalities of Chiapas regarding the renovation of coffee plots and the distribution of seeds under the government federal program (Renard and Torres 2017; Henderson 2017).

For our area of study, producers show a clear preference for traditional varieties of high cup quality, but of low productivity and high sensitivity to rust. In the dilemma between productivity and cup quality, PROCAFE's policy seems to bet on the former to the detriment of the latter, delivering hybrid seeds of high productivity but with inferior qualities to traditional varieties, such as Costa Rica 95.

However, international organizations, such as the World Coffee Research Institute, are embarking on a crusade to design varieties of high resistance, good cup quality, high productivity and resilience to climate variability (Toniutti n.d.; World Coffee Research n.d.). From this research, a new generation of hybrid varieties is being released to the market (for example, Millennium or Casiopea produced in genetic laboratories in Costa Rica) (field-work, Laboratory of Genetics, CATIE, Turrialba, Costa Rica, 3 October 2019). These seeds are not yet available in Mexico for the small producer, but according to the experts who produce them, their improved genetic characteristics will be crucial to cope with periods of prolonged drought and the greater intensity of rainfall predicted by climate models. At the moment, they are only accessible to large producing farms with the financial capacity to acquire them (DJ, 5 October 2019, Seed Bank of the Tropical Agricultural Research and Higher Education Center, CATIE, Turrialba, Costa Rica).

The search for the "magic" variety (productive, of good quality, resistant to rust and accessible price) has generated a web of narratives on both sides of the border. Acquiring seeds of resistant varieties and producing them informally and without certification on the Guatemalan side of the border is becoming an option for coffee growers on the Mexican side, whose experience with government-delivered seeds was unsuccessful. No one knows with certainty which is which in this transfer of seeds and coffee plants. However, informal experimentation, word of mouth and mistrust of "official" seeds form an alternative innovation landscape independent of seed laboratories, with uncertain but very dynamic results.

All this chaotic exchange of seeds, knowledge, new varieties, subsidies and uncertainties around a process of change never before seen at this magnitude rests on institutional weakness and the need for short-term results from producers. In addition, it jeopardizes a much-needed adaptation strategy that will need to be constant in the face of increased climate variability in the medium term.

\subsection{Weather Changes and Coffee Rust: Who's to Blame? Us or the Government?}

Unusual climatic variability is already being felt by coffee farmers. Erratic rainfall, later flowering of coffee plants, and the intensification of rains and their reduced but more destructive duration are commonly mentioned as the impacts of altered weather patterns by coffee growers in the highest-altitude communities in our research project (Talquián, 1700 m.a.s.l. and Unión Juárez, 1200 m.a.s.l., field diary, 2018).

Calendars of sowing, harvesting and pruning coffee trees are trying to be adjusted to match new periods of rain or changing temperature patterns. An incipient narrative linked with the changing weather patterns has a constant presence in the area. However, uncertainty dominates over which course of action to take, as indicated:

"Before everything had a date, because people, well, our parents, (... ) knew "we are going to sow corn now in February, March, because the rains are coming". Right now there is no 
order ( ... ). We can no longer trust the weather. We no longer know what day it rains, nor what day it does not rain". (BR, coffee farmer, 32, Talquián Viejo, October 2018).

Rarely is this instability associated with climate change. The tendency of many of the rural inhabitants of the area is to take responsibility for not having taken care of nature. The belief that their rubbish and logging effected by themselves are the main reasons for climate change is a prevalent feature of this narrative.

When questioned about coffee leaf rust's origin, few coffee farmers connect the phenomenon of climate change with the increase in pests and illnesses. An overwhelming majority of coffee farmers share a narrative that puts the blame for the presence of coffee leaf rust on the ongoing local fumigations that the international program MOSCAMED—a coordinated effort to eradicate the Mediterranean fruit fly, a devastating pest globally_implemented since 1985 (Méndez Espinoza et al. 2006): “Well, right now in these times, everything has changed a lot, with all the technology. We did not know the coffee leaf rust. We began to see it, when those planes began to enter to throw a fly; a mosquito they threw away; it brought an orange powder ... ". (JL, 63, Talquián, 11 November 2018).

Such a belief builds a narrative that expands across both sides of the border with a solid conviction: that coffee leaf rust is sprayed from MOSCAMED's light aircraft following government instructions, "to finish us off", "to destroy our way of life" or "to force us to buy new coffee plants, and make business through it with the big companies" (H. coffee farmer and campesino union leader, 62 years old, Santo Domingo, Unión Juárez Municipality, May 2018 and June 2019).

Regardless, the understanding of what climate change is and the connection with coffee leaf rust is hardly mentioned. Deforestation and pollution of rivers and lands because of the dumping of rubbish are considered the main causes of climate change. The general tendency among respondents is to blame themselves for such a state. Those statements are followed by warnings about the destruction of nature and the punishment humans will suffer because of this:

"God says that times are going to change and yes, well, times are changing, tremors are coming; the rains pass stronger, like the rain right now hits but as if it was mad at you. And yes, then I say, if everyone read the Bible, all this will change; the climates would also return to normal, the tremors would no longer happen, and God would be happy with us now". (B. woman coffee farmer, 32 years old. Community of Talquián Viejo, Municipality of Unión Juárez, Chiapas, 26 October 2017).

\subsection{Migration, Coffee and Next Generations: What Is There for Young Coffee Growers?}

Coffee growers are aware of the uncertainty associated with generational turnover. When asked about the issue of succession, they often remain silent, or say they worry about not knowing what will happen to their land.

The coffee plantations are abandoned because many people have already left for the United States (...). I have many friends who are from here and are in the United States; that is because the lands no longer interest them; there, they dedicated themselves to building or to work in factories; ( . . ) "Why am going to get back to coffee, if it is not going to produce enough for me to live?". That is what they think. We are very few who are interested in coffee production. (MZ. 45. Coffee farmer, Santo Domingo, 28 March 2019).

Today, migration has a different face from the migratory wave that was initiated at the end of the 1990s (Villafuerte and del Carmen Aguilar 2006) as a result of the international coffee crisis: that of the new descending generations of older coffee growers who still work on their plots. Faced with the difficulties of finding a first job in the city, the option of migrating becomes attractive.

On the other hand, young coffee growers that opt to remain in their homeland are taking advantage of digital technologies using social networks and video information through cellular phones. For example, they use YouTube videos to learn new management techniques or how to graft Arabica 
varieties onto Robusta rootstock, a very useful technique to avoid coffee leaf rust, but highly skilled and costly. Once again, this characteristic can be strengthened and aimed specifically at the formation of a new generation of coffee growers with better access to knowledge and information.

However, emigration continues to be a route for improving the family economy, even amongst the younger coffee growers. Seasonal migration to agribusiness fields in the northern states of Mexico or the maquilas of Tijuana prevails among this young population that still insists on producing coffee. This strategy helps the family to continue producing coffee while bringing in extra income. In this strategy, coffee production serves as an anchor at their place of origin.

A variant of this strategy is legal migration to the United States under a temporary employment contract, with a return-trip work visa. The work in these fields is taxing, but as a woman in Unión Juárez told us: "You only have to work there until you can make some good money. During the whole contract you just stay there in the fields working, you don't go out, that's all. It's exhausting, but ..." (C., woman coffee farmer, 53, community of El Desenlace, Unión Juárez, 13 October 2018).

These out-migration flows now overlap with return, voluntary or forced immigration flows. Their presence in our area of study also has varied implications for coffee cultivation.

Regarding forced in-migration, the deportation policy implemented by the Trump administration migrants who left for the U.S. 20 or more years ago are now being forced to return to a land where coffee remains the main economic activity. For those who have been deported, coffee is no longer significant, either economically or professionally. However, for the majority, the only viable option is to return to work the coffee lands that they left in the hands of relatives.

Others decide to return for different reasons (see Mestries 2013) after a long stay in the United States, where they have obtained new professional skills, often relating to gardening, but also in the industrial and commercial sectors. Among the youth who return from the United States, there is a minority that choose to reactivate their parents' coffee parcels, but now seek to bring added value to the production. They have learned about the world of coffee consumption in the north and now want to instill part of that world in their home communities, where cappuccino, macchiato or café latte are not yet part of the coffee-consuming culture. These youth see themselves as entrepreneurs, with better access to knowledge and resources outside the community. They have learned to be baristas and open coffee shops in their home communities, seeking to attract other youth to the region. Their shops become places where young people gather, and they encourage a culture of local coffee consumption in an effort to access the benefits that retail coffee markets in consuming countries obtain from specialty or gourmet coffee establishments.

They also bring new ideas for improving and diversifying coffee-related products and carry out experimental programs relating to agro-ecology, leaf rust management and agro-forestry conservation. For them, migration is no longer an appealing option, because they are deeply committed to coffee production and commercialization. This new brand of coffee grower detaches itself from traditional decision-making spaces like ejido assemblies. The figure of the coffee-growing peasant who inherited the age-old agrarian and ejido struggle is no longer a reference for their identity. Their vision of coffee production is one of a lucrative activity that encompasses everything from growing their own coffee on their family's land to roasting and selling it in their own establishments to creating propriety blends for production. Once again, we might argue that a policy of sustainable coffee and incentives to access regional markets that support these initiatives might open new possibilities for the regional production and sale of coffee, particularly in the Tacaná region, which is a focus of tourism. However, there is no decisive promotion policy in place that targets the new generation and restores the importance of coffee in the region. 
5.4. Coffee Renovation and Remittances for Adapting: Is Out-Migration Maintaining a Much-Depressed Economic Activity, Such as Small-Holder Coffee Farming?

Statistical analyses cannot portray transnational links maintained between those who migrate and those who remain in their places of origin. Organized around family ties, these social relationships in our area of study influence coffee farming in different ways.

During field-work, we have observed that international remittances support a radical—and not gradual-renovation of coffee parcels. The case of B.R. (32 years old), a woman coffee grower (one of the three women interviewed) in the community of Talquián Viejo is a telling example. In one highly risky transaction, she used remittances sent from the United States by her husband to completely eliminate shade on her parcel, where she also introduced hybrid cultivars on all the land, eliminating all traditional varieties. She followed the technical advice of the Rogers Family Company, an international coffee and tea business, which maintains a program of coffee plantation renovation in the zone and encourages the cultivation of sun-grown coffee, supplies inputs and plants for a three-year period and offers technical advice. B.R. hoped to significantly increase her yields, even at the cost of applying agrochemicals to her formerly organic coffee. Her renovation was the most radical of the Talquián community. The rest of the coffee growers (all men) were very critical of her decision but were keeping a close eye on her progress. In our most recent visits (March 2019) we learned that her coffee failed to pass quality standards and was rejected by the regional organic coffee growers' association.

A rather different use of the remittances is that of the Guatemalan families that live simultaneously on both sides of the border, and receive money from family members working in the U.S. These families are buying coffee plots on the Mexican side that have been left untended due to coffee leaf rust. Where some abandon coffee and possibly migrate north, others find niches of opportunity to increase their production with money sent from the same north.

Because of the social land titling on the Mexican side (i.e., ejido land), the community of Unión Juárez-Paso del Norte puts restrictions on trading its land with foreigners. These restrictions can be bypassed easily by purchasing a Mexican birth-certificate in an illegal market of certificates that operates from Unión Juárez and which is an open secret.

The increasing presence of Guatemalans making their homes in the municipality is already triggering negative reactions: Mexican nationals are starting to see Guatemalans as a source of conflict and criminality.

Right now many [Mexican people] are selling their houses and lands, and they [the people from Guatemala], are taking over them because they bring the pay. They say they have money from the United States. If we get stunned, they will take our coffees ... Moreover, even in our homes, they enter; right now they grabbed the wood from here ... . (JM, coffee farmer, 42, Unión Juárez, El Mango section, 11 September 2017).

\subsection{The End of Arabiga Quality Coffee Thanks to Migration as Adaptation? the Robusta Era in Times of Climate Change}

Finally, in the complex picture of interactions between migration, climate change and coffee, another global process takes its particular expression in our area of study: the substitution of traditional Arabica coffee varieties for the rough Robusta (Coffea Canephora) coffee has been accelerated due to a combination of climatic, agricultural and commercial factors and remittances (Bunn et al. 2015).

On the one hand, Robusta's resistance to coffee leaf rust and the increase in temperature that allows its establishment at higher altitudes, previously not suitable for Robusta, offers a solution for some coffee growers to escape the crisis.

In conversations with coffee growers belonging to a social segment of coffee producers that is not particularly interested in the production of quality organic coffee, Robusta seems a plausible alternative to avoid abandonment of coffee plots: "Right now, the only thing that has sustained us for the majority of those that remain (without going to the US) is Robusta. Yes, it is the only one (coffee variety) in 
which there is hope, because the coffee we say, the small coffee, the Bourbon (Arabica variety), is finished." (RJ, 46. Coffee farmer, Unión Juárez, 15 September 2018).

On the other hand, the distribution of seeds and inputs by the Nestle international company-the biggest stockpiler of this coffee variety, which distributes seedlings of cloned Robusta varieties seeking to secure its supply of soluble coffees-facilitates the replacement of Arabicas for Robusta.

Finally, the effect of migration on Robusta's expansion process is also manifested in our study area. In an economic drip effect, part of the remittance flow from migrants residing in the United States is channeled to the purchase of coffee plots in the lower areas of Tacaná Volcano, where Robusta is highly productive, thus contributing to the spread of Robusta varieties. An additional benefit to this strategy is that Robusta production requires less labor and investment. The degree to which remittances have contributed to expanding and reactivating coffee cultivation remains unknown. There are also no data at the scale of our municipalities that allow us to deepen the ownership, demographic and productive changes induced by remittances in this cross-border area.

This whole network of local and international factors (to which should be added the political impulse given to the cultivation of Robusta by the current administration of the president of Mexico, López Obrador), are pushing towards a transformation of the coffee agroforestry systems based on Arabica varieties that have ecological and commercial implications. This has stirred up alarm among some organizations of Arabica coffee growers, who see the expansion of Robusta as a threat to quality shade-grown coffees and to their access to coffee markets differentiated by the quality of the beans (Bunn et al. 2015). Robusta requires less shade-cover and is less heat-sensitive, yields are higher and faster and is more disease-resistant. However, its lower quality traditionally fetches lower prices.

Travelling seeds, intertwined narratives and knowledge, the role and interests of international and governmental actors, long-term and circular migration, intra-regional migration, remittances and deportation policy comprise a complex interactive puzzle that should encourage new ways to conceptualize the nexus of climate change-migration-adaptation.

\section{Conclusions}

In various policy documents on climate change (Rigaud et al. 2018; FAO 2017; Delavelle 2013; Foresight 2011), the notion of migration as a form of adaptation appears undisputed (Black et al. 2011). However, it is rarely combined with an examination of migration policies that promote the closing of borders and the criminalization of migrants (Turhan and Armiero 2017). Similarly, in situ adaptation strategies for coffee are confined to the agronomic and ecosystem sphere (Nalau and Becken 2018) and do not entail a comprehensive assessment that includes political and economic constraints that at different scales may hinder the development of in situ adaptation. Both approaches are sometimes presented as opposing trends on the road to adaptation (Upadhyay and Mohan 2014).

Critical researchers have pointed out that narratives of mainstream adaptation fail to account for the imbalance of power (Felli and Castree 2012) that, for our case, characterized coffee production, and relies on an adaptation conception void of its political content (Bettini 2014; Scoville-Simonds et al. 2019). The coffee-growing landscapes of the transboundary region of Tacaná are an expression of those current imbalances that generate socio-ecological relations that are far from achieving an equitable adaptation (Taylor 2015; Klepp and Chavez-Rodriguez 2018). The global flows of stock market finances, consumer preferences, international biotechnological research and the increasing effects of climate change shape the future of coffee production. In such panorama, however, the burden of adapting amidst restricted possibilities is entirely placed on the coffee farmer's shoulders.

In this paper, we have followed the suggestions of Klepp (2017) for politicizing and denaturalizing the climate change and migration nexus, including in it structural factors and a perspective of justice that is currently absent from dominant narratives and the practice of adaptation. Understanding climate change in the context of an inequitable agricultural commercialization, changes in property regimes, new and old forms of capital accumulation, migratory flows, technological change and the 
emergence of new subjectivities in the rural world can contribute to this reconceptualization of the migration-climate change nexus.

Similarly, addressing migration-adaptation dynamics in context-specific settings without detaching them from the broader migratory processes that are occurring at different scales can also be a way to work towards this aim. The entanglement of processes that happen at different scales has allowed us to highlight the limitation of using labels such as "migration as adaptation" or "adaptation in situ". These labels fail to realize the intrinsically trans-scalar nature of the migration-climate change nexus (Eklund et al. 2016).

At a regional scale, we have highlighted how the interaction between processes that occur at an international scale, such as the reinforcement of United States immigration policies from 2014 onwards in the southern border of Mexico, or the advance of coffee leaf rust across Latin America during 2013 and 2014, alters migration dynamics at the municipal level in an unexpected manner. We have contrasted the narrative of migration as an adaptation with the current situation of reinforcement of border control policies at the Chiapas-Guatemalan border, where thousands of people are trapped, not because of climate hazards but by a securitization approach to migration.

We have taken the renewal of shaded coffee plots attacked by coffee leaf rust as a case study of slow-onset climatic impacts and as an indirect indicator of current climate variability. The attack of the fungus has triggered a series of adaptation strategies in situ, which are linked to the agronomic management of coffee plantations (c.f. Harvey et al. 2018). However, these in situ adaptations will be ineffective if they are not accompanied by measures at other scales, such as policies that offer some protection against the low prices in international markets. We have shown how the price of coffee is the most influencing driver of migration. Likewise, we have presented ethnographic data on the various migratory strategies that intersect in our study territory and affect the financing of adaptation measures in situ at the local level.

In situ adaptation practice focuses exclusively on coffee management actions to adapt to climate variability, emphasizing its biophysical dimension. The isolation of climatic impacts from the broader social and political contexts promotes a depoliticizing view of the nexus between climate change and migration. Policies designed from such an apolitical perspective make recommendations and promote courses of action that do not have regard for the current political scenarios.

Rarely are lines of action established for the promotion of regional markets or marketing strategies that place local producers on a stronger footing to access a highly competitive, restrictive market. International political action does not focus on the transformation of the market power imbalances that characterize the international coffee market, neither in terms of policies for the redistribution of benefits or alternative policies for migration. Can it then be argued that failure to secure prices well above the poverty line results in migration as adaptation?

Beyond a conception of adaptation as a choice between opposites, we suggest attention should focus on the redesign of more integral policies to respond to climate change and its interaction with commercialization and production factors in their multiple manifestations. In this sense, and following Oliver-Smith (2012), the articulation of ecological and social theory can help us to develop a solid understanding of the co-production of society and the environment and to advance adaptation strategies that can be truly effective.

In the policy realm, the main lesson to be learned is that dominant adaptation narratives that are dictating policy guidelines on climate change and migration need to be reformulated to include the harsh realities of today's forms of migration. If we are to promote migration as a form of adaptation, the first step should be towards a complete reformulation of the current migration policy. The question remains whether this is possible in today's world and to what extent this challenges the belief in nation-states as the primary form of political organization on which political boundaries around the world are founded. In the medium term, and with the acceleration of climate impacts, the issue of adaptation will be critical in any policy sector. Therefore, it is worth rethinking new adaptation paradigms that are effective, inclusive and above all defined on principles of social and economic justice. 
Author Contributions: Conceptualization, C.R.-d.-O.; Data curation, P.R.-C. and Y.M.-U.; Formal analysis, C.R.-d.-O., P.R.-C. and Y.M.-U.; Investigation, C.R.-d.-O.; Methodology, C.R.-d.-O.; Visualization, Y.M.-U.; Writing-original draft, C.R.-d.-O.; Writing—review \& editing, C.R.-d.-O.

Funding: This research received no external funding

Conflicts of Interest: The authors declare no conflict of interest.

\section{References}

Avelino, Jacques, Marco Cristancho, Selena Georgiou, Pablo Imbach, Lorena Aguilar, Gustavo Bornemann, Peter Läderach, Francisco Anzueto, Allan J. Hruska, and Carmen Morales. 2015. The Coffee Rust Crises in Colombia and Central America (2008-2013): Impacts, Plausible Causes and Proposed Solutions. Food Security 7: 303-21. [CrossRef]

Bardsley, Douglas K., and Graeme J. Hugo. 2010. Migration and Climate Change: Examining Thresholds of Change to Guide Effective Adaptation Decision-Making. Population Environment 32: 238-62. [CrossRef]

Bebber, Daniel P., Ángela Delgado Castillo, and Gurr Sarah J. 2016. Modelling Coffee Leaf Rust Risk in Colombia with Climate Reanalysis Data. Philosophical Transactions of the Royal Society B: Biological Sciences 371: 20150458. [CrossRef] [PubMed]

Bell, Anne. 2013. A narrative approach to research. Canadian Journal of Environmental Education 8: 95-110.

Bettini, Giovanni. 2014. Climate Migration as an Adaption Strategy: De-Securitizing Climate-Induced Migration or Making the Unruly Governable? Critical Studies on Security 2: 180-95. [CrossRef]

Bettini, Giovanni. 2017. Archaeologies of the Future. In Environmental History of Modern Migrations. Edited by Marco Armiero and Richard Tucker. London and New York: Routledge, pp. 191-205.

Bigo, Didier. 2002. Security and Immigration: Toward a Critique of the Governmentality of Unease. Alternatives 27: 63-92. [CrossRef]

Black, Richard, Stephen R. G. Bennett, Sandy M. Thomas, and John R. Beddington. 2011. Migration as Adaptation. Nature 478: 447-49. [CrossRef]

Blitzer, Jonathan. 2019. How Climate Change Is Fuelling the U.S. Border Crisis|The New Yorker. The New Yorker. April 3. Dispach. Available online: https://www.newyorker.com/news/dispatch/how-climate-change-isfuelling-the-us-border-crisis (accessed on 13 June 2019).

Bunn, Christian, Peter Läderach, Oriana Ovalle Rivera, and Dieter Kirschke. 2015. A Bitter Cup: Climate Change Profile of Global Production of Arabica and Robusta Coffee. Climatic Change 129: 89-101. [CrossRef]

Canet Brenes, Guillermo, Carlos Soto Vízquez, Patricia Ocampo Thomason, Javier Rivera Ramírez, Alejandra Navarra Hurtado, Guadalupe M. Guatemala Morales, and Socorro Villanueva Rodríguez. 2016. La Situación y Tendencias de La Producción de Café En América Latina y El Caribe. San José: Instituto Interamericano de Ciencias Agrícolas (IICAA). Centro Agronómico Tropical de Investigación y Enseñanza (CATIE).

Castañeda, Alejandra. 2016. ¿Qué Es El Programa Frontera Sur? Boletín 1. Observatorio de Legislación y Política Migratoria. Available online: http://observatoriocolef.org/wp-content/uploads/2016/06/BOLET\%C3\%8DN-1Alejandra-Casta\%C3\%B1eda.pdf (accessed on 18 February 2019).

CCAFS. 2015. CGIAR Research Program on Climate Change, Agriculture and Food Security. Available online: https://ccafs.cgiar.org/honduras (accessed on 22 October 2019).

CEPAL (Comisión Económica para América Latina y el Caribe). 2019. Hacia un nuevo estilo de desarrollo. Plan de Desarrollo Integral El Salvador-Guatemala-Honduras-México. Ciudad de México: Diagnóstico, áreas de Oportunidad y Recomendaciones' CEPAL (LC/MEX/TS.2019/6).

Chain-Guadarrama, Adina. 2019. Uso de prácticas de Adaptación basada en Ecosistemas por pequeños cafetaleros en Centroamérica. Agronomía Mesoamericana 30: 1-18. [CrossRef]

COLEF, INM, CONAPO, STPS y SRE. 2016a. Encuesta sobre Migración en la Frontera SUR (EMIF Sur). Tabulados de la serie histórica 2004-2016. Migrantes procedentes de Guatemala a México, vía terrestre. 2004 a 2016, Data bases. El Colegio de la Frontera Norte, Instituto Nacional de Migración, Consejo Nacional de Población, Secretaría del Trabajo y Previsión Social y Secretaría de Relaciones Exteriores, México. Available online: https://www.colef.mx/emif/tabuladossur.php (accessed on 25 February 2019). 
COLEF, INM, CONAPO, STPS y SRE. 2016b. Encuesta sobre Migración en la Frontera NORTE (EMIF NORTE). Tabulados de la serie anualizada 1995-2016. Migrantes procedentes del sur. Data Bases. El Colegio de la Frontera Norte, Instituto Nacional de Migración, Consejo Nacional de Población, Secretaría del Trabajo y Previsión Social y Secretaría de Relaciones Exteriores, México. Available online: https://www.colef.mx/emif/ tabuladossur.php (accessed on 25 February 2019).

Creswell, John W. 2013. Qualitative Inquiry and Research Design: Choosing among Five Approaches. Los Angeles: SAGE Publications.

Eklund, Lina, Clemens Romankiewicz, and Martin Brandt. 2016. Data and Methods in the Environment-Migration Nexus: A Scale Perspective. Die Erde 147: 139-52. [CrossRef]

Delavelle, Fanny. 2013. Climate Induced Migration and Displacement in Mesoamerica. Discussion Paper. London: The Nansen Initiative.

CEPAL (Comisión Económica para América Latina y el Caribe). 2018. Atlas de la migración en los países del norte de Centroamérica (LC/PUB.2018/23), Santiago, Mexico. Available online: https://repositorio.cepal.org/ bitstream/handle/11362/44292/1/S1801072_es.pdf (accessed on 12 September 2019).

FAO (Food and Agriculture Organization). 2017. Migration, Agriculture and Climate Change. Reducing Vulnerabilities and Enhancing Resilience. Report I8297EN/1/12.17. Rome: FAO, 20p.

Felgentreff, Carsten, and Andreas Plott. 2016. Climatic Turn in Migration Studies? Geographical Perspectives on the Relationship between Climate and Migration. DIE ERDE Journal of the Geographical Society of Berlin 147: 73-80.

Felli, Romain. 2013. Managing Climate Insecurity by Ensuring Continuous Capital Accumulation: "Climate Refugees" and "Climate Migrants". New Political Economy 18: 337-63. [CrossRef]

Felli, Romain, and Noel Castree. 2012. Neoliberalising Adaptation to Environmental Change: Foresight or Foreclosure? Environment and Planning A 44: 1-4. [CrossRef]

FIRA (Fideicomisos Instituidos en Relación con la Agricultura). 2016. Panorama Alimentario, café 2016. Available online: https://www.gob.mx/cms/uploads/attachment/file/200636/Panorama_Agroalimentario_Caf_2016. pdf (accessed on 14 December 2018).

Foresight. 2011. Migration and Global Environmental Change: Final Project Report; London: The Government Office for Science.

Frank, Elisa, Hallie Eakin, and David López-Carr. 2011. Social Identity, Perception and Motivation in Adaptation to Climate Risk in the Coffee Sector of Chiapas, Mexico. Global Environmental Change 21: 66-76. [CrossRef]

Gay, C., F. Estrada, C. Conde, H. Eakin, and L. Villers. 2006. Potential Impacts of Climate Change on Agriculture: A Case of Study of Coffee Production in Veracruz, Mexico. Climatic Change 79: 259-88. [CrossRef]

Geddes, Andrew, and Andrew Jordan. 2012. Migration as Adaptation? Exploring the Scope for Coordinating Environmental and Migration Policies in the European Union. Environment and Planning C Government and Policy 30: 1029-44. [CrossRef]

Gemenne, François, and y Julia Blocher. 2017. How can migration serve adaptation to climate change? Challenges to fleshing out a policy ideal. Geographical Journal 183: 336-47. [CrossRef]

Glaser, Barney G, and Anselm L Strauss. 1967. The Discovery of Grounded Theory: Strategies for Qualitative Research. Chicago: Aldine Publishing.

Götz, Schroth, Peter Laderach, Jan Dempewolf, Stacy Philpott, Jeremy Haggar, Hallie Eakin, Teresa Castillejos, Jaime Garcia Moreno, Lorena Soto Pinto, Ricardo Hernandez, and et al. 2009. Towards a Climate Change Adaptation Strategy for Coffee Communities and Ecosystems in the Sierra Madre de Chiapas, Mexico. Mitigation and Adaptation Strategies for Global Change 14: 605. [CrossRef]

Gustin, Georgina, and Mariana Henninger. 2019. Climate Change Is Devastating Central America, Driving Migrants to the U.S. Border. NBC News. July 9. Inside Climate News. Available online: https://www.nbcnews. com/news/latino/central-america-drying-farmers-face-choice-pray-rain-or-leave-n1027346 (accessed on 12 July 2019).

Hannah, Lee, Camila I. Donatti, Celia A. Harvey, Eric Alfaro, Daniel Andres Rodriguez, Claudia Bouroncle, Edwin Castellanos, Freddy Diaz, Emily Fung, Hugo G. Hidalgo, and et al. 2017. Regional Modeling of Climate Change Impacts on Smallholder Agriculture and Ecosystems in Central America. Climatic Change 141: 29-45. [CrossRef]

Hartmann, Betsy. 2010. Rethinking Climate Refugees and Climate Conflict: Rhetoric, Reality and the Politics of Policy Discourse. Journal of International Development 22: 233-46. [CrossRef] 
Harvey, Celia A., Milagro Saborio-Rodríguez, M. Ruth Martinez-Rodríguez, Barbara Viguera, Adina Chain-Guadarrama, Raffaele Vignola, and Francisco Alpizar. 2018. Climate Change Impacts and Adaptation among Smallholder Farmers in Central America. Agriculture Food Security 7: 57. [CrossRef]

Henderson, Thomas Paul. 2017. La Reestructuración de Los Sectores Del Café y El Cacao En México y Ecuador. Control Agroempresarial de La Tierra y Trabajo Campesino. LiminaR. Estudios Sociales y Humanísticos 15 : 128-141. [CrossRef]

Hernández-Gutiérrez, José Carlos, and Ronald Sáenz. 2018. La Securitización Del Fenómeno Migratorio En El Caso Del Programa Frontera Sur. GESI, International Security Studies Group 19: 12.

Huq, Saleemul. 2013. Adapting to Climate Change: A Challenge and Opportunity. World Resources Institute. Available online: https:/www.wri.org/our-work/project/world-resources-report/adapting-climate-changechallenge-and-opportunity (accessed on 23 October 2019).

Imbach, Pablo, Megan Beardsley, Claudia Bouroncle, Claudia Medellin, Peter Läderach, Hugo Hidalgo, Eric Alfaro, Jacob Van Etten, Robert Allan, Debbie Hemming, and et al. 2017. Climate Change, Ecosystems and Smallholder Agriculture in Central America: An Introduction to the Special Issue. Climatic Change 141: 1-12. [CrossRef]

INCAFECH. 2019. El Café En México. Instituto Nacional del Café Chiapas. Gobierno del Estado de Chiapas. Available online: https://www.incafech.gob.mx/ (accessed on 27 October 2019).

INEGI (Instituto Nacional de Estadística. 2014. INEGI (Instituto Nacional de Estadística, Geografía e Informática). 2014. ENADID (Encuesta Nacional de la Dinámica Demográfica). 2014. Tabulados básicos. Available online: https://www.inegi.org.mx/programas/enadid/2014/default.html (accessed on 28 February 2019).

INEGI (Instituto Nacional de Estadística). 2015. INEGI (Instituto Nacional de Estadística, Geografía e Informática). 2015. Censos de población y vivienda 1990, 1995, 2000, 2010 y Encuesta Intercensal 2015. Bases de datos. Instituto Nacional de Estadística Geografía e Informática. Gobierno de México. Available online: https://www.inegi.org.mx/app/areasgeograficas/?ag=07 (accessed on 28 February 2019).

INEGI (Instituto Nacional de Estadística. 2019. INEGI (Instituto Nacional de Estadística, Geografía e Informática). 2019. Calculadora de inflación. Inflación de enero de 2003 a diciembre de 2017. Available online: https://www.inegi.org.mx/sistemas/indiceprecios/CalculadoraInflacion.aspx (accessed on 28 February 2019).

Isacson, Adam, Maureen Meyer, and Gabriela Morales. 2014. Mexico's Other Border: Security, Migration, and the Humanitarian Crisis at the Line with Central America. Washington Office on Latin America-WOLA-. Available online: https://www.wola.org/wp-content/uploads/2014/06/Mexicos-OtherBorder-PDF.pdf (accessed on 15 August 2019).

Klepp, Silja. 2017. Climate Change and Migration. Oxford Research Encyclopedia of Climate Science 1: 1-37. [CrossRef]

Klepp, Silja, and Libertad Chavez-Rodriguez. 2018. Governing Climate Change. The Power of Adaptation Discourses, Policies, and Practices. In A Critical Approach to Climate Change Adaptation. DIscourses, Policies, and Practices. Edited by Silja Klepp and Libertad Chavez-Rodriguez. Routledge Advances in Climate Change Research. London and New York: Routledge Earthscan, pp. 3-34.

Lejtreger, Raquel. 2019. 'La Movilidad Humana En La Agenda Climática de Las Américas: Necesidades y Oportunidades'. San José, C.R.: Organización Internacional para las Migraciónes (OIM). Oficina regional para Centroamérica. Available online: https://publications.iom.int/books/la-movilidad-humana-en-la-agendaclimatica-de-las-americas-necesidades-y-oportunidades (accessed on 28 October 2019).

Markham, Lauren. 2019. Climate Change Is Pushing Central American Migrants to the USLauren Markham. The Guardian. April 6. Available online: https://www.theguardian.com/commentisfree/2019/apr/06/us-mexicoimmigration-climate-change-migration (accessed on 14 August 2019).

McCook, Stuart, and John Vandermeer. 2015. The Big Rust and the Red Queen: Long-Term Perspectives on Coffee Rust Research. Phytopathology 105: 1164-73. [CrossRef]

McNamara, Karen Elizabeth, and Lisa Buggy. 2017. Community-Based Climate Change Adaptation: A Review of Academic Literature. Local Environment 22: 443-60. [CrossRef]

Merlín-Uribe, Yair, Fabien Charbonnier, Armando Contreras-Hernández, Obeimar Balente Herrera Hernández, Lorena Soto-Pinto, Yair Merlín-Uribe, Fabien Charbonnier, Armando Contreras-Hernández, Obeimar Balente Herrera Hernández, and Lorena Soto-Pinto. 2018. Tipología de Estrategias Campesinas En La Caficultura Orgánica de La Sierra Madre de Chiapas. Ecosistemas y Recursos Agropecuarios 5: 411-23. [CrossRef]

Mestries, Francis. 2013. Los Migrantes de Retorno Ante Un Futuro Incierto. Sociológica 28: 171-212. 
Milman, Oliver, Emily Holden, and David Agren. 2018. The Unseen Driver behind the Migrant Caravan: Climate Change. The Guardian, October 30.

Méndez Espinoza, José Arturo, Néstor Estrella Chulím, and Javier Ramírez Juárez. 2006. El programa moscamed en la región fronteriza México-Guatemala: algunos factores asociados a su evolución y permanencia. $R a$ Ximhai, 435-48. [CrossRef]

Nalau, Johanna, and Susanne Becken. 2018. Ecosystem-Based Adaptation to Climate Change: Review of Concepts. Research Report 15. Queensland: Griffith Institute for Tourism, Griffith University.

Neumann, Kathleen, and Henk Hilderink. 2015. Opportunities and Challenges for Investigating the Environment-Migration Nexus. Human Ecology 43: 309-22. [CrossRef] [PubMed]

Newland, Kathleen. 2019. The Global Compact for Safe, Orderly and Regular Migration: An Unlikely Achievement. International Journal of Refugee Law 30: 657-60. [CrossRef]

Oliver-Smith, Anthony. 2012. Debating Environmental Migration: Society, Nature and Population Displacement in Climate Change. Journal of International Development 24: 1058-70. [CrossRef]

Piguet, Etienne, Antoine Pécoud, and Paul de Guchtenerire. 2011. Migración y Cambio Climático. Madrid: Publicación Del Instituto Universitario de Estudios Sobre Migraciones, pp. 161-96.

Presidencia, Gobierno de Honduras. 2018. En La Cumbre Iberoamericana: Presidente Hernández Llama a Integrar Un Bloque En Defensa de Precios Justos Del Café. November 18. Available online: https://www.presidencia.gob.hn/index.php/gob/el-presidente/4995-en-la-cumbre-iberoamericanapresidente-hernandez-llama-a-integrar-un-bloque-en-defensa-de-precios-justos-del-cafe (accessed on 22 October 2019).

Renard, Marie-Christine, and Mariana Ortega Breña. 2010. The Mexican Coffee Crisis. Latin American Perspectives 37: 21-33. [CrossRef]

Renard, Marie-Christine, and Rosa María Larroa Torres. 2017. Política pública y sustentabilidad de los territorios cafetaleros en tiempos de roya: Chiapas y Veracruz. Estudios Latinoamericanos 40: 95-113. [CrossRef]

Ribando Seelke, Clare, and Carla Davis-Castro. 2019. Mexico's Immigration Control Efforts. CRS In Focus IF10215. Congressional Research Service. Available online: www.crs.gov (accessed on 12 February 2019).

Riessman, Catherine Kohler. 2008. Narrative Methods for the Human Sciences. London: SAGE.

Rigaud, Kanta Kumari, Alex de Sherbinin, Bryan Jones, Jonas Bergmann, Viviane Clement, Kayly Ober, Jacob Schewe, Susana Adamo, Brent McCusker, Silke Heuser, and et al. 2018. Groundswell: Preparing for Internal Climate Migration. Washington: World Bank. [CrossRef]

Sach, Jeffrey, Kaitlin Y. Cordes, James Rising, Perrine Toledano, and Nicolas Maennling. 2019. Ensuring Economic Viability and Sustainability of Coffee Production. New York: Columbia Center on Sustainable Investment. Columbia University.

Semple, Kirk. 2019. Central American Farmers Head to the U.S., Fleeing Climate Change. The New York Times. April 13. World. Available online: https://www.nytimes.com/2019/04/13/world/americas/coffee-climatechange-migration.html (accessed on 17 October 2019).

Ruiz Meza, Laura Elena. 2010. Climate Change, Poverty and Migration Processes in Chiapas, Mexico. Climate Change and Labour: The Need for a "Just Transition": International Journal of Labour Research 2: 187-210. [CrossRef]

Ruiz Meza, Laura Elena. 2015. Adaptive Capacity of Small-Scale Coffee Farmers to Climate Change Impacts in the Soconusco Region of Chiapas, Mexico. Climate and Development 7: 100-9. [CrossRef]

Scientific Software Development GmbH. 2018. ATLAS.Ti MAC 8. version 8.4. Berlin: Scientific Software Development GmbH.

Scoville-Simonds, Morgan, Hameed Jamali, and Marc Hufty. 2019. The Hazards of Mainstreaming: Climate Change Adaptation Politics in Three Dimensions. World Development 125: 104683. [CrossRef]

SIAP. 2015. Anuario Estadístico de la Producción Agrícola. 2003-2015. Servicio de Información Agroalimentaria y pesquera. Secretaria de Agricultura y Desarrollo Rural. Gobierno de México. Data Bases. Available online: https://nube.siap.gob.mx/cierreagricola/ (accessed on 26 February 2019).

Sward, Jon, and Samuel Nii Ardey Codjoe. 2012. Human Mobility and Climate Change Adaptation Policy: A Review of Migration in National Adaptation Programmes of Action (NAPAs). Available online: http: //ugspace.ug.edu.gh/handle/123456789/1969 (accessed on 15 October 2019). 
Tacoli, Cecilia. 2009. Crisis or Adaptation? Migration and Climate Change in a Context of High Mobility. In Population Dynamics and Climate Change. Edited by J.M. Guzmán, G. Martine, Gordon McGranahan, D. Schensul and Cecilia Tacoli. New York and London: UNFPA, New York and London: IIED, pp. 104-18.

Taylor, Marcus. 2015. The Political Ecology of Climate Change Adaptation: Livelihoods, Agrarian Change and the Conflicts of Development. New York: Routledge.

Toniutti, Lucile. n.d. Breeding for the Future. World Coffee Reseach. Available online: https://worldcoffeeresearch. org/work/breeding-future/ (accessed on 27 October 2019).

Torre Cantalapiedra, Eduardo, and José Carlos Yee Quintero. 2018. México ¿una Frontera Vertical? Políticas de Control Del Tránsito Migratorio Irregular y Sus Resultados, 2007-2016. LiminaR. Estudios Sociales y Humanísticos 16: 87-104. [CrossRef]

Turhan, Ethemcan, and Marco Armiero. 2017. Cutting the Fence, Sabotaging the Border: Migration as a Revolutionary Practice. Capitalism Nature Socialism 28: 1-9. [CrossRef]

Upadhyay, Himani, and Divya Mohan. 2014. Migrating to Adapt? Contesting Dominant Narratives of Migration and Climate Change. Discussion Paper. New Delhi: The Energy and Resources Insititute.

Valero Martínez, Mario. 2016. Visión geopolítica e histórica de la fronteras de Venezuela y Guyana. Revista Geopolítica 7: 112-2.

Varela Huerta, Amarela. 2015. La Securitización de La Gubernamentalidad Migratoria Mediante La Externalización de Las Fronteras Estadounidenses a Mesoamérica. Revista Contemporánea 2: 15.

Villafuerte, Daniel, and Maria del Carmen Aguilar. 2006. Crisis Rural y Migraciones En Chiapas. Migración y Desarrollo 6: 102-30.

World Coffee Research. n.d. Next-Generation F1 Hybrid Varieties. World Coffee Research. Available online: https://worldcoffeeresearch.org/work/next-generation-f1-hybrids/ (accessed on 20 October 2019).

ELCOLEF. 2018. Cronología de La Caravana Centroamericana'. Observatorio de Legislación Migratoria. Available online: http://observatoriocolef.org/infograficos/cronologia-de-la-caravana-centroamericana/ (accessed on 19 February 2019).

(C) 2019 by the authors. Licensee MDPI, Basel, Switzerland. This article is an open access article distributed under the terms and conditions of the Creative Commons Attribution (CC BY) license (http://creativecommons.org/licenses/by/4.0/). 


\title{
Article \\ Smallholder Telecoupling and Climate Governance in Jambi Province, Indonesia
}

\author{
Yvonne Kunz ${ }^{1, *}$, Fenna Otten ${ }^{1, *}$, Rina Mardiana ${ }^{2}$, Katrin Martens ${ }^{3}$, Imke Roedel ${ }^{1}$ \\ and Heiko Faust ${ }^{1}$ \\ 1 Department of Human Geography, Georg-August-University of Goettingen, 37073 Göttingen, Germany; \\ imke.roe@gmail.com (I.R.); hfaust@gwdg.de (H.F.) \\ 2 Department of Human Ecology, Institut Pertaninan Bogor, Bogor 16680, Indonesia; rina_nrf@yahoo.com \\ 3 Department of Agricultural Economics, Humboldt University Berlin, 10099 Berlin, Germany; \\ katrin.martens@hu-berlin.de \\ * Correspondence: Yvonne.Kunz@geo.uni-goettingen.de (Y.K.); fenna.otten@geo.uni-goettingen.de (F.O.)
}

Received: 26 February 2019; Accepted: 3 April 2019; Published: 10 April 2019

\begin{abstract}
Current debates on climate change have led to an increased demand for sustainable commodities. Serving this demand, sustainability certification schemes and eco-friendly labels have become prominent mechanisms of climate governance. Smallholder farmers in Jambi province, Indonesia, producing palm oil and rubber as the two dominant smallholder crops, are impacted by this distal demand. Zimmerer et al. (2018) suggest analyzing the potential sustainability in such a context with the multilevel smallholder telecoupling framework. Applying this framework to case studies from Jambi province, our first case reveals that smallholder certification for so-called sustainable palm oil does not necessarily influence smallholder towards more sustainable management practices. One explanation might be a discrepancy in sustainability perception between sender and receiver systems. The second case is the setup of an allegedly eco-friendly rubber plantation. The establishment of this model plantation is implemented by a transnational corporation in collaboration with a nature conservation organization, impacting the access to land for adjacent smallholders. The struggle over access to land is not only negotiated between smallholders and the corporation producing "eco-friendly" rubber but also between smallholders and big land mammals lacking access to land since the rubber plantation began to be established. We argue that the concept of sustainability as demanded by the receiving system does not mirror management practices in the sending system, even though the products reach the Global North as supposedly socially and climate-friendly. The smallholder telecoupling framework is helpful for assessing potential sustainability but can be expanded towards conflictive spillovers, second order effects, and a mismatch in sustainability perceptions in order to draw a more comprehensive picture.
\end{abstract}

Keywords: telecoupling; sustainability; multi-stakeholder initiatives; roundtable for sustainable palm oil; sustainable natural rubber initiative

\section{Introduction}

Climate change and its current consequences, as well as damages yet to happen, are prominent in public debate. Land-use and land-use change are regarded as one of the main contributors to climate change (IPCC 2014). Especially in the so-called Global North, this debate leads to an increased awareness towards considerations of the origin of commodities purchased. These considerations apply to the ecological, as well as socio-economic, impacts of the desired goods. Not only goods produced in the vicinity to the consumer are here taken into account but also the distant places of production. Gradually more information, hence more awareness, trickles through on management practices and their impacts, especially on monoculture plantations of boom crops, such as oil palm and 
rubber (Hall 2011), produced in the so-called Global South. In the context of globalization, a rise in information dissemination has led to new moralities and hence a demand for sustainable commodities (Johnson et al. 2014; Eakin et al. 2014). In response to this consumer demand, schemes of sustainability certification for palm oil and rubber were established. These led to initiatives, which "signal to consumers that their products and/or production processes used, hold certain standards regarding environmental, health or social aspects" (Vatn 2015). Private actors are increasingly engaging in climate governance through private rule-making mechanisms like certification or other, often voluntary, multi-stakeholder 'cooperative initiatives' (Chan et al. 2016). Non-state actors, often referred to as Non-Party actors, to distinguish them from the United Nations Framework on Climate Change Convention (UNFCCC), "can help national governments to reach existing climate policy goals and set higher targets" (Hsu et al. 2019). Recognizing this development, Jagers and Stripple (2003) argue that climate governance should not be ascribed to only international climate actors, such as the UNFCCC. They add the notion that climate governance should further be used towards any "purposeful mechanisms and measures aimed at steering social systems towards preventing, mitigating, or adapting to the risks posed by climate change" (ibid., p. 60). From this perspective, the term 'climate governance' also fits to describe the private multi-stakeholder initiatives context as the starting point for this paper. The standards developed by these multi-stakeholder initiatives, initiated in the Global North, were in its infancy set up to steer the management practices of large-scale companies (Hidayat et al. 2018; Brandi et al. 2015). However, not only companies are affected but also the smallholder production of oil palm and rubber at distal places is increasingly targeted by schemes intending to increase sustainability along the value chain. The impacts on smallholders as intended by the initiatives are not always congruent with how local land users perceive the effects. At times, the impacts felt by smallholder are, from the perspective of the initiative, rather unintended and hence are considered as the second order effects. The impacts of climate governance instruments alter land control at these places at a distance.

Current studies on oil palm certification are prevalent. Some focus on biodiversity conservation potential (Azhar et al. 2015) or on deforestation elimination potential (Van der Ven et al. 2018; Carlson et al. 2018) while some on the effectiveness regarding social and environmental performance (Morgans et al. 2018). The analysis of eco-friendly rubber is less frequent. Early studies primarily focused on environmental consequences of rapid monoculture expansions in the tropics (Ahrends et al. 2015), investigated options to halt ecosystems and biodiversity loss, and strongly recommended the adoption of sound certification schemes for sustainable rubber (Warren-Thomas et al. 2015a) and the financial adjustment of payments for ecosystem services if binding regulations are absent (Ekandinata and Vincent 2011; Warren-Thomas et al. 2018). Kennedy et al. (2016) consider the comparably slow uptake of rubber certification as opposed to crops like palm oil, cocoa, or coffee and illustrate shortcomings of those being present. However, Kenney-Lazar et al. (2018) question the potential of 'green' rubber cultivation, especially in resource frontiers. The current literature available hardly looks at second order effects or conflictive spillovers. We would like to contribute to closing this gap by asking the question what sustainability potential the Roundtable for Sustainable Palm Oil (RSPO) and the Sustainable Natural Rubber initiative (SNR-i), as two examples for multi-stakeholder initiatives, have in distal smallholder social-ecological systems, especially when considering conflictive spillovers or second order effects.

One such distal smallholder setting is Jambi province on the island of Sumatra in Indonesia. Indonesia and Malaysia together produce approximately $85 \%$ of palm oil and approximately $30 \%$ of rubber traded worldwide (FAOSTAT 2019). Even though an estimated $60 \%$ of oil palm (Beckert 2016; Indonesia Investments 2017) is produced by companies, smallholder production plays an increasingly crucial role to resource management and sustainability, worldwide as well as in Jambi (Zimmerer et al. 2018; Cohn et al. 2017). For rubber, the figures are even more striking. In Indonesia, "smallholder account for over $78 \%$ of the total volume produced and occupy over $85 \%$ of the total 
area under rubber cultivation" (Kennedy et al. 2016, p. 106), punctuating the relevance of smallholder production in this field.

To assess the potential sustainability for smallholder production, (Zimmerer et al. 2018) propose to utilize the analytical framework of smallholder telecoupling. Applying this framework to two case studies from Jambi province is the paramount intention of this paper. Our first case reveals that smallholder certification for so-called sustainable palm oil under the Roundtable for Sustainable Palm Oil (RSPO) does not necessarily influence the production process towards more sustainable practices. The second case is the establishment of an allegedly eco-friendly rubber plantation by a transnational corporation with the involvement of a nature conservation organization, impacting the access to land for adjacent smallholders. As the second intention of this paper, we argue that within this smallholder telecoupling framework, the sustainability paradigm creates new arenas of conflictive spillovers. The spillovers or second order effects transform perceptions of resource use and control, hence reshape the frontier.

\section{Conceptual Framework}

The frontier in its classic understanding was described as the line pushing back wilderness, to create a space for development at the expense of natural resources (Fold and Hirsch 2009). This idea of a clear-cut line between agricultural land and settlements opposed to the forest as wilderness is (if it has ever been adequate) outdated and does not keep up with current dynamics in land use patterns. Post-frontiers or new frontiers have replaced the old notion, filling it with new understandings of transformation and concepts of land control. According to Peluso and Lund (2011, p. 668), new frontiers are "sites where authorities, sovereignties, rights, and hegemonies of the recent past have been or are currently challenged by new enclosures, territorializations, or property regimes. What is new is not only land grabbing or ownership but also new crops with new labor processes and objectives for growers, new actors and subjects, and new legal and practical instruments for possessing, expropriating, or challenging previous land controls." Rasmussen and Lund (2017, p. 392) add that "frontiers are novel configurations of the relationship between natural resources and institutional orders that happen at particular moments in particular places. [ ... ] Frontiers emerge when a new resource is identified $[\ldots]$. The 'discovery' of new resources [ ... ] opens frontiers and challenges established right." As we will see in the following, concepts of sustainable crop production can be regarded as the discovery of a new crop as they alter land control and hence the access to land. Following the definition of Ribot and Peluso (2003, p. 154), we understand "access to land as the ability to benefit". The new frontiers, with their new objectives for growers, new actors and subjects, and 'new resources' are stuffed with complex, beyond place-based observable aspects. We hence argue that the innovative telecoupling framework is particularly suitable to analyze new frontier settings.

Telecoupling is an emerging analytical concept in land system science reacting to an increasingly complex and distal cause and impact context, as well as a reaction to an increasingly process-oriented system (Kapsar et al. 2019). It aims to support research striving to unravel drivers of intended as well as unintended changes in social-ecological systems (Friis and Nielsen 2017). Understanding and explaining contemporary land-use changes "requires a conceptual framework geared toward capturing not only the place-based and site-specific factors of change but also the multidirectional flows of capital, produce, and information linking it to processes in distal places" (ibid.: w.p.).

The role of the 2 to 2.5 billion smallholders worldwide in socio-ecological systems in these gradually more telecoupled systems are of crucial importance in land use science. According to the Food and Agricultural Organization of the United Nations (FAO), farmers are considered as smallholder who grows agricultural products for the market and family consumption on less than 10 hectares of land (FAO 2012). We extend this definition to a maximum of 20 ha as some respondents of our sample hold more than 10 ha but still meet the remaining indicators of the smallholder definition. We follow the invitation of Zimmerer et al. (2018) to analyze potential sustainability as demanded by the Global North by applying the smallholder telecoupling framework. Telecoupling 
occurs when a change in one social-ecological system impacts one or more social-ecological systems at a geographical distance while this change would not necessarily have been expected or assumed (Eakin et al. 2014). Land system science has been very place-based in the past; the telecoupling concept, in contrast, emphasizes networks and interactions amongst systems (ibid.). These interactions do not only encompass material flows but also socioeconomic as well as environmental interactions (Liu 2014). The telecoupling framework furthermore explicitly considers feedbacks in the analysis of land use change and sustainability research. Feedbacks can, for example, be "reciprocal interactions among different coupled systems" (ibid., p. 3). The basic telecoupling framework analyzes the systems, the agents acting in them, flows of material, ideas, technologies, and people, as well as causes and effects. The systems are subdivided into sending, receiving, and spillover systems. The definition of the systems is context dependent (ibid.). In our case, the sending systems are the systems providing material, hence rubber and palm oil. The receiving system, in turn, receives materials; in our case, allegedly sustainable or eco-friendly palm oil and rubber.

The smallholder telecoupling framework as proposed by Zimmerer et al. (2018) follows this basic telecoupling framework just introduced. It is then argued, that in dependence to the basic framework, telecoupled smallholder social-ecological systems can be analyzed along four factors. The first factor consists of the (1) telecoupled global systems affecting smallholders or the linkages of smallholders; in our case, the demand of sustainably produced commodities, a demand which also reaches out to smallholder systems. Closely linked to this first factor are the (2) the resource use of the smallholder and land access in the sending system, forming a second analysis factor. (3) The governance, including public and private institutions, markets, and national-level governance are described as the third factor. In our case, this third factor consists mainly of multi-stakeholder initiatives. The fourth analysis component is the (4) local interactions among smallholders in their communities and landscapes (ibid.). To our knowledge, neither oil palm nor rubber smallholders have been analyzed by applying the concept of telecoupling ${ }^{1}$. We would like to contribute to the telecoupling framework by analyzing oil palm and rubber smallholders and thereby expanding the framework if necessary. Analyzing interactions triggered at a distance to the systems where changes occur, supports a better understanding of local social-ecological system alterations. Further research could apply the telecoupling framework in a more exhaustive manner by analyzing changes in the social-ecological system in the receiving system as well (e.g., the impacts of sustainable palm oil production in Indonesia on rapeseed farmers in the European Union). In this article, the focus remains on altered land control in the sending system though.

Taking account of these four analysis components for smallholder telecouplings and their sustainability potentials demanded by consumers mainly in the Global North, to us also means to take on a perspective across scales with a focus on power asymmetries. In other words, this research endeavors to narrate from the lens of political ecology (Zulu 2009).

\section{Methodology}

The sustainability potential of smallholder production is analyzed along two initiatives: the Roundtable for Sustainable Palm Oil (RSPO) and the Sustainable Natural Rubber initiative (SNR-i). We knew of cases of RSPO certification in our research area which we visited on purpose. In the case of the SNR-i, we followed an inductive approach and learned about this case while on the field.

\subsection{Study Sites}

Jambi province is located on the island of Sumatra, the third largest island in Indonesia and the fifth largest island in the world (Barber 2005). Jambi province borders the provinces of Riau

1 Even though we know of one much appreciated article which explores palm oil production using the lens of telecoupling, but without focusing on smallholder production. For this article see (Wicke 2014). 
in the north, the South China Sea in the east, the province of South Sumatra in the south, and the provinces of West Sumatra and Bengkulu in the west. There are four national parks in Jambi province, which comprise an area of 693,354 hectares: Kerinci Sebelat National Park in the west, Bukit Tigapuluh in the north, Bukit Duabelas National Park in the center, and Berbak National Park in the eastern part of the province (Beckert 2016). These national parks seem to be important last resorts as the development from the forested area towards monoculture plantation is rampant. According to Laumonier et al. (2010), between 1985 and 2007, 1.7 million hectares of forest had been cleared, which is an estimated $71 \%$ of the forest in 1985. In 2013, only $30 \%$ of the land in Jambi province was covered with rainforest, predominantly in the highlands, and $55 \%$ of the land mass was agricultural land (Drescher et al. 2016). Parts of the land are obviously also taken up by settlements to host approximately 3.5 million inhabitants of the province (in 2017) (Badan Pusat Statistik Jambi 2019), of which 49\% were working in the agricultural sector in 2014 (Badan Pusat Statistik Jambi 2015).

Data used in this paper were collected in four villages spread across Jambi province. The research regarding the implementation, impacts, and sustainability potential for certified palm oil was conducted in three villages: Mekar Jaya (with one RSPO certified farmer group since 2014), Merlung, and Sungai Rotan (at the time of research, both still in the RSPO certification process). The village Muara Sekalo was the study site for the impacts and potentials of the so-called eco-friendly rubber under the Sustainable Natural Rubber initiative (SRN-i) (see Figure 1). The project is situated on the border of the National Park Bukit Tigapuluh ('Thirty Hills') and enclaves the village Muara Sekalo, with its 1200 inhabitants (village survey 2012). Villagers have, since long, predominantly cultivated rubber besides paddy and vegetables for subsistence, though today, generally both rubber and oil palms are grown. Paddy farming is almost completely abandoned. While the village Sungai Rotan also borders the Bukit Tigapuluh National Park in the northern part of the province, Mekar Jaya is in the vicinity to the Bukit Duabelas National Park.

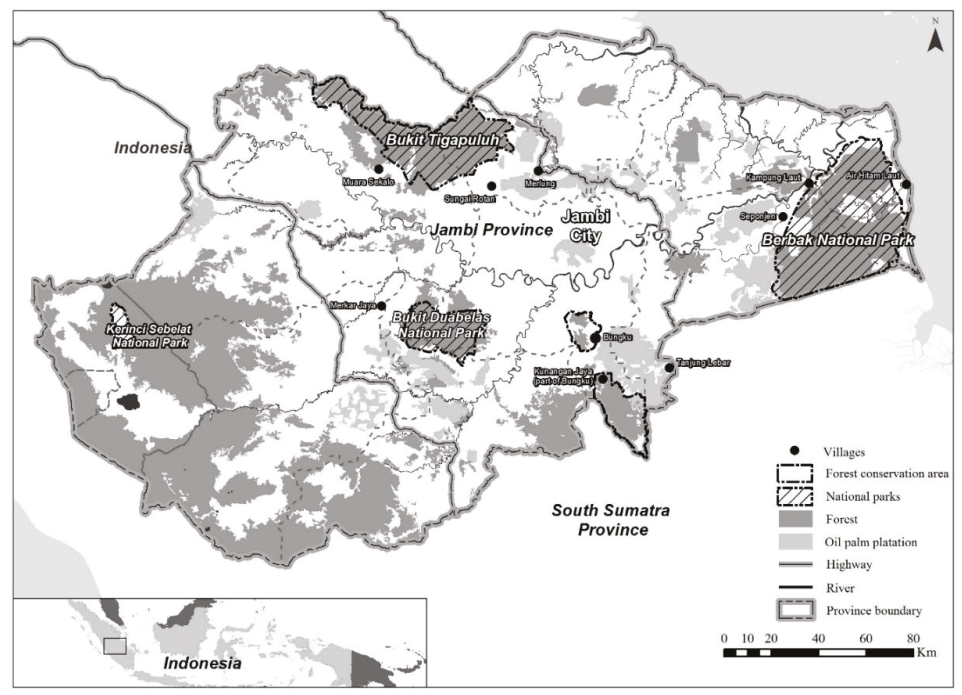

Figure 1. Study Sites.

\subsection{Multi-Stakeholder Initiatives at the Study Sites: RSPO and SNR-i}

As already mentioned, the villages Mekar Jaya, Merlung, and Sungai Rotan were selected as research sites as all three villages have farmer groups who are either already certified by the RSPO or are in the process of receiving recognition as RSPO certified farmer groups. Muaro Sekalo is the research village illuminating the impacts of the Sustainable Natural Rubber initiative (SNR-i). 


\subsubsection{The Roundtable on Sustainable Palm Oil (RSPO)}

Launched in 2004, the RSPO is a multi-stakeholder initiative supported by the Worldwide Fund for Nature (WWF) and private industry actors in Europe. It is listed by the United Nations Environment Program as one of over 250 climate initiatives (Climate Initiative Platform 2019) and states to support the Sustainable Development Goal 13 on Climate Action (RSPO 2018). For the first time, plantations were certified in 2008; in the same year, the first certified sustainable palm oil was sold (Rival et al. 2016). In 2018, around $19 \%$ of the worldwide traded palm oil was certified by the RSPO. With almost 4000 members, the RSPO aims at reaching full traceability of the palm oil supply chain (RSPO 2018). Compliance to RSPO standards is audited by a third-party audit company.

In order to reach this traceability and to work towards the self-proclaimed climate goals in the name of sustainability, eight principles that are subdivided into 39 criteria were formulated ${ }^{2}$. These principles and criteria $(\mathrm{P} \& \mathrm{C})$ are frequently reviewed to improve their relevance, especially for different grower groups ${ }^{3}$ (RSPO 2010). The overarching themes of the P\&C are transparency, laws and regulations, economic and financial viability, environmental responsibility, conservation, biodiversity, as well as workers' and communities' rights. In November 2018, the RSPO launched official cooperation with the High Carbon Stock Approach (HCSA) "to establish a No Deforestation Joint Steering Group (NDJSG) focused on providing guidance on the implementation of no deforestation requirements in High Forest Cover Landscapes" (RSPO, and HCSA 2018). Growers, processors and traders, manufacturers, banks and investors, retailers, and NGOs are among the members of the RSPO (Rival et al. 2016). Independent smallholders, as the relevant group for this research, need to be organized in a farmer group in order to apply for RSPO certification.

The literature lists several potential benefits the RSPO certification can provide to a smallholder. These are improved market access, higher incomes through higher productivity, and better quality of harvests (Brandi et al. 2015). Improved management practices, as a principle of the RSPO, are expected to produce higher yields. As smallholders are paid according to the weight of their harvest, higher productivity would result in higher yields, which would then translate into higher market prices. It is worth mentioning here that there are no price premiums for certified sustainable palm oil on international markets (Brandi 2017).

Challenges for smallholders to join the certification process is the capital- and time-consuming processes, which consist of trainings, as well as the fees for administration, monitoring, and auditing (Cheyns 2011). Smallholder hardly considers this effort as a long-term investment, which could later pay off through higher yields (Nagiah and Azmi 2012). Compliance with RSPO P\&C is limited through a lack of agricultural skills, as well as through a lack of incentives, for example, price premiums (Jelsma and Schoneveld 2016).

\subsubsection{The Sustainable Natural Rubber Initiative (SNR-i)}

The Sustainable Natural Rubber initiative (SNR-i) has been developed under the framework of the International Rubber Study Group (IRSG) as a voluntary and collaborative industry project in 2014.

The objective of the initiative is to ensure that the rubber industry can build on its best practices plus demonstrate and communicate throughout the natural rubber value chain. In this context, a Sustainable Natural Rubber Working Group (SNRWG) was established in 2012 with a view to defining voluntary sustainability standards regarding the broader natural rubber sector. The working group members representing the complete natural rubber (NR) value chain (including representatives from international organizations) developed an Action Plan to explain the factors driving this

2 For detailed information on Principles and Criteria see https://www.rspo.org/key-documents/certification/rspoprinciples-and-criteria.

3 For the process of developing Principles and Criteria suitable for smallholder production (draft stage) see https://www. rspo.org/principles-and-criteria-review/public-consultation-rspo-smallholder-standard. 
initiative and brought forward proposals for its design and implementation. The Action Plan defined a set of five criteria for a voluntary verification system targeted on wide stakeholder participation. From these criteria, indicators have been developed for the implementation of SNR-i that may allow organizations to participate in this voluntary initiative on a self-certification basis. Self-certification means that there is no external auditing. The main themes to be improved under the initiative are the improvement of natural rubber plantations, to enhance the quality of natural rubber, to support forest sustainability through the protection/conservation of protected areas, to demonstrate appropriate water management, and to demonstrate the highest respect for human and labor rights. As is the case for the RSPO, the SNR-i also has a set of criteria, even if far less detailed ${ }^{4}$. By October 2017, 43 companies/organizations had completed the self-declaration on the SNR-i. The majority of these 43 self-declared registrants are processors. The smallest part of the members falls under the plantation category (9\%) (SNR-i 2017).

\subsection{Data Collection}

The research villages were visited during several fields stays in 2016 (Merlung) and 2017 (Muara Sekalo, Sungai Rotan, and Mekar Jaya). To gain a deeper understanding of the effects of multi-stakeholder initiatives in the palm oil and rubber sector, a range of qualitative as well as quantitative methods were applied. Using a case study approach, main methods applied were participant observation and semi-structured problem-centered guideline interviews $(n=64)$; as well as focus group discussions (6) with women and farmer groups were conducted during the time spent in the villages (on average one week per village) (see Supplementary Materials). In Sungai Rotan and Mekar Jaya, the Sustainability Assessment of Food and Agricultural Systems (SAFA) framework was additionally applied, even with a small number, of only 10 respondents (for further information see Appendix A). This framework was developed by the FAO, and it targets several dimensions of sustainability. The questionnaire comprises of 100 multiple and single choice questions, focusing on good governance, environmental integrity, economic resilience, and social well-being. In Merlung, the social power network mapping method was implemented to gather in-depth information about multi-stakeholder governance. It helps to identify networks that "tend to be located outside existing hierarchies" (Schiffer and Waale 2008). It hence helps to understand how smallholders are impacted in their decision-making processes and what their intentions are. In addition to the interviews in the villages, expert interviews with non-governmental organizations and government officials (e.g., with RSPO representatives in Jakarta), mostly on the provincial and district level, were conducted.

\section{Results}

The results for the two cases, namely the certification for so-called sustainable palm oil under the Roundtable for Sustainable Palm Oil (RSPO) and the allegedly 'eco-friendly' natural rubber cultivation following Sustainable Natural Rubber initiative (SNR-i), are discussed separately and along the four central criteria identified by the smallholder telecoupling framework. The data on the RSPO concerns the impacts of a climate governance instrument on smallholders directly, as the program also targets the production of a smallholder. The SNR-i case is less straightforward. Here, the initiative targets large-scale production and thereby 'only' affecting smallholders' access to land as a second order effect.

\subsection{Smallholder Telecouplings under the Roundtable on Sustainable Palm Oil}

Oil palm smallholders in Jambi province are impacted by a growing consumer awareness towards social and ecological sustainability impacts of commodity production. This growing awareness has led

4 For detailed information http://snr-i.org/Voluntary\%20Guidelines\%20and\%20Criteria\%20Version\%201_13_1.htm. 
to the establishment of certified palm oil schemes. An increasing number of certificates for sustainable palm oil is available on the market (Rival et al. 2016; Pacheco et al. 2017).

It is worth mentioning that the RSPO, as other certification schemes as well, equips itself with the interpretation of sovereignty on what sustainability actually is. The RSPO itself states in this context that it "has developed a set of environmental and social criteria which companies must comply with in order to produce Certified Sustainable Palm Oil" (RSPO 2019). Looking at the stakeholders deciding on these criteria shows that the vast majority of board members belong to investor groups. Governmental actors, as well as grower groups of smallholders, are not represented. It can hence be argued that sustainability, as defined by the representative of investors and few non-governmental organizations engaged in nature protection, is rather a compromise, subjective, and certainly not a very inclusive understanding of the term (Ruysschaert and Salles 2014). Against this background, it might be argued here that the RSPO is rather geared towards business development than towards genuine sustainability.

\subsubsection{Telecoupled Systems_-Demand for Sustainable Palm Oil}

To date, the Roundtable for Sustainable Palm Oil (RSPO) remains the most popular scheme, in terms of quantity certified. An increase in the demand for sustainable palm oil in the receiving system resulted in $74 \%$ of all palm oil imported to the European Union being RSPO certified palm oil (European Sustainable Plam Oil 2019). From the initial setup to certify palm oil produced by large-scale companies, there has been a shift towards the recognition of the importance of smallholder production (RSPO 2018). Today, 55,000 certified schemes and independent smallholders produce certified palm oil, translating to $9 \%$ of the total area for RSPO certified palm oil, being under smallholder's production (RSPO 2018). In order to sell certified sustainable palm oil, farmers need to be organized in a farmers group. In other words, individuals cannot apply for certification and only groups of individuals can. According to interview partners who are members of such a farming group, a certain minimum collective plantation size needs to be reached to apply for the certification process. Smallholders who were interviewed further state that by getting organized in a farmers group, there is an improvement in bargaining positions, savings in management costs, and it can be helpful when striving for loans or subsidized inputs. By talking to smallholders, it becomes obvious that most RSPO P\&C, as they have been set up mostly by the receiving system, are quite complex to understand, difficult to obey to or simply not applicable to small-scale farming realities. For example, the reduction of greenhouse gas (GHG) emissions is an intention behind sustainable agricultural practices under the RSPO. Smallholders obviously lack the necessary technological equipment, skills, and incentive to track GHG emissions from the application of fertilizer. The mere recording of emissions does not necessarily lead to a change in agricultural practices. The limited economic capacity of farmers to adhere to these principles, and their motivation being to achieve wellbeing, reflects an imbalance of indicators. They are legitimized by discourses among experts, consumers, and politicians from the receiving system. This is not to say indicators should only reflect small-scale producers' perceptions, but the information on trade-offs and feedbacks between sustainability dimensions and target-oriented support (such as the provision of machinery for replanting oil palm trees), or extension services, is still lacking.

\subsubsection{Smallholders' Resource Use and Access to Land}

One RSPO criterion is the legal land ownership or, in other words, a clear tenure status is crucial in the RSPO certification scheme. One goal of the RSPO on their way to a sustainable value chain is to reduce or avoid deforestation. In this context, another criterion is that RSPO only accepts palm oil from plots which were not deforested after 2005. To reduce soil degradation and to improve the responsible use of agrochemicals (criteria under principle 4), a fertilizer schedule has to be maintained by the smallholders. Commitment to long-term economic and financial viability, as again another criterion, 
calls for the maintenance of a schedule for fertilizer and harvest. A commitment to transparency is listed as the very first principle of the RSPO.

According to statements from interviews, however, many farmers do not hold a land title recognized by the national organization in charge of issuing land titles. According to an expert, working for an Indonesian NGO focusing on palm oil, many independent smallholders migrated to Sumatra. They bought land from local people and do not know when their land had been reclassified to agricultural land. He further explained that this criterion is more feasible for companies as it is possible to compensate for non-compliance by protecting another forest or by planting a new forest. The fertilizer schedule is regarded as one of the major challenges among smallholder interviewed. The application of fertilizer is weather-dependent. In dry times, the soil does not take up the fertilizer which is regarded as wasteful if applied anyway. In the rainy season, the excretion is washed away and equally regarded as wasteful. In case of heavy rains, the plantations can at times not be accessed which hinders the fertilizer's application. Often, the fertilizer needed is not available in accessible stores.

Smallholder, however, also reports on positive impacts through certification: they have a better understanding on fertilizer use (due to training received), use fewer pesticides, have better access to organic fertilizer, and also better access to high-quality seeds. At the same time, results show that many farmers have never heard about certification for sustainable palm oil, even if they belong to a certified group. Our findings support the findings of Brandi (2017) that even among certified smallholders, some do not know about the RSPO or the principles and criteria. Some of those who are certified and are also aware of the certification claim that they have not changed their management practices from the time prior to certification as the audit would not reach their plot anyway. "I am not going to change anything unless there is an audit on my plantation" was the statement of one smallholder interviewed.

\subsubsection{National Institutions}

Adhering to the national laws and land tenure regulation, mentioned in the context of legal land ownership above, is also amongst the criteria listed by the RSPO. This national-level governance frame was named as the biggest hurdle in focus group discussions on challenging RSPO criteria. Farmers need to verify legal ownership through a national level land certificate, which the majority of the farmers in Jambi do not have (Kunz et al. 2016). The farmer groups in Mekar Jaya and Sungai Rotan alike were supported though, in receiving certification or being in the certification process by one Indonesian non-governmental organization (NGO). This NGO helps rural villages that lack market access and governmental support in forming farmer groups and guides them through the RSPO certification process. They also support farmer groups in receiving the Indonesian Roundtable for Sustainable Palm Oil (ISPO) certificate. The principles and criteria for the Indonesian certificate are granted when obeying to national laws. Principles and criteria here are thus congruent with the national law. According to interviewees, the NGO also takes care of the costs for sustainability certification, which includes the acquisition of a formal land title. The same NGO also carries out training with the farmers.

\subsubsection{Local Interactions}

Throughout the interviews and focus group discussions, the involvement in farmer groups has been mentioned as having a positive impact on a smallholder. The membership in farmer groups can in many cases be traced back to the initiation of the certification process under the RSPO. While an increase in palm oil production is mentioned as having led to a decline in a bond among villagers, the farmer group compensates for this decline. "Before [oil palm expansion] $]^{5}$, there were lots of emotional bonds, a sense of togetherness and everyone was family" was a statement in one focus group discussion. What is described in this statement was something we found in all villages,

5 Amended by the authors. 
a concept summarized under the term 'gotong-royong'. Literally, this term translates to 'mutual cooperation'. To community members in all the places we visited in Indonesia, it is a matter, of course, to participate in 'gotong-royong' activities. This can be cleaning up the village, renovating the kindergarten, improving basic infrastructure, and alike. Usually, community members actively participate in these activities. If participation is not possible, financial compensation can be accepted as a supplement. According to interview partners, with an increase in palm oil adoptions, an increase in supplementing payments has been observed. In turn, this means, that the value of the mutual cooperation is in decline, while competition between farmers is increasing.

Furthermore, many smallholders state that they obtain information on oil palm management through friends, neighbors, etc., working for a company on an oil palm plantation. In this context, the word also spreads on certification-related issues. In Merlung, a smallholder stated to have been advised by a palm oil company to initiate the certification process as otherwise, they will not be able anymore to sell their fresh fruit bunches.

\subsection{Smallholder Telecouplings under the Sustainable Natural Rubber Initiative (SNR-i)}

Jambi province has for long been a smallholder-dominated landscape; rubber cultivation in agroforestry systems was widespread. Increasingly, these systems are substituted by monoculture cultivation systems (Feintrenie and Levang 2009). Opposing to developments in the palm oil industries, rubber cultivation in Jambi was for a very long time not at all affected by demands for more sustainable management practices, but, this has changed with the recent establishment of a large-scale 'model' plantation for sustainable rubber cultivation.

\subsubsection{Telecoupled Systems_-Demand for Eco-Friendly Rubber}

While negative social-ecological consequences and land dispossession "have attracted considerable attention from scientific and academic communities, public awareness_-particularly in terms of consumer demand for standards and certification-has been slow to develop in comparison to other agro-commodity crops" (Kennedy et al. 2016).

By now, however, producers of natural rubber (NR) are increasingly under pressure to cap negative environmental impacts. Especially agro-industrial rubber cultivation has expanded rapidly, and the area under cultivation has doubled within the last decade and is projected to swallow up to another 8.5 million hectares to meet demands (Warren-Thomas et al. 2015a). New frontiers of rubber expansion include biodiversity hotspots in Southeast Asia and many protected areas (Ahrends et al. 2015; Warren-Thomas et al. 2015a). In response to this massive expansion in biodiversity hotspots, initiatives for sustainability standards arose, mostly industry-led, resulting in voluntary guidelines like the SNRi (Kennedy et al. 2016). These rather weak guidelines do not target smallholders per se but still indirectly exert influence on them.

Lately, tire producers increasingly claim to take sustainability issues into account. The tire industry is the main purchaser of natural rubber; it consumes about 70\% of the global trade volume (Clay 2010). Michelin was the first tire producing company to announce a 'zero deforestation' policy (WWF 2016), which is embedded in their sustainable natural rubber policy. The policy's guiding principles are based on the SNR-i criteria aiming to establish sustainability of the natural rubber value chain. The French company is a core member of the Sustainable Natural Rubber Working Group (SNRWG) that developed the SNR-i criteria.

Michelin (2017) states that they established model plantations in Sumatra to produce 'eco-friendly' rubber "in both social and environmental terms". On those plantations, the company indicates to cooperate with local communities, applies best management practices, and spares half of the concession for conservation.

Two years ago, the Indonesian rubber company PT LAJ started its business and initiated the establishment of this model plantation in cooperation with Michelin. The whole concession amounts to more than 60,000 ha. According to inhabitants of Muara Sekalo, roughly half of the concession will 
be a rubber plantation, while the other half is designated for conservation issues, including a buffer zone to the 'Thirty Hills' national park and an elephants reserve. According to the local customary law, the parts of this concession are claimed by villagers.

\subsubsection{Smallholders' Resource Use and Access to Land}

These overlapping land tenure regulations between de-jure and de-facto tenure cause contradictions (cf. Kunz et al. 2017). On-site, people cultivate land, which the Ministry of Environment and Forestry has allocated to the company to produce eco-friendly natural rubber to be processed by Michelin. PT LAJ compensates villagers in case they claim the land within the concession, but not everyone recognizes the payments straightforward. In case of non-compliance, as the last consequence, the company takes legal action, the Corporate Social Responsibility assistant of the company reports. In many cases, locals accept the offered compensation payments, yet the process was decelerated.

Furthermore, members of a women's group vividly demonstrated that they and many others did not want to abandon their rubber and oil palm plots that now lay within the concession, as they prefer to stay independent farmers. As a response to their resistance, they were intimidated for giving their land to the company. They had no choice; in the end, the company would have won. Effectively, there is a single villager, who confronted the company and could keep his plot. If needed, he would even have defended himself before the court. Other villagers did not follow his example, because they do not know their rights, he said, and it was not in the interest of the previous village government to inform inhabitants about their rights. The village government, he continues, who negotiated the deal, had their own particular interests.

The limited agency of smallholders concerning their land claims was compounded by the difficulties they faced regarding independent farming. Since the establishment of the plantation by PT LAJ in 2016, more and more elephants encroached the villagers' plots within and outside the concession area and even the village settlement. Although such incidents were common before, elephants cannot be driven back as easily anymore; they became more aggressive and destroyed especially young rubber and oil palm plantations in search of a feed.

Those young plantations inside the concession were finally given to the company since farmers could not afford to replant their plots more than once. They accepted the compensation payment and started working on their remaining plots outside the concession and eventually for the company.

Villagers hold the company responsible for this because parts of the elephants' habitat are destroyed by the establishment of the plantation. According to interview partners working for PT LAJ, the activities on the plantation currently consist of forest clearing.

\subsubsection{National Institutions}

In Jambi province, there is potential for sustainable rubber production by smallholders because $94 \%$ of the land is managed by independent smallholders ( $87 \%$ in Sumatra, respectively) (Directorate General of State Crops 2015). Nonetheless, there has not yet evolved a broad-scale initiative for sustainable rubber production; neither the local farmers aligned their cultivation practices to sustainability standards independently nor did governmental institutions or market mechanisms support this step. Significant regional or national level policies do not exist, though Kenney-Lazar et al. (2018, p. 112) found that "an active engagement on the part of the state in terms of planning and targeting commodity programs to improve sustainable intensification, supporting social capital for strong collective actions and grassroots institutions at the local level and providing incentives for environmentally friendly agricultural practices, is crucial to the successful development and adoption of certification".

On the contrary, in Jambi, the institutional environment deters the engagement of smallholders since market-induced price incentives like premiums are ruled out through oligopolistic value chains (Kennedy et al. 2016). Only nine processing factories purchase the produce of approximately 250,000 smallholder farmers (Kopp et al. 2014a, 2014b). Grassroots initiatives like farmer groups did 
form to counter these disadvantageous market conditions or to demand governmental support for environmentally friendly management.

\subsubsection{Interactions between PT LAJ and the Local Community}

PT LAJ initiated training for village farmers on best management practices in rubber monocultures. According to one participant, the main objective was to improve smallholder's productivity, proving good on farmers' plots as well as on the company's plantation. However, the training did not focus on ecological aspects but plantation establishment and harvesting techniques improving yields. Such training will not be repeated on a regular basis. The company counts on knowledge sharing between the participants and other village farmers. A rubber farmer who participated in the training said that he learned a lot and applies his new tapping skills now on his own plots. He wished he would have gained this knowledge long before. However, this farmer stated that other participants do not apply their new skills or even share their knowledge with others.

Further, there are plans for a partnership scheme between PT LAJ and local farmers, but information remains vague. It is uncertain when the plans of such collaboration will be addressed, but data strongly suggests that they will be realized only once the company's core plantation will be fully established. So far, PT LAJ has acquired approximately two-thirds of the concession designated for the rubber monoculture; they are in the process of planting trees there, and it might take another two to three years until the first rubber trees will produce sap. Therefore, positive feedbacks cannot be assessed, but knowledge transfer might increase farmers' productivity and thus their economic situation.

None of the villagers is aware of the fact that the company's rubber plantation will produce 'eco-friendly' rubber. Only a few interviewees knew that PT LAJ is somehow cooperating with the French tire producer Michelin and the World Wide Fund for Nature (WWF).

\section{Discussion and Conclusions}

Multi-stakeholder sustainability initiatives, here regarded as climate government instruments, impact smallholders' land use practices. They introduce new actors and new sets of regulations to social-ecological smallholder landscapes. The intention of the multi-stakeholder initiatives addressed in this article, namely RSPO for oil palm and the SNR-i for rubber, is a socially and ecologically more sustainable way of production. We have claimed and proven that we can assess the sustainability potential of these two initiatives by applying the smallholder telecoupling framework. This approach seems particularly suitable as it helps to reveal unintended or second-order effects at a distance to the places where the triggers were kicked off.

Both cases disclose that the multi-stakeholder initiatives have brought new actors to the scene. In the case of rubber certification, Michelin and the WWF have entered the smallholder ecological-system. In the RSPO case, it was the Indonesian NGO to deliver the new legal and practical instrument to the smallholders. In both sites, previous land controls are challenged whereby so far it was enough to go with a local level recognized title deed. With the emergence of the new actors and the regulations, the control of the land was altered. At least in the SNR-i case, according to Peluso and Lund (2011), this leads to new dependencies, hence new hegemonies and indicators for arising new frontiers. They further argue that agrarian landscapes have been transformed by various processes, including protected area expansion amongst others. Our cases show that a sustainablization of these landscapes also alter forms of land control. These alterations, especially in the rubber case, are accompanied by a decline in the agency and an increased vulnerability. The worsening livelihood situation of the smallholder is an unintended spillover effect of sustainability certification.

Regarding environmental benefits, our RSPO data is not exhaustive enough to draw a comprehensive picture. In combination with existing studies, we can, however, underline that RSPO certification does not seem to achieve large-scale conservation effects because of implementation and control challenges, as well as due to weak standards, in general. In some cases, it can contribute to reducing impacts on a small scale: for example, reduced usage of agrochemicals 
(Brandi 2017). The SNR-i case in comparison shows that there are, until now, no environmental benefits. On the contrary, deforesting an area, even if this area might 'only' be a secondary forest, cannot contribute to a sustainable production process. The RSPO, with its policy prohibiting deforestation after 2005, has acknowledged this aspect, but the SNR-i apparently not yet. Although Michelin gave a 'zero-deforestation' pledge in addition to the SNR-i guidelines (Michelin 2016), the pledge is weak, since it only considers primary forest for unrestricted protection. Further areas are only protected if identified as high-carbon stock (HCS) or with high conservation value (HCV) (ibid.). Therefore, the forested area within the concession will not be preserved. If this deforestation then negatively affects the Sumatran elephant as our case reveals, the term sustainability would not seem appropriate anymore. The decrease in habitat for the Sumatran elephant is again a second order effect of sustainability certification. According to the WWF, the Sumatran elephant is a critically endangered species. "The leading threat to Sumatran elephants is the loss of their habitat to an unending parade of chainsaws and bulldozers" (WWF 2019). If then the same WWF contributes to the destruction of this habitat under the umbrella of an eco-friendly model plantation for rubber monocultures, a perfidious peak has been reached. At the same time, the training provided to smallholders to not take environmental aspects into account. They are, according to what interview partners reported, a classic production intensification training.

The social benefits of the RSPO, according to Li (2015), have neither been sufficiently studied nor are they included in socio-economic analyses considering contributions to wealth and jobs. According to our data, the smallholder socially benefits from being organized in farmer groups in the context of RSPO certification. However, farmers could also be supported in setting up farmer groups without being certified. The benefits of increased knowledge exchange and increased bargaining powers would remain even without the RSPO. If farmers benefit economically cannot be answered with our data set, a tendency can be given though. Farmers name the input costs for certification as a challenge but not as the biggest hurdle. This can be traced back to the support they receive from the Indonesian NGO. If farmers had to cover the costs for certification themselves, this would exclude them from the system. At the same time, they do not gain price premiums through RSPO certification because it is expected that farmers are able to generate better yields due to improved management practices. This part has not been covered by our research though. It is quite obvious, at the same time, that the RSPO certification adds stress to the smallholders interviewed. They claim that they need to be certified as they can otherwise no longer access the market. This does not mirror the market reality, as China and India are large importers of palm oil and do not emphasize on certified palm oil (Hein and Kunz 2018). Again, the SNR-i polls off worse. Many farmers are in a replanting process. The decreasing habitat for elephants due to the so-called 'eco-friendly' plantation leads to an increase in human-elephant conflicts. Farmers reported that they had to replant several times after their young plants were destroyed by elephants. As the second order effects of the model plantation, the expenditures of smallholder increase. As savings are limited, they lose their independence and start working at the plantation of PT LAJ.

In the case of the Roundtable for Sustainable Palm Oil, it can be argued that the challenges lie in the implementation and control of the rather weak principles and criteria, two aspects reinforcing each other. Further, a discrepancy in the sustainability perception between consumer and producer can explain the limited success of the instrument. Farmers are striving for an increased income and hence an improved livelihood. This might work out on a long-term perspective. Smallholder often follows a shorter-term vision, though. In the case of the Sustainable Natural Rubber Initiative, it can be argued that contrary to the self-description of the Michelin Group, smallholders and their livelihoods are neglected. The creation of new jobs for the local communities in the course of the plantation establishment gives the impression they were unemployed beforehand. Furthermore, some farmers became landless through the large-scale enclosure and ended up as workers on the plantations of PT LAJ or other landowners, a case of primitive accumulation. Referring to an interviewee, the land 
compensations paid by PT LAJ are below district compensation standards; they are necessary but not a sufficient condition to build a new livelihood.

This analysis using the smallholder telecoupling framework has revealed second order spillover effects which would have remained hidden otherwise. We strongly urge the concept to take on a more critical perspective. Zimmerer et al. (2018) rather reveal positive spillover effects, such as "the interaction among smallholder producers can lead to the clustering of sustainability-enhancing land use" (ibid.: w.p.). By consciously adding the term conflictive spillovers to the analytical framework, a more comprehensive sustainability potential picture can be drawn.

Supplementary Materials: The supplementary material are available online at http:/ /www.mdpi.com/2076$0760 / 8 / 4 / 115 / s 1$, the supplementary material consist of the quantitative as well as qualitative questionnaires which were applied in different villages.

Author Contributions: Conceptualization, Y.K.; methodology, I.R.; K.M., F.O.; writing—original draft preparation, Y.K.; F.O. writing-review and editing, Y.K.; I.R.; K.M., F.O.; R.M.; H.F.; supervision, H.F.; funding acquisition, H.F.

Funding: This publication was funded by the Deutsche Forschungsgemeinschaft (DFG, German Research Foundation) - project number 192626868 - in the framework of the collaborative German-Indonesian research project CRC 990 (SFB): "EFForTS, Ecological and Socioeconomic Functions of Tropical Lowland Rainforest Transformation Systems (Sumatra, Indonesia).

Acknowledgments: Cartography by Chunyan Xu, Department of Human Geography, Georg-August-University of Goettingen, 37073 Göttingen, Germany, chunyan.xu@stud.uni-goettingen.de.

Conflicts of Interest: The authors declare no conflict of interest. 


\section{Appendix A. SAFA Smallholders Survey}

\section{Basic Information}

1. Name of assessor:

2. Assessing organization:

3. Date of assessment:

4. Name of person being interviewed:

5. Gender of the person being interviewed:
○ Female
- Male

6. Is this person the farm owner?
$\bigcirc \quad$ Yes
○ No

7. Name of the farm:

8. The village of the farm:

9. Country of the farm:

10. Does the interview take place on or close to the farm?
○ Yes
$\circ \quad$ No

11. If you do know the GPS coordinates of your farm, please type them here:

12. OR Collect the GPS coordinates of the interview (function in the app)

13. Phone number of interviewee:

14. E-Mail of interviewee (if any):

15. What are the main crops and products that you produce?

Main product 1: Main product 6:

Main product 2: Main product 7:

Main product 3: Main product 8:

Main product 4: Main product 9:

Main product 5: Main product 10:

16. Which best describes your level of commercialization? (check all that apply)
- I am a subsistence farmer
- I sell mostly to local markets/customers
- I am a fully commercialized farmer (sell goods mostly for export)
- I am a contract farmer (with a company or a public-private partnership)

17. Do you produce any livestock on your farm?

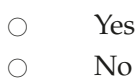

18. What is the size of the farm (local units and preferably, in hectares)? 


\section{Mission Explicitness}

1. Do you have a statement about the farm's goals and values that you follow and that everyone on your farm understands? [weight: 1]

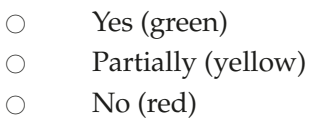

\section{Accountability}

2. Do you keep accurate records of your production processes (e.g., planting and harvesting information, input use) so they can be made available to producer organizations, customers or suppliers when required? [weight: 1]

$$
\begin{aligned}
& \text { Always or often (green) } \\
& \text { Sometimes (yellow) } \\
& \text { Never or rarely (red) }
\end{aligned}
$$

\section{Participation}

3. Do you belong to a producer organization (or another agriculturally focused organization)? [weight: 1]
a. Yes (green)
b. No (red)

4. How much value do you feel the farm receives from being a part of the organization? [weight: 1]
a. Significant value (green)
b. Some value (yellow)
c. Little or no value (red)

\section{Conflict Resolution}

5. How often have you been able to peacefully and successfully resolve any problems or conflicts that you have experienced with your suppliers, workers, producer organization or buyers? [weight: 1]

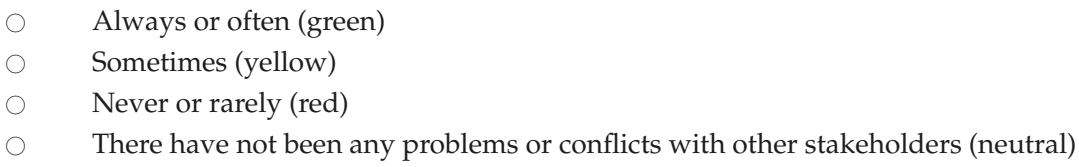

\section{Sustainability Management Plan}

6. Do you have a farm management plan that provides for the success of your production in the long run? [weight: 1]

$$
\begin{aligned}
& \text { Yes (green) } \\
& \text { No (red) }
\end{aligned}
$$

7. How successful has this plan been? [weight: 1]

Very successful (green) 
Somewhat successful (yellow)

Not at all or limited success (red)

8. Which elements are part of your plan? [weight: 1] (green for 3 choices or more, yellow for 2 choices, red for 1 choice or less)

$\begin{array}{lllll}\text { Finances } & \square & \text { Expansion/Staff } & \square & \text { Quality } \\ \text { Soil fertility management } & \square & \text { Health and Safety } & \square & \text { Processing or adding value } \\ \text { Environmental management } & \square & \text { Marketing } & \square & \text { Other }\end{array}$

Profitability

9. Do you produce crops, animals, or agricultural products for sale or trade? [weight: 2]

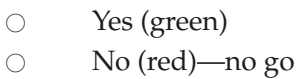

10. Do you know your farm revenue for the last production year? [weight: 2]

$\begin{array}{ll} & \text { Yes (green) } \\ & \text { No (red) }\end{array}$

11. Do you know your paid labor costs for the last production year? [weight: 1]

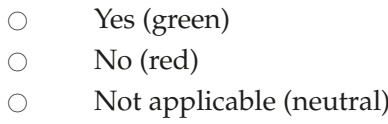

12. Do you know your fertilizer, pesticide, and seeds/plant material costs for the last production year? [weight: 1]

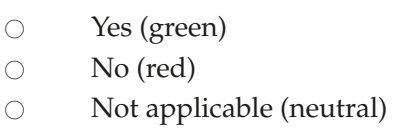

13. Do you know your animal feed, veterinary care, and juvenile stock costs for the last production year? [weight: 1]

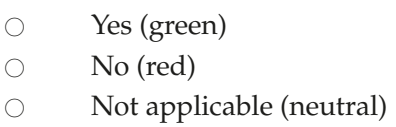

14. During the last five years, how often were farm revenues greater than costs? [weight: 1]

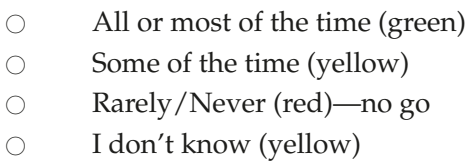

\section{Product Diversification}

15. How many significant crops, products, or services are offered for sale? [weight: 1]

Three or more significant crops, products, or services (green)

Two significant crops, products, or services (yellow) 


\section{One significant crop or product (red)}

16. Do you do any processing or value adding in order to increase revenue from services or the sale price of your crops or agricultural products (e.g., tourism, butchered meat, drying coffee or fruit, processing jam)? [weight: 1]

Yes (green)

No (yellow)

\section{Stability of Market}

17. How many buyers do you have for your significant crops or products? [weight: 1]

I usually have multiple people or places to sell my product(s) to (green)

I I usually have one or two people or places to sell my product(s) to (yellow)

I do not have a regular person or place to sell to (red)

18. How is your relationship with your most important buyer? [weight: 1]

Very reliable and consistent (green)

Somewhat reliable and consistent (yellow)

Unreliable (red)—no go

19. Do you feel that you have a choice in where to sell your products? [weight: 1]

$\quad$ Yes (green)
$\quad$ No (red)

Fair pricing and transparent contracts

20. Do you understand how buyer(s) calculate or establish prices paid? [weight: 1]
Always or often (green)
Sometimes (yellow)
Never or rarely (red)

21. What type of market information did you know during the last production year? [weight: 1] Check all that apply (any of the first three answers gets a green score for the question):

Prices paid by different buyers throughout the region for the same product

Price my buyer received for the product

Retail price of the product

None (red)

\section{Liquidity}

22. Check the sources from which you could realistically get a loan if you needed one: [weight: 1] (two or more of the first four answers is green, one is red)

Informal sources, such as friends, relatives, or religious groups

Banks, government lending institutions

Directly from buyers (exporter, importer, roaster, trader)

NGOs, cooperatives, farmer associations, or microfinance group

My only option would be to ask a loan shark (red)—no go 
23. If you requested a loan during the last year, how much did you receive compared to the amount that you requested? [weight: 1]

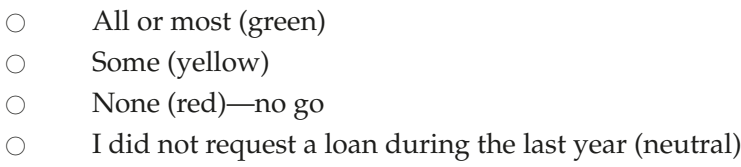

24. Have you set aside savings? [weight: 1]

$$
\begin{array}{ll}
\bigcirc & \text { Yes (green) } \\
& \text { No (red) }
\end{array}
$$

Safety Nets

25. Do you have crop-related insurance? [weight: 1]



26. Do you have a risk management plan that accounts for minimum costs or support in case of harvest loss (e.g., community supported schemes, agreements with cooperatives)? [weight: 1]

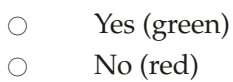

27. Have you implemented on-farm measures to reduce risk from variability in natural conditions and inputs (e.g., building a water tank)? [weight: 1]

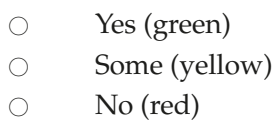

Food Quality

28. Do you take actions to maintain high-quality in your crops and products (e.g., hygienic processing, proper storing and packaging, grading)? [weight: 1]

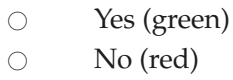

29. During the last two years, have you had a technical quality assessment of any of your main crops or products? [weight: 1]



\section{Certified Products}

30. Do you produce any crops, animals, or products that meet, or are certified, to a standard? [weight: 1]

$$
\begin{array}{ll}
\bigcirc & \text { Yes (green) } \\
& \text { No (yellow) }
\end{array}
$$


I had a certification, but it was rescinded/taken away (red)-no go

31. How much of your main products or crops are sold as certified? [weight: 1]

All or most (more than $80 \%$ ) (green)

Some (40-80\%) (yellow)

Not much or none (less than $40 \%$ ) (red)

Legitimacy

32. How do you ensure legal and regulatory compliance in general, including any standard, voluntarily entered into? [weight: 1]

(green for 2 choices, yellow for 1 choice, red no choice)

I use board agendas, other official records or notes of rights and compliances

I keep licenses and permits, if required by law

I regularly report on compliance to auditors

\section{GHG Mitigation Practices}

33. Which statement best describes the current area covered by trees on your farm? [weight: 1]

About half or more of my farm is covered by trees (green)

Less than half of my farm is covered by trees (yellow)

I do not have any trees on my farm (red)

34./35. During the last production year, was there any change to the number of trees on your farm? [weight: 1]

Increase (include planting new trees from cuttings or from seed) (green)

Decrease (removing focus crop trees, shade trees, natural forest trees, or other crop trees) (yellow)

No change (green)

36. What is your main tillage method? [weight: 1 for both GHG and Land]

Conventional (red)

Reduced (yellow)

No-till (green)

37. Does your farm consist mostly of ruminant production (e.g., cattle, goats, sheep)? [weight: 1]

Yes (red)

No (green)

38. What is the main type of manure management system used on the farm? [weight: 1]

Open-air lagoon or discharged into water bodies (red)

Compost or biodigestion (green)

Direct use (collected and spread on cropping area, left on pasture) (yellow) 


\section{Air Pollution Prevention Practices}

39. Do you use a smokeless fuel or chimney to vent smoke when cooking? [weight: 1]

$$
\begin{aligned}
& \text { Yes (green) } \\
& \text { No (red) }
\end{aligned}
$$

40. Do you ever burn your fields? [weight: 1 for both Air pollution and Species conservation]

$$
\begin{aligned}
& \text { Yes (red) } \\
& \text { No (green) }
\end{aligned}
$$

\section{Soil Improvement Practices}

41. What is the main type of fertilizer used on the farm? [weight: 1 for GHG and Soil]

Natural fertilizers applied according to crop and soil needs (green for GHG and Soil)

Natural fertilizers applied without knowledge of crop or soil needs (yellow for GHG and green for Soil)

A combination of natural and synthetic fertilizers (yellow for GHG and Soil)

Synthetic fertilizers applied according to crop and soil needs (yellow for GHG and Soil)

Synthetic fertilizers applied without knowledge of crop or soil needs (red for GHG and yellow for Soil)

None (green for GHG and red for Soil)

42. Which of the following are used to improve soil fertility on the farm? [weight: 1] two or more of the first four answers is green, one is yellow

Cover crops

Nitrogen fixing annual or perennial plants

Intercropping

Crop rotation for maintaining soil health

None (red)

\section{Nutrient Balance}

43. How do you determine how much fertilizer (synthetic or natural) to apply to your crop(s)? [weight: 1]

- We apply fertilizer based on a careful assessment of our soil and crops (including farmer observation, professional tests, or analyses) (green)

We apply fertilizer based on general advice for the region or for our crop(s) (yellow)

We are not able to fertilize (red)

We do not use enough fertilizer, but we apply as much as we can afford (yellow)

\section{Land Conservation and Rehabilitation Practices}

44. Which of the following are ways that you manage your soil? [weight: 1] (two or more of the first three answers are green, one is yellow)

Maintain a permanent soil cover through the mulch, planted soil cover, etc.

Terracing or contour planting on areas of significant slope

Hedgerows (e.g., trees and shrubs)

Soils are often bare between cropping cycles (red) 


\section{Hazardous Pesticides}

45. Do you use any synthetic (chemical) pesticides on your farm? [weight: 1 for Pesticides and Water pollution]

$\begin{array}{ll}\bigcirc & \text { Yes (red) } \\ & \text { Only occasionally (yellow) } \\ & \text { No (green) }\end{array}$

46. Do any of the synthetic pesticides used on your farm have a red band around the container or on the label? [weight: 1]

$$
\begin{array}{ll}
\bigcirc & \text { Yes (red)—no go } \\
\bigcirc & \text { No (neutral) }
\end{array}
$$

47. Do the pesticides used on your farm have labels that you understand? [weight: 1]

Yes, they all have labels with instructions on dosage, safety, etc., that I understand (green)

- Some do not have readable labels (or are unlabeled) (red)—no go

48. Do you ever mix pesticides? [weight: 1 ]

$$
\begin{array}{ll}
-\quad \text { Yes (red)—no go } \\
-\quad \text { No (green) }
\end{array}
$$

Ecosystem Diversity

49. Did you convert any natural land (prairie, forest, or savannah) to production land during the last five years? [weight: 2 for Ecosystem diversity and weight: 1 for Land]

Yes (red)

No, there is no natural land on the farm (neutral)

No, natural land on the farm was left as it is (green)

\section{Species Conservation Practices}

50. Do you have any of the following on your farm to preserve or restore natural species? [weight: 1] (two or more of the first three answers are green, one is yellow)

Permanent set-aside (land taken out of production to create a habitat for biodiversity)

Rehabilitated or restored natural areas

Hedgerows or buffer zones

None (red)

51. Check all of the pest and disease management practices used for the main crop(s) during the last production year: [weight: 1 for both Species conservation and Hazardous pesticides] (All four first choices should be marked for green, yellow if only some are marked)

Conduct regular visual examinations of plants to detect pests or disease

Use traps, repellents (including repellent species), and natural pesticides

Create or preserve places (including plant species) for beneficial predators of pests to live Maintain written record of pest infestation, treatments, and results

I use synthetic pesticides specific to the crop and/or pest at the proper dosage and timing (yellow) 
I apply synthetic pesticides preventatively (e.g., on a regular schedule regardless of whether a pest or disease threat currently exists) (red)

52. Which statement best describes the diversity of your farming system? [weight: 1]

I produce multiple (4+) types of crops and/or livestock in the same area (green)

I I produce 2-3 types of crops and/or livestock in the same area (yellow)

- The majority of my farm is used to produce a single crop or one type of livestock (red)

Saving Seeds and Breeds

53. For the main crops and livestock produced on the farm, do you use any locally adapted varieties of seeds or breeds? [weight: 2]

Yes (green)

No (red)

54. What is the main source of your seeds or breeds? [weight: 1]

Saved by the farmer, obtained from neighbors, or from a local seed bank (or breeding program for livestock) (green)

A combination of local and non-local sources (yellow)

- Completely reliant on external non-local sources (red)

Water Conservation Practices

55. Do you use water conservation practices on the farm? [weight: 1]

Yes (green)

No (red)

Sometimes (yellow)

56. Do you irrigate your crops? [weight: 1]

$\bigcirc \quad$ Yes (neutral)

- No (green)

57. What form of irrigation do you use? [weight: 1]

Manual irrigation (hand watering) (yellow)

Surface irrigation (red)

Drip irrigation (green)

Water Pollution Prevention Practices

58. Which of the following statements apply to your farm? [weight: 1]

The land I use for cultivating crops and / or for pasturing animals is directly next to natural waterways (red)

Pesticide application equipment is cleaned in natural water bodies (red)

Untreated domestic or processing water is discharged into natural water bodies (red)

None (green) 
Renewable and Recycled Materials

59. How do you manage crop residues, processing residues, and organic matter? [weight: 2]

Reused (e.g., through compost, as a soil cover, animal feed, biofuel, or other uses) (green)

Burned or discharged into waterways (red)

Left in piles or taken off farm (yellow)

60. Do you recycle or reuse metal, plastic containers or bags (with the exception of agrochemical containers), paper or cardboard? [weight: 1]

Yes (green)

No (red)

Not applicable (neutral)

Energy Use/Energy consumption/Renewable energy

61. If you use electricity, charcoal, wood, or fuel sources of energy, are you improving your efficiency? [weight: 1]

- I can demonstrate that I reduce energy use (e.g., through fuel-efficient stoves, solar drying, well-maintained machinery, switching from wood to gas) (green)

I I have made some efforts to reduce energy, but I have not applied them to most of my farm (yellow)

- I do not make any attempts to reduce energy (red)

62. If you used wood or charcoal for energy during the last production year, what was the main source? [weight: 1]

Purchased, I don't know (yellow)

Managed natural forest with limited extraction (green)

Unlimited forest use (red)

Managed plantations or planted woodlots (green)

Tree pruning (green)

Not applicable, I do not use wood or charcoal energy (neutral)

63. Do you use any of the following renewable energy sources for a significant portion of your energy needs? [weight: 1] (any green answer gets green for the indicator)

Solar (green)

Hydropower or geothermal (green)

Wind (green)

Biofuel from the farm or household waste (green)

None of the above (yellow)

Food Loss and Waste Reduction

64. Which of the following best describes your pre- and post-harvest losses (i.e., the amount of crop lost during production, storage, and transport) during the last production year? [weight: 1]

Minimal (less than 10\%) (green)

Some (10-30\%) (yellow)

Substantial (more than $30 \%$ ) (red) 
65. Do you take active steps to reduce pre- and post-harvest losses on your farm (through improving storage and transport methods, pest/disease management, harvesting at the appropriate time, etc.) [weight: 1]

- Yes (green)

- No (red)

Animal Health and Welfare

66. Do you have access to veterinary care for the livestock on your farm? [weight: 1]

I do not have access (red)

I have access, but it is problematic (unqualified personnel, too costly, too distant, or it is inhumane) (yellow)

- I have access to veterinary services that are of good quality, affordable, and nearby (green)

67. Which statement best describes the way livestock diseases are managed on the farm? [weight: 1]

$0 \quad$ I give animals medication routinely to prevent them from becoming sick (red)

- I follow my veterinarian or a local expert's recommendation for the treatment of diagnosed diseases (green)

- I do not consult professionals or experts about animal diseases (yellow)

I I do not provide my livestock with any veterinary care (red)

Legend

Single choice

Multiple choice 


\section{References}

Ahrends, Antje, Peter M. Hollingsworth, Alan D. Ziegler, Jefferson M. Fox, Huafang Chen, Yufang Su, and Jianchu $\mathrm{Xu}$. 2015. Current trends of rubber plantation expansion may threaten biodiversity and livelihoods. Global Environmental Change 34: 48-58. [CrossRef]

Azhar, Badrul, Norzanalia Saadun, Chong L. Puan, Norizah Kamarudin, Najjib Aziz, Siti Nurhidayu, and Joern Fischer. 2015. Promoting landscape heterogeneity to improve the biodiversity benefits of certified palm oil production: Evidence from Peninsular Malaysia. Global Ecology and Conservation 3: 553-61. [CrossRef]

Badan Pusat Statistik Jambi. 2015. Jambi Dalam Angka 2015; Jambi: Badan Pusat Statistik Jambi.

Badan Pusat Statistik Jambi. 2019. Luas, Penduduk, Tingkat Kepadatan, Rumah Tangga, Rata-rata Rumah Tangga, Kabupaten/Kota. 2000-2017. Available online: https://jambi.bps.go.id/dynamictable/2018/07/13/653/ luas-penduduk-tingkat-kepadatan-rumah-tangga-rata-rata-rumah-tangga-kabupaten-kota-2000-2017. html (accessed on 29 January 2019).

Barber, A. J., ed. 2005. Sumatra: Geology, Resources and Tectonic Evolution. Geological Society Memoirs 31. London: The Geological Society.

Beckert, Barbara. 2016. A Post-Frontier in Transformation: Land Relations between Access, Exclusion and Resistance in Jambi Province, Indonesia. Ph.D. thesis, University of Göttingen, Göttingen, Germany.

Brandi, Clara A. 2017. Sustainability Standards and Sustainable Development-Synergies and Trade-Offs of Transnational Governance. Sustainability Development 25: 25-34. [CrossRef]

Brandi, Clara, Tobia Cabani, Christoph Hosang, Sonja Schirmbeck, Lotte Westermann, and Hannah Wiese. 2015. Sustainability Standards for Palm Oil. The Journal of Environment \& Development 24: 292-314. [CrossRef]

Carlson, Kimberly M., Robert Heilmayr, Holly K. Gibbs, Praveen Noojipady, David N. Burns, Douglas C. Morton, Nathalie F. Walker, Gary D. Paoli, and Claire Kremen. 2018. Effect of Oil Palm Sustainability Certification on Deforestation and Fire in Indonesia. Proceedings of the National Academy of Sciences of the United States of America 115: 121-26. [CrossRef] [PubMed]

Chan, Sander, Robert Falkner, Matthew Goldberg, and Harro van Asselt. 2016. Effective and geographically balanced? An output-based assessment of non-state climate actions. Climate Policy 18: 24-35. [CrossRef]

Cheyns, Emmanuelle. 2011. Multi-stakeholder initiatives for sustainable agriculture: limits of the 'Inclusiveness' paradigm. In Governing through Standards: Origins, Drivers and Limitations. Edited by Ponte Stefano, Gibbon Peter and Vestergaard Jakob. Londres: Palgrave Macmillan, pp. 210-35.

Clay, Jason W. 2010. World Agriculture and the Environment: A Commodity-by-Commodity Guide to Impacts and Practices. Washington: Island Press.

Climate Initiative Platform. 2019. Search Initiatives. Available online: http:/ climateinitiativesplatform.org/index. php/Special:RunQuery/QueryData (accessed on 11 February 2019).

Cohn, Avery S., Peter Newton, Juliana D. B. Gil, Laura Kuhl, Leah Samberg, Vincent Ricciardi, Jessica R. Manly, and Sarah Northrop. 2017. Smallholder Agriculture and Climate Change. Annual Review of Environment and Resources 42: 347-75. [CrossRef]

Directorate General of State Crops. 2015. Tree Crop Estate Statistics of Indonesia 2015-2017 Rubber. Unpublished manuscript. Available online: http:/ / ditjenbun.pertanian.go.id/tinymcpuk/gambar/file/statistik/2017/ Karet-2015-2017.pdf (accessed on 6 February 2019).

Drescher, Jochen, Katja Rembold, Kara Allen, Philip Beckschäfer, Damayanti Buchori, Yann Clough, Heiko Faust, Anas M. Fauzi, Dodo Gunawan, Dietrich Hertel, and et al. 2016. Ecological and Socio-Economic Functions Across Tropical Land Use Systems After Rainforest Conversion. Philosophical Transactions of the Royal Society B: Biological Sciences 371: 20150275. [CrossRef] [PubMed]

Eakin, Hallie, Ruth DeFries, Suzi Kerr, Eric F. Lambin, Jianguo Liu, Peter J. Marcotullio, Peter Messerli, Anette Reenberg, Ximena Rueda, Simon R. Swaffield, and et al. 2014. Significance of Telecoupling for Exploration of Land-Use Change. In Rethinking Global Land Use in an Urban Era. Strüngmann Forum Reports. Edited by Karen C. Seto and Anette Reenberg. Cambridge: The MIT Press, pp. 141-61.

Ekandinata, Andree, and Grègoire Vincent. 2011. Rubber Agroforests in a changing landscape: Analysis of land use/cover trajectories in Bungo district, Indonesia. Forests, Trees and Livelihoods 20: 3-14. [CrossRef]

European Sustainable Plam Oil. 2019. Choosing Sustainable Palm Oil: Progress Report on the Import and Use of Sustainable Palm Oil in Europe. 
FAO. 2012. Smallholders and Family Farmers. Available online: http:/ / www.fao.org/fileadmin/templates/nr/ sustainability_pathways/docs/Factsheet_SMALLHOLDERS.pdf (accessed on 11 February 2019).

FAOSTAT. 2019. Available online: http://www.fao.org/faostat/en/\#data/QC (accessed on 18 February 2019).

Feintrenie, Laurène, and Patrice Levang. 2009. Sumatra's Rubber Agroforests: Advent, Rise and Fall of a Sustainable Cropping System. Small-Scale Forestry 8: 323-35. [CrossRef]

Fold, Niels, and Philip Hirsch. 2009. Re-thinking frontiers in Southeast Asia. Geographical Journal 175: 95-97. [CrossRef]

Friis, Cecilie, and Jonas $\varnothing$. Nielsen. 2017. Land-use change in a telecoupled world: The relevance and applicability of the telecoupling framework in the case of banana plantation expansion in Laos. EES 22: 30. [CrossRef]

Hall, Derek. 2011. Land grabs, land control, and Southeast Asian crop booms. The Journal of Peasant Studies 38: 837-57. [CrossRef]

Hein, Jonas, and Yvonne Kunz. 2018. Adapting in a carbon pool? Politicising climate change at Sumatra's oil palm frontier. In A Critical Approach to Climate Change Adaptation. Edited by S. Kleep and L. C. Rodríguez. Abingdon-on-Thames: Routledge.

Hidayat, Nia K., Astrid Offermans, and Pieter Glasbergen. 2018. Sustainable palm oil as a public responsibility? On the governance capacity of Indonesian Standard for Sustainable Palm Oil (ISPO). Agriculture and Human Values 35: 223-42. [CrossRef]

Hsu, Angel, Niklas Höhne, Takeshi Kuramochi, Mark Roelfsema, Amy Weinfurter, Yihao Xie, Katharina Lütkehermöller, Sander Chan, Jan Corfee-Morlot, Philip Drost, Pedro Faria, and et al. 2019. A research roadmap for quantifying non-state and subnational climate mitigation action. Nature Climate Change 9: 11-17. [CrossRef]

Indonesia Investments. 2017. Palm Oil. Available online: https:/ /www.indonesia-investments.com/business / commodities/palm-oil/item166? (accessed on 18 February 2019).

IPCC. 2014. Climate Change 2014: Synthesis Report. Contribution of Working Groups I, II and III to the Fifth Assessment Report of the Intergovernmental Panel on Climate Change. Geneva: IPCC.

Jagers, Sverker C., and Johannes Stripple. 2003. Climate Governance beyond the State. Global Governance 9: 385-99. [CrossRef]

Jelsma, Idsert, and George Christoffel Schoneveld. 2016. Towards More Sustainable and Productive Independent Oil Palm Smallholders in Indonesia: Insights from the Development of a Smallholder Typology. Bogor: Center for International Forestry Research (CIFOR).

Johnson, Sharon, Peter Lacy, Rob Hayward, Edd McLEan, and Angela Jhanji. 2014. The Consumer Study: From Marketing to Mattering: The UN Global Compact-Accenture CEO Study on Sustainability. UN Global Compact Reports. Available online: http:/ / www.fairtrade.travel/source/websites/fairtrade/documents / Accenture-Consumer-Study-Marketing-Mattering_2014.pdf (accessed on 11 February 2019).

Kapsar, Kelly, Ciara Hovis, Ramon Bicudo da Silva, Erin Buchholtz, Andrew Carlson, Yue Dou, Yueyue Du, Paul R. Furumo, Yingiie Li, Aurora Torres, and et al. 2019. Telecoupling Research: The First Five Years. Sustainability 11: 1033. [CrossRef]

Kennedy, Sean F., Beria Leimona, and Zhuang-Fang Yi. 2016. Making a green rubber stamp: Emerging dynamics of natural rubber eco-certification. International Journal of Biodiversity Science, Ecosystem Services \& Management 13: 100-15. [CrossRef]

Kenney-Lazar, Miles, Grace Wong, Himlal Baral, and Aaron J. M. Russell. 2018. Greening rubber? Political ecologies of plantation sustainability in Laos and Myanmar. Geoforum 92: 96-105. [CrossRef]

Kopp, Thomas, Zulkifli Alamsyah, Raja S. Fatricia, and Bernhard Brümmer. 2014a. Have Indonesian Rubber Processors Formed a Cartel? Analysis of Intertemporal Marketing Margin Manipulation. Ljubljana, Slovenia. August 26. Available online: http:/ /ageconsearch.umn.edu/bitstream/182675/2/Kopp-Have_Indonesian_ rubber_processors_formed_a_cartel_Analysis-142_a.pdf (accessed on 19 February 2019).

Kopp, Thomas, Zulkifli Alamsyah, Raja Sharah Fatricia, and Bernhard Brümmer. 2014b. Have Indonesian rubber processors formed a cartel?: Analysis of intertemporal marketing margin manipulation. 2014 International Congress. European Association of Agricultural Economists. Ljubljana, Slovenia. August 26. Available online: http:/ /ageconsearch.umn.edu/bitstream/182675/2/Kopp-Have_Indonesian_rubber_processors_ formed_a_cartel_Analysis-142_a.pdf (accessed on 19 February 2019).

Kunz, Yvonne, Jonas Hein, Rina Mardiana, and Heiko Faust. 2016. Mimicry of the Legal: Translating De Jure Land Formalization Processes into De Facto Local Action in Jambi Province, Sumatra. Journal of South-East Asian Studies 10: 47-64. 
Kunz, Yvonne, Stefanie Steinebach, Christoph Dittrich, Brigitta Hauser-Schäublin, Ir Rosyani, Endriatmo Soetarto, and Heiko Faust. 2017. 'The fridge in the forest': Historical trajectories of land tenure regulations fostering landscape transformation in Jambi Province, Sumatra, Indonesia.!Forest Policy and Economics 81: 1-9. [CrossRef]

Laumonier, Yves, Yumiko Uryu, Michael Stüwe, Arif Budiman, Budi Setiabudi, and Oki Hadian. 2010. Eco-floristic sectors and deforestation threats in Sumatra: Identifying new conservation area network priorities for ecosystem-based land use planning. Biodiversity and Conservation 19: 1153-74. [CrossRef]

Li, Tania Muurray. 2015. Social Impacts of oil Palm in Indonesia: A Gendered Perspective from West Kalimantan. Bogor: Center for International Forestry Research (CIFOR).

Liu, Jianguo. 2014. Forest Sustainability in China and Implications for a Telecoupled World. Asia and the Pacific Policy Studies 1: 230-50. [CrossRef]

Michelin. 2016. Sustainable Natural Rubber Policy: Reference Document 2016 Edition. Unpublished Work, Last Modified February 6, 2019. Available online: https://c402277.ssl.cf1.rackcdn.com/publications/ 1062/files/original/SUSTAINABLE_NATURAL_RUBBER_POLICY_VD.pdf?1495831479 (accessed on 11 February 2019).

Michelin. 2017. Sustainable Natural Rubber Policy: Reference Document 2017 Edition. Unpublished manuscript, last modified February 6, 2019. Available online: https:/ / purchasing.michelin.com/en/document-area/ (accessed on 11 February 2019).

Morgans, Courtney L., Erik Meijaard, Truly Santika, Elizabeth Law, Sugeng Budiharta, Marc Ancrenaz, and Kerrie A. Wilson. 2018. Evaluating the effectiveness of palm oil certification in delivering multiple sustainability objectives. Environmental Research Letters 13: 64032. [CrossRef]

Nagiah, Claudine, and Reza Azmi. 2012. A Review of Smallholder Oil Palm Production: Challenges and Opportunities for Enhancing Sustainability-A Malaysian Perspective. Journal of Oil Palm and the Environment 3: 114-20. [CrossRef]

Pacheco, Pablo, Sophia Gnych, Ahmad Dermawan, Heru Komarudin, and Beni Okarda. 2017. The Palm Oil Global Value Chain: Implications for Economic Growth and Social and Environmental Sustainability. Bogor: Center for International Forestry Research (CIFOR).

Peluso, Nancy L., and Christian Lund. 2011. New frontiers of land control: Introduction. The Journal of Peasant Studies 38: 667-81. [CrossRef]

Rasmussen, Mattias B., and Christian Lund. 2017. Reconfiguring Frontier Spaces: The territorialization of resource control. World Development 101: 388-99. [CrossRef]

Ribot, Jesse C., and Nancy L. Peluso. 2003. A Theory of Access. Rural Sociology 68: 153-81. [CrossRef]

Rival, Alain, Didier Montet, and Daniel Pioch. 2016. Certification, labelling and traceability of palm oil: Can we build confidence from trustworthy standards? OCL 23: D609. [CrossRef]

RSPO. 2010. National Interpretation RSPO Principles and Criteria for Sustainable Palm Oil Production: For Independent Smallholders Republic of Indonesia. Geneva: RSPO.

RSPO. 2018. Impact Report 2018. Geneva: RSPO, Available online: https://rspo.org/key-documents/impactreports (accessed on 11 February 2019).

RSPO. 2019. How we Are. Available online: https://www.rspo.org/about\#who-we-are (accessed on 25 February 2019).

RSPO, and HCSA. 2018. RSPO and HCSA Collaborate to Implement No Deforestation in High Forest Cover Landscapes. News Release. 2018. Available online: http://highcarbonstock.org/wp-content/uploads/ 2018/11/Joint-RSPO-HCSA-Statement-on-NDJSG-final-211118.pdf (accessed on 25 February 2019).

Ruysschaert, Denis, and Denis Salles. 2014. Towards global voluntary standards: Questioning the effectiveness in attaining conservation goals. Ecological Economics 107: 438-46. [CrossRef]

Schiffer, Eva, and Douglas Waale. 2008. Tracing Power and Influence in Networks: Net-Map as a Tool for Research and Strategic Network Planning. International Food Policy Research Institute (IFPRI), IFPRI discussion papers.

SNR-i. 2017. SNR-i Update-Q3 2017. Available online: http://www.snr-i.org/news_details.php?nid=73 (accessed on 25 February 2019).

Van der Ven, Hamish, Catherine Rothacker, and Benjamin Cashore. 2018. Do eco-labels prevent deforestation? Lessons from non-state market driven governance in the soy, palm oil, and cocoa sectors. Global Environmental Change 52: 141-51. [CrossRef] 
Vatn, Arild. 2015. Markets in environmental governance. From theory to practice. Ecological Economics 117: 225-33. [CrossRef]

Warren-Thomas, Eleanor, Paul M. Dolman, and David P. Edwards. 2015a. Increasing Demand for Natural Rubber Necessitates a Robust Sustainability Initiative to Mitigate Impacts on Tropical Biodiversity. Conservation Letters 8: 230-41. [CrossRef]

Warren-Thomas, Eleanor M., David P. Edwards, Daniel P. Bebber, Phourin Chhang, Alex N. Diment, Tom D. Evans, Frances H. Lambrick, James F. Maxwell, Menghor Nut, Hannah J. O'Kelly, and et al. 2018. Protecting Tropical Forests from the Rapid Expansion of Rubber Using Carbon Payments. Nature Communications 9: 911. [CrossRef]

Wicke, Birka. 2014. Palm Oil as a Case Study of Distal Land Connections. In Rethinking Global Land Use in an Urban Era. Strüngmann Forum Reports. Edited by Karen C. Seto and Anette Reenberg. Cambridge: The MIT Press, pp. 163-80.

WWF. 2016. WWF Statement on New Zero Deforestation Policy from Michelin. News Release. June 17. Available online: https:/ / www.worldwildlife.org/press-releases/wwf-statement-on-new-zero-deforestation-policyfrom-michelin (accessed on 19 February 2019).

WWF. 2019. Sumatran Elephant: Elephas Maximus Sumatrensis. Available online: https://www.wwf.or.id/en/ about_wwf/whatwedo/forest_species/species/sumatran_elephant/ (accessed on 26 February 2019).

Zimmerer, Karl S., Eric F. Lambin, and Steven J. Vanek. 2018. Smallholder telecoupling and potential sustainability. EES 23: 30. [CrossRef]

Zulu, Leo C. 2009. Politics of scale and community-based forest management in southern Malawi. Geoforum 40: 686-99. [CrossRef]

(C) 2019 by the authors. Licensee MDPI, Basel, Switzerland. This article is an open access article distributed under the terms and conditions of the Creative Commons Attribution (CC BY) license (http:/ / creativecommons.org/licenses/by/4.0/). 

Article

\title{
Understanding the Disaster-Migration-Violent Conflict Nexus in a Warming World: The Importance of International Policy Interventions
}

\author{
Michael Brzoska \\ Institute for Peace Research and Security Policy at the University of Hamburg, 22415 Hamburg, Germany; \\ brzoska@ifsh.de
}

Received: 4 March 2019; Accepted: 29 May 2019; Published: 31 May 2019

\begin{abstract}
The importance and extent of some of the linkages between disasters, migration and violent conflict are not very well understood. There has been controversy in the empirical analytical literature both over core elements of the nexus and over the mechanisms driving it. One reason for the current state of the pertinent literature is the widespread neglect of international policy interventions in the policy fields of disaster risk reduction, conflict prevention and peacebuilding, migration management as well as humanitarian and development assistance. This contribution highlights the importance of international interventions in these fields with respect to elements of the nexus. Based on a brief review of the comparative empirical evidence concerning the disputed links between disasters, migration and violent conflict it demonstrates how international policy interventions are affecting them. The study concludes with a call for more research into the ways in which international policy interventions contribute to shaping the disaster-migration-violent conflict nexus, arguing that a better understanding would enhance the potential for better policies to address its negative consequences.
\end{abstract}

Keywords: climate change; disasters; violent conflict; migration; disaster risk reduction; conflict prevention; humanitarian assistance; development assistance

\section{Introduction}

Among the many social consequences of climate change, migration and armed conflict continue to occupy a special place. The threat of "climate conflicts" and "climate refugees," as well as the causal links between them, are often listed among the most dire consequences of climate change (Wahlström and Lövin 2018; Gore 2019). Stressing the risks of armed conflict and migration linked to climate change in general, and climate- or weather-related disasters in particular, resonates with audiences who are less interested in ecological concerns and who are focused on other issues, such as national and societal security (Diez et al. 2016; Wallace and Silander 2018). The widespread concern about the links between climate change-related disasters, armed conflict and migration, also deepens the appreciation of the importance of widening the scope of potential policy instruments for dealing with negative consequences of climate change such as violent conflict and migration beyond mitigation and adaptation. Policy advocates, such as non-governmental organizations, national governments and international organizations, have shown awareness of the multiple policy dimensions that are relevant to links between climate change, disasters, violent conflict and migration. Indeed, they have motivated discussion of climate change in a number of policy fields beyond immediate climate change adaptation-related measures, including disaster risk reduction (DRR), conflict prevention, migration management and humanitarian and development assistance (Vivekananda et al. 2014; Mobjörk et al. 2016a, 2016b). While the actual implementation of policies addressing the listed consequences of climate change has been deemed inadequate, primarily from the perspective of deficits in developing synergies among policy fields (Rüttinger et al. 2015; Chen et al. 2017; Hore et al. 2018), 
there have been a host of activities put in place at local, regional, national and international levels. All those activities, which directly or indirectly affect the connections between disasters, armed conflict and migration, are summarily referred to as policy interventions in this contribution. For reasons explained below, the focus here is on policy interventions by international actors, such as international organizations and governments of countries not themselves victims of a particular disaster.

As will be shown in Section 2.2, the role of international policy interventions is not reflected in much of the empirical research directly investigating core elements of the climate change-migration-violent conflict nexus, contrary to what can be said about the policy debate. To put it even stronger: Much of the academic literature on the consequences of climate change for migration and violent conflict in general, and the climate change-migration-violent conflict nexus in particular (Buhaug 2015; Buhaug 2017; Koubi 2017), often neglects the importance of international policy interventions in the listed policy fields. This is true both for the researchers who find climate change to be a major driver of these phenomena and for those who remain cautious. On both sides of the debate, there is only limited recognition of the importance of international policy interventions addressing disasters, violent conflict and migration, contrary to the more frequent consideration of relevant national and local practices and policies (Theisen 2017; Sakaguchi et al. 2017). Much of the quantitative research only uses local or national structural variables, while qualitative research tends to be biased towards local and national social and political dynamics. In summary, much of the analysis occurs in a world marked by the absence of international policy interventions.

The core argument of this contribution is that an underestimation of the role and importance of international policy interventions limits the validity of empirical research on the contribution of climate change to the incidence of violent conflict and the extent of migration linked to it, contributing to the lack of consensus in the research field. It might also help to explain why current research on the consequences of climate change for violent conflict has been less clear than the analysis of temperature dynamics in historic periods in various regions (Zhang et al. 2007; Carleton et al. 2017; Zhang et al. 2015).

The objective of the following sections is to support this argument by focusing on one type of ecological consequence linked to climate change, namely that of extreme weather events leading to disasters, and their connection to violent conflict, as well as the role of large scale population movements, whether forced or voluntary, here summarily referred to as migration, in this context. This triangle of interconnected relations (Scheffran et al. 2012; Brzoska and Fröhlich 2016; Abel et al. 2019) is here conceptualized as the disaster-migration-violent conflict nexus, further explained in Section 2.1 below. The emphasis of this contribution is on climate- and weather-related disasters. However, as at least part of the literature does not distinguish between weather- or climate-related disasters on the one hand and other types of disasters, such as geophysical disasters, on the other (Eastin 2013; Brzoska 2018), and insofar as the consequences of disasters of all types are similar in important respects—such as a loss of assets and income, displacement and post-disaster assistance-the following discussion will not strictly limit itself to the former types of disasters.

The argument about the importance of international policy interventions does not imply that international actors have played or are playing a dominant role in shaping the disaster-migration-violent conflict nexus. However, as will be demonstrated below, ignoring international policy interventions leads to problematic conclusions. The first type of problem concerns research into the connections between disasters, violent conflict and migration. Ignoring international policy interventions has skewed past research results. A second issue related to the main argument addresses the possibility of shaping the future consequences of climate change for disasters, violent conflict and migration, for which detailed, empirically grounded knowledge about the effects and effectiveness of international policy interventions would be helpful. The following brief discussion of the disaster-migration-violent conflict nexus and the state of research of its contested elements indicates the prevailing lack of consideration of international policy interventions in much of the pertinent research. This is contrasted, in Section 3 , with developments in four relevant international policy fields. The subsequent section is devoted to showing how international policy interventions may shape selected mechanisms identified in the 
literature as driving interactions between disasters, migration and violent conflict. In the concluding section, possible future developments with respect to international policy interventions are discussed.

\section{Disasters, Violent Conflict, Migration and International Policy Interventions}

\subsection{The Disaster-Migration-Violent Conflict Nexus}

Disasters, violent conflict and migration reinforce each other to some extent with causal chains that can run in both directions (Table 1). However, some links in this nexus are stronger than others (Scheffran et al. 2012; Ide and Scheffran 2014; Ide et al. 2016; Schilling et al. 2017). Thus, disasters and violent conflict are clearly major causes of population displacement. Violent conflict, as well as migration, are factors that increase vulnerability to hazards, for instance when humanitarian assistance is withheld for security reasons, or when migrants settle in particularly risky environments (Harris et al. 2013; Siddiqi 2018).

Table 1. Linkages between weather- and climate-related disasters, violent conflict and migration.

\begin{tabular}{cccc}
\hline \multirow{2}{*}{ “Cause" } & Disasters & Consequences for & Migration \\
\cline { 2 - 4 } Disasters & $\mathrm{X}$ & $\begin{array}{c}\text { Limited and contradictory } \\
\text { evidence because of the } \\
\text { complexity of conflict } \\
\text { dynamics }\end{array}$ & $\begin{array}{c}\text { Major cause of migration, } \\
\text { but often local and short } \\
\text { term }\end{array}$ \\
\hline Violent conflict & $\begin{array}{c}\text { Generally strong effects } \\
\text { because of increased } \\
\text { vulnerability of affected; } \\
\text { obstacles to disaster risk } \\
\text { reduction }\end{array}$ & X & Major cause of migration \\
\hline Migration & $\begin{array}{c}\text { Dependent on the relationship } \\
\text { between migration and } \\
\text { vulnerability in origin and } \\
\text { host communities }\end{array}$ & $\begin{array}{c}\text { Limited and contradictory } \\
\text { evidence because of the } \\
\text { complexity of conflict } \\
\text { dynamics }\end{array}$ & \\
\hline & Note: Contested linkages in bold. & X \\
\hline
\end{tabular}

Note: Contested linkages in bold.

While disasters are the subject of a vast academic literature, their effects on violent conflict are not very well understood (Brzoska 2018). This is true both for the more conceptual level of differing assumptions about the consequences of disasters for individual and collective behavior and for the factors that shape such behavior. The same is true for the link between migration and violent conflict (Brzoska and Fröhlich 2016; Klepp 2017; Koubi et al. 2018).

In this section, I will first provide a brief review of the comparative empirical evidence in the controversial research on the links between disasters and violent conflict on the one hand and between migration and violent conflict on the other. This is followed by a discussion of conceptual thinking that explains the empirical evidence. It will first be shown that the role of international policy actions is widely ignored in the empirical literature, while conceptual thinking makes clear that international actors are likely to be of major importance for the disaster-migration-violent conflict nexus.

\subsection{Empirical Evidence on the Contested Elements of the Disaster-Migration-Violent Conflict Nexus}

Even though the majority of more recent work indicates the weak conflict-enhancing effects of both disasters and displacement on violent conflict in specific circumstances, the results remain contested (Buhaug 2015; Theisen 2017; Brzoska 2018). The following discussion first presents a number of important studies on the relationship between disasters and violent conflict before then bringing in disaster-related migration as a possible contributor to violent conflict.

A number of studies have established a strong and statistically significant relationship between disaster events and armed violence (Nel and Righarts 2008; Berrebi and Ostwald 2011). Two recent 
studies using careful statistical analysis have confirmed the link between extreme events and violent conflict-limited, however, to droughts and specific local situations—in which minority groups were excluded from political participation while being dependent on agriculture (Von Uexkull et al. 2016; Schleussner et al. 2016).

Another group of studies found no relation between disasters and violent conflict or even a reduction in the occurrence of violence. Salehyan and Hendrix (2014), for example, found that there was less political violence following droughts than in years with sufficient water availability and good harvests. However, in another paper with a different co-author, Hendrix has argued that communal conflicts tend to cluster in areas where land and water are scarce (Hendrix and Brinkman 2013). No increase in the onset of violent conflict was also found by Slettebak (2012) and Bergholt and Lujala (2012), who focused on economic growth as a prime consequence of disasters with relevance for violent conflict.

Skepticism towards the proposition that disasters generally increase the likelihood of violence also comes from those studying cooperation in the wake of such events (Akcinaroglu et al. 2011; Kelman 2012). An often-quoted case is the post-tsunami peace process in Aceh, Indonesia (Le Billon and Waizenegger 2007). Kelman (2012) has forcefully argued that in general, disasters have the capacity to enhance dynamic processes already under way, in the direction of both more and less conflict.

The number of quantitative or comparative studies on disaster-related migration and violent conflict as causal or at least incidental for armed conflict is small. An often-quoted study by Reuveny (2007), covering both slow-onset and disaster events, supports the assumption that extreme events will lead to more conflict in receiving communities via migration. However, because of a selection bias toward cases supporting his assumption, it is problematic to extend the result beyond the cases included in the analysis. Another important study found a statistically significant link between disaster-induced migration and violent conflict by investigating a global dataset of major floods over the period from 1985 to 2009 (Ghimire et al. 2015). However, while conflict intensity (measured by the involvement of a country in an armed conflict) was related to displacement in the wake of major floods, conflict onset was not. These results suggest that flood displacement increases the likelihood that armed conflicts will continue but not the likelihood of the onset of an armed conflict.

Raleigh et al. (2008), as well as Salehyan and Gleditsch (2006), find little evidence of a significant link between environmental migration and the onset of violent conflict. They argue that migrants generally have limited resources to organize violence. Brzoska and Fröhlich (2016) argue that short-term displacement is less likely to be linked to violence than permanent relocation, which puts stress on host communities when the prospects of temporary relocation are low.

In summary, the message of the empirical evidence on the plausibility of the disaster-migrationviolent conflict nexus is far from universal. Differing methodologies and solutions to methodological issues such as selection bias and endogeneity are a major cause of these differences, as are the differing time periods and locations included in the analysis (O'Loughlin et al. 2014; Buhaug 2015; Ide 2017; Brzoska 2018).

Furthermore, most studies are also marked by a lack of consideration of external interventions of the types mentioned above. With few exceptions, studies focus on the local and the national context. Indicators of state capacity or state fragility, for instance, are often incorporated into quantitative models and are also discussed in qualitative work (Theisen 2017; Sakaguchi et al. 2017). One good example is the sophisticated analysis by Nardulli et al. (2015). They explicitly take note of the potential of natural disasters-in their analysis, storms and floods-to instigate cooperation or conflict. They also, in addition to structural factors, attempt to model agency and process in violent behavior. Their independent variables are two measures of civil unrest. They find that the disasters in their sample are linked to higher mean levels of unrest. They empirically consider a variety of conditions and mechanisms but omit international policy interventions. A strong study by Omelicheva (2011), analyzing the effects of different types of natural disasters-droughts, earthquakes, floods, storms and others-on political instability also exclusively focuses on internal factors. Pre-existing, country-specific conditions, particularly the characteristics of the given political regime, dominate the effect of disasters 
on political instability. Qualitative case studies often mention international policy interventions in passing, but their emphasis is generally on local conflict dynamics (Van Baalen and Mobjörk 2018).

One example of research that explicitly considers international policy interventions is the thorough analysis of the consequences of disasters by Eastin $(2013,2016,2018)$. He stresses the importance of disputes over international humanitarian assistance for a number of cases, including the dispute over the sharing and dispensation of relief aid after the 2005 tsunami, which had an impact on the collapse of the peace process in Sri Lanka, as well as the dispute over the 1984-1985 decision by the Mengistu regime in Ethiopia to withhold food aid from rebel-controlled areas (Eastin 2013, p. 27). In general, he stresses both the levels and the transparency, inclusiveness and fairness of relief allocations for the formation of grievances leading to, or aggravating, violent conflict. However, in his formal models (Eastin 2016, 2018), he does not explicitly consider external policy interventions. Kikuta (2019) has investigated the crucial role of international assistance through shaping the incentives of armed groups in a recent study on the peace process in post-tsunami Sri Lanka. Another example of a study stressing international policy interventions is the study by Ghimire et al. (2015), who emphasize the current importance of international humanitarian assistance in most disaster management situations but do not include it as a factor in their quantitative analysis. The importance of international policy interventions, in this case in the form of international protection of certain types of migrants, also is stressed in the work on their perceptions on armed conflict by Koubi et al. (2018). It is also clearly visible in the recent research on environmental peacebuilding (Krampe 2017; Ide 2018).

This brief and selective literature review indicates both the widespread neglect of the role of international policy interventions in the pertinent academic literature as well as their importance where they are considered. To the extent international policy interventions influence the incidence as well as the consequences of disasters, migration and violent conflict, their neglect may lead to invalid conclusions about the disaster-migration-violent conflict nexus. To the degree that international policy interventions dampen or increase, in any case shape, the human, social, economic and political effects of disasters, their different formats and volumes might explain at least some of the differing and partially contradictory results of empirical investigations into the disaster-migration-violent conflict nexus. Considering international policy interventions may add more plausibility to models of the relationship between disasters, migration and violent conflict.

In order to further illustrate the role of international policy interventions, the next section is devoted to brief descriptions of development of conceptual thinking, policies and activities in four policy fields. Three of these directly concern the legs elements of the disaster-migration-violent conflict nexus. The fourth, humanitarian and development assistance has a broader scope. It also provides the overall financial framework in which the three other policy fields must fit.

The brief overview over developments in the four policy fields is followed by a more detailed discussion of contested links of the disaster-migration-violent conflict link. Again, the importance of international policy interventions is demonstrated through their potential to shape these links.

\section{International Policy Interventions Addressing Disasters, Violent Conflict and Migration}

\subsection{Disaster Risk Reduction}

Most types of disasters are likely to increase with climate change. In many ways, disasters already provide insights into the social consequences of climate change. Economic, social and political disruption, often seen as long-term effects of slow-onset climate change, are frequent features of weather-related disasters (Field et al. 2012).

While climate change has been an element in pushing disaster-related international policies and measures in recent years (Kelman et al. 2015, 2016), the policy field as such has been gaining importance over several decades (Paton and Johnston 2006; United Nations 2015a). A crucial feature has been the shift from a focus on post-disaster management towards the internationally dominant approach of disaster risk reduction (DRR). In addition to preventing or mitigating the consequences of disasters 
originating from geophysical, meteorological and climatic events, DRR also addresses the reduction of vulnerabilities of affected communities and their capacity to reconstruct, often under the slogan "build back better". Resilience has come to be the term of choice in DRR for bridging prevention, preparedness and a reduction of vulnerability with the preservation and restoration of basic structures and services in cases of disaster (Turnbull et al. 2013). Various recent policy statements and decisions put climate change at the forefront of international policy attention, including the Sendai Framework for Disaster Risk Reduction 2015-2030, adopted by the United Nations in 2015 (United Nations 2015a).

As part of the recent discussions and decisions in the DRR field, there has been an increased recognition of the importance of local and national actors. This has been accompanied by a shift in the funding of disaster-related activities. International financial institutions funding national activities have become increasingly important, e.g., through the Global Facility for Disaster Reduction and Recovery (GFDRR), a grant-funding mechanism managed by the World Bank. Increasing resilience with or without reference to disasters is also the objective of other international funding programs (United Nations 2019).

In terms of financial volumes, humanitarian assistance to alleviate immediate needs continues to dominate international disaster-related activities (see below). Humanitarian assistance largely focuses on large-scale disasters, even though there is recognition in the DRR policy field, to quote the Sendai Framework, that "[r]ecurring small-scale disasters and slow-onset disasters particularly affect communities, households and small and medium-sized enterprises, constituting a high percentage of all losses" (United Nations 2015a, p. 4). International post-disaster assistance, as part of development assistance, is also extensive, although it is rarely considered adequate, considering needs (Development Initiatives 2018).

The extent to which appeals for assistance issued by the United Nations (UN) and other organizations receive funding depends on a number of factors (Nelson 2012; Gard and Veitayaki 2017). While data on the funding of appeals (Table 2) indicates the degree of the shortfalls, it also suggests that the international community has invested substantial sums in addressing humanitarian assistance related to disasters.

Table 2. UN emergency assistance appeals and funding by disaster type, 2001-2017.

\begin{tabular}{cccc}
\hline \multicolumn{1}{c}{ Disaster Type } & Appeal in US\$ mn & Share of Appeal Funded \\
\hline Weather-related & & 7.005 & $56 \%$ \\
\hline & Drought & 1.296 & $49 \%$ \\
\hline & Storm/Flood & 5.691 & $58 \%$ \\
\hline Other & 18 & $19 \%$ \\
\hline Geo-physical & 4.191 & $75 \%$ \\
\hline Other & 2.330 & $69 \%$ \\
\hline All & 13.527 & $64 \%$ \\
\hline
\end{tabular}

Sources: UN OCHA Financial Tracking Service, UN-coordinated (Flash) Appeals.

The DRR policy field has had successes. While the number of disasters has continued to rise in the new century, the death toll, a frequent measure of their worst impact on humans, has not, according to the international disaster database EM-DAT ${ }^{1}$.

1 https://emdat.be/. 


\subsection{Conflict Prevention and Peacebuilding}

While for the DRR policy field the debate on the consequences of climate change has been an important driving factor for several years, climate change has only recently begun to play a motivating role in the wider peacebuilding field. However, with the number of violent conflicts increasing once again, following a period of fewer armed conflicts between the mid-1990s and late-2010s ${ }^{2}$, and with growing concern in the policy community about the importance of climate change for violent conflict, this has changed (United Nations and World Bank 2018).

Over the past decades, expanding international support for conflict prevention and peacebuilding has largely been driven by the assumption that peace could be established everywhere through a liberal agenda, first authoritatively developed in the UN Secretary General's Agenda for Peace (United Nations 1993). In addition to promoting individual rights, democracy and functioning states as foundations for peace, it also stressed the importance of international support in fostering and nourishing the road to peace and the prevention of violent conflict. In addition to typical instruments available to the UN, such as peacekeeping, organization, the monitoring of elections and the establishment of a legal order, it also emphasized the need for financial assistance (United Nations 2016).

Correspondingly, international support for conflict prevention and peacebuilding grew substantially after the end of the Cold War. One indicator of this is the extent of international peace missions. Not only have they been substantial in number, averaging 48 active missions per year since the early 2000s and more than 60 during the period from 2008 to $2017^{3}$, but they have become more comprehensive.

The record of international efforts to support conflict prevention and peacebuilding has been mixed. For a while in the late 1990s and early 2000s, success cases dominated. The number of armed conflicts dropped substantially. While a good part of this drop can be ascribed to the end of the systemic conflict between the East and West during the Cold War period, international policy measures such as peacekeeping and assistance with peacebuilding in post-conflict societies also contributed to this outcome (Human Security Report 2005; Doyle and Sambanis 2016).

Since then, the record has been less than impressive, with the number of violent conflicts growing again, not least because of the large number of persistent and recurring violent conflicts. Various explanations, ranging from a lack of support from the international community (particularly in the form of financial assistance) to the inappropriateness of the liberal peacebuilding model to local situations in many parts of the world have been proposed to explain the problems of international peacebuilding support (Turner and Kühn 2015). Despite these problems, international engagement in conflict prevention and peacebuilding is set to increase, including by international financial institutions such as the World Bank (United Nations and World Bank 2018).

\subsection{Migration Management}

The significance of disasters and conflict to migration has long been recognized (Klepp 2017). Distinctions between classes of migrants in migration management based on sharp legal differences continue to be important but have become more blurred when it comes to migrants fleeing conflict and disaster (UNDP 2009).

For many years, international organizations such as the United Nations High Commissioner for Refugees (UNHCR) and the International Organization for Migration (IOM) have supported millions of people who have left their homes. The volumes of financial support are large—about US $\$ 8.3$ billion in 2018 (UNHCR 2017) - but insufficient in view of the great number of displaced persons, which reached more than 68 million in late 2018, according to the $\mathrm{UNHCR}^{4}$.

According to data from the Uppsala Conflict Data Program, https://ucdp.uu.se/.

Data according to SIPRI Multilateral Peace Operations Database, https://www.sipri.org/databases/pko.

https://www.unhcr.org/figures-at-a-glance.html. 
With the growing number of displaced persons and refugees, migration management has undergone several changes (Hyndman 2000; Klepp 2017; Nash 2018). It is generally recognized that a broader perspective is needed. Rather than viewing migrants as temporary victims of misfortune, attempts to focus on improving their livelihoods, either in the host location or in the location of origin, are favored by the international community (Foresight 2011; Nash 2018). The discourse on the social consequences of climate change has contributed to changes in migration management. Climate change is likely to produce further migration, but migration is also a coping strategy, which, at least in some cases, can reduce the consequences of climate change, particularly in regions of origin (Foresight 2011; Kumari-Rigaud et al. 2018).

Another development has been the growing resistance, particularly among several governments in the Global North against most types of international migration. The European Union, for instance, spends substantially more money on the improvement of border control than other forms of migration-related policies (Darvas et al. 2018).

\subsection{Humanitarian and Development Assistance}

Funding levels, modes and priorities continue to loom large in the three policy fields mentioned above. Both humanitarian assistance focused on the immediate needs of persons in crisis and development assistance aimed at improving people's longer-term prospects go far beyond DRR, peacebuilding and migration management.

Furthermore, many activities financed under humanitarian and development assistance without specific objectives related to disasters, migration or violent conflict are relevant to these policy fields. This is obviously so for poverty reduction programs, but also for other programs aimed at reducing people's vulnerability. Building resilience and reducing conflict risks have become major goals of development assistance as preconditions for meeting the Sustainable Development Goals (SDG; United Nations and World Bank 2018).

Both humanitarian and development assistance have grown substantially in financial terms over the past two decades (OECD 2019). Official Development Assistance (ODA) by OECD members doubled between 2000 and 2017, while humanitarian assistance more than quadrupled. Within development assistance, funding addressing conflict prevention and peacebuilding, and recently migration, has grown particularly fast.

Development (and less so humanitarian) assistance has long been criticized as a failure, and indeed, compared to the high-minded goals of international assistance, its achievements have fallen short (Easterly 2007). With this said, its achievements have been numerous. A recent example concerns the Millennium Development Goals (MDGs) established by the international community to be achieved by 2015. Extreme poverty, to take one example, has declined significantly over the last two decades, and the number of people living in extreme poverty fell from 1.9 billion in 1990 to 836 million in 2015, with most progress occurring since 2000 (United Nations 2015b). In Sub-Saharan Africa, the poorest world region, the number of people living in extreme poverty increased over this period, yet the percentage of extremely poor people in the total population decreased by about 15 percent. While the percentage drop fell far short of the MDG goal of halving extreme poverty, it represented a change from an earlier trend of increases (World Bank 2016).

\subsection{Complementarities and Synergies of International Policy Interventions}

The three policy fields of DRR, conflict prevention and migration management have had their own separate trajectories, both institutionally and with respect to project programming, even where there was clear overlap. Only recently has this become less pronounced. Climate change, has become an important common concern for conflict prevention and peacebuilding activities as well as development policy in general, and at the same time, migration and violent conflict are increasingly realized as undermining efforts to alleviate the economic and social consequences of climate change (Mobjörk et al. 2016b; 
Schilling et al. 2017; United Nations and World Bank 2018). Environmental peacebuilding explicitly aims to integrate environmental concerns with conflict prevention and peacebuilding (Ide 2018).

The lack of coordination of policy fields has been seen as a major factor limiting the effectiveness of international policy interventions on the disaster-migration-violent conflict nexus. As indicated above, shortcomings and contradictions are a frequent feature of international policy interventions in the various policy fields.

The above discussion also indicated, however, the extent and consequences of international policy interventions in the various policy fields have begun to shape the patterns of disaster-related migration and affected the incidence and severity of violent conflict. Even if synergies are less developed than seen as possible in the critical discussion of international policy interventions, it is unlikely that disasters, migration and violent conflict, and thereby also their interaction, have not been influenced by international policy interventions.

It is therefore critical to consider international policy interventions in research into the consequences of climate change. The following sections will discuss in further detail the ways in which international policy interventions can affect the disaster-migration-violent conflict nexus. Getting deeper into the disaster-migration-violent conflict nexus reveals a multitude of possible causal mechanisms linking the components, which often operate in combination with each other (Seter 2016; Mobjörk et al. 2016a; Brzoska 2018). A number of those repeatedly stressed in the relevant literature will be discussed in the following section, focusing on how they might be shaped by international policy interventions.

\section{Mechanisms of the Disaster-Migration-Violent Conflict Nexus and International Policy Interventions}

\subsection{Resource Scarcity and Competition}

Disasters destroy lives and assets. They reduce resource availability and income opportunities. There are short-term economic losses depending on the scale, type and location of the disaster (Kousky 2014). It is often assumed that destruction and scarcity lead to increased economic competition among people and social groups, creating conflict. The likelihood of violent conflict is said to grow with the level of resource scarcity as migration may increase scarcity at receiving locations. There is some evidence of a link between increased local competition over scarce resources and violence (Ghimire et al. 2015; Buhaug et al. 2015; Van Baalen and Mobjörk 2018), but this finding is not universal (Klomp and Bulte 2013; Couttenier and Soubeyran 2013). Violent conflict seems more likely where degrees of income loss and resource availability tend to differ among various potentially conflicting groups (Ide 2015; Brzoska 2018). The same problems of a lack, as well as of an unequal allocation and distribution, of resources are relevant to post-disaster recovery activities. Priorities need to be set, which will likely benefit certain groups over others, fueling conflict.

Humanitarian assistance in immediate disaster situations and development assistance in post-disaster recovery, discussed in Section 3.4, have been the primary international policy measures for alleviating resource scarcity and competition. However, DRR (Section 3.1), and to a lesser extent conflict prevention measures (Section 3.2), have also contributed by reducing risks and vulnerability and by strengthening local resilience (Table 3 ).

At least in some cases, humanitarian and post-disaster assistance has led to increases in resource availability to all relevant groups, not only those immediately affected (Bernath 2016). While situations differ, Mabiso et al. (2014) have argued, on the basis of health statistics, that post-disaster situations are generally not marked by resource scarcity, both for disaster victims and for host communities, but even in situations where destruction and income loss outweigh international humanitarian assistance, the provision of goods and services can alleviate resource scarcity and reduce hostility among various groups, including migrant and host communities. The economics of refugee inflows are complex, generally producing both winners and losers in host communities. However, humanitarian agencies also increasingly realize that they may need to support host communities directly, for instance through local demand for goods and services (Rodella-Boitreaud and Wagner 2011). 
Table 3. International policy interventions and mechanisms in the disaster-migration-violent conflict nexus.

\begin{tabular}{ccccc}
\hline & $\begin{array}{c}\text { Disaster Risk } \\
\text { Reduction }\end{array}$ & $\begin{array}{c}\text { Conflict Prevention } \\
\text { And Peacebuilding }\end{array}$ & $\begin{array}{c}\text { Migration } \\
\text { Management }\end{array}$ & $\begin{array}{c}\text { Development and } \\
\text { Humanitarian } \\
\text { Assistance }\end{array}$ \\
\hline $\begin{array}{c}\text { Resource scarcity } \\
\text { and competition }\end{array}$ & $\begin{array}{c}\text { Strengthening of } \\
\text { resilience, reduction } \\
\text { of risks and } \\
\text { vulnerabilities }\end{array}$ & $\begin{array}{c}\text { Integrated approaches } \\
\text { to conflict prevention } \\
\text { and peacebuilding }\end{array}$ & $\begin{array}{c}\text { Inclusive allocation } \\
\text { of resources }\end{array}$ & $\begin{array}{c}\text { Alleviation of } \\
\text { resource scarcity }\end{array}$ \\
\hline $\begin{array}{c}\text { Perceptions of } \\
\text { justice and trust } \\
\text { building }\end{array}$ & $\begin{array}{c}\text { Ethnic sensitivity and } \\
\text { inclusivity }\end{array}$ & Conflict management & $\begin{array}{c}\text { Ethnic sensitivity } \\
\text { and inclusivity }\end{array}$ & $\begin{array}{c}\text { Inclusivity, in- } \\
\text { and post-disaster }\end{array}$ \\
\hline $\begin{array}{c}\text { Changes in } \\
\text { balance of forces }\end{array}$ & Conflict sensitivity & $\begin{array}{c}\text { Supplies of military } \\
\text { goods, peacekeeping, } \\
\text { military interventions }\end{array}$ & $\begin{array}{c}\text { Type of migration } \\
\text { management }\end{array}$ & $\begin{array}{c}\text { Type and form of } \\
\text { delivery of } \\
\text { assistance }\end{array}$ \\
\hline $\begin{array}{c}\text { Migration } \\
\text { patterns }\end{array}$ & Strengthening of \\
resilience & $\begin{array}{c}\text { Conflict management, } \\
\text { reconciliation } \\
\text { measures }\end{array}$ & $\begin{array}{c}\text { Intensity and type } \\
\text { of migration } \\
\text { management }\end{array}$ & $\begin{array}{c}\text { Location of in- and } \\
\text { post-disaster } \\
\text { support }\end{array}$ \\
\hline
\end{tabular}

Note: Potential major effects in bold.

Humanitarian assistance is not available in all situations. It is particularly difficult to provide humanitarian assistance in war situations (Kostner and Meutia 2011; Harris et al. 2013; Vivekananda et al. 2014). In their analysis of post-disaster shortages, Mabiso et al. (2014) found that there is a difference between situations of violent conflict and situations outside of violent conflicts. The data on UN appeals reported in Table 4 indicates that there is less international responsiveness to emergencies in countries where violent conflict exists than in those without violent conflict.

Table 4. UN emergency assistance appeals and funding, countries with and without armed conflict, 2001-2017.

\begin{tabular}{ccc}
\hline Countries & Appeal in Mio US\$ & Share of Appeal Funded \\
\hline With armed conflict & 5.742 & $58 \%$ \\
\hline Without armed conflict & 7.785 & $68 \%$ \\
\hline All & 13.527 & $64 \%$
\end{tabular}

Sources: UCDP/PRIO Armed Conflict Dataset version 18.1; UN OCHA Financial Tracking Service, UN-coordinated (Flash) Appeals.

\subsection{Perceptions of Injustice and Trust Building}

Objectively measured changes in resource availability both in absolute terms and by group is often viewed as a relevant factor in the initiation, escalation and de-escalation of collective violence. However, behavior may be more shaped by perceptions, for instance related to relative disaster losses, and by the delivery of post-disaster assistance than by actual availability (Nardulli et al. 2015). Grievances, often with a long history of exclusion and along ethnic lines, are difficult to measure directly; however, a long tradition of sociological disaster research indicates that pre-disaster perceptions are fundamental and can make disasters "windows of opportunity" for both alleviating conflict and aggravating it (Drabek 1986; Skidmore and Toya 2014; Calo-Blanco et al. 2017). Sociologists and psychologists studying disasters in the past have diagnosed that compassion among and toward victims tends to drive social relations. Thus, instead of assuming that disasters will divide societies, some authors have argued that they can lead to more solidarity among people and greater social cohesion. Resource scarcity during and immediately following disasters, in this view, is a driver for cooperation, which has the potential to lower existing levels of conflict (Kelman 2012; Walch 2014).

Beyond affecting local inter-group conflict, disasters are also important for the perception of institutions and institutional actors, particularly governments. Well-handled disaster relief can boost 
government legitimacy and reduce the incentive to use violence, both locally and in the form of armed conflict (Tierney 2007). On the other hand, the perception of insufficient, bad or corrupt assistance may aggravate local conflict.

The same is true for international humanitarian and development assistance. For international humanitarian and development actors, neutrality towards affected groups and conflict-sensitivity are core principles. In practice, however, it is often difficult to remain neutral, for instance when local governments restrict these agents' actions or when local power groups exploit them.

\subsection{Changes in the Balance of Forces}

Disasters, at least in some cases, affect the capabilities of collective actors who are potentially or already exerting violence (Eastin 2013; Walch 2016, 2018). Several mechanisms are relevant. One is the weakening of governments to control populations and potential insurgents because they need to divert resources to alleviate the consequences of disasters. It is often argued that governments lose assets in disasters and need to reduce funding for police and military forces. Breakdowns of public security are quite frequent. However, there is also evidence that levels of repression by governments are increasing following disasters (Nardulli et al. 2015; Wood and Wright 2015). Furthermore, disaster assistance delivered by military forces may allow governments to gather intelligence and gain local support. Disasters may also specifically affect the capabilities of rebel groups. They can make it easier for aspiring or active rebel groups to recruit followers, particularly when governments are perceived as providing insufficient or biased support, while reducing their resources for waging violence (Salehyan and Hendrix 2014; Walch 2014, 2018; Van Baalen and Mobjörk 2018). In cases where disasters weaken both sides, they can make violent conflicts ripe for resolution. Kreutz (2012) found that disasters increase the likelihood that parties will agree to a ceasefire. The effect is less pronounced for peace agreements.

Conflict prevention and peacebuilding interventions by international actors directly aim to lower the chances that local conflicts will escalate to violence. As indicated above, they can take many forms, from activities by non-governmental organizations to robust peacekeeping.

Humanitarian and post-disaster assistance, on the other hand, may offer rebels the chance to appropriate external resources for their purposes, as has been shown to be the case for humanitarian and development aid (Uvin 1999; Wood and Sullivan 2015; Zürcher 2017).

\subsection{Migration Patterns}

The crucial factor shaping the importance of migration in the disaster-migration-violent conflict nexus seems to be the inter-group conflict in receiving regions (Klepp 2017; Koubi et al. 2018). If migrants are predominantly from the same ethnic and social groups as those in the host community, migration will be less likely to instigate or increase violent conflict than in cases where host and migrant groups have been in conflict (Salehyan and Gleditsch 2006; Raleigh et al. 2008; Barnett and Webber 2010). The solidarity effect, which can often be found in disaster situations, is likely to be weaker and cooperation more difficult to organize when there are already conflicts between migrant and host community populations prior to the population movement.

Migration management (Section 3.3) and humanitarian assistance can help to increase levels of solidarity with migrants, but their more important effect seems to be the reduction of the possible negative consequences of migration on resource scarcity in host communities. An important issue in this context is that of refugee camps. UNHCR recently estimated that about $40 \%$ of all refugees reside in camps (UNHCR 2014). While there is a growing tendency to view camps as problematic (Verdirame and Pobjoy 2013), camps have advantages that may reduce the conflict potential of migration. Refugees who live in camps are less likely to compete for limited economic opportunities and scarce resources, such as water and land. In many situations, camps are also the quickest and most economical way of providing protection and life-saving assistance in the event of a large-scale refugee influx. However, camps also limit opportunities for migrants, which reduces the possibility of their contributing to 
economic activities in the receiving regions (UNHCR 2014). Furthermore, they may facilitate violence by making it easier for militant groups to recruit followers (Wood and Sullivan 2015). Activities to prevent or channel migration through border management, as currently favored by governments in several governments in the Global North (Section 3.3) may have similar effects on violence by stimulating discontent and easing recruitment for armed groups.

Another important issue related to migration is the return of displaced persons to their pre-disaster locations (Arai 2012). Post-disaster recovery will be affected both by the return of displaced persons to their home locations and by immediate post-disaster migration. Humanitarian organizations have been caught in many cases in the dilemma between providing support to needy people and remaining neutral in conflict situations (Hammond 2015).

Again, it seems that humanitarian assistance, here in the form of migration management, has the potential to enhance the differences between disasters, which happen in situations of open, violent conflict and situations where relations are basically peaceful. Although humanitarian assistance may help warring parties to maintain their activities, it may have a pacifying effect outside of such situations (Wood and Sullivan 2015).

\section{Conclusions}

International policy interventions have not received much attention in the research into the links between disasters, migration and violent conflict. The focus has primarily been on local conditions shaping this nexus. However, as is shown in discussing the pertinent policy fields of disaster risk reduction, conflict prevention and peacebuilding, migration as well as humanitarian and development assistance, such interventions are extensive. More recent work, for instance on peacebuilding, has been more attentive, but has yet to extend to the core elements of the nexus. The scope and effectiveness of international policy interventions will depend on a number of conditions in the locations in which they are implemented, including their design and extent, but still they are likely to often shape the disaster-migration-violent conflict nexus, whether directly or indirectly.

This widespread deficit may contribute to the lack of consensus in empirical research on core elements of the nexus. For instance, the finding that disasters have no, or only a minor, effect on violent conflict, as well as on the links between migration and violent conflict, may be shaped by the mitigating effect of international policy interventions. On the other hand, international policy interventions, such as humanitarian assistance, may have provided a material basis for violent conflict.

The effects of international policy intervention are not uniform. On the one hand, through reducing the risk of disaster and disaster vulnerability, strengthening resilience, alleviating resource scarcity, improving trust in institutions and providing post-disaster assistance, international policy measures can reduce the likelihood that disasters will lead to violent conflict, directly or via migration, that migration in the wake of disasters will lead to violent conflict and that the existence of violent conflict will worsen the consequences of disasters.

However, at least in certain cases, international policy measures can have the effect of increasing the likelihood or intensity of violent conflict. This is likely to be the case where assistance related to disasters is perceived, by groups already in conflict with others or national governments, to be unfairly distributed, or where international assistance is exploited by one of the conflict parties to its own advantages.

In both cases, however, the consideration of international policy interventions adds to the understanding of the disaster-migration-violent conflict nexus and the mechanisms driving it. Recognition of the importance of international policy interventions might help to explain the differences in the outcomes of the relevant literature.

A better understanding of the role of international policy interventions is important for a better understanding of the conditions and mechanisms that shape the disaster-migration-violent conflict nexus. Improved knowledge about the ways in which international policy interventions shape the nexus under which conditions may help to improve our understanding of the nexus. 
More research on the effects of international policy interventions also has the potential to improve interventions in the policy fields that directly or indirectly affect the nexus.

The importance of international policy interventions to shape the consequences of climate change, including for disasters, migration and violent conflict, has increasingly been recognized in the policy world. A better understanding, based on empirical research, could help in devising more appropriate policies to address the negative consequences of climate change through international policy interventions. This is particularly relevant for the potential of synergies among relevant policy fields. The assessment of the type and scope of appropriate international policy interventions-for conflict prevention and management, the way in which assistance is provided to migrants, the forms of disaster risk reduction interventions as well as the allocation of humanitarian and development assistance, but particularly the interactions between these types of interventions would benefit from a better understanding of the conditions and mechanisms through which they affect the disaster-migration-violent conflict nexus.

The international community has set itself high goals with the Sustainable Development Goals (SDGs) for 2030 on all three legs of the disaster-migration-violent conflict nexus and has promised to muster additional resources to help achieve them. Deeper knowledge of the disaster-migration-violent conflict nexus, and particularly the way in which international policy interventions affect it, would be very useful for increasing the likelihood of achieving the SDGs linked to climate change, migration and violent conflict.

Funding: This research has received no external funding.

Acknowledgments: Data for Tables 1 and 2 was collected by Helge Martin. I am grateful for Stellenbosch University for hosting me during the time of writing of this article.

Conflicts of Interest: The author declares no conflict of interest.

\section{References}

Abel, Guy J., Michael Brottrager, Jesus Crespo Cuaresma, and Raya Muttarak. 2019. Climate, conflict and forced migration. Global Environmental Change 54: 239-49. [CrossRef]

Akcinaroglu, Seden, Jonathan M. DiCicco, and Elizabeth Radziszewski. 2011. Avalanches and Olive Branches: A Multimethod Analysis of Disasters and Peacemaking in Interstate Rivalries. Political Research Quarterly 64: 260-75. [CrossRef]

Arai, Tatsushi. 2012. Rebuilding Pakistan in the Aftermath of the Floods: Disaster Relief as Conflict Prevention. Journal of Peacebuilding and Development 7: 51-65. [CrossRef]

Barnett, Jon, and Michael Webber. 2010. Accommodating Migration to Promote Adaptation to Climate Change. Background Paper for the 2010 World Development Report. Washington, DC: World Bank.

Berrebi, Claude, and Jordan Ostwald. 2011. Earthquakes, Hurricanes and Terrorism: Do natural disasters incite terror? Public Choice 149: 383-403. [CrossRef]

Bergholt, Drago, and Päivi Lujala. 2012. Climate-related natural disasters, economic growth, and armed civil conflict. Journal of Peace Research 49: 147-62. [CrossRef]

Bernath, Andreas. 2016. Klimakatastrophen, Vertreibung und Gewalt: Eine Makro-Qualitative Untersuchung Sowie Eine Einzelfallstudie über den Zusammenhang von Umweltbedingten Bevölkerungsbewegungen und Gewaltsamen Konflikten. Ph.D. dissertation, University of Hamburg, Hamburg, Germany. Available online: http://ediss.sub.uni-hamburg.de/volltexte/2016/7823/pdf/Dissertation.pdf (accessed on 29 May 2019).

Brzoska, Michael. 2018. Weather Extremes, Disasters, and Collective Violence: Conditions, Mechanisms, and Disaster-Related Policies in Recent Research. Current Climate Change Reports 4: 320-29. [CrossRef]

Brzoska, Michael, and Christiane Fröhlich. 2016. Climate change, migration and violent conflict: Vulnerabilities, pathways and adaptation strategies. Migration and Development 5: 190-210. [CrossRef]

Buhaug, Halvard. 2015. Climate-Conflict Research: Some Reflections on the Way Forward. Wiley Interdisciplinary Review of Climate Change 6: 269-75. [CrossRef]

Buhaug, Halvard. 2017. Climate Change and Conflict: Taking Stock. Peace Economics, Peace Science and Public Policy 22: 331-38. [CrossRef] 
Buhaug, Halvard, Tor A. Benjaminsen, Espen Sjaastad, and Ole Magnus Theisen. 2015. Climate Variability, Food Production Shocks, and Violent Conflict in Sub-Saharan Africa. Environmental Research Letters 10: 125015. [CrossRef]

Calo-Blanco, Aitor, Jaromír Kováŕík, Friederike Mengel, and José Gabriel Romero. 2017. Natural disasters and indicators of social cohesion. PLoS ONE 12: e0176885. [CrossRef] [PubMed]

Carleton, W. Christopher, David Campbell, and Mark Collard. 2017. Increasing temperature exacerbated Classic Maya conflict over the long term. Quaternity Science Reviews 163: 209-18. [CrossRef]

Chen, Chen, Jessica Hellmann, Lea Berrang-Ford, Ian Noble, and Patrick Regan. 2017. A global assessment of adaptation investment from the perspectives of equity and efficiency. Mitigation and Adaptation Strategies for Global Change 23: 101-21. [CrossRef]

Couttenier, Mathieu, and Raphael Soubeyran. 2013. Drought and Civil War in Sub-Saharan Africa. Economic Journal 124: 201-44. [CrossRef]

Development Initiatives. 2018. Global Humanitarian Assistance Report 2018. Available online: www.devint.org (accessed on 29 May 2019).

Diez, Thomas, Franziskus von Lucke, and Zehra Wellmann. 2016. The Securitisation of Climate Change, Actors, Processes and Consequences. London: Routledge.

Doyle, Michael W., and Nicholas Sambanis. 2016. Making War and Building Peace United Nations Peace Operations. Princeton: Princeton University Press.

Drabek, Thomas E. 1986. Human System Responses to Disaster. An Inventory of Sociological Findings. New York: Springer. Easterly, William. 2007. Was Development Assistance a Mistake? American Economic Review 97: 328-32. [CrossRef]

Eastin, Joshua C. 2013. Violent Eruptions: Natural Disasters, War, and Peace. Ph.D. dissertation, University of Washington, Seattle, WC, USA. Available online: https://digital.lib.washington.edu/ (accessed on 29 May 2019).

Eastin, Joshua. 2016. Fuel to the Fire: Natural Disasters and the Duration of Civil Conflict. International Interactions 42: 322-49. [CrossRef]

Eastin, Joshua. 2018. Hell and high water: Precipitation shocks and conflict violence in the Philippines. Political Geography 63: 116-34. [CrossRef]

Foresight. 2011. Migration and Global Environmental Change; Final Project Report. London: The Government Office for Science.

Gard, A. Rowan, and Joeli Veitayaki. 2017. In the wake of Winston-Climate change, mobility and resiliency in Fiji. International Journal of Safety and Security Engineering 7: 157-68. [CrossRef]

Ghimire, Ramesh, Susana Ferreira, and Jeffrey H. Dorfman. 2015. Flood-Induced Displacement and Civil Conflict. World Development 66: 614-28. [CrossRef]

Gore, Al. 2019. Migrant Caravans Caused by Climate Change. Available online: https://www.newswars.com/algore-migrant-caravans-caused-by-climate-change/ (accessed on 29 May 2019).

Hammond, Laura. 2015. Neutrality and Impartiality. In Routledge Handbook of Humanitarian Action. Edited by Jenny H. Patterson and Roger MacGinty. London: Routledge, pp. 87-97.

Harris, Katie, David Keen, and Tom Mitchell. 2013. When Disasters and Conflicts Collide. London: Overseas Development Institute.

Hendrix, Cullen, and Henk-Jan Brinkman. 2013. Food Insecurity and Conflict Dynamics: Causal Linkages and Complex Feedbacks. Stability: International Journal of Security and Development 2. [CrossRef]

Hore, Katherine, Ilan Kelman, Jessica Mercer, and J. C. Gaillard, eds. 2018. Climate Change and Disasters. Handbook of Disaster Research. Cham: Springer, pp. 145-59.

Human Security Report. 2005. Oxford: Oxford University Press.

Hyndman, Jennifer. 2000. Managing Displacement: Refugees and the Politics of Humanitarianism. Minneapolis: University of Minnesota Press.

Ide, Tobias. 2015. Why Do Conflicts over Scarce Renewable Resources Turn Violent? A Qualitative Comparative Analysis. Global Environmental Change 33: 61-70. [CrossRef]

Ide, Tobias. 2017. Research Methods for Exploring the Links between Climate Change and Conflict. Wiley Interdisciplinary Review of Climate Change 8: 1-14. [CrossRef]

Ide, Tobias. 2018. The Impact of Environmental Cooperation on Peacemaking: Definitions, Mechanisms, and Empirical Evidence. International Studies Review. [CrossRef]

Ide, Tobias, P. Michael Link, Jürgen Scheffran, and Janpeter Schilling. 2016. The Climate-Conflict Nexus: Pathways, Regional Links and Case Studies. In Handbook on Sustainability Transition and Sustainable Peace. Edited by Hans Günter Brauch, Úrsula Oswald Spring, John Grin and Jürgen Scheffran. Dordrecht: Springer, pp. 285-304. 
Ide, Tobias, and Jürgen Scheffran. 2014. On Climate, Conflict and Cumulation: Suggestions for Integrative Cumulation of Knowledge in the Research on Climate Change and Violent Conflict. Global Change, Peace and Security 26: 263-79. [CrossRef]

Field, Christopher B., Vicente Barros, Thomas F. Stocker, and Qin Dahe, eds. 2012. Managing the Risks of Extreme Events and Disasters to Advance Climate Change Adaptation. Cambridge: Cambridge University Press.

Kelman, Ilan. 2012. Disaster Diplomacy: How Disasters Affect Peace and Conflict. Abingdon: Routledge.

Kelman, Ilan, Jean-Christophe Gaillard, and Jessica Mercer. 2015. Climate change's role in disaster risk reduction's future: Beyond vulnerability and resilience. International Journal of Disaster Risk Science 6: 21-27. [CrossRef]

Kelman, Ilan, J. C. Gaillard, James Lewis, and Jessica Mercer. 2016. Learning from the history of disaster vulnerability and resilience research and practice for climate change. Natural Hazards 82: 129-43. [CrossRef]

Kikuta, Kyosuke. 2019. Postdisaster Reconstruction as a Cause of Intrastate Violence: An Instrumental Variable Analysis with Application to the 2004 Tsunami in Sri Lanka. Journal of Conflict Resolution 63: 760-85. [CrossRef]

Klepp, Silja. 2017. Climate Change and Migration. In Oxford Research Encyclopaedia of Climate Science. Online.

Klomp, Jeroen, and Erwin Bulte. 2013. Climate change, weather shocks, and violent conflict: A critical look at the evidence. Agricultural Economics 44: 63-78. [CrossRef]

Kostner, Markus, and Rina Meutia. 2011. Considerations for Responding to Natural Disasters in Situations of Fragility and Conflict. Washington: World Bank.

Koubi, Vally. 2017. Climate change, the economy, and conflict. Current Climate Change Reports 3: 200-9. [CrossRef]

Koubi, Vally, Tobias Böhmelt, Gabriele Spilker, and Lena Schaffer. 2018. The Determinants of Environmental Migrants' Conflict Perception. International Organisation 72: 905-36. [CrossRef]

Kousky, Carolyn. 2014. Informing climate adaptation: A review of the economic costs of natural disasters. Energy Economics 46: 576-92. [CrossRef]

Krampe, Florian. 2017. Towards Sustainable Peace: A New Research Agenda for Post-Conflict Natural Resource Management. Global Environmental Politics 17: 1-8. [CrossRef]

Kreutz, Joakim. 2012. From Tremors to Talks: Do Natural Disasters Produce Ripe Moments for Resolving Separatist Conflicts? International Interactions 38: 482-502. [CrossRef]

Kumari-Rigaud, Kanta, Alex de Sherbinin, Bryan Jones, Jonas Bergmann, Viviane Clement, Kayly Ober, Jacob Schewe, Susana Adamo, Brent McCusker, Silke Heuser, and et al. 2018. Groundswell: Preparing for Internal Climate Migration. Washington, DC: The World Bank.

Le Billon, Philippe, and Arno Waizenegger. 2007. Peace in the wake of disaster? Secessionist conflicts and the 2004 Indian Ocean tsunami. Transactions of the Institute of British Geographers 32: 411-27. [CrossRef]

Mabiso, Athur, Jean-François Maystadt, Joachim Vandercasteelen, and Kalle Hirvonen. 2014. Refugees, Food Security and Resilience in Host Communities. Washington, DC: International Food Policy Research Institute.

Mobjörk, Malin, Maria-Therese Gustafsson, Hannes Sonnsjö, Sebastian van Baalen, Lisa Maria Dellmuth, and Niklas Bremberg. 2016a. Climate-Related Security Risks. Towards an Integrated Approach. Stockholm: SIPRI/Stockholm University/The Swedish Institute of International Affairs.

Mobjörk, Malin, Dan Smith, and Lukas Rüttinger. 2016b. Towards a Global Resilience Agenda. Action on Climate Fragility Risks. The Hague: Clingendael Institute; Berlin: Adelphi; Stockholm: SIPRI.

Nardulli, Peter F., Buddy Peyton, and Joseph Bajjalieh. 2015. Climate Change and Civil Unrest: The Impact of Rapid-onset Disasters. Journal of Conflict Resolution 59: 310-35. [CrossRef]

Nash, Sarah L. 2018. From Cancun to Paris: An Era of Policy Making on Climate Change and Migration. Global Policy 9: 53-63. [CrossRef]

Nel, Philip, and Marjolein Righarts. 2008. Natural Disasters and the Risk of Violent Civil Conflict. International Studies Quarterly 52: 159-18. [CrossRef]

Nelson, Travis. 2012. Determinants of disaster aid: Donor interest or recipient need? Global Change Peace and Security 14: 109-26. [CrossRef]

O'Loughlin, John, Andrew M. Linke, and Frank DW Witmer. 2014. Modeling and Data Choices Sway Conclusions about Climate-Conflict Links. Proceedings of the National Academy of Sciences of the United States 111: 2054-55. [CrossRef] [PubMed]

Organisation for Economic Co-operation and Development. 2019. Detailed aid statistics: Official bilateral commitments by sector. OECD International Development Statistics (database). [CrossRef]

Omelicheva, Mariya Y. 2011. Natural Disasters: Triggers of Political Instability? International Interactions 37: 441-65. [CrossRef] 
Paton, Douglas, and David Johnston, eds. 2006. Disaster Resilience: An Integrated Approach, 2nd ed. Springfield: Thomas Publisher.

Raleigh, Clionadh, Lisa Jordan, and Idean Salehyan. 2008. Assessing the Impact of Climate Change on Migration and Conflict. Working paper for Social Dimensions of Climate Change. Washington, DC: The World Bank.

Reuveny, Rafael. 2007. Climate change-induced migration and violent conflict. Political Geography 26: 656-73. [CrossRef]

Rodella-Boitreaud, Aude-Sophie, and Natascha Wagner. 2011. Natural Disaster, Conflict and Aid Allocation. Geneva: The Graduate Institute for International and Development Studies.

Rüttinger, Lukas, Dan Smith, Gerald Stang, Dennis Tänzler, and Janani Vivekananda. 2015. A New Climate for Peace: Taking Action on Climate Change and Fragility Risks. Berlin: Adelphi.

Sakaguchi, Kendra, Anil Varughese, and Graeme Auld. 2017. Climate Wars? A Systematic Review of Empirical Analyses on the Links between Climate Change and Violent Conflict. International Studies Review 19: 622-45. [CrossRef]

Salehyan, Idean, and Kristian Skrede Gleditsch. 2006. Refugees and the Spread of Civil War. International Organisation 60: 335-66. [CrossRef]

Salehyan, Idean, and Cullen S. Hendrix. 2014. Climate shocks and political violence. Global Environmental Change 28: 239-50. [CrossRef]

Scheffran, Jürgen, Michael Brzoska, Jasmin Kominek, P. Michael Link, and Janpeter Schilling. 2012. Climate Change and Violent Conflict. Science 336: 869-71. [CrossRef] [PubMed]

Schilling, Janpeter, Sarah Louise Nash, Tobias Ide, Jürgen Scheffran, Rebecca Froese, and Pina von Prondzinski. 2017. Resilience and Environmental Security: Towards Joint Application in Peacebuilding. Global Change, Peace and Security 29: 107-27. [CrossRef]

Schleussner, Carl-Friedrich, Jonathan F. Donges, Reik V. Donner, and Hans Joachim Schellnhuber. 2016. Armed-Conflict Risks Enhanced by Climate-Related Disasters in Ethnically Fractionalized Countries. Proceedings of the National Academy of Sciences of the United States 113: 9216-21. [CrossRef]

Seter, Hanne. 2016. Connecting climate variability and conflict: Implications for empirical testing. Political Geography 53: 1-9. [CrossRef]

Skidmore, Mark, and Hideki Toya. 2014. Do Natural Disasters Enhance Societal Trust? Kyklos 67: 255-79.

Siddiqi, Ayesha. 2018. Disasters in conflict areas: Finding the politics. Disasters 42: S161-S172. [CrossRef]

Slettebak, Rune T. 2012. Don't blame the weather! Climate-related natural disasters and civil conflict. Journal of Peace Research 49: 163-76. [CrossRef]

Theisen, Ole Magnus. 2017. Climate Chane and Violence. Insights from Political Science. Current Climate Change Reports 3: 210-21. [CrossRef]

Tierney, Kathleen J. 2007. From the Margins to the Mainstream? Disaster Research at the Crossroads. Annual Review of Sociology 33: 503-25. [CrossRef]

Turnbull, Marilise, Charlotte Sterrett, and Amy Hilleboe. 2013. Towards Resilience. A Guide to Disaster Risk Reduction and Climate Change Adaptation. Bourton: Emergency Capacity Building Project.

Turner, Mandy, and Florian P. Kühn. 2015. The Politics of International Intervention: The Tyranny of Peace. London: Routledge.

UNDP. 2009. Human Development Report 2009: Overcoming Barriers: Human Mobility and Development. New York: United Nations Development Program.

United Nations High Commissioner on Refugees. 2014. UNHCR Policy on Alternatives to Camps. Geneva: UNHCR.

United Nations High Commissioner for Refugees. 2017. Biennial Programme Budget 2018-19 of the Office of the United Nations High Commissioner for Refugees. United Nations Doc A/AC.96/1169. New York: UNHCR.

United Nations Secretary General. 1993. An Agenda for Peace. UN Doc A/47/277. New York: United Nations.

United Nations. 2015a. Sendai Framework for Disaster Risk Reduction 2015-2030. A/RES/69/283. New York: United Nations.

United Nations. 2015b. Millennium Development Goals Report 2015. New York: United Nations.

High-level Independent Panel on Peace Operations. 2016. Operations on Uniting Our Strengths for Peace: Politics, Partnership and People. New York: United Nations.

Inter-agency Task Force on Financing for Development. 2019. Financing for Sustainable Development Report 2019. New York: United Nations.

United Nations and World Bank. 2018. Pathways for Peace: Inclusive Approaches to Preventing Violent Conflict. Washington: World Bank.

Uvin, Peter. 1999. The Influence of Aid in Situations of Violent Conflict. Paris: OECD. 
Van Baalen, Sebastian, and Malin Mobjörk. 2018. Climate Change and Violent Conflict in East Africa: Integrating Qualitative and Quantitative Research to Probe the Mechanisms. International Studies Review 20: 547-75. [CrossRef]

Verdirame, Guglielmo, and Jaxon M. Pobjoy. 2013. The End of Refugee Camps? In The Ashgate Research Companion to Migration Law, Theory and Policy. Edited by Satvinder S. Juss. London: Routledge, pp. 471-90.

Vivekananda, Janani, Janpeter Schilling, and Dan Smith. 2014. Climate resilience in fragile and conflict-affected societies: Concepts and approaches. Development in Practice 24: 487-501. [CrossRef]

Von Uexkull, Nina, Mihai Croicu, Hanne Fjelde, and Halvard Buhaug. 2016. Civil conflict sensitivity to growing season drought. Proceedings of the National Academy of Sciences 113: 12391-96. [CrossRef] [PubMed]

Wahlström, Margot, and Isabella Lövin. 2018. Climate Change Impacts on Security-Now the UN Must Act. Available online: https://www.government.se/opinion-pieces/2018/07/climate-change-impacts-on-security--now-the-un-must-act/ (accessed on 29 May 2019).

Walch, Colin. 2014. Collaboration or obstruction? Rebel group behavior during natural disaster relief in the Philippines. Political Geography 43: 40-50. [CrossRef]

Walch, Colin. 2016. Conflict in the Eye of the Storm. Micro-dynamics of Natural Disasters, Cooperation and Armed Conflict. Ph.D. dissertation, Upsala University, Uppsala, Sweden. Available online: http://uu.diva-portal.org/smash/record.jsf?pid=div076\%307882366\&dswid=59 (accessed on 29 May 2019).

Walch, Colin. 2018. Weakened by the storm: Rebel group recruitment in the wake of natural disasters in the Philippines. Journal of Peace Research 55: 336-50. [CrossRef]

Wallace, Donald, and Daniel Silander. 2018. Climate Change, Policy and Security. State and Human Impacts. London: Routledge.

Wood, Reed M., and Christopher Sullivan. 2015. Doing Harm by Doing Good? The Negative Externalities of Humanitarian Aid Provision during Civil Conflict. Journal of Politics 77: 736-48. [CrossRef]

Wood, Reed M., and Thorin M. Wright. 2015. Responding to Catastrophe. Repression Dynamics Following Rapid-onset Natural Disasters. Journal of Conflict Resolution 60: 1446-72. [CrossRef]

World Bank. 2016. Poverty in a Rising Africa. Africa Poverty Report. Washington, DC: World Bank.

Zhang, David D., Peter Brecke, Harry F. Lee, Yuan-Qing He, and Jane Zhang. 2007. Global climate change, war, and population decline in recent human history. Proceedings of the National Academy of Sciences of the United States of America 104: 19214-19. [CrossRef]

Zhang, David D., Qing Pei, Harry F. Lee, Jane Zhang, Chun Qi Chang, Baosheng Li, Jinbao Li, and Xiaoyang Zhang. 2015. The pulse of imperial China: A quantitative analysis of long-term geopolitical and climatic cycles. Global Ecology and Biogeography 24: 87-96. [CrossRef]

Darvas, Zsolt, Guntram Wolff, Francesco Chiacchio, Konstantinos Efstathiou, and Inês Gonçalves Raposo. 2018. EU Funds for Migration, Asylum and Integration Policies. Study for the Directory General for Internal Policies Department. Brussels: European Parliament.

Zürcher, Christoph. 2017. What do we (not) know about Development Aid and Violence? A Systematic Review. World Development 98: 506-22. [CrossRef]

(C) 2019 by the author. Licensee MDPI, Basel, Switzerland. This article is an open access article distributed under the terms and conditions of the Creative Commons Attribution (CC BY) license (http://creativecommons.org/licenses/by/4.0/). 

Article

\title{
Keeping People in Place: Political Factors of (Im)mobility and Climate Change
}

\author{
Caroline Zickgraf \\ Department of Geography, Faculty of Sciences, The Hugo Observatory: Environment, Migration, Politics, \\ University of Liège, 4000 Liège, Belgium; caroline.zickgraf@uliege.be
}

Received: 1 May 2019; Accepted: 11 July 2019; Published: 29 July 2019

\begin{abstract}
While those 'trapped' or who choose to stay in areas affected by climate change represent a substantial policy issue, there only a small amount of empirical work specifically targeting such populations. The scant attention that is afforded to immobility often emphasizes financial constraints as factors driving (involuntary) immobility. As an essential part of the mobility spectrum, the complexity of immobility in crisis, including its political dimensions, warrants thorough investigation. In response to these gaps, this contribution locates environmental immobility within mobilities studies, its conceptual complexities, and, finally, illustrates the importance of political factors in shaping (im)mobilities. The findings are based on semi-structured interviews conducted in two developing countries experiencing the impacts of climate change. We delve into the socio-cultural and economic nature of (im)mobilities as they interact with political forces, specifically by exploring international bilateral agreements (Senegal) and a relocation program (Vietnam). In political spaces that are dominated by a desire to limit human mobility and (re)produce stasis, we challenge traditional dichotomies between mobile/immobile and sedentary/migration polices by underlining how policy interventions can simultaneously promote mobility and immobility, demonstrating complex co-existing mobilities. Keeping people in place can, in fact, mean allowing the very same people to move.
\end{abstract}

Keywords: immobility; climate change; environmental migration and mobility; trapped populations; migration governance; Senegal; Vietnam; planned relocation

\section{Introduction}

Traditionally, research on human mobility responding to climate change delineates three objects of study: migration, displacement, and planned relocation. Nestled within the burgeoning field, a small group of scholars have begun to elaborate its hidden facet: immobility (Black et al. 2013; Black and Collyer 2014). Until recently, it was assumed to be unproblematic: migration was the abnormal behavior worthy of our academic gaze and in need of explanation. Thus, people tended to focus on population movements rather than the lack of mobility, as objects of political and humanitarian concern, in keeping with the idea that migrants or displaced people were the victims of climate change, its human faces (Gemenne 2011). In recent years, however, scholarly attitudes towards immobility are shifting: actors are moving away from deterministic, sedentary biases that favor immobility a priori. Stimulated by the findings of the UK Foresight Report in 2011, terms like 'trapped populations' emerged, which acknowledge that those who do not move may in fact be amongst the most vulnerable to the impacts of climate change (Foresight 2011; Ayeb-Karlsson et al. 2018). Not all people have the same capabilities—or desires for that matter-to leave their homelands for 'greener pastures'.

Researchers of this less-understood facet of the environment-migration nexus make concerted efforts to understand why some people do not move in the face of climate change and environmental degradation, or how population movements that do occur may be limited in temporal or spatial 
scope, e.g., trapped in transit (De Haas 2014). As for explanatory mechanisms, much of the early work focused on the lack of financial capital as a barrier to migration: migration has a (financial) price, and many of the poorest people cannot simply afford to pay it. Economic factors, while indeed hugely influential, fall short of fully demystifying immobility in the contexts of climate change, just as economic drivers do not solely explain why migration occurs. Recent work rightfully expands on the causes by considering social factors and recognizing that immobile populations cannot all be deemed 'trapped' (Suliman et al. 2019). Many people choose to stay, citing place attachment and cultural motivations, for instance (Adams 2016; Farbotko 2018; Mortreux and Barnett 2009). These are important advances, but we still have not painted the full picture. Social understandings must be deepened, but other factors, too, should enter the 'immobility equation'. In this article, we assert that the political nature of immobility is one such case.

The following article joins the vast majority of current scholarship in offering multi-causal understandings of environmental mobility, but here we seek to explain how politics, particularly their material manifestation in policy interventions, drive (im)mobility outcomes in areas undergoing significant environmental degradation. This article seeks to complement rather than contradict previous scholarship on immobility and 'trapped populations' (Foresight 2011; Black et al. 2013; Black and Collyer 2014). It contributes to the body of scholarship by incorporating the political factors that contribute to keeping people in place through two qualitative case studies that represent two different environmental mobility contexts of international labor migration (Senegal) and internal planned relocation (Vietnam), without diminishing the role of other factors in 'keeping people in place'.

Lastly, our intention is not to take a normative position on immobility resulting, at least in part, from policy interventions, that is to say, we privilege neither immobility nor mobility. Rather, we attempt to show both positive and negative aspects, the good and the bad of it, as articulated by those who are affected by local environmental degradation. Immobility can be a choice that is enabled by policies, while restrictive or maladaptive policies can also be a 'trapping factor' that limits people's abilities to leave (when they want to) (Foresight 2011; Black and Collyer 2014). Moreover, we assert that policy interventions aimed at enabling movement can, in fact, also enable immobility.

\section{Narratives on (Im)mobility and Environmental Change}

The study of immobility is relatively young within environmental migration scholarship compared to other areas of research (Zickgraf 2018a; Ayeb-Karlsson et al. 2018). It has rarely been studied in its own right, perhaps reflecting a 'mobility bias' (Jónsson 2011; Schewel 2019). That is not to say that it is without precedent: it is widely accepted that in any given place experiencing out-migration, there are just as many people, if not more, that do not embark on internal or international migration journeys: because they cannot, because they do not wish to, or some combination thereof (Carling 2002; Carling and Schewel 2018).

Like many concepts in environmental migration studies, immobility first found its way into more 'mainstream' migration studies. In many cases, it has rather provided the backdrop against which migration takes place, providing a control group, rather than being expressly examined as a decision in itself. For instance, within transnational studies, research began including the experiences of non-migrants as counterparts to migrants, more specifically as family members 'left behind' (Olwig 1999). Early currents in the field did little to understand how and why people made the choice not to migrate. They were often seen instead as the magnets attracting remittances back 'home'. Non-migrants were studied as secondary actors within transnational and translocal networks whose inclusion was studied as evidence of the (developmental) impacts of migration. In recent years, scholars have moved towards a stronger understanding of non-migrants within transnational networks as agents in their own right, but still without explanation of their motivations for staying.

One of the most influential studies to explicitly consider this question was Carling's 2002 study of involuntary immobility in Cape Verde, which crafted the aspirations-ability framework that pointed out how poverty in a culture of migration limited the abilities of people to leave Cape Verde, despite their 
aspirations to do so ${ }^{1}$. Although the study did not expressly target environmental context, it nonetheless drew immobility into the sphere of migration studies and theories of understanding on how migration occurs for some and not for others. Refugee and forced migration scholars have also added to the ways in which we understand immobile people and populations, again emphasizing its involuntary forms. This body pays particular attention to the ways that war, armed conflict, and violence disrupt or stifle mobility as much as they can also necessitate it. Lubkemann's (2008) study of involuntary immobility in wartime Mozambique did not only add empirically to our understandings of how immobility occurs in conditions of war, but also theoretically moved to decouple displacement from migration, arguing that the involuntarily immobilized experience disruption and disempowerment traditionally associated with movement, and that, in fact, migration even in forced contexts can result in empowerment, an important antecedent to narratives on migration as adaptation and trapped populations. He then moved for a reconceptualization amongst forced migration scholars to include how involuntary immobility can be a form of displacement in situ.

These two traditionally compartmentalized fields, migration studies and refugee studies, are bridged by environmental mobility studies in that the field includes migration and displacement as possible mobility outcomes, along with planned relocation (Piguet 2018). Acting as a connective thread amongst these studies is the emphasis on a lack of agency in immobility, manifested in the emergence and increasing popularity of the term 'trapped populations', denoting a population that has the need and desire to move, but lacks the ability (Foresight 2011; Black and Collyer 2014). The report used evidence from various study sites in which migration was only a coping strategy accessible to some, their last resort, with others staying in place because of conflict or poverty, or because disasters decreased financial resources with which to migrate (Foresight 2011; Gray and Mueller 2012; Penning-Rowsell et al. 2013).

In doing so, the report, and its consequent publications, laid the foundation for targeted research into those people who do not move in contexts of environmental degradation (Black et al. 2011, 2013; Thiede and Brown 2013; Black and Collyer 2014). With many acknowledging the need to migrate and the potential benefits of migration, immobility became the (potentially) abnormal, undesirable response to such adverse conditions. Academics, NGOs and IOs have begun to at least acknowledge that climate change and environmental degradation will not always result in migration, and can in fact limit mobility options (Murphy 2014; Nawrotzki and Bakhtsiyarava 2016; Nawrotzki and DeWaard 2018; Rigaud et al. 2018). Unlike previous work that nearly exclusively referenced migration or displacement ${ }^{2}$ under the 'mobility umbrella', this body of literature integrates immobility within the mobilities paradigm, as a mobility outcome in the wake of an extreme environmental event (Black et al. 2013; Hasegawa 2013) or slow-onset changes (Black et al. 2011; Adams 2016; Nawrotzki and Bakhtsiyarava 2016; Farbotko 2018).

In terms of mechanisms that 'trap' or 'immobilize', the Foresight report and the subsequent publications often emphasize the financial barriers to migration, particularly for natural resource-based livelihoods, whose dwindling assets can interrupt normal migratory responses to environmental change. Even before Foresight several studies in the 1990s noted how poverty limited mobility options in the face of slow and sudden-onset disasters. Herren (1991) study of the response to droughts in North Central Kenya in thee 1980s found that the poorest were the worst affected precisely because they had no option other than to remain, whereas their middle-income counterparts were able to move away temporarily.

In this way, they have much in common with the work of Carling (2002) as poverty was an essential barrier to effecting migration among Cape Verdeans, in that people aspire to migrate but lack the ability to do so. Environmental degradation broadly, and climate change specifically, add an

\footnotetext{
This model has since been updated (Carling and Schewel 2018).

And, to a lesser extent, planned relocation.
} 
important element by exacerbating poverty and vulnerability. It is thus essential to consider economic factors not only as preexisting vulnerability factors driving migration or immobility but also as they feedback into the web of causalities. Much of this scholarship, in and out of environmental contexts, also reference multiple forms of capital (human, social) required to move or that act as barriers to migration (Black and Collyer 2014; Chan 1995; Logan et al. 2016).

While capital constraints undoubtedly contribute to trapping people in situ or post-initial movement, as was also found in our own work ${ }^{3}$, the spotlight given to economic factors has yet to be sufficiently shared with other factors of immobility. As this nascent concept evolves, its evidentiary complexity is growing (Ayeb-Karlsson et al. 2018). Some recognize the importance of social networks and lack of affective ties outside the community of origin in hindering migration (and even displacement), while others are more inclined to discuss the choice to stay and voluntary immobilities rather than labelling 'trapped populations' (Adams 2016; Farbotko 2018; Suliman et al. 2019). In the latter, immobility is not necessarily equated with trapped populations, and place attachment, kinship obligations, and other socio-cultural factors are brought into play. Several examples of relocation programs demonstrate how political interventions must take into account socio-cultural factors and place attachment in order to be successful (Piggott-McKellar et al. 2019). Mortreux and Barnett (2009), for example, demonstrate the importance of religion in driving immobility amongst Tuvaluans, many of whom maintained faith in God's protection of their villages. In the case of relocation in Vunidogoloa in Fiji, elders' reluctance to leave ancestral burial grounds delayed the relocation process for decades (Charan et al. 2017).

We reiterate that immobility is never mono-causal, political factors do not act alone but rather in conjunction with social, economic, environmental and demographic factors to shape immobility patterns and outcomes. Thus, we extend the multi-causality widely accepted in explaining migration to immobility aspirations and capabilities (Carling and Schewel 2018). Political drivers of migration, of course, have long been recognized both within migration studies more broadly and within environmental migration scholarship primarily in terms of conflict (Lubkemann 2008; Foresight 2011). Yet as a driver of immobility, or as a constraint on mobility trajectories, political drivers have received scant attention as they link to environmental contexts outside of acting as trapping forces (Black and Collyer 2014). More commonly, we offer political solutions to avert, minimize and address environmental displacement, e.g., disaster risk reduction programs, or political solutions to facilitate migration as adaptation, e.g., relocation programs and bilateral agreements. We rarely explicitly examine how these policy interventions may affect and effect immobilities.

It is important to note how we conceptualize immobility in what follows. Firstly, mobility and immobility are not fixed categories, one can become immobile after being mobile and vice versa, just as one can move back and forth between irregular and regular migration statuses (Collyer 2007; De Haas 2014). Secondly, labelling immobile or mobile people is a tricky endeavor because all people are to some extent mobile and immobile at the same time. No one is constantly in motion or constantly in stasis. Following others, we therefore move away from the immobility/mobility dichotomy (Glick Schiller and Salazar 2013; Siraj and Bal 2017). As Gutekunst et al. (2016, p. 20) argue, "mobility is always bounded, regulated, mediated and intrinsically connected to forms of immobility and unequal power relations." We thus take immobility as relational and complex (Urry 2002; Adey 2006; Cresswell 2010).

Terminologically, we engage with but do not employ 'trapped populations' for several reasons. Firstly, the complexity of narratives collected requires a more neutral term, we think best offered by immobility. Trapped begins from a more normative stance than our combined case studies support, in that it requires a desire (or aspiration) to move that was not always present in our data. Immobility, or immobile, as we employ it, does not speak to agency, there are those in the study who wanted to leave,

3 Most explicitly this drove immobility in a case study on Comoros within the IMMOBILE project, although it is beyond the scope of this contribution. 
those who did not, and those whose aspirations were not easily categorized into either. Additionally, our exploration of how policy interventions influence immobility are not essentially negative (or positive) and therefore we do not wish to advocate for policies exclusively as 'trapping factors' nor as facilitating factors.

\section{Methods}

The findings draw on over three years of qualitative fieldwork conducted between 2014 to 2017 in Senegal and Vietnam. The research was designed to understand why some people did not migrate, or stopped migrating, in the face of environmental changes in locations characterized by high mobility and heavy reliance on natural resource-based livelihoods. ${ }^{4}$ Here, we focus on data collected in an urban fishing quarter in the north-western city of Saint-Louis, Senegal, and two rural villages in the Mekong River Delta of Vietnam. ${ }^{5}$ Contexts on these sites are provided in the following section.

We relied on semi-structured interviews as the primary methodological tool, alongside focus groups and moderate participant observation. A common interview guide was developed for both countries, with each being translated into local languages and reviewed with an interpreter in order to ensure cultural appropriateness and accuracy. In Senegal, 40 interviews were conducted with local residents in French, with the help of a local Guet Ndarian who translated to and from Wolof. ${ }^{6}$ As a local, he also acted as an essential gatekeeper in the tightly-knit community. Initial fieldwork in 2014 stimulated a second fieldwork in 2016, with the two separate fieldworks affording insights into the evolution of experiences and perspectives in Guet Ndar. ${ }^{7}$ In Vietnam, 40 interviews were conducted with local residents in two villages-Trần Đề in Sóc Trăng Province (coastal) and Thanh Bình in Đồng Tháp Province (riverain)—over the period of August to September 2016. Local partners in Can Tho University facilitated contacts with local authorities, whose approval was required prior to research. A $\mathrm{PhD}$ student translated between English and Vietnamese in both sites.

In interviews ranging in length from $30 \mathrm{~min}$ to an hour and a half, depending on the willingness of the participant, people were asked about a range of topics: their individual, household, and community vulnerabilities, their impacts on people's lives, people's responses and the responses of authorities, their mobility histories, previous experiences and outcomes, and current (im)mobility motivations, aspirations and capabilities. Biographical information was also collected to consider demographic variables.

Sampling was purposeful, and-to the extent possible-we deployed maximum variation sampling in which we particularly aimed to include a variation in gender, age, livelihood, and life phase amongst participants. This design enriched the data with a diversity of perspectives in each site. Importantly, we conducted interviews with non-migrants (with no history of migration out of the study sites for more than three months), return migrants, seasonal migrants that had returned temporarily, and relocated people (relocated by the government in Vietnam, and those who organized their own short-distance moves out of Guet Ndar but within the city). This was done in order to grasp the wide array of (im)mobility aspirations, capabilities and experiences and perspectives. The interviews were audio-recorded with the permission of participants, anonymized, and were then manually coded for pre-determined and emergent themes. Lastly, in addition to locally affected populations, the studies included interviews with local, regional, and national authorities where permitted and with key

4 Findings are drawn from the IMMOBILE project (2015-2018) in Senegal and Vietnam, financed by the Belgian Fund for Scientific Research (FNRS) and additional earlier fieldwork, using the same methods and general interview guide, was conducted by the author in Senegal the European FP7 Project HELIX (High-End cLimate Impacts and eXtremes) in 2014.

5 A third case study, in four coastal villages in Ngazidja, Comoros has been excluded from the following analysis precisely because there was a lack of policies targeted at recurrent displacement, a problem in and of itself.

6 A few of the interview participants spoke French and therefore interviews were conducted directly between interviewer and interviewee.

7 The only difference in the methods of these two separate fieldworks in Senegal was that the first explicitly centered on the impacts of climate change whereas the second included climate change along other environmental factors. 
stakeholders from civil society (NGOs, IOs, academia) who shed light on the contexts of (im)mobility, including political interventions.

Summarizing the main ideas that emerged from these interviews with affected populations and key stakeholders, as well as quoting them directly, we use this data and compiled background documents, secondary literature, and fieldnotes to elaborate the environment-migration context in these two countries before exploring how political interventions in both locations influenced local (im)mobilities.

All subjects gave their informed consent for inclusion before they participated in the study. The study was conducted in accordance with the Declaration of Helsinki, and the protocol was approved by the Ethics Committee of the IMMOBILE Project.

\section{Policy Responses to Impacts on (Im)mobility Outcomes in Senegal and Vietnam}

The following sections draw evidence from the three study sites in two countries to examine the impacts of political factors as they respond to and facilitate (im)mobility responses to the impacts of climate change. The first section explores the case of Senegal's bilateral agreements with Mauritania regarding international fishing migration, while the second looks at how relocation programs affects and effects internal (im)mobility. We consider that internal and international migration, labor migration and relocation efforts are distinct contexts, and therefore assert that these studies provide a wider berth of evidence from which to draw our conclusions.

\subsection{Senegal: Bilateral Agreements and International (Im)mobility}

\subsubsection{Context of Guet Ndar, Saint-Louis}

Senegal has witnessed dramatic changes along its coast, due to man-made interference, but also linked more or less directly to climatic factors, the most important of which are flooding, coastal erosion, soil salinization, mangrove degradation, and changes in fishing regimes (Amara et al. 2019; Ndour et al. 2018). These environmental changes threaten the livelihoods of the approximately 600,000 people directly or indirectly working in the Senegalese fishing industry (FAO 2008). Chief amongst these affected communities, Guet Ndar is a small urban fishing quarter in the second largest city of Senegal, Saint-Louis. Renowned for its skilled fishermen and almost exclusively dependent on the fishing sector, the small sandy spit of land ${ }^{8}$ is wedged between the Atlantic Ocean and the Senegal river, a short walk across the bridge from the most famous sites of the former French colonial capital. Several thousand people live together in tightly packed living conditions in one of the most densely populated districts in West Africa, with limited space and land continually shrinking due to sea level rise and coastal erosion (Cormier-Salem 2014; Ndour et al. 2018).

A historical reliance on maritime fishing has made Guet Ndarians some of the most skilled artisanal fishermen in West Africa, fiercely attached to and $\operatorname{proud}^{9}$ of their traditional livelihoods, but also highly sensitive to environmental changes. As soon as the 1980s, the Senegalese commercial sector began showing signs of distress, and between 1996 and 2007, catches declined by between twenty to forty per cent (Binet et al. 2012). By the 2000s, overfishing by foreign trawlers (EU, Russian, Asian) decimated local fish stocks and diminished biodiversity, resulting in extensive local petitions amongst artisanal fi to retract foreign licenses. Participants perceived this industrial overfishing as the number one threat to their livelihoods. Even though the Senegalese government acquiesced, illegal foreign trawling continues to plague the country, and was continually mentioned as a persistent problem.

8 This stretch of land, including but not limited to Guet Ndar, is known as the Langue de Barbarie spit.

9 Fishermen frequently mentioned their expertise and pride in it in interviews but also in focus groups and informal meetings. 
Adding to the pressure, climate change has further exacerbated local vulnerability (although only one participant cited climate change). ${ }^{10}$

Today, a growing number of artisanal fishermen compete for a declining amount of fish, at the same time that they must defend their homes, equipment, and infrastructure from the sea. Senegal is ranked as the world's eighth most at-risk country in terms of the sea-level rise (Amara et al. 2019). Partial or entire home destruction is well underway on its coastal frontlines, with older fishermen and locals reporting a dramatic encroachment over the past decades. Two participants had their coastal front rooms destroyed, with others sleeping in fear when waves slammed into their rooms at night (increasing wave intensity has also caused several deaths at sea). Climate change not only impacts the livelihoods of fishermen, but also those of women in the fishing industry. Coastal erosion leaves women who transform the fish by salting, smoking, etc., with smaller and smaller spaces to perform their work. Female respondents, whose livelihood infrastructures were less mobile than their male counterparts, cited dangerous working conditions on top of decreased income because of the lack of fish to transform and sell.

Unlike women left with few mobility options, the overexploited fish stocks have pushed Senegalese fishermen to extend their navigation range, and therefore fish further offshore, often in other parts of the country but also in the neighboring countries of Guinea-Bissau and Mauritania. Guet Ndarians are, in fact, no strangers to migration: long-distance, seasonal regional mobility has long been an integral part of Guet Ndarian and Senegalese fishing styles dating back centuries, with them moving across the sub-region from Mauritania to Sierra Leone (Binet et al. 2012). Fishing migration is therefore an essential element of artisanal fisheries (Seck 2014). In interviews and informal meetings in gathering places, Guet Ndarian retired fishers proudly boasted of their seasonal adventures across West Africa and beyond over their careers. However, these patterns were historically short-term and seasonal. Traditional patterns of temporary seasonal migration abroad, alternated with local fishing seasons, have faded dramatically and are being increasingly replaced by longer term international fishing excursions because of the changes in maritime and biodiversity impacts of climate change (Seck 2014), with many participants in the study now reporting only brief annual visits home for religious celebrations. The temporal aspects of fishing migration are not the only markers of change: what was once a migration all over the West African coast has been channeled into a more specific geographical pattern, that of migration to its northern neighbor, Mauritania. Senegalese migrant fishers now take most of their catches from Mauritania (with $48 \%$ of the migrant fishers' catch landed in Senegal), followed by Guinea Bissau (33\%), The Gambia (19\%) and Guinea (<1\%) (Belhabib et al. 2014). Guet Ndar's proximity to the border have made the local fishermen particularly economically dependent on their access to Mauritania's waters and intensive exploitation of these neighboring fishing grounds (Hallaire 2015).

\subsubsection{Senegal-Mauritanian Bilateral Agreements and International Labor Migration}

In response to the impacts of overfishing by foreign trawlers and exacerbating impacts of climate change, Senegal has taken a number of actions, all of which we cannot name here. ${ }^{11}$ In 2006 and 2012, they revoked foreign trawler licenses, in 2004 they created several Marine Protected Areas (MPAs) to allow for adequate fish reproduction, including in Saint-Louis, for example. Local fishing authorities, community leaders and participants alike agreed that these measures did little to meet the demands of the burgeoning artisanal fishing industry. Nearly all male, active fishermen interviewed named bilateral agreements with Mauritania as the only effective policy measure currently in place, even if it was far from ideal or desirable: participants cited racism, discrimination, exploitation, and abuse at the hands of locals and coast guard officials in Mauritania. To put this into context, Senegal and

10 This demonstrated the lack of general awareness in Guet Ndar regarding the threat of climate change and the importance of sensitizing affected communities to its impacts.

11 For more extensive information, see Seck (2014). 
Mauritania have a tense history when it comes to borders and the fishing industry. The 1989 border conflict remains strong in the memories of Guet Ndarian retired fishermen, many of whom were among the tens of thousands forcibly expulsed from Mauritania (Parker 1991). In groups and individually, they vividly recounted stories of physical abuse and the traumatic experience of being forced out of Mauritania.

The two countries were able to find some common ground in recent decades over their waters, despite these historical conflicts. Senegal reached an agreement with the government of Mauritania in 2001 to both countries' benefit. This accord was designed to provide skilled fishers to the Mauritanian fishing industry, traditionally a country whose livelihoods are agricultural rather than maritime-based. For the Senegalese, primarily Guet Ndarian, beneficiaries, it provided some relief by enabling migration to richer waters. The stipulations around the agreement are continually renegotiated, resulting in various iterations since the agreement was reached in 2001 (Seck 2014). From 2009, Senegalese fishers that obtained one of the licenses could then embark in circular labor migration, after a period of fishing for Mauritania (first landing their catch), ${ }^{12}$ they could return to Senegal with 40,000 tons of fish annually (landing their second catch) (Seck 2014). The number of licenses was increased from 300 to 400 in 2015, and the catch upped to 50,000 tons. This agreement decreased the reliance on local fish stocks, increased their incomes (and abilities to remit), while allowing fishers to return regularly to their homes in Senegal, even if Guet Ndarians complained that the number remained vastly insufficient to meet the increasing demand placed by a growing number of artisanal boats.

However, political tensions between the neighboring countries resurfaced when the fishing accord was not renewed upon its expiration in 2016, after the Senegalese side refused a Mauritanian demand that fish caught in its waters should be landed in Mauritania. ${ }^{13}$ The lack of an accord distressed research participants that were active fishers, who then had to rely on alternative mobility strategies. They could still fish in Mauritania legally, but only in and for Mauritania, meaning they were obliged to stay longer periods in Mauritania under contract with factories. Their second mobility option was to irregularly fish in Mauritanian waters (short distances). Their last option was to remain in Senegalese waters and decrease their incomes, food intakes, and other expenses, adding to already high poverty in the quarter (Seck 2014; Hallaire 2015). Participants decried the withdrawal of licenses because it was their preferred mobility option. It enabled them to fish short periods, return home, and repeat the cycle. Mauritania also struggled without an agreement: the lack of skilled fishermen landing their catch in the country meant that their fish processing factories did not have adequate material to continue operations. ${ }^{14}$

The failure to reach a new agreement was compounded by the political tensions on both sides: Guet Ndarians, even before the cessation, decried physical abuse, corruption, detainment, and the confiscation of their materials by the Mauritanian coast guard. For its part, Mauritania complained of irregular fishing by Guet Ndarians in Mauritanian waters (which indeed many respondents engaged in at one time or another). This tension culminated in the death of a young Senegalese fisherman, shot by the Mauritanian coast guard, which triggered protests in Saint Louis. With mounting economic and social pressure, negotiations recommenced and a new, similar agreement was reached in 2018: 400 licenses would again be allotted for 400 boats, enabling the catch of 50,000 tons of fish annually. ${ }^{15}$ The deal was subject to the inspection and weighing of each catch, to be strictly enforced by the Senegalese government and monitored by Mauritanian authorities. As in past iterations, Senegal will give its

12 The length of time varies by fishing type and boat size. Larger boats, that fish in tandem, fish for fifteen days.

13 Le Point, "Sénégal-Mauritanie: ce que dit le nouvel accord de pêche" 4 July 2018. Last accessed 28 April 2019. https://www.lepoint.fr/economie/senegal-mauritanie-ce-que-dit-le-nouvel-accord-de-peche-04-07-2018-2233234_28.php.

14 RFI Afrique, "L'accord de pêche entre la Mauritanie et le Sénégal finalisé" 20 December 2018. Last accessed 25 April 2019. http://www.rfi.fr/afrique/20181220-accord-peche-mauritanie-senegal-finalise-usines-poisson-nouakchott.

15 Le Monde, "Le Sénégal et la Mauritanie signent un nouvel accord de pêche." 4 July $2018 . \quad$ Last accessed 5 June 2019. https://www.lemonde.fr/afrique/article/2018/07/04/le-senegal-et-la-mauritanie-signent-un-nouvel-accord-de-peche_ 5325948_3212.html. 
neighbor 10 EUR for each ton of fish caught in its waters. The agreement covers the span of one year, with the possibility of renewal for an additional year.

\subsubsection{Impacts on (Im)mobility}

The series of bilateral agreements between Senegal and Mauritania respond to the impacts of overfishing and climate change by encouraging international, circular labor migration schemes. Although the number of licenses are far from adequate for the thousands of Guet Ndarian fishermen suffering from diminished biodiversity and depletion of local fish stocks, they provide relief to those able to obtain them, and the lack of an agreement for two years forced them to seek alternative mobility strategies, some of which were illegal. However, if we move away from simplistic binaries between immobility and mobility, we can also see how the agreement facilitates immobility. The agreement enables the departure of Guet Ndarians abroad, but also their return. Through this political mechanism they can increase their incomes by catching fish abroad, and increase their remittances back to Guet Ndar (which then enables short distance movement away from coastal erosion's threats to their homes), before returning to their traditional homes and families (Zickgraf 2018b). Importantly, this can be done legally, and decreases pressure to permanently move elsewhere in search of work or to fish irregularly and augment risks for imprisonment, fines, abuse, and even death. Evidence of this is clearly demonstrated by the positive reception of the agreements by research participants, and the demand to scale up its purview so that more can take advantage of the scheme.

This desire to both move and to stay in place characterizes (im)mobility strategies in Guet Ndar. Fishers have long migrated, and have no wish to cease movement, but many also recoiled or even laughed at the thought of moving permanently somewhere else. This is primarily due to socio-cultural factors as they drive immobility aspirations. When asked why he did not build or purchase a home in Mauritania since he was living there eleven months a year, one respondent exclaimed "Because I am Guet Ndarian! I am Senegalese! My home is here!". ${ }^{16}$ Their desire was to move and to return. The movement was a necessity ("The fish migrate and so must we"17), the return was the aspiration. This extends to the community's mobility strategies to deal with the residential impacts of coastal erosion: many of those fisher families that benefit (although not all were able to earn enough abroad) from Mauritanian remittances and income use them to construct second homes on the mainland or further down the Barbary Spit, in Hydrobase, for example (Zickgraf 2018b). Despite the ongoing coastal erosion, they do not abandon their primary residences in Guet Ndar, but rather move back and forth between homes. When asked to explain this strategy, respondents emphasized their cultural attachment and obligations to maintain traditional homes in Guet Ndar, homes that have been held for generations. This is echoed across livelihoods, genders, and is especially important for elders. This was religious as well, ancestral burial grounds in Guet Ndar acted as an anchoring force. Many men and women refused the thought of entirely leaving their ancestors behind, even for those who recognized the impending danger. When confronted with asked about this, one elderly woman scoffed, "Let [the sea] come! I was born here and I will die here." 18 In the second study period, with increasing awareness of the irreversibility and imminence of disappearing land, fewer respondents completely rejected the notion of internal relocation to other parts of Saint-Louis, but partial (im)mobility (with one foot in Guet Ndar) was an adamant condition. Here, political factors coalesce with cultural notions of migration and place attachment. The bilateral agreements simultaneously facilitate mobility and immobility, challenging our external notions of migrant versus non-migrant, the aspiration to go versus the aspiration to stay, and that politics and policies either enable/force migration or they enable/force stasis.

16 Author's translation. Interview, Guet Ndar, Saint-Louis, Senegal. August 3, 2014.

17 Author's translation. Interview in Guet Ndar, Saint-Louis, Senegal. July 26, 2014.

18 Author's translation. Interview, Guet Ndar, Saint-Louis, Senegal. July 20, 2014. 
However, we must also see how policies are embedded in macro-level political structures and attitudes. This case study is primarily one of international migration, and therefore subject to border controls and enforcement, and requires international cooperation. The case of Mauritania and Senegal shows how these policies can easily fall prey to political tensions, and result in less desirable (im)mobility patterns in the community when bilateral agreements are rescinded: fishers being increasingly 'stuck' in Mauritania, separated from their families for longer durations, or 'stuck' in Guet Ndar, with their families but without sufficient resources to protect themselves from the impacts of sea level rise and coastal erosion.

\subsection{Vietnam: Relocation Programs and Internal (Im)mobility}

\subsubsection{Context of the Mekong River Delta}

Similar to Senegal, Vietnam is especially vulnerable to the effects of climate change, from intensifying and more frequent disasters to slow-onset effects including sea-level rise. According Dasgupta et al. (2009), given a 1-meter sea-level rise, Vietnam would be the world's most affected developing country in terms of population (10.8\%), GDP (a 10.2\% reduction), and the number of wetlands inundated $(28.7 \%)$. A two-meter rise would see almost half of the country's agricultural area inundated (Warner et al. 2009).

Perhaps nowhere are the impacts of climate change in Vietnam more menacing than in the Mekong River Delta (MRD) region, which importantly produces the majority of the country's staple food and holds much of its arable land (Ho and Shimada 2019; Warner et al. 2009). ${ }^{19}$ The region holds urban and rural dwellers, home to one of the most populated regions of the country. Its agriculture is largely dependent on rice and fish production. As such, sea level rise (SLR), drought, coastal erosion and soil salinization are threatening rural livelihoods and concomitantly storms, severe floods, and landslides threaten people's homes. The two villages studied, Thanh Bình and Trần Đề, represent two rural populations that are faced with both impacts. The former is a riverain population, spared from the coastal threats, but parts of the province facing riverbank erosion, mudslides, and rainfall variability. The latter escapes mudslides, but must cope with saline water intrusion, storm surges, sea level rise. Both experience the region's characteristic flooding, and are susceptible to increased rainfall variability.

Residents of the two rural villages, unlike their Senegalese counterparts, exhibit various livelihoods: respondents were fishers, rice farmers, shrimp farmers, small-scale fruit farming, livestock, and manual labor (drivers, handymen, and labor-for-hire). Nonetheless, they are all highly vulnerable to the changing environmental conditions. Droughts are particularly difficult for rice production, which requires flooding and the nutrients it brings, without which saline intruding in the south cannot be expelled. Rainfall and temperature variability plague harvesting and planting cycles. Aquaculture fares better with saline water intrusion, but is costly and requires some technical expertise. Manual laborers are dependent on agricultural production for employment and to run local economies, so when farming fails, they are left unemployed and impoverished. In order to cope with environmental stress, people reported using traditional flood coping mechanisms, such as stacking furniture during the wet season. Fishers could fish further distances, and during severe storms in Trần Đề, families evacuated to local community centers or sought shelter with neighbors. In situ responses to drought, rainfall variability, riverbank erosion, mudslides, and saline water intrusion were less obvious in both sites. While some tried their hand at diversifying crop production, others reported doing nothing at all owing to their poverty and with few strategies available to them, reporting living "day by day".

Whereas Guet Ndar called upon international migration, MRD respondents almost exclusively cited internal migration in response to the impacts of environmental degradation, or no mobility

19 As of 2009, it accounted for 40 percent of the country's cultivated land surface and produced more than a quarter of the country's GDP. Half of Vietnam's rice is produced in the Mekong River Delta, 60 percent of its shrimp harvest, and 80 percent of the national fruit crop. Ninety percent of Vietnam's total national rice export comes from the MRD (Warner et al. 2009). 
at all. Migration to the cities offered youth and those active on the labor market a way to escape the vulnerability of rural, natural resource-based livelihoods. Many participants had either left and returned, or had children engaged in internal urban migration. Those interviewed had adult children living in and around Ho Chi Minh City, with nearly all citing economic motivations for the move. They lamented the lack of local job opportunities as well as the limited, and decreasing, agricultural production, which could only support a few family members owing to the size of plots and their degradation. Primarily, their migrant children found employment in urban or peri-urban factories. This internal migration diversified household income, as several immobile households received small-scale remittances, a welcome material comfort for the elderly, unemployed, small-scale fishers, farmers, and poor manual laborers that stayed behind. That being said, financial remittances were small owing to the low wages and high cost of living in Ho Chi Minh and could rarely support the entire family, if they were sent at all. In fact, several people had since returned to the study sites and surrounding area after becoming disillusioned with their inability to save their earnings in the big city. Lastly, these remittances were unable to protect families from storm surges, mudslides and riverbank erosion, leaving residents to watch as their homes were battered and/or destroyed in extreme events.

\subsubsection{Resettlement Schemes in the Mekong River Delta}

The sharp increase in environmental degradation has had great detrimental consequences for the MRD, negatively impacting agricultural productivity and human security. These direct and indirect detrimental effects are pressuring the authorities and the residents of Mekong River Delta to find solutions to cope with and adapt to their changing environment. Similar to Senegal, population movements have been one such solution envisioned by the government. Whereas Senegal saw international labor migration (leading to internal self-relocation) as its key migration pathway, two main migration patterns can be discerned in the Mekong Delta: the abovementioned labor out-migration to Ho Chi Minh City (but also to other intraregional areas) and internal planned relocation within the MRD.

The former, internal labor migration, is discouraged by local and national authorities, with Ho Chi Minh City under mounting population pressure. Local authorities in the Thanh Bình District in Đồng Tháp province interviewed stated that they did not want to encourage rural-to-urban flows and wanted to keep young people in place. In order to do so, the government subsidized seeds and rice for local farmers and were looking to rather attract industry to the district in order to create local jobs and decrease out-migration. ${ }^{20}$ Outside of agricultural subsidies to address livelihood impacts, the primary instrument of protecting people from environmental hazards in order to keep them in place was, in fact, to move them. The country's environmental and climatic threats have lead the national government to design programs specifically targeting households vulnerable to environmental hazards, chiefly through the national government-designed and locally implemented, 'Living with Floods' (LWF) program ${ }^{21}$. In 1996, the resettlement program was launched with the objective to build houses for relocated residents of the Delta affected by severe flooding, and the government has since engaged in large-scale relocation in several regions (Danh and Mushtaq 2011; Dun 2011; Chun 2015; MECLEP 2017). After catastrophic floods in the MRD in 2000, the government introduced the concept of LWF into its disaster mitigation and management policies, based on the premise that flood risks should be mitigated, while also recognizing that floods are crucial to agricultural livelihoods, food security, and the country's economic development (Chun 2015). LWF's resettlement program primarily targets households vulnerable to riverbank erosion, landslides or frequent storms in order to relocate them into "resettlement clusters" (RC). The program enables participants to acquire houses in nearby relocation sites identified by the local authorities for those deemed eligible, typically due to residential

20 Interview with local officials from the Department of Natural Resources, Thanh Bình District. 7 September 2016.

21 The overarching Living with Floods Policy includes two programs: (1) construction of dykes and (2) resettlement schemes. 
rather than livelihood exposure. Poor program participants then have access to preferential loans for home construction. All resettlement sites must be $0.5 \mathrm{~m}$ higher than the peak of flooding in 2000, and since 2004, houses must be no smaller than 32 square meters (Danh and Mushtaq 2011).

A key feature of the LWF is local implementation. Local authorities are largely responsible for designing relocation, selecting participating households, and implementing the move, and funding varies from one district to another. Generally, households were selected based on exposure to hazards and poverty levels, with the dual objective of decreasing physical exposure and poverty levels. However, participant selection criteria were largely left to local authorities to determine, resulting in localized processes rather than transparent, harmonious selection processes (Chun 2015).

The program focuses on maintaining and sustaining local livelihoods while simultaneously decreasing exposure to natural hazards; therefore, most relocations take place within short distances, 1-2 km, often within districts wherever possible (MECLEP 2017; Warner et al. 2009), although our own respondents moved slightly farther. In a 2006 national decision, the priority to minimize distances was made explicit:

Population distribution shall be conducted mainly within communes, districts and provinces. Where population should be relocated to other provinces, agreement should be reached between provinces where people leave and those where they move to in order to arrange them in the planned areas so as to stabilize their life and production for permanent settlement. ${ }^{22}$

Reflecting this approach, in Nam Can district in Ca Mau province, an estimated 4000 households were relocated to a new site only about a kilometer away (MECLEP 2017). Similarly, relocation in and to the villages under study entailed short distance moves to nearby sites, approximately 6 kilometers, often keeping communities together to minimize adverse social impacts and maintain economic productivity. Respondents had repeatedly been displaced or evacuated during storm, flood, or mudslide events, they were then moved short distances away from their original property and often together. Some participants were not moved under the program, but, facing the same risks, sold their land and financed their own move to Thanh Bình from nearby Hòa Bình. This allowed the community to continue to their previous livelihoods as their source of income by being near enough to their croplands to commute back and forth.

\subsection{3. (Im)mobility Impacts}

The (im)mobility impacts of the LWF program, as in Senegal, demonstrate the connectedness of mobility and immobility aspects in that both government actions facilitated movement and in doing so enabled a degree of stasis. LWF and local authorities did not wish to promote long-distance, internal migration, and resettlement was actually a means of keeping people in place. This coincided with the wishes of the elder people interviewed (if not the younger), who neither aspired to leave nor felt they had the ability at their age. As one 40-year-old farmer and fisherman in Trần Đề explained:

Most young people migrate. Middle-aged and older people prefer to live off of the land and be supported by the local authorities. [ . . . ] It's difficult to find a good job. The young move to earn money for the family. They work and earn money, and we live day by day. ${ }^{23}$

Older respondents additionally had no desire to leave their villages for other regions or places for cultural reasons. When asked why, they simply stated that they were born and grew up in the districts or province. Therefore, Vietnamese respondents were satisfied with being moved in several

22 Decision No. 193/2006/QD-TTg, issued on 24 August 2006 on 'Approving the Program on population distribution in natural disaster- and special difficulty-hit areas, border regions, islands, areas inhabited by free migrants, and important and very important areas of protective forests and strictly protected zones of special-use forests in the 2006 to 2010 period, and orientations up to 2015', cited in (Chun 2015, p. 10). For more relevant national decisions, see (Chun 2015).

23 Interview in Trần Đề, Soc Trang province, Vietnam. 6 September 2016. 
aspects. Firstly, relocation provided them physical security by providing new, safer housing, and in doing so decreased their mental distress caused by recurrent environmental shocks and displacement. This physical security instilled a sense of stability that people repeatedly lauded, stability being a central theme in interviews and a basic cultural value. Even if their livelihoods were uncertain, the stability of a home, after years of recurrent disasters, was more important than their income. Their satisfaction came, secondly, from the fact that they did not have to move far-remaining within their districts or provinces. This was important to people because they maintained their social networks and sense of community. Owing to this consideration on the part of the LWF and local authorities, they were welcomed into their new communities by the existing population and did not report any social disintegration or negative cultural outcomes because of the cultural and geographical proximity between sites.

In these regards, the program was a success. It kept people (relatively) in place, which aligned with their own (im)mobility aspirations. However, its participants did not have universal praise for the program. While meeting the objective of safeguarding people from environmental hazards, many people were economically worse off. Despite the program's emphasis on alleviating poverty, it did not enable income diversification because livelihood sources remained unchanged. They were not offered new plots of land to farm or training in new trades. People had to commute to their existing plots and fields, the commute itself being a costly struggle for many. Their lack of change in livelihoods meant that people still faced the agricultural and economic impacts of climate change and environmental degradation. Additionally, for some, their economic situation was actually worse than before because they accrued debt in the process. Although some assistance was offered, many of them were obliged to take on government loans to construct their new homes. Even if the terms of these loans were favorable for poor households, considering that they already struggled with climate impacts on livelihoods, repaying their debts was particularly difficult. One 58-year-old farmer took on debt in 2012 to move to Thanh Bình to escape intense flooding. At the time, his crops being relatively good, he expected to pay the debt to the local authorities off without trouble. Since 2014, however, he struggled with decreased flooding, low soil fertility, increased heat and diseases in his rice crops. These had crippling effects on his livelihood and ability to repay. Two participants reported that the debt accumulation from relocation prevented them from sourcing medication or affordable cancer treatments. Echoing studies on LWF in other sites, vulnerability to the impact of hazards on livelihoods thus remained for those relocated (Chun 2015; Entzinger and Scholten 2015, 2016). The implications of this for future (im)mobility are twofold. On one hand, the economic vulnerability not being treated by LWF means that economic incentives for rural-to-urban migration persist. On the other hand, poor households with dwindling resources because of climate change, and accrued debt because of relocation, may be even less able to engage in migration in the future or to independently enact other coping and/or adaptation strategies. ${ }^{24}$ Nonetheless, even with debt, most wanted to stay put once relocated. Illustrating the importance of immobility aspirations, one 72-year-old woman, relocated because of mudslides in 2012, relied on her five children living within the district for income. However, as their incomes were unstable, she had no means of repaying her loans. Asked about her aspirations to leave, she replied:

[Respondent]: I don't have money to leave. But even if I did, I wouldn't go because the local authorities support me with the land and I was born and grew up here, even if life is difficult.

[Interviewer]: What about your children?

[Respondent]: I don't want them to go far away. No, they can live here. When there are troubles, we can help each other. [ ... ] No, never anywhere else. Never. ${ }^{25}$

24 It is also important to consider in light of findings that the poorest households are the most likely to migrate in the MRD (Entzinger and Scholten 2016). Migration decreases as income increases.

25 Interview in Thanh Bình village, Dong Thap province, Vietnam. 8 September 2016. 


\section{Conclusions}

The results from this research stress the importance of considering how political factors respond to, but also result in, (im)mobility in the context of climatic change. Although the cases of Senegal and Vietnam have notable differences-one entails bilateral agreements facilitating international migration, while the other uses planned relocation programs for internal migration-we assert that their different contexts, mechanisms, and objectives can both be viewed with similar lenses. Generally, literature compartmentalizes migration, displacement and, especially, planned relocation; yet their commonalities transcend these divisions. Taken at face value, these two policy interventions aimed to enable mobility as a response to climatic and environmental change for their citizens: in Senegal, international agreements with Mauritania responded to coastal livelihood threats for active male fishermen and in Vietnam relocation programs treated residential threats through short-distance movement of primarily older households. The positive aspects of these programs demonstrate how promoting population movement can act as an adaptation strategy to climate change, in keeping with the migration-as-adaptation discourse (Black et al. 2011). Yet, we argued that the very same policies can also be read as facilitating (im)mobility. Our modest analysis undoubtedly has its limitations: there are many more political factors at various scales that have far-reaching consequences on how people enact mobility and immobility in the face of climatic and environmental changes. Future research possibilities in an emerging literature abound. One might scale up to the international, multi-lateral migration and/or climate mobility policies and see how they combine with national and local ones, or examine at how policies are designed to (re)produce uneven, gendered immobilities. We would assert that transnational, translocal, and mobilities studies and methods would be of particular value.

The analysis also challenged the dominant either/or readings of populations' aspirations and capabilities. Both populations (largely) desired to stay put for socio-cultural reasons, excluding them from warranting the label of 'trapped population', but they also expressed the need to move because of the impacts of environmental degradation and climate change on their everyday lives and livelihoods. Their aspirations were complex, to both desire stasis and movement. Treating the complexity of aspirations and capabilities in future research should allow for theoretical advances, but also reality-based policy approaches. By no means do political factors account exclusively for (im)mobility, but if we do not analyze them as they feedback into (im)mobility in a web of causalities, we limit our abilities to understand phenomena of climate change's impacts on migration, displacement and relocation. Our case studies demonstrate that neither a sedentary bias or a mobility bias should cloud our judgment. Policies, like people, do not necessarily fit neatly into oppositional boxes. Keeping people in place can, in fact, mean allowing the very same people to move.

Funding: The research leading to these results has received funding from the European Union Seventh Framework Programme FP7/2007-2013 under grant agreement no. 603864 (HELIX: High-End cLimate Impacts and eXtremes; http://www.helixclimate.eu) as well as support from the Belgian Fund for Scientific Research (FRS-FNRS; http://www.frs-fnrs.be), which financed the IMMOBILE project (2015-2018) ((Im)mobility in Crisis: Migration, Immobility and Environmental Changes).

Conflicts of Interest: The author declares no conflict of interest.

\section{References}

Adams, Helen. 2016. Why Populations Persist: Mobility, Place Attachment and Climate Change. Population and Environment 37: 429-48. [CrossRef]

Adey, Peter. 2006. If Mobility Is Everything Then It Is Nothing: Towards a Relational Politics of (Im)Mobilities. Mobilities 1: 75-94. [CrossRef]

Amara, Rachid, Mamadou Diop, Cheikh Diop, and Baghdad Ouddane. 2019. Chapter 37-The Senegalese Coastal and Marine Environment. In World Seas: An Environmental Evaluation, 2nd ed. Edited by Charles Sheppard. Cambridge: Academic Press, pp. 855-73. [CrossRef] 
Ayeb-Karlsson, Sonja, Christopher D. Smith, and Dominic Kniveton. 2018. A Discursive Review of the Textual Use of 'Trapped' in Environmental Migration Studies: The Conceptual Birth and Troubled Teenage Years of Trapped Populations. Ambio 47: 557-73. [CrossRef] [PubMed]

Belhabib, Dyhia, Viviane Koutob, Aliou Sall, Vicky W. Y. Lam, and Daniel Pauly. 2014. Fisheries Catch Misreporting and Its Implications: The Case of Senegal. Fisheries Research 151: 1-11. [CrossRef]

Binet, Thomas, Pierre Failler, and Andy Thorpe. 2012. Migration of Senegalese Fishers: A Case for Regional Approach to Management. Maritime Studies 11: 1. [CrossRef]

Black, Richard, and Michael Collyer. 2014. 'Trapped' Populations: Limits on Mobility at Times of Crisis. In Humanitarian Crises and Migration. Edited by Susan F. Martin, Sanjula Weerasinghe and Abbie Taylor. London: Routledge, pp. 287-305.

Black, Richard, Stephen R. G. Bennett, Sandy M. Thomas, and John R. Beddington. 2011. Climate Change: Migration as Adaptation. Nature 478: 447-49. [CrossRef] [PubMed]

Black, Richard, Nigel W. Arnell, W. Neil Adger, David Thomas, and Andrew Geddes. 2013. Migration, Immobility and Displacement Outcomes Following Extreme Events. Environmental Science \& Policy 27: S32-S43. [CrossRef]

Carling, Jørgen. 2002. Migration in the Age of Involuntary Immobility: Theoretical Reflections and Cape Verdean Experiences. Journal of Ethnic and Migration Studies 28: 5-42. [CrossRef]

Carling, Jørgen, and Kerilyn Schewel. 2018. Revisiting Aspiration and Ability in International Migration. Journal of Ethnic and Migration Studies 44: 945-63. [CrossRef]

Chan, Ngai Weng. 1995. Choice and Constraints in Floodplain Occupation: The Influence of Structural Factors on Residential Location in Peninsular Malaysia. Disasters 19: 287-307. [CrossRef]

Charan, Dhrishna, Manpreet Kaur, and Priyatma Singh. 2017. Customary Land and Climate Change Induced Relocation-A Case Study of Vunidogoloa Village, Vanua Levu, Fiji. In Climate Change Adaptation in Pacific Countries: Fostering Resilience and Improving the Quality of Life. Climate Change Management. Edited by Walter Leal Filho. Cham: Springer International Publishing, pp. 19-33. [CrossRef]

Chun, Jane M. 2015. Planned Relocations in the Mekong Delta: A Successful Model for Climate Change Adaptation, a Cautionary Tale, or Both? Washington: Brookings Institute.

Collyer, Michael. 2007. In-Between Places: Trans-Saharan Transit Migrants in Morocco and the Fragmented Journey to Europe. Antipode 39: 668-90. [CrossRef]

Cormier-Salem, Marie-Christine. 2014. Participatory governance of Marine Protected Areas: a political challenge, an ethical imperative, different trajectories. Senegal case studies. S.A.P.I.EN.S. Surveys and Perspectives Integrating Environment and Society 7. Available online: http://journals.openedition.org/sapiens/1560 (accessed on 1 July 2019).

Cresswell, Tim. 2010. Towards a Politics of Mobility. Environment and Planning D: Society and Space 28: 17-31. [CrossRef]

Danh, Vo Thanh, and Shahbaz Mushtaq. 2011. Living with Floods: An Evaluation of the Resettlement Program of the Mekong Delta of Vietnam. In Environmental Change and Agricultural Sustainability in the Mekong Delta. Edited by Mart A. Stewart and Peter A. Coclanis. Dordrecht: Springer Netherlands, pp. 181-204. [CrossRef]

Dasgupta, Susmita, Benoit Laplante, Craig Meisner, David Wheeler, and Jianping Yan. 2009. The Impact of Sea Level Rise on Developing Countries: A Comparative Analysis. Climatic Change 93: 379-88. [CrossRef]

De Haas, Hein. 2014. Migration Theory: Quo Vadis? IMI WP-100-2014/DEMIG Project Paper 24. Oxford: University of Oxford.

Dun, Olivia. 2011. Migration and Displacement Triggered by Floods in the Mekong Delta. International Migration 49: e200-e223. [CrossRef]

Entzinger, Han, and Peter Scholten. 2015. Relocation as an Adaptation Strategy to Environmental Stress: Lessons from the Mekong River Delta in Vietnam. In Migration, Environment and Climate Change Policy Brief Series. MECLEP Policy Brief Series, 6; Geneva: IOM.

Entzinger, Han, and Peter Scholten. 2016. Adapting to Climate Change through Migration: A Case Study of the Vietnamese Mekong River Delta; Findings from the MECLEP Project. Geneva: International Organization for Migration (IOM). Available online: https://environmentalmigration.iom.int/adapting-climate-changethrough-migration-case-study-vietnamese-mekong-river-delta-vietnamese (accessed on 29 March 2019).

Foresight. 2011. Foresight: Migration and Global Environmental Change Final Project Report. London: The Government Office for Science. 
FAO (Food and Agriculture Organization of the United Nations). 2008. Vue Générale Du Secteur Des Pêches National: La République Du Sénégal. Available online: ftp://ftp.fao.org/Fi/DOCUMENT/fcp/fr/FI_CP_SN.pdf (accessed on 7 June 2019).

Farbotko, Carol. 2018. Voluntary Immobility: Indigenous Voices in the Pacific. Forced Migration Review 57: 81-83.

Gemenne, François. 2011. How They Became the Human Face of Climate Change. Research and Policy Interactions in the Birth of the 'Environmental Migration' Concept. In Migration and Climate Change. Edited by A. Pecoud, E. Piguet and P. De Guchteneire. Cambridge and Paris: Cambridge University Press/UNESCO, pp. 225-59.

Glick Schiller, Nina, and Noel B. Salazar. 2013. Regimes of Mobility across the Globe. Journal of Ethnic and Migration Studies 39: 183-200. [CrossRef]

Gray, Clark L., and Valerie Mueller. 2012. Natural Disasters and Population Mobility in Bangladesh. Proceedings of the National Academy of Sciences 109: 6000-5. [CrossRef]

Gutekunst, Miriam, Andreas Hackl, Sabina Leoncini, Julia Sophia Schwarz, and Irene Götz. 2016. Bounded Mobilities: Ethnographic Perspectives on Social Hierarchies and Global Inequalities. Bielefeld: Transcript Verlag.

Hallaire, Juliette. 2015. The Mobility Strategies of the Senegalese Fishermen at the Senegal-Mauritania Maritime Border. Portuguese Journal of Social Science 14: 87-105. [CrossRef]

Hasegawa, Reiko. 2013. Disaster Evacuation from Japan's 2011 Tsunami Disaster and the Fukushima Nuclear Accident. IDDRI, Sciences Po Re Port 5: 1-54.

Herren, Urs J. 1991. 'Droughts Have Different Tails': Response to Crises in Mukogodo Division, North Central Kenya, 1950s-1980s. Disasters 15: 93-107. [CrossRef]

Ho, Thanh Tam, and Koji Shimada. 2019. The Effects of Climate Smart Agriculture and Climate Change Adaptation on the Technical Efficiency of Rice Farming-An Empirical Study in the Mekong Delta of Vietnam. Agriculture 9: 99. [CrossRef]

Jónsson, Gunvor. 2011. Non-Migrant, Sedentary, Immobile, or 'Left behind'? Reflections on the Absence of Migration. Working Paper 39. Oxford: The International Migration Institute (IMI), Oxford Department of International Development.

Logan, John R., Sukriti Issar, and Zengwang Xu. 2016. Trapped in Place? Segmented Resilience to Hurricanes in the Gulf Coast, 1970-2005. Demography 53: 1511-34. [CrossRef] [PubMed]

Lubkemann, Stephen C. 2008. Involuntary Immobility: On a Theoretical Invisibility in Forced Migration Studies. Journal of Refugee Studies 21: 454-75. [CrossRef]

MECLEP. 2017. Making Mobility Work for Adaptation to Environmental Changes: Results from the MECLEP Global Research|Environmental Migration Portal. International Organization for migration (IOM). Available online: https://environmentalmigration.iom.int/making-mobility-work-adaptation-environmental-changesresults-meclep-global-research (accessed on 30 April 2019).

Mortreux, Colette, and Jon Barnett. 2009. Climate Change, Migration and Adaptation in Funafuti, Tuvalu. Global Environmental Change 19: 105-12. [CrossRef]

Murphy, Daniel W. A. 2014. Theorizing Climate Change, (Im)Mobility and Socio-Ecological Systems Resilience in Low-Elevation Coastal Zones. Climate and Development 7: 380-97. [CrossRef]

Nawrotzki, Raphael J., and Maryia Bakhtsiyarava. 2016. International Climate Migration: Evidence for the Climate Inhibitor Mechanism and the Agricultural Pathway. Population, Space and Place 23: e2033. [CrossRef] [PubMed]

Nawrotzki, Raphael J., and Jack DeWaard. 2018. Putting Trapped Populations into Place: Climate Change and Inter-District Migration Flows in Zambia. Regional Environmental Change 18: 533-46. [CrossRef] [PubMed]

Ndour, Abdoulaye, Raoul A. Laïbi, Mamadou Sadio, Cossi G. E. Degbe, Amadou T. Diaw, Lucien M. Oyédé, Edward J. Anthony, Philippe Dussouillez, Hyacinthe Sambou, and El hadji Balla Dièye. 2018. Management Strategies for Coastal Erosion Problems in West Africa: Analysis, Issues, and Constraints Drawn from the Examples of Senegal and Benin. Ocean \& Coastal Management 156: 92-106. [CrossRef]

Olwig, Karen Fog. 1999. Narratives of the Children Left behind: Home and Identity in Globalised Caribbean Families. Journal of Ethnic and Migration Studies 25: 267-84. [CrossRef]

Parker, Ron. 1991. The Senegal-Mauritania Conflict of 1989: A Fragile Equilibrium. The Journal of Modern African Studies 29: 155-71. [CrossRef]

Penning-Rowsell, Edmund C., Parvin Sultana, and Paul M. Thompson. 2013. The 'Last Resort'? Population Movement in Response to Climate-Related Hazards in Bangladesh. Environmental Science \& Policy 27: S44-S59. [CrossRef] 
Piggott-McKellar, Annah E., Karen E. McNamara, Patrick D. Nunn, and Seci T. Sekinini. 2019. Moving People in a Changing Climate: Lessons from Two Case Studies in Fiji. Social Sciences 8: 133. [CrossRef]

Piguet, Etienne. 2018. Theories of Voluntary and Forced Migration. In Routledge Handbook of Environmental Migration and Displacement. Edited by Robert McLeman and François Gemenne. London: Routledge, pp. 17-28.

Rigaud, Kanta Kumari, Alex de Sherbinin, Bryan Jones, Jonas Bergmann, Viviane Clement, Kayly Ober, and Jacob Schewe. 2018. Groundswell: Preparing for Internal Climate Migration. Washington: World Bank.

Schewel, Kerilyn. 2019. Understanding Immobility: Moving Beyond the Mobility Bias in Migration Studies. International Migration Review, 0197918319831952. [CrossRef]

Seck, Aichetou. 2014. Les Pêcheurs Migrants de Guet-Ndar (Saint-Louis Du Sénégal): Analyse d'une Territorialité Diverse Entre Espaces de Conflits et Espaces de Gestion. Liège: University of Liège.

Siraj, Nasrin, and Ellen Bal. 2017. 'Hunger Has Brought Us into This Jungle': Understanding Mobility and Immobility of Bengali Immigrants in the Chittagong Hills of Bangladesh. Social Identities 23: 396-412. [CrossRef]

Suliman, Samid, Carol Farbotko, Hedda Ransan-Cooper, Karen Elizabeth McNamara, Fanny Thornton, Celia McMichael, and Taukiei Kitara. 2019. Indigenous (Im)Mobilities in the Anthropocene. Mobilities 1-21. [CrossRef]

Thiede, Brian C., and David L. Brown. 2013. Hurricane Katrina: Who Stayed and Why? Population Research and Policy Review 32: 803-24. [CrossRef]

Urry, John. 2002. Mobility and Proximity. Sociology 36: 255-74. [CrossRef]

Warner, Koko, Charles Ehrhart, A. de Sherbinin, Susana Adamo, and Tricia Chai-Onn. 2009. In Search of Shelter: Mapping the Effects of Climate Change on Human Migration and Displacement. Available online: http: //www.careclimatechange.org/files/reports/CARE_In_Search_of_Shelter.pdf (accessed on 30 March 2019).

Zickgraf, Caroline. 2018a. Immobility. In Routledge Handbook on Environmental Displacement and Migration. Edited by François Gemenne and Robert McLeman. London: Routledge.

Zickgraf, Caroline. 2018b. 'The Fish Migrate and so Must We': The Relationship between International and Internal Environmental Mobility in a Senegalese Fishing Community. Journal Medzinarodne Vztahy 16: 5-21.

(C) 2019 by the author. Licensee MDPI, Basel, Switzerland. This article is an open access article distributed under the terms and conditions of the Creative Commons Attribution (CC BY) license (http://creativecommons.org/licenses/by/4.0/). 

MDPI

St. Alban-Anlage 66

4052 Basel

Switzerland

Tel. +41616837734

Fax +41 613028918

www.mdpi.com

Social Sciences Editorial Office

E-mail: socsci@mdpi.com

www.mdpi.com/journal/socsci

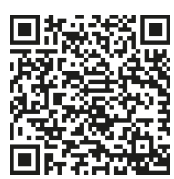



MDPI

St. Alban-Anlage 66

4052 Basel

Switzerland

Tel: +41 616837734

Fax: +41 613028918

www.mdpi.com 